PNL-2832

UC-15

\title{
Proliferation Resistance Design of a Plutonium Cycle (Proliferation Resistance Engineering Program - PREP)
}

January 19, 1979

Prepared for the U.S. Department of Energy under Contract EY-76-C-06-1830

Pacific Northwest Laboratory Operated for the U.S. Department of Energy by Battelle Memorial Institute 
NOTICE

This report was prepared as an account of work sponsored by the United States Government. Neither the United States nor the Department of Energy, nor any of their employees, nor any of their contractors, subcontractors, or their employees. makes any warranty, express or implied, or assumes any legal liability or responsibility for the accuracy, compieteness or usefulness of any information, apparatus, product or process discicsed, or represents that its use would not infringe privately owned rights.

The views, opinions and conclusions contained in this report are those of the contractor and do not necessarily represent those of the United States Government or the United States Department of Energy.

PACIFIC NORTHWEST LABORATORY

operated by

BATTELLE

for the

UNITED STATES DEPARTMENT OF ENERCY

Under Contract EY-76-C-06-1330

\author{
Printed in the United States of America \\ trailable irom \\ National Technical Information Service \\ Unted States Department of Commerce \\ 5285 Port Royai Road \\ Springtield, Virginia 22151
}

Price: Printed Copys

, Microfiche 53.60

NTIS

-Pages Selling Price

$001.025 \quad 5.00$

$0.86 .050 \quad 54.50$

Usi-075 $\quad \$ 5.25$

076.703 56.00

$107.125 \quad 56.50$

$125.750 \quad 57.25$

$15:-175 \quad 58.00$

$176-200 \quad 59.79$

$207.225 \quad 59.2=$

$726-250-53.52$

$251 \cdot 275 \quad$ sia. 75

$376-30 x=51100$ 


\section{9}

PROLIFERATION RESISTANCE DESIGN OF

A PLUTONIUM CYCLE

(Proliferation Resistance Engineering

Program - PREP)

Pacific Northwest Laboratory:

R.J. Sorenson R.J. Kofoed

F.P. Roberts R.J. Brouns

R.G. Clark R.F. Eggers

Sandia Laboratories, Livermore:

J.C. Gibson

System Planning Corporation:

F.L. Adelman J.F. Fagan, Jr.

J. Ballantine

Human Affairs Research Center:

C.R. Schuller P. A. Morris

D. Lowenfeld A. M. Hanhardt, Ir.

January 19, 1979

Prepared for the

U.S. Department of Energy

under Conträct EY-76-C-06-1830

Pacific Northwest Laboratory

Richiani, Washington 99352 
.

- 
SUMMARY

This document describes the proliferation resistance endineering concepts developed to counter the threat of proliferation of nuclear weapons in an International Fuel Service Center (IFSC). These concepts include:

1. Facility design and process considerations that provide passive resistance to proliferation, or enable the application of active use-denial technology.

2. Technical aspects of a command, control and communication system $\left(c^{3}\right)$ necessary to initiate active use-denial penalties.

3. Description of active use-denial technology that is either currently available or under development in other DOE programs.

In addition, descriptions of the basic elements of an International Fuel Service Center, including fuel reprocessing, fuel refabrication, product storage, transportation systems, the reactor facility, waste management process, and an advanced safequards system are rresented. Possible methods for resisting proliferation such as processing alternatives, close-coupling of facilities, process equipment layout, maintenance philosophy, process control and process monitoring are discussed.

The political and institutional issues in providing proliferation resistance for an International Fuel Service Center are analyzed in terms of trree major issues, namely, (1) political acceptability of introducing passive and active use-denial technologies into an IFSC located in a host country; (2) the value of multinational presence in enhancing or reducing proliferation resistance; and (3) issues of organization, management and operation of a proliferation resistant IFSC. The conclusions drawn from a study of the major issues are: (1) use-denial can provide time for international response in the event of a host nation takeover. Passive usedenial is more acceptable than active use-denial, and acceptability of active-denial concepts is highly dependent on sovereignty, energy dependence and economic considerations; (2) multinational presence can enhance 
proliferation resistance; and (3) use-denial must be nonprejudicial with balanced interests for governments and/or private corporations being served.

The incremental costs imposed on the design, construction and operation of an IFSC by including the PRE concepts have been estimated. Comparisons between an IFSC as a national facility, an IFSC with minimum multinational effect, and an IFSC with maximum multinational effect show incremental design costs to be less than $2 \%$ of total cost of the baseline non-PRE concept facility. The total equipment acquisition cost increment is estimated to be less than $2 \%$ of total baseline facility costs. Personnel costs are estimated to increase by less than $10 \%$ due to maximum international presence.

The work performed in the PRE program has shown that the concepts as viewed on an integrated basis have been developed to the stage where they could be considered as plausible. Further work must be performed to make a conceptual definition possible. 
SUMMARY

1.0 INTRODUCTION .

THREAT DEFINITION

GENERALIZED FUEL CYCLE DESCRIPTION.

TECHNICAL APPROACH.

EVALUATION CRITERIA.

2.0 PROLIFERATION RESISTANCE ENGINEERING CONCEPTS .

2.1 DESIGN CONSIDERATIONS FOR PROLIFERATION RESISTANCE

ENGINEERED FACILITIES . . . . . . . . . . . . . . . . 2-7

2.2 THE COMMAND, CONTROL AND COMMUNICATION SYSTEM . . . . . 2-9

2.2.1 Institutional Framework and Assumptions . . . . . 2-9

2.2.2 Graded Responses. . . . . . . . . . . . . 2-11

2.2.3 Relationship of the Command, Control and Standard Communication System $\left(C^{3}\right) . .+. .20 .13$

2.2.4 Organization . . . . . . . . . . . . . . 2-14

2.2.5 Implementation . . . . . . . . . . . . . 2-19

2.2.6 Steps Required to Deactivate the Use-Denial System . 2-25

2.2.7 Representative Denial Empioying Enable Logic . . . 2-28

2.2.8 Combined Disabie/Enable Logic . . . . . . . . 2-31

2.2.9 Design Process Overview . . . . . . . . . . 2-33

2.3 ACTIVE USE-DENIAL TECHNOLOGY . . . . . . . . . . . 2-35

2.3.1 Genera1. Concepts. . . . . . . . . . . . . 2-35

2.3.2 Implementation . . . . . . . . . . . . . . 2-40

3.0 BASELINE FACILITY DESCRIPTION . . . . . . . . . . . . . . 3-1

3. 1 THE FUEL REPROCESSING PLANT . . . . . . . . . . . $3-1$

3.1.1 Process Description. . . . . . . . . . . . 3-1

3.1.2 Reprocessing Plant Facility Description. . . . . 3-5

3.2 THE REFERENCE FUEL REFABRICATION FACILITY. . . . . . . 3-8

3.3 PLUTONIUM STORAGE AND TRANSPORTATION SYSTEMS. . . . . . . $3-9$

3.4 THE REACTOR FACILITY. . . . . . . . . . . . . . 3-12

3.4 .1 Core. . . . . . . . . . . . . . . . . 3-12

3.4.2 Reactor Control System. . . . . . . . . . 3-14

3.4.3 Heat Transport System . . . . . . . . . . 3-15 
3.4.4 Auxi1iary Systems . . . . . . . . . . . 3-15

3.4.5 Reâctor Refueling System . . . . . . . . . 3-16

3.5 WASTE MANAGEMENT PROCESS . . . . . . . . . . . . 3-14

3.6 ADVANEED SAFEGUARDS SYSTEM. . . . . . . . . . . . . $3-21$

3.6.1 Advanced Safeguards System Description . . . . . 3-21

3.6.2 Access and Operational Control . . . . . . 3-22

3.6.3 Dynamic Material Accounting . . . . . . . . . 3-24

3.7 POSSIBLE METHODS FOR RESISTING PROLIFERATION. . . . . . 3-28

3.7.1 Processing Alternatives . . . . . . . . . . 3-28

3.7.2 Physical Structures. . . . . . . . . . . 3-36

3.7.3 Close Coupling of Facilities. . . . . . . . 3-37

3.7.4 Process Equipment Layout . . . . . . . . . . . $3-38$

3.7.5 Maintenance Philosophy and Use-Denial. . . . . 3-42

3.7 .6 Process Control . . . . . . . . . . . . . 3-44

3.7.7 Process Instrumentation . . . . . . . . . . 3-48

3.8 INTERFACES BETWEEN THE FACILITIES AND THE $C^{3}$ SYSTEM . . . 3-50

3.8.1 Proposed Systems within the $C^{3}$ Concept . . . . . 3-50

4.0 APFLICATION OF PROLIFERATION. . . . . . . . . . . . . . . . 4-1

4.7 APPLYING DELAY TECHNOLOGY . . . . . . . . . . . . . . . . 4-1

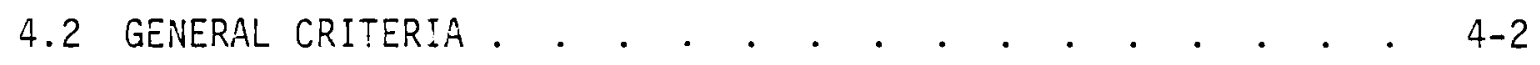

4.3 TECHNICAL CRITERIA . . . . . . . . . . . . . . . . . . . . . 4-3

4.4 DEVELOPMENT OF DELAY STRATEGIES . . . . . . . . . . . . 4-4

4.5 tRANSiENT STRATEgies. . . . . . . . . . . . . . . . . . $4-4$

4.6 DELAY EXAMPLES. . . . . . . . . . . . . . . . . . . . . 4 4-6

4.7 ASSESSMENT OF THE SEIECTED USE-DENIAL STRATEGIES . . . . 4 4-9

5.0 POL ITICAL AND INSTITUTIONAL ISSUES IN PROVIDING PROLIFERATION
RESISTANCE FOR AN INTERNATIONAL FUEL SERVICE CENTER

5.1 GENERAL CONCLUSIONS . . . . . . . . . . . . . . . 5-1

5.1.1 Proliferation Resistant Technology. . . . . . . 5-2

5.1 .2 Goals of Proliferaticn Resistant Technology. . . . 5-3

5.7.3 Institutional Definitions. . . . . . . . . . 5-4 
5.2 POLITICAL ACCEPTABILITY OF PROLIFERATION RESISTANT

IFSC DESIGNS . . . . . . . . . . . . . . . . 5-7

5.2.1 Definition of the Acceptability Problem . . . . 5-7

5.2.2 Domestic Policy Issues. . . . . . . . . . . 5-8

5.2.2.1 Sovereignty Issues: For Potential Hosts. . 5-8

5.2.2.2 Sovereignty Issues: Partner Nations . . . 5-9

5.2.2.3 Economics. . . . . . . . . . . . 5-11

5.2.2.4 Status of Domestic Energy Programs:

Energy Independence. . . . . . . . 5-13

5.2.2.5 Environmental and Safety Considerations . . 5-15

5.2.2.5.1 Waste Management Issues. . . . 5-16

5.2.2.5.2 Decommissioning Nuclear
Facilities... . . . 5-16

5.2.2.6 Domestic Political Opposition . . . . . 5-16

5.2.3 Foreign Policy Issues. . . . . . . . . . 5-18

5.2.3.1 Attitude Towards Participation in
Multinational Organizations . . . . . 5-19

5.2.3.2 Antecedent Relations with Partners. . . 5-20

5.2.3.3 Regional Military Conditions. . . . . . 5-20

5.2.3.4 Commitment of the Goals of the NPT. . . . 5-21

5.2.3.5 Nuclearr Weapons Ambitions and Alternative

Paths to Nuclear Capability. . . . . . 5-22

5.2.3.6 Importance of Good Alliance Relations. . . 5-22

5.2.3.7 International Economics . . . . . . . 5-23

5.2.4 The Importance of Political Processes:

Introduction to Case Studies. . . . . . . . . 5-24

5.2.4.1 Case Study: France. . . . . . . . . 5-26

5.2.4.2 Characteristics of the West German $5-37$

Nuclear Program . . . . . . . . . . 5-37

5.2.4.2.1 The Organization of the FRG
Nuclear Energy Program . . . 5-38

5.2.4.2.2 The West German Commitment
to Nuclear Development . . . 5-41

5.2.4.2.3 FRG Attitudes Toward Nuclear Nonproliferation . . . . . . 5-43

5.2.4.2.4 West German Commitment to the Plutonium Economy . . . . 5-46

5.2.4.2.5 Internai Opposition from Antinuclear Groups . . . . 5-47 


\subsection{Sovereignty Issue Affecting}

West German Participation in an IFSC.

5.2.4.2.7 Summary and Conclusions. . . . 5-51

5.2.4.3 Brazil . . . . . . . . . . . . . 5-53

5.2.4.4 Argentina. . . . . . . . . . . . 5-55

5.2.4.5 Mexico. . . . . . . . . . . . 5-58

5.2.4.6 Pakistan . . . . . . . . . . . . 5-61

5.2.4.7 Iran. . . . . . . . . . . . . . 5-63

5.2 .4 .8 Japan . . . . . . . . . . . . . $5-65$

5.2.4.9 Republic of China . . . . . . . . . 5-68

5.2.4.10 Republic of Korea . . . . . . . . . 5-69

5.3 ISSUES OF ORGANIZATION, MANAGEMENT, AND OPERATION . . .

5.3.1 Political and Institutional Issues Involved
in Passive Use-Denial Systems . . . . . 5-73

5.3.2 Political and Institutional Issues in Active
Use-Denial Acceptability Issues. . . . . 5-74

5.3.2.1 Institutional Design for the Exercise
of C3 Functions... . . . . . . 5-75

5.3.2.2 Extreme Case--Host. Nation Take-Over
with Multinational Hostages . . . . . 5-77

5.3.3 Issues of Management Control and Organization . . . 5-78

5.4 MULTINATIONAL PRESENCE IS A FACTOR IN RETARDING OR

ENHANCING THE PROLIFERATION RESISTANCE OF AN IFSC . . . . 5-31

5.4.1 Multinational Factors Tending to Reduce the Overall Proliferation Resistance of IFSC's. . . . 5-81

5.4.2 Factors Which Tend to Enhance the Overall

Proliferation Resistance of Multinational IFSC's. . 5-84

5.4.3 Multinational Presence as a Factor in Reducing the Attractiveness of an IFSC for Potential Host Nation Take-Over . . . . . . . . . . . 5-85

5.5 SUMMARY AND CONCLUSIONS. . . . . . . . . . . . . .

\begin{tabular}{l}
6.0 COST IMPACT ON THE IFSC RESULTING FROM PROLIFERATION \\
RESISTANCE ENGINEERING... \\
\hline
\end{tabular}

6.1 SUMMARY OF THE PNL ESTIMATE . . . . . . . . . . . . . 6-1

6.2 COST ESTIMATE PREPARED BY SPC. . . . . . . . . . . $6-2$

6.2.1 Facility Model for Costing . . . . . . . . . 6-2

6.2.2 Cost Impact of Equipment for Proliferation
Resistance Design... . . . . . . . 6-3 


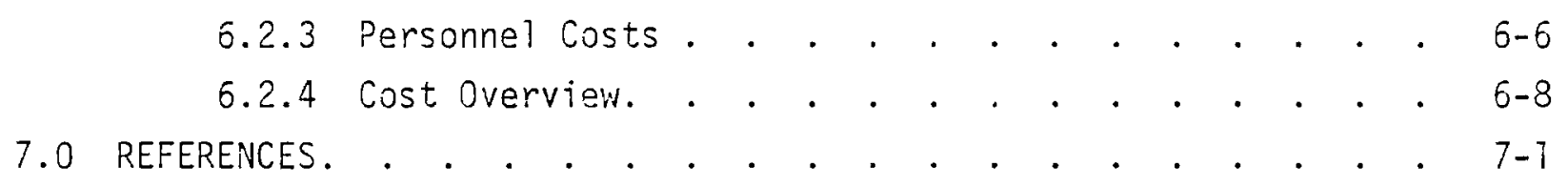




\section{FIGURES}

1.1 A simplified PTutonium Fuel Cycle. . . . . . . . . . 1-4

1.2 Proliferation Resistance Engineering Technical Approach . . 1-7

2.1 Annual Plutonium Flows in an IFSC Having 8 LMFBRs . . . . 2-6

2.2 Safeguards System Structure for a Typical Facility . . . . 2-15

2.3 Interactions of $\mathrm{C}^{3}$ system With IFSC Facilities . . . . 2-15

$2.4 C^{3}$ Organization. . . . . . . . . . . . . 2-16

2.5 Graded Denial Actions and Control Source Location . . . . 2-18

2.6 Steps Required to Deactivate Use-Denial System . . . . 2-26

2.7 Enable Denial Logic . . . . . . . . . . . . . . 2-29

2.8 An Integrated System With Active Denial Penalties . . . . 2-36

2.9 Example of a Generalized Active Deniai Penalty Node. . . , 2-36

2.10 Graded Penalty Response . . . . . . . . . . . . 2-39

2.11 Remote Controller. . . . . . . . . . . . . . . 2-42

2.12 Coded Electromechanical Switching Service. . . . . . . 2-43

2.13 Device for Using Controlled Explosion . . . . . . . . 2-44

2.14 Tamper Detecting Sensor . . . . . . . . . . . . . 2-45

2.15 Loadout Valve Assembly With Use-Denial Capability . . . 2-47

2.16 Storage Facility Using Access Denial Technology . . . . . 2-48

2.17 Application of Foaming . . . . . . . . . . . . . 2-49

2.18 Application of Use Denial to Transport Vehicle . . . . . 2-51

2.19 Plutonium Transfer Vehicle With Access-Denial Characterisitics 2-52

2.20 Thermite Plutonium Denial Concept. . . . . . . . . 2-53

2.21 Thermite Reaction Product . . . . . . . . . . . . 2-54

2.22 Plutonium Oxide Shipping Container With a Thermite Charge. . 2-55

2.23 Fuel Fabrication Facility - Safeguards Conceptual Design . . 2-56

3.1 Fue1 Reprocessing Flow Diagram. . . . . . . . . . 3-2

3.2 Section Elevation of the Plant. . . . . . . . . . 3-13

3.3 Plan View of the Plant . . . . . . . . . . . . . 3-13

3.4 Reactor Core Assemblies . . . . . . . . . . . . . 3-14

3.5 Reacior Refueling . . . . . . . . . . . . . . . 3-17

3.6 Safeguards Structure. . . . . . . . . . . . . . 3-23 
3.7 Reference Process Case . . . . . . . . . . . . . 3-31

3.8 Coprocessing With High Decontamination. . . . . . . . 3-31

3.9 Coprocessing With Partial Decontamination . . . . . . . 3-32

3.10 Reference Process Case, But With Spike Addition . . . . 3-32

3.11 Reference Process Case, But With U/Pu Blending . . . . . 3-33

3.12 Coprocessing With Spike Addition . . . . . . . . . 3-33

3.13 Oxide Conversion by Direct Denitration . . . . . . . . 3-34

3.14 Oxide Conversion by Coprecipitation . . . . . . . . 3-35

3.15 Close Coupling of Reprocessing and Fliel Fabrication Plants . 3-39

3.16 Generalized System Diagram Showing The Interfaces With The C3 System. . . . . . . . . . . . . . . . . 3-51

3.17 Functional Electronic Block (FEB) Interfaces. . . . . . 3-55

3.18 Use-Denial--Liquid Transfer. . . . . . . . . . . . 3-57

4.1 Graded Response: Dumping Sill Into High-Level Waste. . . . 4-8

4.2 Distributed Penalty Nodes . . . . . . . . . . . . 4-9

5.1 Political Interaction Matrix . . . . . . . . . . . 5-13

\section{TABLES}

3.1 Functional Areas in Fuel Receiving and Storage Station. . . 3-5

3.2 Process Cells and Functions. . . . . . . . . . . . 3-7

3.3 Forms and Quantities of Plutonium at an IFSC . . . . . . 3-9

3.4 Constituents of High-Level Liquid Wastes . . . . . . . 3-20

4.1 Possible Use-Denial Steps at Extraction Node . . . . . . 4-6

4.2 Possible Delay Steps at Purification Node . . . . . . . 4-7

6.1 Equipment Cost Impact. . . . . . . . . . . . . 6-7

6.2 Labor Costs. . . . . . . . . . . . . . . . . 6-7

6.3 Cost Summary. . . . . . . . . . . . . . . . . . $5-9$ 


\section{PROLIFERATION RESISTANCE DESIGN \\ OF A PLUTONIUM CYCLE}

\subsection{INTRODUCTION}

This study on proliferation resistance design of a plutonium cycle was initiated by the Department of Energy (DOE) as part of the Nonproliferation Alternative Systems Assessment Program (NASAP). The aim of the study is to identify and evaluate technical and procedural methods that might be used in a plutonium cycle to inhibit diversion of plutonium and delay its subsequent use in nuclear devices by a national adversary. Specific objectives are:

- To develop methods of delaying the recovery of weapons usable material from sensitive facilities subsequent to takeover and operation and/or modification of these facilities to produce weapons-usable material. Time delays for all potential paths from the international fuel service center (IFSC) need to be comparable.

- To develop methods for structuring the design and operations of facilities to enhance their proliferation resistance.

- To evaluate the effectiveness of the methods for enhancing proliferation resistance.

- To assess the relative incremental costs.

- To assess operational difficulties of proliferation resistance relative to a base-line design which builds on previously developed integrated safeguard concepts.

- To assume a multinational presence in an IFSC involved directly in facility operations, and to include one case of national (non-IFSC) operations with multinational inspectors only. 
The President's Nuclear Energy Policy Statement of April 7, 1977 and his energy message of Apri1 20, 1977 express concern regarding proliferation of nuclear weapons. Accordingly, the Administration is stressing assessment and development of alternative nuclear systems which offer less risk of nuclear weapons proliferation. These alternative approaches must be developed to the point that prudent choices may be made in balancing nonproliferation objectives with performance, safety, environmental, resource, and economic considerations.

The NASAP program is to provide recommendations in the development of nuclear systems which have potential for reducing the risks of proliferation while satisfying the short-and long-term needs for nuclear energy. Since there are serious concerns about the use of plutonium, and the plutonium fuel cycle has the potential for diversion into a usable form for weapons, this program was initiated in order to assess methods which would inhibit its malevolent use. As such, the goal of this conceptual study is to identify and evaluate passive and active use-denial measures which would prevent the malevolent use of plutonium from an IFSC. The objective of the deniai measures is to enhance the proliferation resistance by delaying the adversary from obtaining weapons-usable material. These concepts must also be effective against covert theft from within.

This interim report attempts to show that the PREP concept has been developed to the stage where it can be considered a plausible idea. Although significant work still must be done to make a conceptual definition possible, some portions of this report (such as the reprocessing section) include details of the state-of-the-art to give the reader greater insight.

\section{THREAT DEFINITION}

For this study we are defining the threat in both overt and covert terms. The primary overt threat involves the host nation physicaliy taking over the IFSC and trying to either obtain the material that is onsite or to use the facilities in some mode to produce weapons-usable 
material. Of lesser emphasis is the ability of the host nation to covertly divert material in quantities too small to be detected by the International Atomic Energy Agency's (IAEA) standard accounting procedures.

This study considers both the material and the facility. Use of the material must be denied in process, storage, and transit. The facility must also be denied in case of host nation takeover and subsequent operation of the plant; either as designed and operated, or with alterations such that, if the host nation operated the plant long enough, it could produce a significant quantity of strategic material.

The overall goal of this study is to provide an "adequately long" conversion time from the takeover--of material or the facility--to the production of material in weapons-usable form. For the purpose of this study, the term "adequately long" is tentatively defined as four to six weeks.

\section{GENERALIZED FUEL CYCLE DESCRIPTION}

The simplified plutonium fuel cycle diagram shown in Figure 1.1 illustrates the system that is being used as the basis for this study. A plutonium system is being considered because most fuel cycles (including that of thorium), have a plutonium subcycle. Thus the plutonium case is assumed to be the most difficult system to safeguard.

The host nation provides physical protection measures to counter the subnational threat. The outer boundary surrounding the IFSC depicts an in-place, modern, up-to-date physical security system for which the host nation has primary responsibility. However, the fuel service center staff may observe or monitor this physical protection system. The only fuel cycle material coming into the IFSC will be spent light water reactor (LWR) fuel for reprocessing. Following this operation, some form of plutonium is transferred to a fuel fabrication facility. The fabricated fuel is placed in a plutonium core reactor, and at the end of its life in the reactor it is transferred to a recovery facility and reprocessed. Then the material is 


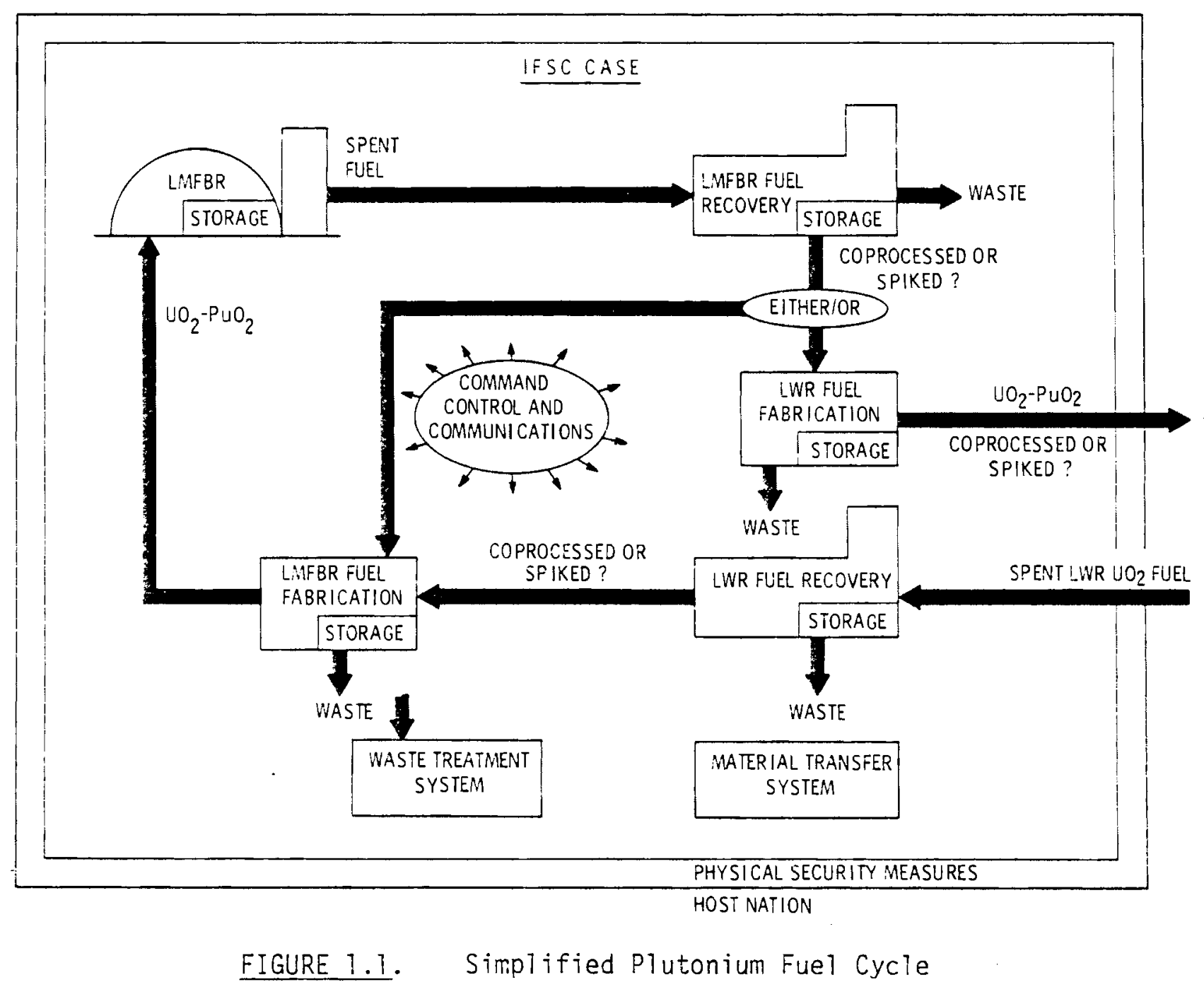

reprocessed. Then the material is either recycled with in the fuel service center or transferred offsite as protected mixed oxide (Mox) fuel.

The study considers both material attractiveness and where the point at which material is most vulnerable within the IFSC. The balanced approach provides that the most protection will be given to the most attractive or vuinerable material. 


\section{TECHNICAL APPROACH}

The technical approach for this study builds on previously developed and currently sponsored DOE work. After DOE laboratory interfaces were developed, a workshop was held to gather technical ideas, direction, and contributions from various experts in determining potential approaches for this conceptual study. At the conclusion of the detailed study, this report will be subjected to review by recognized experts from a variety of disciplines in the governmental, industrial and academic communities.

The study will describe techniques to reduce the potential for nuclear proliferation in the plutonium fuel cycle. Since it is not within the scope of this study to evaluate every possible component in a plutonium system, the approach will be to study six generic cases, which represent the key elements of plutonium subsystems located on a single site:

- Reprocessing Plant

- $\mathrm{UO}_{2}-\mathrm{PuO}_{2}$ Fuel Fabrication Plant

- Plutonium Core Reactor
- Material Transfer System

- Storage

- Waste Handling

The work will involve a preliminary evaluation of the feasibility and effectiveness of techniques to reduce the potential for nuclear proliferation. Using currently-available technology or that which will probably be available in the near future, the study will assemble safeguards system ideas for conceptual fuel cycle facilities. These systems will be evaluated against criteria based on the extent to which nations are inhibited from obtaining weapons-usable plutonium but are not unreasonably denied the peaceful use of nuc? ear power.

Key contributors to the overal1 study are: Pacific Northwest Laboratory (PNL), System Planning Corporation (SPC), Sandia Laboratories, Livermore (SLL), Battelle-Human Affairs Research Center in Seattle (HARC), Naval Research Laboratory (NRL), and Alijad Chemical - Idaho. It is a multicontractor, mutidiscipline team. 
Pill has overall responsibility for the program, and the design of the processes, facilities, and operations. SPC has primary responsibility for defining the role of the $c^{3}$ system, including the enable and disable logic and techniques. SLL will identify use-denial technology, based on both the military weapons program and safeguards work at SandiaAlbuquerque. NRL has responsibility for technology winich includes the identification and definition of anticompromise and use-denial concepts. NRL may also evaluate some of the systems and the alternate approaches developed by other DOE contractors. Much of this NRL technology is postPueblo-era technology and involves use-denying data information via computer codes. Allied Chemical of Idaho has assisted in the area of defining the engineered safeguard system (ESS) which would be in place in the IFSC. And finally, Battelle-HARC has the responsibility for the political and institutional issues which result from such a system and assessing the value of the multinational presence.

Figure 1.2 depicts the technical approach to the development of the proliferation resistance engineering (PRE) concept.

\section{EVALUATION CRITERIA}

Criteria are needed to systematically evaluate the utility of the various approaches resulting from this study. The level of effectiveness of these proliferation resistance designs can be determined by comparing the time and difficulty for obtaining plutonium from spent LWR fuel. In other words, there will be no time path to weapons-usable material from the proliferation resistant facility which is more attractive than from spent fuel. Also, the path to weapons-usable plutonium in which the host nation takes over and modifies the facility's operation to recover plutonium will be significantly less attractive than to recover it from spent fuel. The concepts developed in this study should require the utilization of developed technology, whenever possibie. In no case should extensive (high risk) research and development be required. The implementation of proliferation 


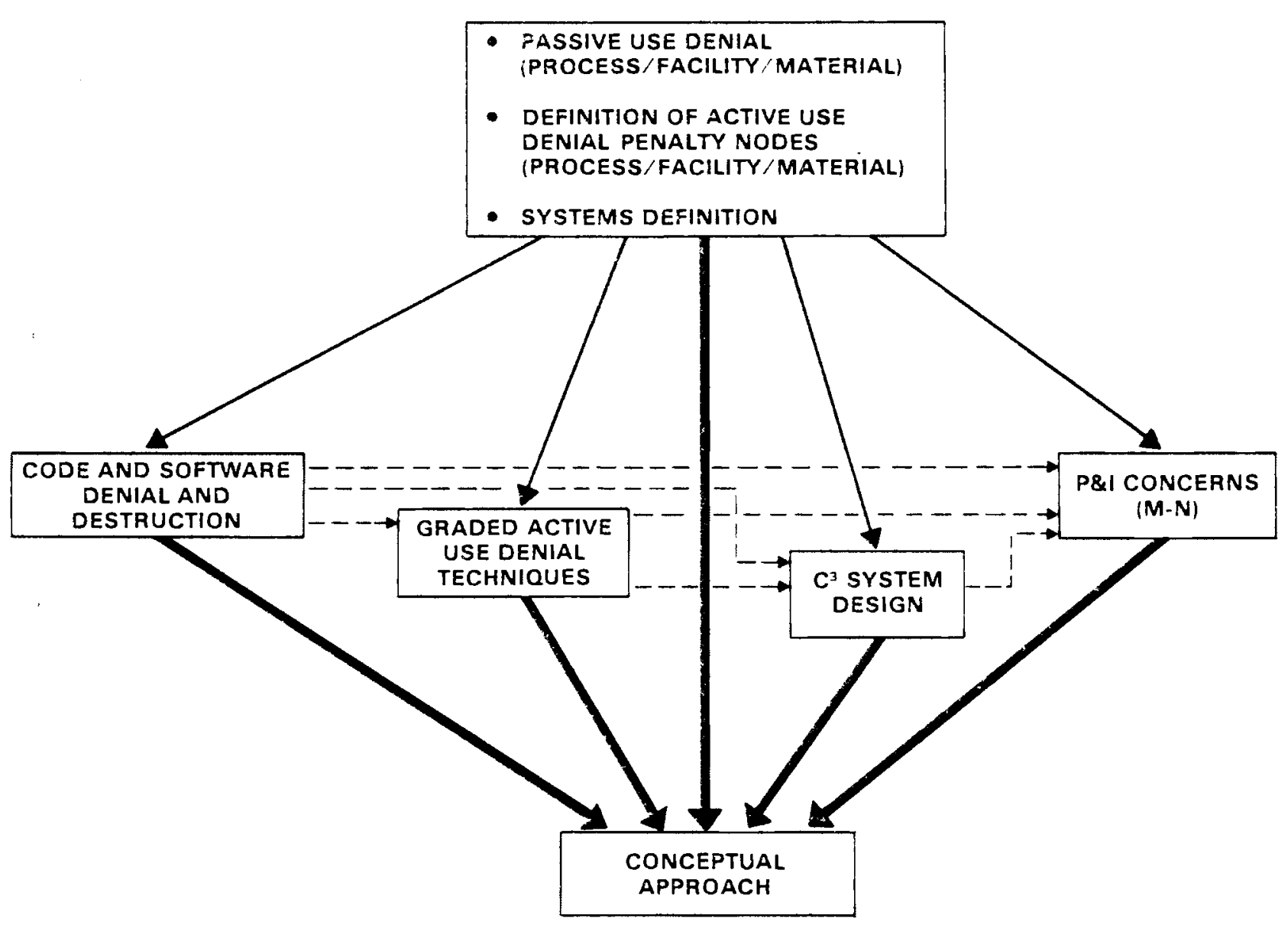

FIGURE 1.2. Proliferation Resistance Engineering Technical Approach

resistance design must also have an acceptably small impact on the economic operation of the IFSC. And finaliy, the results must be politically acceptable.

Attempts are being made to design an acceptably conservative level of resistance. Although it is not enough to deny the facilities or material for just days, denial for months appears to be unattainable for the overa 71 balanced system. However, since use of many components in the system can be denied for months, it appears possible to prevent access by the host nation to weapons-usable plutonium for at least four to six weeks. This time is assumed to be adequate for the diplomatic process. 
The evaluation of proliferation resistance effectiveness for the takeover case will utilize the pertinent attributes developed by the NASAP program, when they become available. Some of the attributes to be considered are:

- Time (Primary)

- Resources

- Detectability

- Institutional Restrictions
- for host nation (after takeover) to convert the material at the IFSC into a usable form (metal)

- that identify unique and special requirements for the host nation to convert material into a usable form. (Could include technical, manpower, costs, etc.)

- capability for detecting clandestine activities by the host country (prior to takeover) which would impact on the time necessary to convert material.

- could include technical and nontechnical consideration

This report describes the baseline facility (chapter 2.0), including the advanced safeguards system (2.6); gives the PRE concepts (3.0), including the command, control, and communication system (3.2); considers active use-denial technology concepts (3.3); details the interfaces between the various facilities and the $\mathrm{C}^{3}$ system (3.4); considers the application of active use-denial technology (4.0); gives political and institutional considerations (5.0); and provides a tentative cost impact for implementing PFE (6.0). 


\subsection{PROLIFERATION RESISTANCE ENGINEERING CONCEPTS}

This section describes the proliferation resistance engineering concepts being developed in this study to counter the threat of proliferation. These include 1) the facility design and process considerations that provide passive resistance to proliferation, or enable the application of active use-denial technology; 2) the technical aspects of the command, communication and control system $\left(C^{3}\right)$ necessary to initiate active use-denial penalties; and 3) a description of active use-denial technology that is either currently available or under development in other DOE programs.

The terms active and passive use-denial are used throughout this report. The term active use-denial is intended to mean actions which actually interrupt a process, isolate plutonium or perform some chemical or physical reaction to convert plutonium to some form that is difficult to use. Passive use-denial is distinct from active use-denial, in that no action is required to protect the plutonium from malevolent use. Passive use-denial includes facility designs, operational modes and processes that enhance proliferation resistance. It also includes any design, operational or process features which are needed to make active use denial effective. Examples of passive use-denial features include:

Process Selection

- reference case

- alternate cases

Plant Design

- maintenance (Remote/Contact/None)

- space 1 imitations

- restriction of process flexibility

- no low-level cells

\section{Operatioral Characteristics}

- close coupling of sequential processes

- minimization of buffer storage

- limitation of quantities in interfacility transfers 
The approach to active use-denial involves a characterization of the overali fuel service center to determine requirements for material or facility denial. A node can be defined at various locations in order to invoke a penalty and interrupt the process or deny access to or use of the material. Under the present concept, the responses would be a series of increasingly severe actions (graded responses). Each step in the series could be sequentialiy applied as the certainty of the takeover threat increased. Examples of graded responses are shown below:

Reversible - 1st Level Response

- override operator controi

-- Invalidate software code

-- Invalidate coded clutches, e.g., valves

- initiate automated shutdown

- stop material transfers/place material under penalty system

Reparable - 2nd Level Response

- destroy process instrumentation signal paths

- destroy manual control capability - external to shielding, e.g., air supply valve to air-lift

- destroy computer codes

Repiaceable - 3rd Level Response

- destroy control mechanical controls - external to shielding, e.g., air supply valve to air-lifts

- disable decontamination capability

- deny material use, e.g., dump to high-level waste (HLW), foam

- mechanical/chemical dilution acts

- The first step would be quickly reversible and would result in no serious loss of production or material. The second level reponse should result in a situation that requires both time and human interaction to reverse. The ultimate step might result in serious 
disruption to equipment or material and require time-consuming replacement of equipment or material. The approach to active use-denial is outlined below:

- identify key points in process, plant and storage

- define use-denial nodes

- develop a graded response at each node

- design a graded response system

-- Reversible

-- Repairable

-- Replaceable

The main proliferation concerns of this study include potential actions by the host nation to do one or more of the following:

- physically take over the facilities in the IFSC and divert existing plutonium inventories

- continue operation of facilities to produce additional plutonium

- modify the facilities followed by subsequent operation to produce plutonium in weapons-usable form

- covertiy divert plutonium from the IFSC in quantities too small to be detected by the standard IAEA accounting procedures.

The ease with which a nation can remove covertly diverted material without detection by internationally controlled surveillance and containment methods will depend upon the specific design of the facilities, their processes and their operating procedures. Similarly, the time from takeover until weapons-usable material becomes available will depend upon the specific design of the facilities, their processes, operating procedures, and technical expertise.

The overall goal of this study is to provide "adequately long" conversion time from the takeover of the facility or material from anywhere in the IFSC to produce material in weapons-usable form. In response to takeover threats, the PREP design approach considers the overt case as two distinct problems: 
- Takeover, modification, and operation of reprocessing facility

- the facility is unusable

- modifications are not feasible

- Takeover material anywhere in the IFSC--in process, storage or transit-for removal and processing in previously constructed facilities

- the material is diluted (chemically/physically)

- removal of material is difficult and time consuming

- processing of material is difficult and time consuming (both dissolution and purification)

The major effort of this study has been to consider the overt threat or physical takeover of the IFSC. The response to the threat will first of ali be to provide a delay time in excess of a certain number of weeks before obtaining or converting the material into a weapons-usable form. Secondary criteria may include cost, detectability of preparations, and technical difficulty.

The approaches to both types of threats are summarized belew:

Threat

Covert

(small amounts of material within accounting uncertainty)

Overt

(physical takeover)
Approach

Examine effectiveness of surveillance and containment in limiting diversion

Examine how function and multinational presence can be structured to delay acquisiticn of weapons-grade material, in the event of takeover 


\section{lilaterial Quantities}

To place the magnitude of the proliferation threats in perspective, it is important to understand that the quantities of plutonium involved in a fuel service center are very large. A hypothetical fuei service center illustrates the possible magnitude. The center, as already defined in section 1 , contains a reprocessing plant with an annual throughput of 1500 metric tons, a fuel fabrication plant with an annual throughput of 600 metric tons of mixed oxide, and eight LMFBRs. Spent, low enriched uranium fuel is received from outside the IFSC. Plutonium, in excess of that required to fuel the eight reactors, is shipped from the center as mixed oxide LWR fuel. Figure 2.1 is a simplified diagram of the hypothetical center and its annual material flows. It is clear that the metric ton quantities of plutonium involved in the operation of the center represent an enormous source of weapons-usable material.

The differences between the various facilities lie in their capabilities of separating and purifying plutonium. The reprocessing plant can purify plutonium waste from spent fuels or other plutonium mixtures. With modifications, it is conceivabie that the waste management and refabrication plants can be used to assist in the separation of significant quantities of plutonium. All of the facilities contain quantities of plutonium that would be attractive to an adversary.

In general, the desigris need to be focused on use-denial of the material, use-denial of the facility, and prevention of facility modifications that would allow the adversary to convert material into weapons-usable forms. The primary proliferation resistance requirements for the six generic parts of the fuel cycle are as follows:

\begin{tabular}{|c|c|}
\hline Facility & Use-Denial Requirements \\
\hline Reactor plant & Material \\
\hline Reprocessing plant & $\begin{array}{l}\text { Material use-denial } \\
\text { Facility use-denial }\end{array}$ \\
\hline Refabrication plant & $\begin{array}{l}\text { Material use-denial } \\
\text { Facility modification }\end{array}$ \\
\hline Storage facilities & aterial use-denial \\
\hline Transportation & Material use-denial \\
\hline Waste management plant & Facility modification \\
\hline
\end{tabular}


ANNUAL PLUTONIUM FLOWS WITH EIGHT LMFBRS

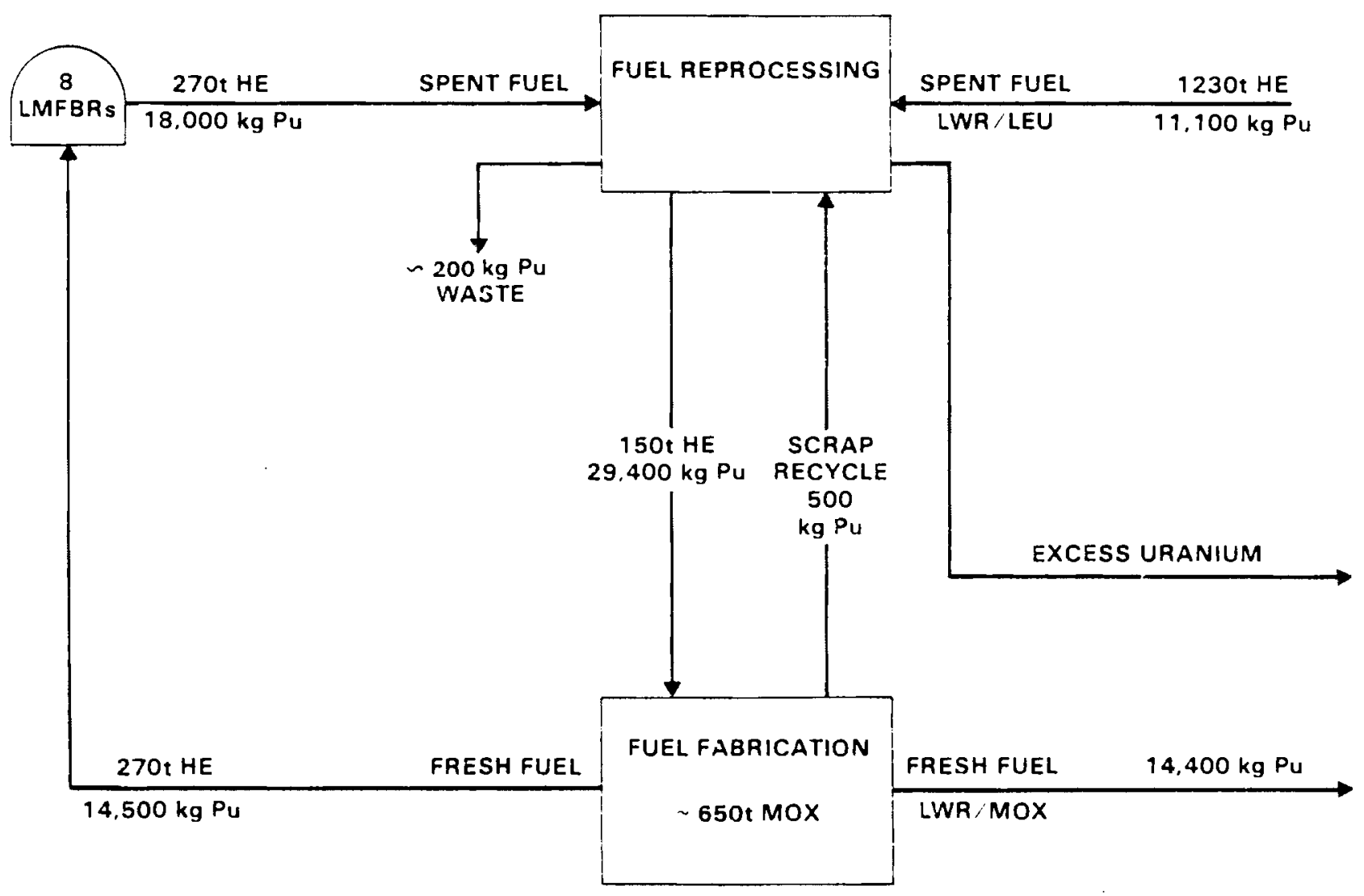

FIGURE 2.1. Annual Plutonium Flows in an IFSC Having 8 LMFBRs 


\subsection{DESIGN CONSIDERATIONS FOR PROLIFERATION RESISTANCE ENGINEERED FACILITIES}

The idea of designing the facilities for proliferation resistance is relatively new. Previous designs included surveillance, physical security and access limitations. More recently, advancements have been made in the concept of engineered safeguards systems, and innovations have been made in storage vaults and SNM transport systems. In general, these have been directed at preventing or detecting covert diversions and thefts, but not at the threat of a host nation physically taking over a facility and its contained SNM. This study, however, is primarily concerned with this threat and will address the question of how facility design can delay the host nation from obtaining the IFSCs weapons-usable plutonium.

Two questions relate to design that enhances deterrence to proliferation:

- How can facility design enhance passive deterrences to the threat of takeover by the host nation?

- How can facility design simplify and increase the effectiveness of active use-denial methodology and help prevent circumvention of the penalties applied by the denial actions?

Design areas that have been identified for study and evaluation are:

- physical structure

- process equipment and piping layout

- process instrumentation

- process controls

- maintenance phitosophy

- remotization and automation of the processes

- access to SNM in process streams and storage

- engineered safeguards systems

Preliminary Design criteria for proliferation-resistant facilities will be identified as the conceptualization of PRE continues. Preliminary criteria include this partial list:

- All paths to weapons-usable plutonium should require an equivalent time. In other words, the time should be equal to or greater than the time required to obtain plutonium from spent fuel in a clandestine facility. 
- The safety of plant forces and the surrounding populace should not be jeopardized by intentional or accidental triggering of use-denial penalties.

- Environmental protection and safety systems should not be compromised by the facility designs or by the actions applied by the use-denial systems.

- The effectiveness of conventional safeguards should not be lessened as the result of the design.

Presentiy, the concept development for proliferation resistance is at an early stage. Conceptual designs require further definition of the nonproliferation requirements and synthesis of available technology into piausible systems. Systematic approaches to conceptual designs wiil be essential, and appropriate anaiytical methods may have to be developed to evaluate all of the alternatives.

Some of the factors that must be considered are discussed in the following sections. 


\subsection{THE COMMAND, CONTROL AND COMMUNICATION SYSTEM}

It is envisioned that a command, control and communication system $\left(C^{3}\right)$ will be essential in a proliferation-resistant IFSC that utilizes active usedenial technology. The system provides the capability for receiving intelligence that is needed from the various facilities in the IFSC to make decisions for activitating the use-denial actions (or rescinding decisions that have been made) and to send activating signals which authorize and arm the usedenial penalties.

This section describes the institutional framework in which the $\mathrm{C}^{3}$ system must function and the nature of the graded responses to adversary actions which are to be involved. Included are the relationship of the $c^{3}$ system to normal facility operation and the organizational structure in which the $\mathrm{C}^{3}$ system will operate. The constraints on the implementation of the system such as safety, cost reliability and protection against false alarms are key considerations. Finally, descriptions are given of representative logic systems which can be used in the $c^{3}$ system design.

\subsubsection{Institutional Framework and Assumptions}

The actions that a $\mathrm{c}^{3}$ system would be designed to invoke are obstructive and/or destructive. When executed as intended, these actions may engender hostility. The existence of a $c^{3}$ system of this kind is therefore a manifestation of a set of declared and accepted understandings among the parties of the multinational consortium, one of whom is the host nation, and between the consortium and the IAEA. Consortium member nations will likely formalize these understandings with treaties or other records of accord. The commercial interests that constitute the consortium will further formalize the understandings with contracts.

The willing entry into these treaties and contracts has certain implications. First, given the multinational nature of the activity, and the understood existence of the $\mathrm{c}^{3}$ system, the treaties, in effect, constitute--

- a statement by the host nation that it has no intention of taking control of SNM at the center, or the center itseif, for the purpose of creating nuc? aar weapons, 
- recognition by the nost nation of the prospect of externally applied actions to SNM at the center and the center itself, in the event that at some future time it shouid abrogate and attempt to divert SNM, and

- acceptance by the host nation of the legitimacy of a multinational presence at the center operating in roles to which the consortium and the host nation have agreed.

Second, the implications of the host nation's legitimate concern for the safety of its citizens, and its ultimate sovereignty (unless an extraterritorial entity is created) leads to a set of assumptions which influence $c^{3}$ system design.

The host nation is assumed to fulty understand--

- ail of the fixed design and construction details of the center

- all of the process design and operating details

- the location and nature of storage of all materials at all times

- the design, procedures and operation of the conventional safeguards system

- the design, procedures and operation of the $c^{3}$ system and the set of graded action it is designed to invoke.

It is assumed that the host nation can be denied access to the changeable codes that are usad within the $c^{3}$ system for the control of the active measures at its disposal. This is the only information assumed to be unavailable to the host nation.

It is also assumed that the host nation has trusted experts in its employ whether they be $i$ ts own or other nationals. These experts will provide an independent assessment to the host nation of the safety, reliability, environmental impact, vulnerability to false alarms, etc. The assessment by these experts wiil provide a basis for approval of the IFSC by the host nation under its own regulatory and licensing structure.

This assumed independent assessment has positive value in that it enhances the base for the host nation and its citizens to accept the IFSC. The negative aspect is that the experts would gain such technical knowledge and competency through the detailed disciosures th:t from the very outset, they would be able to design schemes to circumvent the system. 
The existence of these experts and the concern with possible circumvention would dictate a high level of sophistication in the $c^{3}$ system design.

\subsubsection{Graded Responses}

There is a central focus in the design and discussion of the $\mathrm{C}^{3}$ system-the active measures invoked will be of graded severity. The least severe measures will be invoked first and progressively more severe measures will be invoked as the reality of a takeover becomes more certain. Graded measures are essential because damages created by each such measure are twofold and the steps leading to their invocation are inevitably uncertain. There is the intangible damage to the relations between the consortium and the host nation and the tangible monetary damage to materials, facilities, or production at the IFSC. The signals that will lead to the invocation of active measures by the $\mathrm{C}^{3}$ system will be those that indicate that a takeover by the host nation is imminent or in progress. As it happens in the early assessment stages of any military attack there will be uncertainty as to the exact nature and intent of what appears to be in progress. For example, a peaceful daylight protest demonstration by several thousand students could be just that or it could be a cover for the first steps of a takeover.

The measures of graded severity that could be invoked by a $C^{3}$ system are illustrated by the following examples:

- Materials

- disrupt closed loop system controlling access to $\mathrm{PuO}_{2}$ storage vault

- lock vault doors

- initiate thermite in $\mathrm{PuO}_{2}$ canisters

- Facility cperability

- scramble process computer software (Controlled shutdown)

- disrupt operation of process instrumentation

- coded disablement of process control equipment, transportation immobilization 
The denial responses in each functional area range from mild to destructive. The gradation has been 1 isted to demonstrate that responses of increasing severity are available as the uncertairity of the situation surrounding an overt takeover diminishes.

A $C^{3}$ system operates within a context of the active responses it invokes. A major element of that content is the immediacy of the impacts made by those responses. Disruption of all of the material flows at an IFSC may not affect (for several months or more) any IFSC electric power generation capability. The fuel delivery process that is ordinarily carried out over several months, and the quality assurance and inspection procedures employed in fueling reactors are such that reactors outside the IFSC whose fuel is supplied by the IFSC would experience no impact on their generated electrical power for several months following total cutoff of fuel supplies by the IFSC. (a) The absence of any immediate effects on power generation inside or outside the IFSC means that any active disruption of the IFSC, except for the power-generating reactors, will have only monetary effects. Also, these effects will be confined to the consortium and the host nation. This, in turn, means that those operating a $\mathrm{C}^{3}$ system can be somewhat iess concerned about invoking active disruption measures.

Disruption of power-generating reactors at the IFSC could be quite another matter, depending upon who the power users are. If the IFSC supplies a significant amount of power to the host nation, then disruption of this power would be a plausible final denial action having a major economic impact on the host nation. The disruption of significant amounts of electric power to nations other than the host creates the possibility of political and military initiatives by these nations to lead to the restoration of electric

(a) This time delay can, of course, te enhanced by increasing the lead time used by offsite reactors in obtaining fresh fuel. Increasing this lead time incurs monetary costs associated with nonproductive inventory, but of greater concern, it increases the amount of SNM in storage at many sites outside the IFSC. An institutional al cernative exists for offsite customers in the form of a guarantee of a time?y fuel supply from a high confidence second source, e.g., the U.S. 
power. The significance of these observations related to electric power is that they provide one design avenue to deterrence; a host nation could be chosen that would depend on the IFSC for a significant part of its electric power.

\subsubsection{Relationship of the Command, Control and Standard Communication System (c3)}

The IFSC will consist of a number of individual large facilities, including a reprocessing plant, a fabrication plant, a storage facility, a waste management facility, one or more power-generating reactors and a transportation system. Each such facility will have some form of internal safeguards structure that controls its operation in terms of management, process control, materials accounting and safeguards. A representative comprehensive internal structure of this kind is that used in a fuel reprocessing plant, an example of which is shown in Figure 2.2.(a)
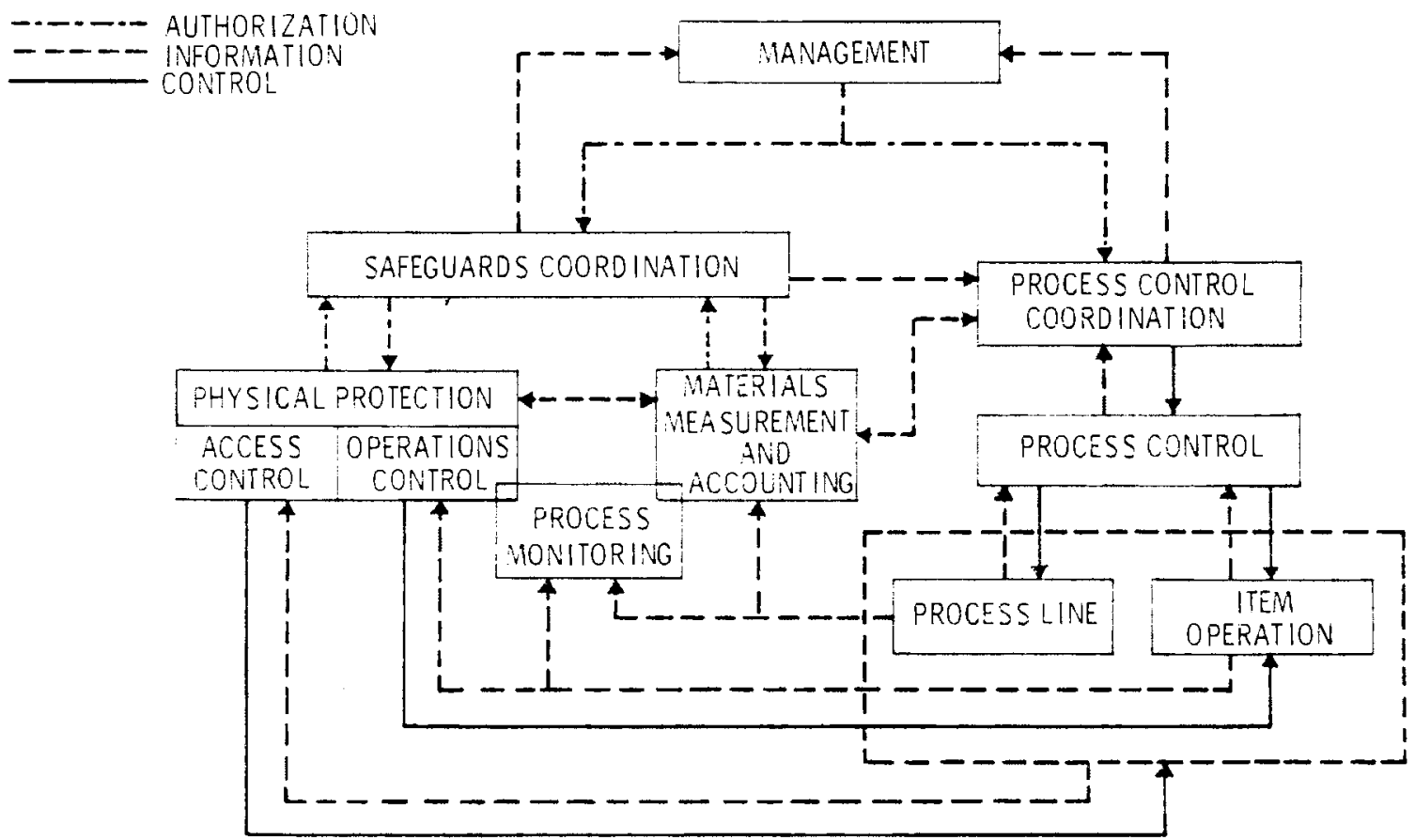

FIGURE 2.2. Safeguards System Structure for a Typical Facility

(a) Figure is reproduced from E. A. Hakkila, et al., Coordinated Safeguards for Materials Management in a Fuel Reprocessing PTant, Report LA-683T, Vol. I, Los Alamos Scientific Laboratory, 17 August 1977. The report uses the facility at Barnwell, Sc, as a reference facility. 
The $C^{3}$ system presentiy under consideration is motivated by and responsive to a set of considerations different from that which lead to the structure of Figure 2.2. The $C^{3}$ system is designed to respond to the threat of a large-scale overt takeover. The safeguards structure of Figure 2.2 is a response to the conventional terrorist or diverter subnational threat and the covert national (preparation for an overt takeover) threat. The difference between safeguards and $C^{3}$ in terms of the underlying concerns, and the nature of the responses each might invoke, argues that the two systems should be functionally independent to minimize undesired interactions. Thus, the safeguard system can be viewed as a source of supplementary information inputs to the $c^{3}$ system, and the control activities of the $C^{3}$ system directly impact the operational processes within the facility. These interactions are shown in Figure 2.3, where Figure 2.2 represents a typical facility, but the interconnections of Figure 2.2 have been omitted in the interest of simplicity.

A goal in the consideration of the $\mathrm{C}^{3}$ system is that it be transparent in the normal operation of the facility. That is, with the exception of the presence of the multinational oversight at a given facility, the day-to-day operators and operation of a facility need not be aware of the existence of the $c^{3}$ system. In the absence of the overt takeover that motivates and invokes the $c^{3}$ system, people and machines associated with the facility should operate in exactly the same fashion as they would if there were no $c^{3}$ system.

\subsubsection{Organization}

The organizational structure within which a $C^{3}$ system will operate is shown in Figure 2.4. The shareholders and board of directors explicitly illustrate than an IFSC would resemble a civilian type of activity. That model rather than a military model is appropriate in considering the $c^{3}$ system. While the IFSC is a commercial activity, its existence will be the result of treaties and understandings among a consortium of nations which will have ongoing concern with the successful operation of the center. The primary interest of the consortium in an IFSC is not in the fuel reprocessing and fabrication as such. Rather, the primary interest 


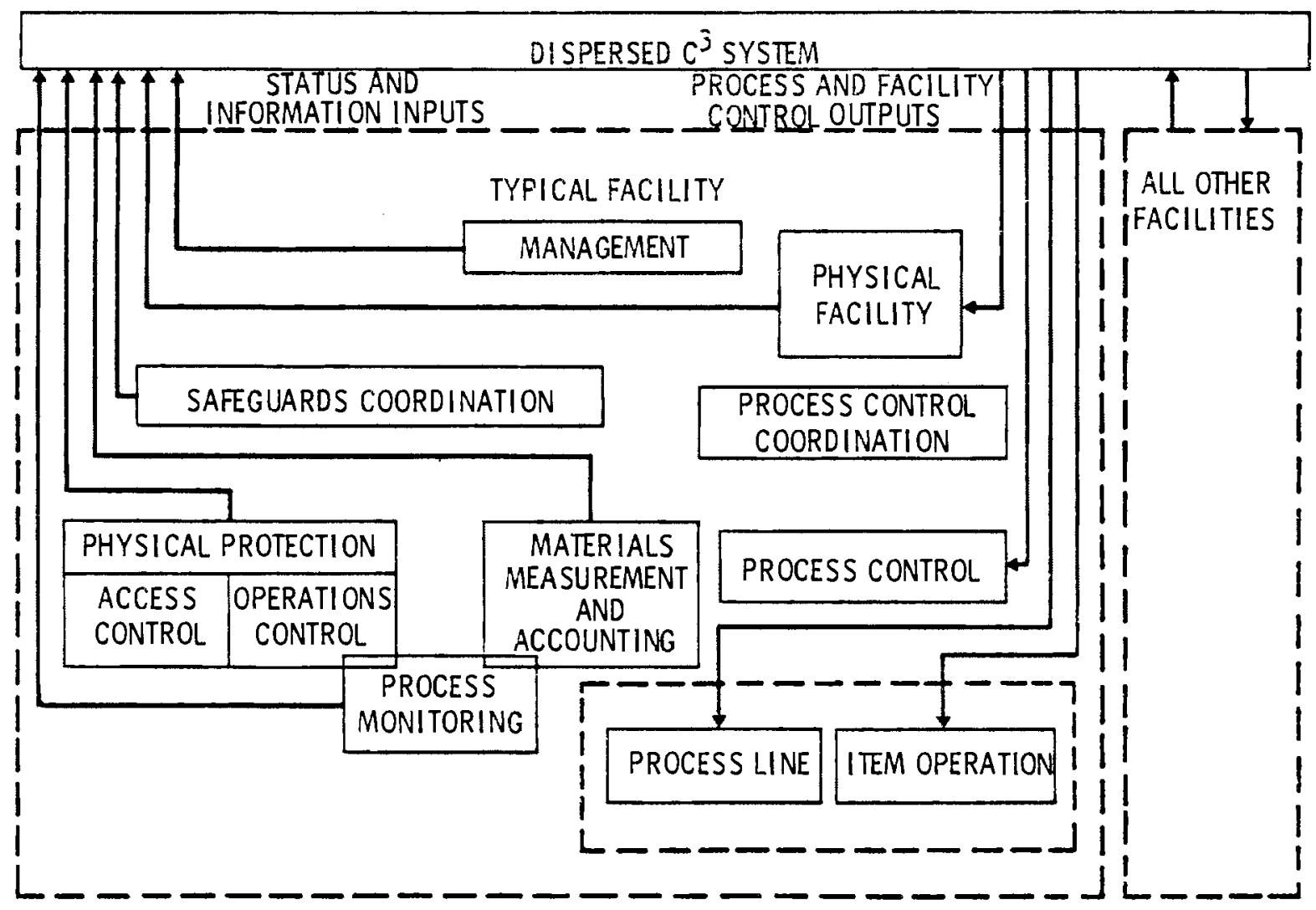

FIGURE 2.3. Interactions of $\mathrm{C}^{3}$ System with IFSC Facilities

is in the electric power whose production is made possible by the fuel produced at the IFSC. This delineation is emphasized because it determires the attitudes of a 11 members of the consortium, except the host nation, with regard to actions that might adversely impact any but power-generating capabilities at the IFSC.

Figure 2.4 also shows the geographicaliy dispersed nature of the $c^{3}$ system with elements inside and outside the host nation. The $c^{3}$ headquarters outside the host nation will have the overall authority and responsibility for the operation of the $\mathrm{C}^{3}$ system in accordance with the policies created by the board of directors and implementing instructions from the operating officers. The $\mathrm{c}^{3}$ headquarters may be staffed at a decision-making level by representatives of each of the nations participating in the consortium. Decisions that impact the operation and operability of the center will be made under procedures endorsed by the board of directors and accepted by the 


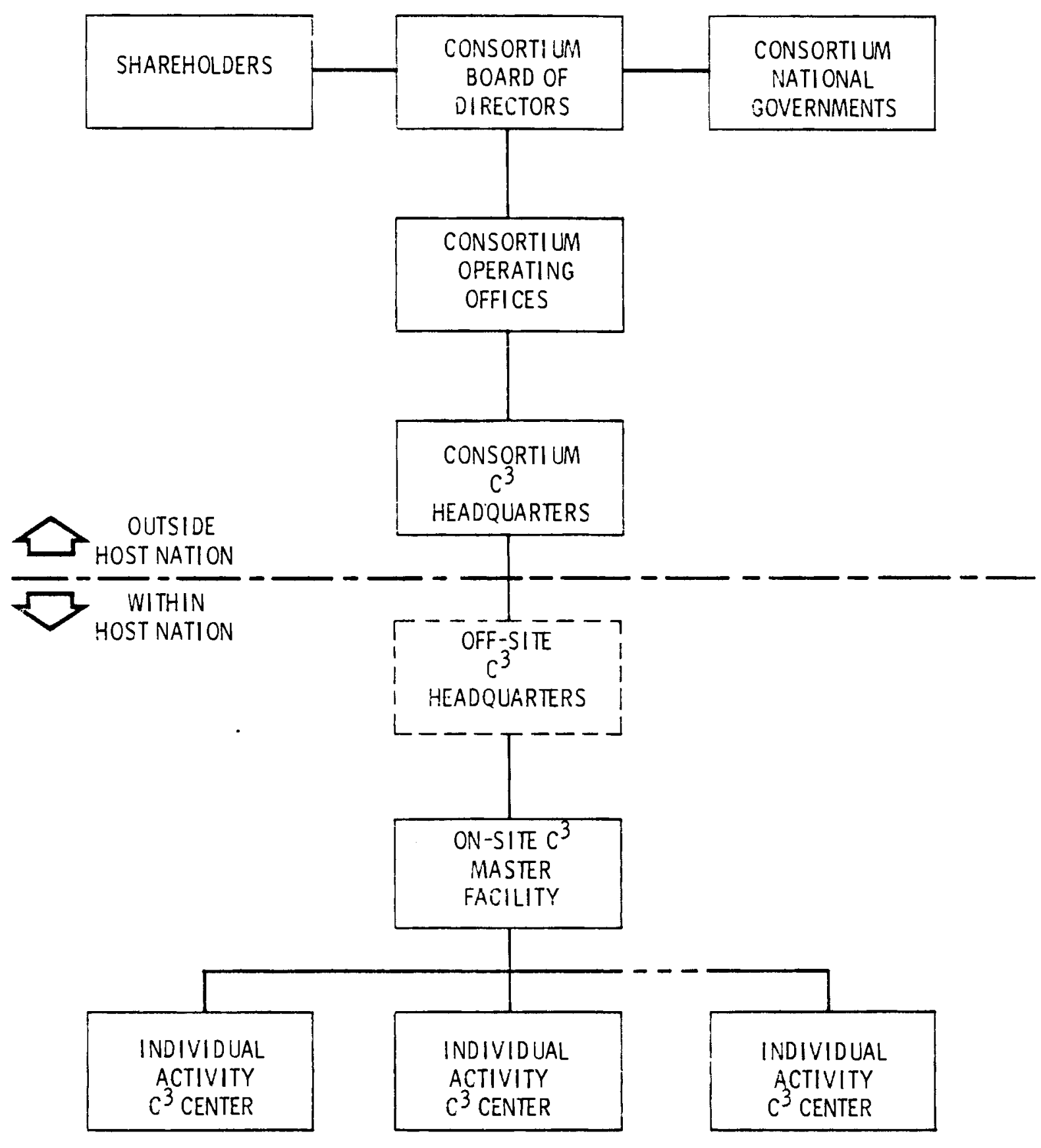

FIGURE 2.4. $C^{3}$ Organization 
national governments in the consortium. The $c^{3}$ headquarters are shown in the figure as located outside the host nation specifically to isolate it and permit its continued function in the event of a takeover by the host nation.

Within the host nation an off-site $c^{3}$ headquarters and an on-site master $\mathrm{C}^{3}$ facility are shown. Both have multinational staffs that operate under the same decision-making rules as the $c^{3}$ headquarters outside the host nation. The off-site headquarters within the host nation, shown in dotted lines, is functionally redundant, and further analys is may show that the $c^{3}$ system can be designed to function with acceptable confidence without it. The off-site headquarters has the same capability as the on-site master $c^{3}$ facility. The off-site headquarters provides backup operation and communication capability to enhance system reliability in the face of conventional equipment malfunction. Its existence off-site, in a population center near the IFSC, provides a highly visible point that must also be disabled as part of an overt takeover by the host nation. This requirement increases the coordination problem of the host in a takeover. The taking of multinational hostages at an off-site center further raises the hostage negotiation level after a takeover.

The function of the multinational groups at the on-site $c^{3}$ master facility and the two headquarters groups is to receive status information from the $C^{3}$ centers at each of the activities that constitute the IFSC, remotely monitor key aspects of the processes at each facility, and, in the event of a takeover, implement graded responsive actions in accordance with previously established procedures.

The organization chart of Figure 2.4 displays geographical diversity and progressively greater responsibility (from bottom to top). It is not meant to suggest sequential communication and decision paths. The consortium $\mathrm{c}^{3}$ headquarters, the off-site $C^{3}$ headquarters and the on-site $c^{3}$ master facility have independent communications among themselves and through the on-site master, the tiwo off-site headquarters have communications with each of the individual activity $\mathrm{C}^{3}$ centers. The decisions allocated to each are shown in Figure 2.5. In the figure, the desisions and the consequent actions have been ordered in 


\section{Consortium $\mathbf{C}^{3}$ Headquarters \\ Off-site $C^{3}$ Headquarters \\ On-site $\mathrm{C}^{3}$ Master Facility \\ Individual Activity $\mathbf{C}^{3}$ Center}

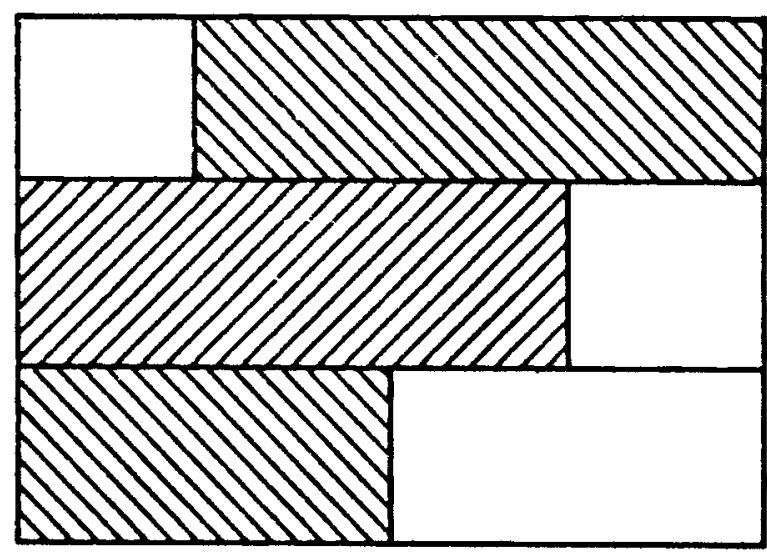

LEAST

MOST

Value of Material or Activity Denied to Host Nation After Takeover

\section{FIGURE 2.5. Graded Denial Actions and Control Source Location}

terms of the value of material or activity denied to the host nation after a takeover as a result of the actions. The concept of value at the present stage of the analysis is an abstraction that remains to be further defined. One clear component of value is that an action must be invoked when needed, or it may never have meaning. For example, it is not meaningful to deny access to a material storage vault after the stored material has been removed.

The control sources for the available graded denial actions are distributed as follows: decisions will be made at the lowest possible level that has the authority, since progressively higher decision centers are increasingly more remote from the actuality of the situation; the entire situation will be displayed at all centers; when the lowest level center with authority to execute an action is inoperative (perhaps because it has been overrun), the decision requirement passes up to the next operative center; decisions associated with the lowest value actions in Figure 2.5 are excluded from the control of the consortium $\mathrm{C}^{3}$ headquarters (this keeps the lowest level decisions within the independent decision domain of the lowest level headquarters and does not burden the highest level headquarters with these lowest level 
decisions); the low middle range of decisions is within the scope of all four decision-making groups and can be independently executed by all groups; progressively higher level decisions are excluded from the control of the lowest level center, and the highest va?ue decisions are limited to the control of consortium $\mathrm{C}^{3}$ headquarters where the senior most decision makers are located.

The role of IAEA and its on-site inspectors is not explicitly shown in Figures 2.4 or 2.5. The IAEA presence provides another international presence which is sensitive to other than normal activities at each activity center and within the overall facility. The IAEA representatives can informally report their sense of other than normal activities to IAEA headquarters for evaluation and transmission to the consortium operating officers. They also constitute another potential path to alerting the outside in the event of a takeover by the host nation.

\subsubsection{Implementation}

This section describes example logical systems that couid be used to control the active graded responses invoked by the $c^{3}$ system. The systems presented are intended to demonstrate the feasibility of the denial functions. They are not represented as definitive or optimal designs. Arriving at final designs will require substantial additional detailed work that takes into account the actual design parameters of the IFSC.

The following terms are defined to provide a more precise understanding of the $c^{3}$ concept.

Denial Action A denial action consists of an action or set of actions taken by a person or apparatus to bring about a change in the state of operability or functioning of equipment, or the accessibility of SMM at a location within an IFSC. The denial action is caused by the insertion of a control signal that would ordinarily be electrical in form. 
Denial Node A denia? node is a iocation within an IFSC where a denial action takes place. It is, for examele, a location where a change of one of the following types that consitute denial actions colild take place.

- disruption of a facility control system

- disruption of a process computer

- changes in a process flow or operation

- obstruction of people or material movement paths

- changes in accessibility of SNM

- changes in the physical and/or chemical form of SNM

- other undefined actions

Thus, for the present purpose, an IFSC consists of a large number of points identified simply as denial nodes. A generic denial is accompiished at a denial noce by some (unspecified; denial action. Enabling $C^{3}$ system An enabling $C^{3}$ system is one in which the generation of the signals that constitute the major output of the system permits al1 normal IFSC activities to continup without interference. The absence of the required signals at some activity within the IFSC will cause denial actions to be invoked and these in turn will lead to interference with normal activities. In the limit, if all of the people associated with an enabling $C^{3}$ system were to vanish, and hence all of the enabling signals were to cease, al1 processes at the IFSC would stop, and al1 materials would be impounded.

Disabling $C^{3}$ system $A$ disabling $C^{3}$ system is one in which the generation of the signals that constitute the major output of the system prevents the continuation of normal (and abnormal) IFSC activities. The presence of the disabling signals at some activity within the IFSC will cause denial actions to be invoked and these in turn will lead to interference with normal (and abnormal) activities. Again, in the limit, if a 11 the people associated with a disabling $C^{3}$ system were to vanish, and hence no disabling signals were ever created, $a 11$ processes at the IFSC would continue and the state of all materials would persist as they would if there were no $\mathrm{C}^{3}$ system. 


\section{Requirements on $C^{3}$ System Implementation}

A conflicting set of requirements is placed on the implementation of the $\mathrm{C}^{3}$ system. Enumerating them makes it clear that any implementation (when finally chosen) represents a set of arbitrary design compromises and choices. The conflict in the requirements stems from the fact that most denial actions taken to delay the availability of material to the host nation and operability of facilities by the host nation impact the ordinary activities of the IFSC and the sensibilities of the host nation.

The safety requirements are primarily upon the design of the denial actions. The denial actions should be such that some change in the accessibility or state of the materials or equipment

- does not injure facility workers in the ordinary industrial accident sense

- does not expose workers to excessive doses of radiation

- does not lead to criticality conditions

The delay being sought will be achieved (in almost all cases) by effecting some change in the materials or equipment within the IFSC as a result of some active denial actions invoked by the $c^{3}$ system. Each such change will have associated recovery times and costs. The concern with these times and costs leads to requirements which again are fundamentally requirements on the design of the denial actions, namely that--

- the recovery time be a maximum (cost here is secondary) when the denial action is correct and recovery is being accomplished by the host nation alone.

- the recovery time and cost be a minimum when the denial actions invoked by the $C^{3}$ system are inappropriate, i.e., the result of a false alarm.

- the recovery time and cost be a minimum when the denial action is correct, but a diplomatic process has been successful and recovery is being accomplished by the consortium. 
These requirements are upon both the denial actions and the $c^{3}$ system elements that invoke them. The kinds of elements that will be involved in the denial actions are expected to be relatively simple electrical detonators, electromechanical devices, mechanica? devices, hydraulic devices and pneumatic devices. There is a significant amount of experience with these devices which suggests that the reliability requirement ${ }^{(a)}$ will focus upon the parts of the $c^{3}$ system that generate the control signals to invoke the denial actions. In any case the reliability requirement is stated for the overall $c^{3}$ system in classical terms; namely, that the $\mathrm{c}^{3}$ system should function--

- with very high reliability when it is required to function

- with very few false alarms that are due to procedural or equipment disorders or in response to spurious stimuli

Fallback manual modes of operation are always provided since any facility design anticipates failure of process equipment and controls, instrumentation, communications, and power. In this sense, the design of each part of the facility becomes an integral part of the $c^{3}$ system design, and specifically the facility design shouid be such that--

- any manual overrides provided do not provide a means for circumvention of $c^{3}$ denial actions

- the elimination or minimization of manual overrides does not compromise facility safety.

Reliability

The question of $c^{3}$ reliability is central to the entire design. Two aspects of the question merit further attention here; the failsafe and false alarm aspects.

(a) A third alternative which is not of interest here, is to ignore this question in the design process and let the disruptive actions take place, or not, in the event of a failure, purely as a random consequence of the balance of the design. 
Since the end result of the $c^{3}$ system operation is the invocation of active denial steps which lead to graded levels of disruption, the consequences of a failure in the system are of particular interest.

The designer has several options open to him. A design can be constructed to prevent the end result denial action from taking place in the event of any possible failure. (a) The alternate design could assure that the end result disruptive action will take place in the event of any possible failure. (a)

The choice between failure with no action or failure with action at each denial node is initially within the scope of the gross system design. Guaranteed failure with no action invites the host nation to seek means to induce a failure in preparation for or during the early phase of an overt takeover. Guaranteed failure with action means expense to recover from an incorrect action. The overall system designer might choose to work guaranteed failure with action into (some of) the lowest level denial nodes, al though the center would have to be prepared to incur the recovery costs; this option would serve to remind the host nation operating personnel that the $c^{3}$ system, while usually invisible, is present and operating right down to the end function.

Two additional attractive options are available to the designer. First, the operating condition of every denial channel can be tested and essentialiy monitored continuousiy. In the event that a failure (actual or incipient) of any kind is detected, the $c^{3}$ system can bring the IFSC to a high alert state and initiate actions to respond to the detected failure. Second, the design of each denial channel can be such that the choice of failure with or without guaranteed action can be an operating choice at consortium $C^{3}$ headquarters rather than a fixed choice made at the time of design. An operating choice might, for example, be made by the $c^{3}$ system in going from guaranteed

(a) Both the high reliability and low false alarm rate question lead to the statistics of infrequent events. These statistics are inherentiy unsatisfactory because they provide a basis for only the most unsatisfactory kinds of assurances to lay decision makers. A statement such as "the probability of a false alarm in any 24 hour period is $10^{-5}$," is not assuring to a layman who has ever witnessed or become aware of any rare event, for example a U.S. military aircraft crashing into the Empire State Building, or an electric power lojs in the entire Northwest quadrant of the U.S. 
action at some deniai nodes in response to external stimuil. These stimuli might include, for exampie, one or more unexplained equipment failures or other occurrences at the IFSC in a relatively short period of time, or alarm signals from one or more intrusion sensors.

A deliberate design approach is available to counter false alarms. This approach is incorporated in the representative enable and disable logic systems described below. The approach is to use a three-step process in the activation of each denial action--called authorize, arm and initiate. The design approach calls for the three steps to be executed in the sequence stated, each in response to a specific command. It also requires that the actual denial action does not occur until the last of the three commands has been received. (a) The three-step process is commonly used by the military to reduce the probability of unintended actions, i.e., faise alarms.

Making the paths independent for the three steps results in an overall false alarm probability which is the product of the probabilities of false alarms along each path. Thus, if the probability of a false alarm along each independent path during a 24 -hour period is $10^{-4}$ (a plausible value) the overall faise alarm probability is $\left(10^{-4}\right)^{3}=10^{-12}$. (b) Although a probability of false alarm in 24 hours of $10^{-4}$ is not likely to be acceptable to the consortium, a probability of $10^{-12}$ does seem likely to be accepted. A false aiarm probability of $10^{-12}$ associated with a denial action at one denial node,

(a) The multiple command process is used, for example, in detonating the warhead of an air defense missile. The authorized stop here is the connection of the firing circuit to an electrical power source. The arm step is accomplished by an arming mechanism when the missile accelerates as it leaves the launcher. The initiate step then takes place in response to a command from the missile guidance system.

(b) This type of logic, which reduces the false alarm probability, simultaneously reduces the reliability of the denial action. If the reliability of each of the three independent paths in a one-year period is 0.995 , the overall reliability is $(0.995)^{3}=0.985$. This effect is not of consequence for individual path reliabilities greater than, say, 0.98 , which can be achieved. As a point of reference, Sandia Laboratories, in its military technology work, has achieved path reliabilities which, stated in these terms, are greater than 0.999 . 
and the likely presence of $10^{2}$ to $10^{4}$ denial nocies over the entire IFSC implies a false alarm probability over the entire IFSC of $10^{-10}$ to $10^{-8}$. This range of values still appears likely to be acceptable to the consortium.

Finally, it should be noted that there is nothing unique about the use of a three-step process. A smaller or larger number of steps could be used. Using a smaller number of steps will increase the false alarm probability as seen above. Using a iarger number of steps will further decrease the false alarm probability, at the cost of additional equipment complexity. Experience suggests that the use of three steps will be adequate, but going to a larger number is an available design choice that remains open.

\subsubsection{Steps Required to Deactivate the Use-Denial System}

A system employing disable logic is described here first because it is conceptually simpler and easier to describe than the enable logic discussed in subsection 2.2.7.

A representative logic system for cancellation of the denial signal at a typical denial node through the use of disable logic is shown in Figure 2.6. At the first sign of an actual (or perhaps impending) takeover, the authorize signal is transmitted by the $\mathrm{C}^{3}$ system to the control equipment which activates the authorize gate. The activated gate is displayed (by means of lights and horns) at the denial node to alert people and is displayed also at the several $C^{3}$ centers. In the event that the problem that led to the transmission of the authorize signal is resolved, or if it is determined that the signal was the result of a mechanical false alarm, the $c^{3}$ system can transmit a signal to reset the authorize gate. (a) The ability to generate reset signals is limited to consortium $C^{3}$ headquarters to minimize the likelihood that the host nation could use the resets to defeat the system.

(a) The use of coded signals for both activation and reset will reduce the suspectibility of false alarms and a! so to reset signals generated by the hos: nation. The use of coding is equally applicable in the enable approach. 


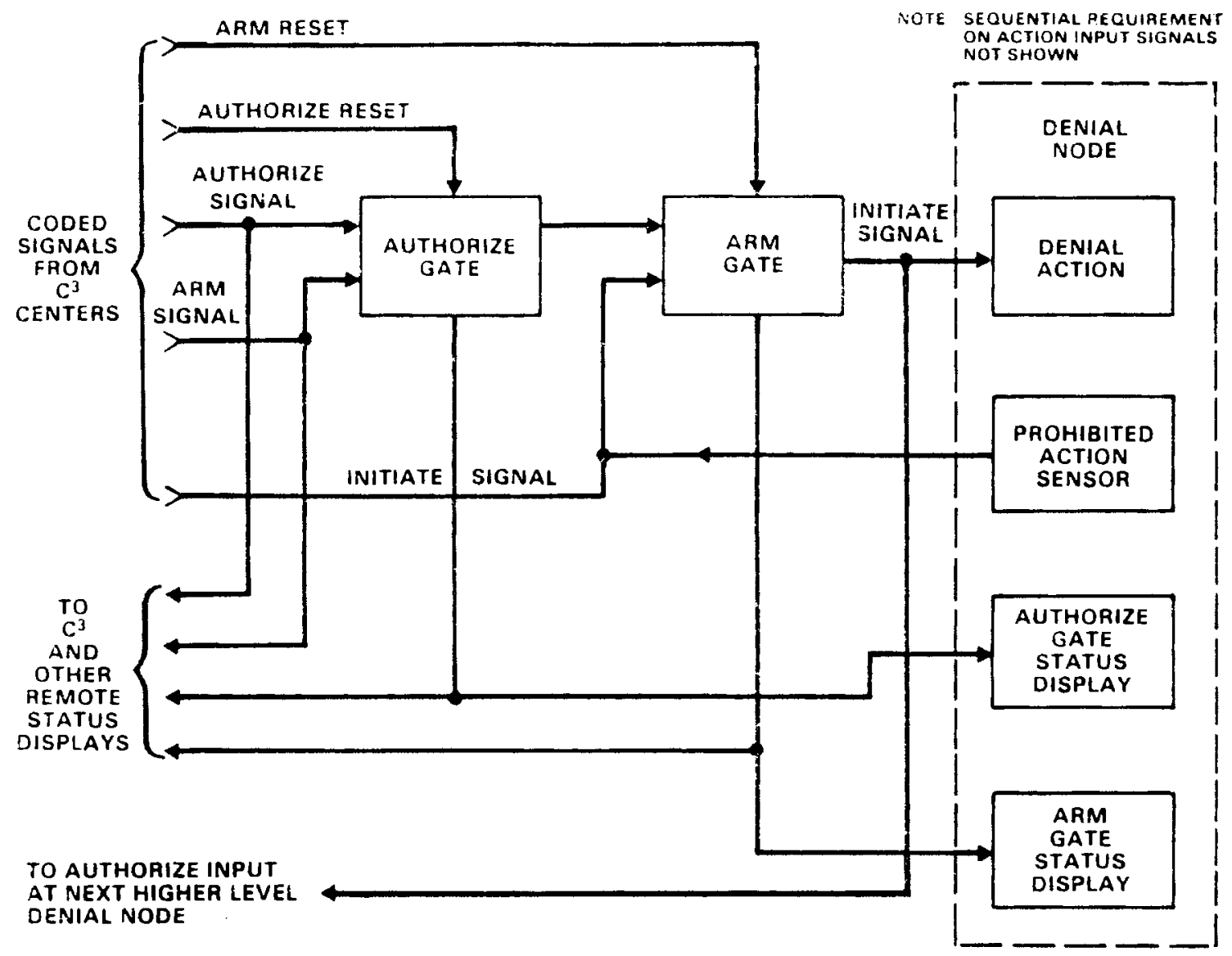

FIGURE 2.5. Steps Required to Deactivate Use-Denial System

If the cause that ied to the authorize signal persists and the situation grows more intense, the $c^{3}$ system will transmit an arm signal which can now pass through the authorize gate that was previously activated and activate the arm gate. Again, provisions for local and remote displays and gate reset are shown in Figure 2.6.

If the situation grows sti11 more intense and a decision is made witnin the $c^{3}$ system to carry out the denial action at this particular node, then the initiate signal is transmitted. Upon receipt, this signal can pass through the arm gate which had been previousiy activated. No recall or reset mechanism is provided for the initiate signal. A prohibited action sensor is shown within the denial node in Figure 2.6. This sensor will be appropriate at most nodes, but most likely not at al1 nodes. It generates an initial signal in response to its detection of a prohibited action at a node. A prohibited action is one that becomes so designated after authorize 
and arm signals have been received. For example, a crane used to move SinM containers might be a denial node, and operating its controls after the authorize and arm signals have been received could be the prohibited action. An example of the denial action in this case could be electrically destroying the windings of the crane motors.

A connection is shown in Figure 2.6 from the initiate signal line to the authorize signal input at the next higher level denial node. This connection is shown as an example to make expicit the opportunities for interconnection that exist among the nodes. As an alternate to the connection shown, a choice could be made to take the arm signal, after it has come through the authorize gate, as an authorize input signal at the next higher level. In this case, the initiate signal from the lower level node could be used as an arm signal at. the higher level node. The logic offers a large number of possible design choices.

It would serve only to unnecessarily complicate Figure 2.6 to show apparatus that implement the sequential requirement on the authorize, arm, and initiate signals because this capability is straightforward.

It is, however, evident in Figure 2.6 that, as previously noted, the use of the three-step approach (authorize, arm and initiate) is not unique.

Figure 2.6 also demonstrates some of the assertions made earlier concerning the properties of a disabling approach. It is clear from the figure that the denial action will not occur unless the deliberate decisions to authorize, arm and initiate are made by a decision group which is able to act and communicate its decisions to the logic system at the denial node. If the decision groups within the host nation are prevented from acting because they are taken hostage then the decision and action burdens revert to consortium $c^{3}$ headquarters. Note from Figure 2.6 that this level implies taking multinational hostages at a number of $c^{3}$ locations (typically six) and a number of operating and decision-making multinationals at these locations (typically 48). This level of multinational hostage-taking invites responses by several nations and raises the question of an act of war. The 
ability of the $c^{3}$ groups within and without the host nation to execute their role is also totally dependent upon communications that work. In order for the disable logic to function, communications from the $c^{3}$ centers to the denial nodes must also function. In order for the $c^{3}$ decision makers at locations removed from the individual IFSC functional activities to be able to understand and assess the situation, communications from the IFSC to the $C^{3}$ activities and among the $c^{3}$ activities must function. Thus, in the disable logic, at least those communications directed to the denial nodes must function in order for the denial logic to work. One immediate suggestion that emerges from this observation is that for at least some denial nodes, the loss of communications with the balance of the $c^{3}$ system will constitute a prohibited action whose occurrence cculd lead to an initiate signal if authorization and arming have al ready occurred.

Finally, it must be noted that the implementation of denial nodes and the creation of disable logic systems constitute an inviting situation for the prospective saboteur. He need only find a way in this circumstance to activate the authorize, arm, and initiate signals, or to cause one of the $c^{3}$ groups to do so. The heightened concern regarding the saboteur reinforces the need for the conventional safeguards system to deal with the saboteur as part of the sub-nationāi threat.

\subsubsection{Representative Denial Employing Enable Logic}

A representative logic system employing enable logic is shown in Figure 2.7. The right half of the figure and the function of the elements is identical to what is shown in Figure 2.6. The difference between them 1 ies in the source of the coded authorize, arm and initiate signals. In Figure 2.7, they are generated within the denial logic and passed to the balance of the system unless prevented from doing so by gates on the individual signals controlled by delay timers.

The action of the timers is as follows: Suppose that the authorize timer is a four-hour delay timer. After it has been reset to zero, it produces no output to close the gate for the authorize signal until four hours have elapsed. After four hours have eiapsed, it the timer has not 


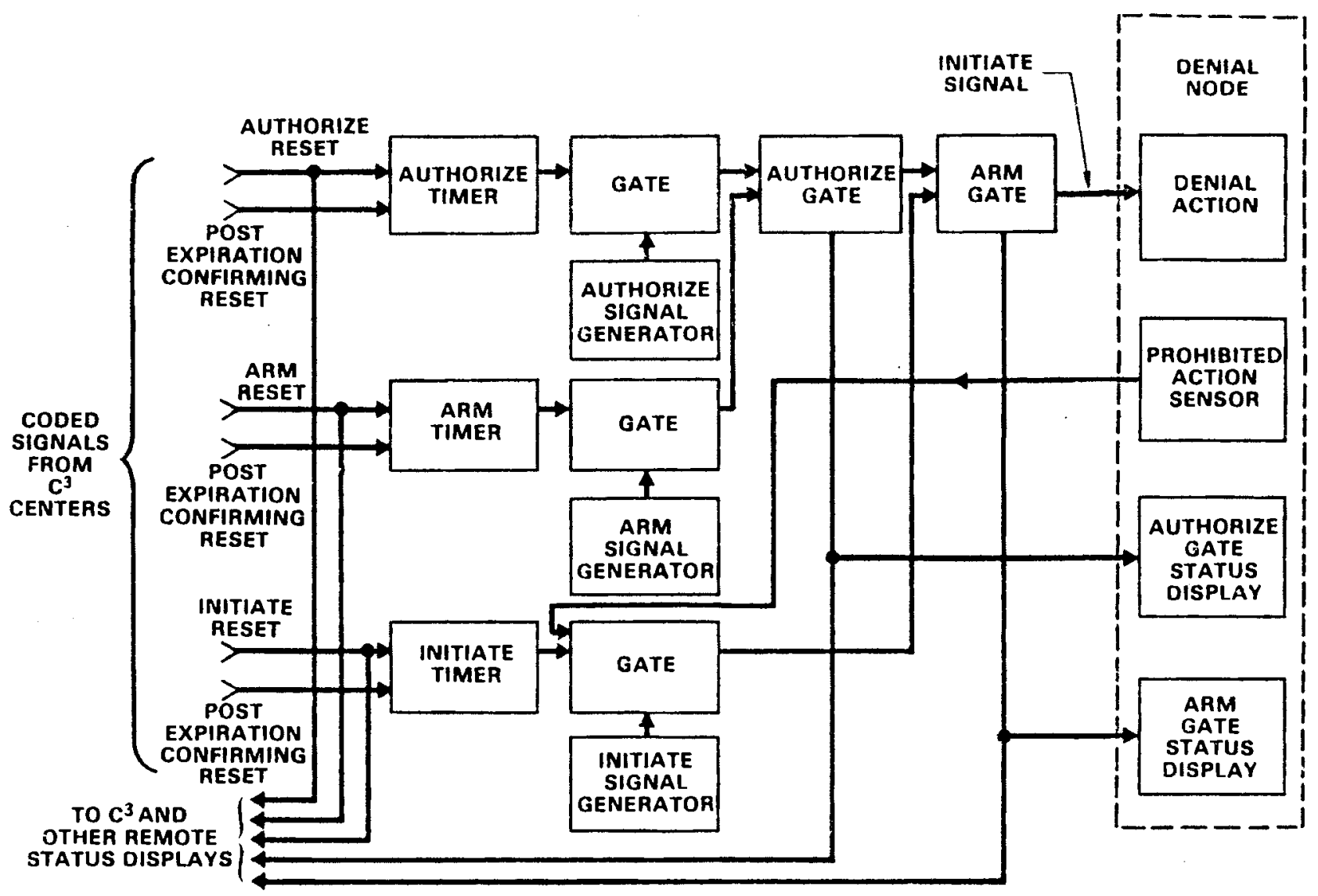

FIGURE 2.7. Enable Denial Logic

been reset by a signal on the authorize reset imput 1 ine, it will produce a signal that will close the gate and permit the coded authorize signal to pass to the authorize gate and close the gate. The arm timer and initiate timer function similarly. Thus, if as before, the authorize timer has a four-hour delay and the initiate timer has a six-hour delay, and all timers are reset simultaneously at time equals zero, the following sequence of events will occur. In the absence of an authorize reset signal, at time equals four hours, the authorize signal will activate the authorize gate and this status will be displayed at the denial node and the remote displays. In the absence of an arm reset signal, at time equals five hours, the arm signal will activate the arm gate and this status vill be dispiayed at the denial node and the remote displays. In the absence of an arm reset signal, at time equais five hours, the arm signal will activate the arm gate and this 
status will be displayed. At ary time aiter this, a signal from the prohibited action sensor wili close the gate and permit the coded initiate signal to pass from the initiate signal generator to and through the arm gate causing the denial action. If no signal is received from the sensor by time equal to six hours, the initiate timer will at that time cause the gate to close, either immediately or perhaps after a small fixed further delay, and permit the coded initiate signal to pass through and cause the denial action to occur.

Under ordinary circumstances, without any indication of actual or impending takeover, the lowest level $c^{3}$ activity charged with responsibility for a given node would routinely transmit the coded authorize, arm and initiate reset signals. If trouble were indicated, the responsible center would deliberately not transmit the coded authorize reset signal. If the indications of takeover persisted, the coded arm reset, and ultimately the coded initiate reset signals, would not be transmitied and consequence would be the denial action. The timers are designed so that after their time delay has expired they will no longer accept reset signals from the $c^{3}$ centers that ordinarily provide them. Thus, if after the time delay has expired, a determination is made that the circumstances that led to the local failure to provide a reset signal are no longer operative, or if the failure was a mechanical one, a reset can be provided from consortium $\mathrm{C}^{3}$ headquarters. This reset path is shown in Figure 2.7 as a post-expiration confirming reset.

It is likely that there would be nodes in an enable logic system in which no post-expiration confirming reset path is provided in the design. The characteristics of the nodes deemed appropriate for this approach remain to be completely defined, but high value (to the host) nodes where the timer delays are relatively long seem likely prospects. The rationale here is that at least to the extent of authorization and arming, these nodes are no longer under outside control in a hostage negotiation and the prohibited action sensor becomes controlling. 
Although the tie from the initiate signal to the logic of the next higher level node which is shown explicitly in Figure 2.7 , is not shown in Figure 2.6, ties of this kind are equally possible in the enable logic.

In the system employing disable logic, hostages might be taken to prevent their possible action. If hostages are taken in a system employing enabie logic, the purpose is to force them to act, i.e., to transmit the reset signals under their control and request transmission of those not under their control.

A hostage negotiation situation using enable logic is different from that using disable logic. With enable logic, the host nation (after a takeover) will seek to maintain communication to and from consortium $\mathrm{C}^{3}$ headquarters. The communications must be available to persuade the decision makers at $c^{3}$ headquarters to send the reset signals under their control. The communications required to transmit the reset signals must also be operative. Thus, broadly stated, with an enable logic, the host nation after a takeover is strongly motivated to keep all communications paths intact, while with a disable logic the host nation after a takeover is strongly motivated to put all communications out of operation.

Note also that in the case of enable logic, the communication system becomes a prime target for the saboteur, since its disruption $\$ 11$ lead to the invocation of denial actions. Again, the conventional safeguards system that responds to the saboteur as part of the sui-national threat is strongly required.

\subsubsection{Combined Disable/Enable Logic}

Some denial nodes within the IFSC are of particularly high value to the host nation after a takeover. Within this group there are some where time in executing denial actions is of the essence. One example of such a node is the SiM storage vault. The naterials stored are of great value. Rendering the vault inaccessible involves critical timing, since it must be accomplished before the SiM canisters are removed if it is to be meaningful. 
At high value nodes where timeiness is essential it is appropriate to consider the use of a combination of disable logic and enable logic to produce the signals that cause the denial action to occur. Combination here means that both the disable and enable logics are present and complete in every detail, as they would be if they were alone. The logic systems operate independently and either one, by itself, can cause the denial action to occur.

The motivation for the comination of logic systems at high value nodes where timeliness is of special concern, is as follows: If a node is equipped with disable logic only, the denial can be invoked promptly, provided the communications to the node are not disrupted. Thus, the addition of enable logic, which will function with certainty despite a loss in communication, provides a reliable backup. If a node is equipped with enable logic, the deniai can be invoked with certainty, but there are practical limits on timeliness. It appears linlikely that one would wish to use timers whose delay is much less than 15 to 30 minutes in an enable logic system. Thus, the addition of disable logic, which can function immediately provides a timeliness backup in the event that at least one of the redundant communication paths from a $c^{3}$ headquarters to the node is functioning.

The applicability of disable and enaile logic can tinen be summarized as follows: For the majority of lower value denial nodes and in particular for those that can be controlled from the individual activity $c^{3}$ center, an overall design would likely employ either disable logic or enable logic at such nodes. Tie design decision as to which is preferred at a particular node must await a more detailed definition of tice IFSC and the nature of the nodes available. For most of the higher value nodes, and in particular for the nighest value nodes that are solely under the control of the consortium $C^{3}$ neadquarters, one would expect to $f_{i}$ ind a combination of disable and enable logic. Again, the final determination must await a mora detailed definition of the IFSC. 
The choice of disabie logic or erabie logis at a node that employs only one will be determined by the nature of the node, since the cost of the two logic systems will be about the same. The selection of the nodes at winich combined logic is used will again be dominated by the nature of the node, but the additional cost of the second logic system and the associated communication, computer and display burden will be a consideration.

\subsubsection{Design Process Overview}

The block diagram shown in Figure 2.6 and the similar one shown later in Figure 2.7 are initial logical designs that serve to demonstrate the plausibility of the implementation of a concept. In translating this logical design into a final detailed design and design specification, a set of steps will be followed to insure that--

- the logic is correct in that it responds correctly to the functional requirements

- the estimated reliability as computed has at least the desired value

- the behavior of the system in the event of an isolated failure, a multiple failure, or a common mode failure (e.g., power supply) is as desired, i.e., fail with no action or take action in the event of a failure

- the logic cannot be defeated by signals injected from the outside by radio or over physical communication paths to the outside (e.g., wires or fiber optics).

A representative set of steps in reaching the final design and specifications is that which has been followed in developing DOE and NASA space flight equipment:

- One individual (or group) develops the initial design and specifications.

- Several other individuals (or groups) then do independent detailed design reviews in search of design deficiencies.

- The conclusions of all of the reviewers are shared with the original designer in a meeting where the deficiencies are discussed and an opportunity is provided for the discussion to stimulate an identification of additional deficiencies.

- The original designer takes the results of the reviewers' work in the meeting, and refines the design and specifications.

- The process is repeated until $: 0$ remaining deficiencies can be found. 
This process has been a major component in the development of equipment such as the unmanned Navy TRANSIT sateliites, more than half of which have been orbiting without failure of any kind for more than five years. 


\subsection{ACTIVE USE-DENIAL TECHNOLOGY}

This section provides examples of existing denial technology, used in other applications, that may contribute to PRE for the protection of a reactor fuel cycle. These examples have yet to be used to engineer an integrated PREP concept. The examples in this report are simply illustrations of defense-related technologies that represent high reliability technology, exhibit a potentially low premature rate, and have potential tamper-safing characteristics.

Other related concepts which are based, in part, on weapon release procedures are multi-key procedures, command logic, and security comunications. A final example from defense-related activities is not discussed in this portion of the report. This is computer software protection and anticompromise technologies developed by the NRL after the Korean Pueblo incident.

\subsubsection{General Concepts}

Figure 2.8 shows how the basic elements of an integrated proliferation resistance system might interact. The $\mathrm{C}^{3}$ or security command, control, and communication system is on the upper left of the figure. The array of sensors is on the right and would include the normal safeguards' processing sensors. The disruptive actuators and active denial penalties form the basis for design of a denial penalty node. These penalty nodes are physically distributed throughout the protected facility. Figure 2.9 is an example of a generalized active denial penalty node.

Examples of active use-denial elements for a PRE concept exist in the form of a variety of hardware. These items are:

- sensors

- disruption actuators 


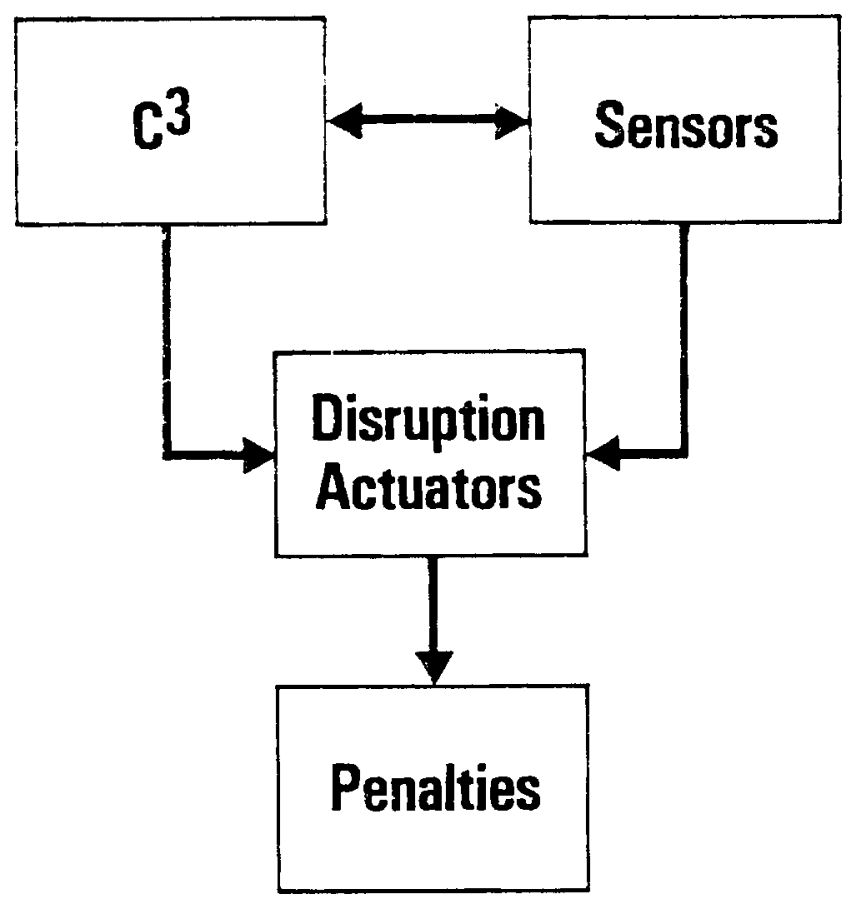

FIGURE 2.8. An Integrated System With Active Denial Penalties

TAMPER PROOF SENSOR

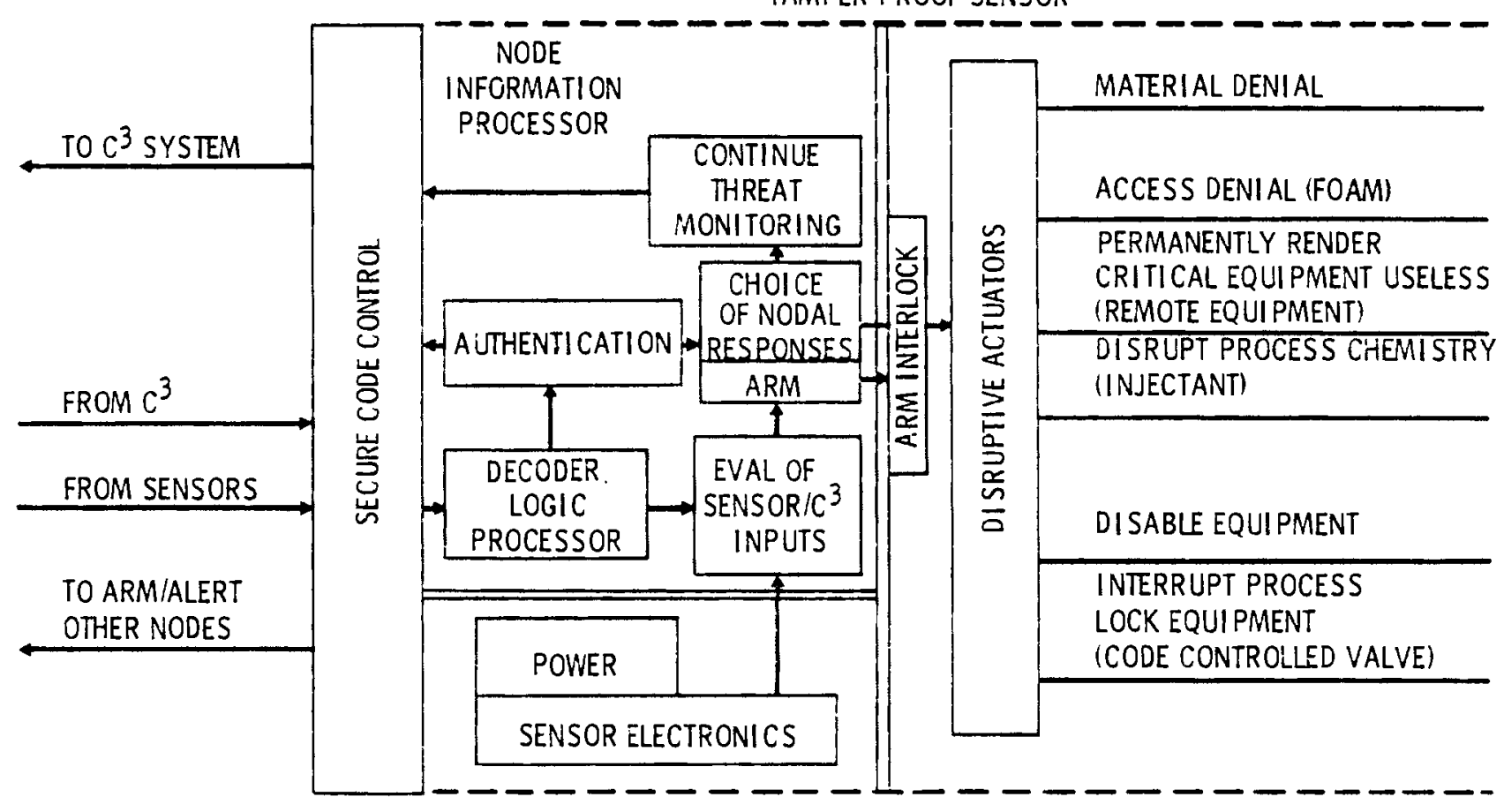

FIGURE 2.9. Example of a Generalized Active Jenial Penalty Node 
- transportation and storage máterial denial penal ty equipment

- facilities and process penalties to protect material involved in the processes and deny use of critical facilities to any intruder.

\section{Sensor Summary}

Acoustical sensors can monitor position and identity of reactor fuel elements in a cooling pool to ensure detection of any tampering or theft. A whole range of intruder detection sensors are presented in the Sandia Intrusion Detection Handbook, SAND76-00554. Examples of these are microwave, acoustic, infrared, seismic, and magnetic motion or penetration detectors. Alarm assessment sensors are basically closed circuit TV systems that allow a central command post to remotely and very quickly assess the cause of an alarm and determine the next course of action.

An important group of sensors are those that detect covert tamperings. Without protection, covert tampering could subvert some of the active use-denial elements of the concept. Random code control, fiber opicic transmission links, and fiber optic seals are particularly useful to ensure that there has been no tampering with critical code control elements of a system. And finally, there are the self-contained, sensorinitiated protection systems that could be used to tamper-proof critical parts of the system. These could be designed for intruder activation and, in some cases, they could also be the source of the most severe penaity actuation. Some representative code-controlled component examples are systems controllers, encoders, decoders, coded switches, strong-link safety switches, and electrical initiators. All of these have been developed in one form or another for defense programs.

\section{Transportation and Storage Penalties}

Transportation and storage penalty examples developed for PREP include the vehicle immobilization concept which has its origin in the safe secure transport (SST) systems. The SST systems were developed for DOE to 
transport critical materials and weapons in tne U. S. Lockup and disable penalties (including code control of remoze nandling equipment) are extensions of defense program command and control technology. Use of foam to impede access is an example of an access denial penalty that is applicable to both the transportation and storage modes. Finally, there is the material denial penalty where the character of the target SNM material is altered in order to deny its usefulness as a weapon material for a significant period of time. See section 2.3.3 for further information on material denial.

By coupling some of these penalties, it should be possible to delay a host nation's acquisition of SNM long enough to permit sanctions and other international responses to be effective against the seizure of an IFSC.

Facilities and Process Penalties

Facilities and process penalties are meant to deny use of critical equipment and material targeted from the process inventory. Process valves that can be remotely controlled througn the use of coded signals are applicable PREP denial techniques. Foaming to deny access and use is an example of possicle facilities and process denalties. Finally, existing technology indicates the ultimate intruder-activated penalty system could be used to severely damage critical equipment.

The illustration (Figure 2.10) shows how a system response might be graded in severity. Graded penalties are important to ensure that the penalty will fit the seriousness of the intruder's actions. The first response to an alarm should not be to impose the severest penalty. Besides sending an alert signal to the off-site $c^{3}$ centers, the first penalty could be to send a coded signal inhibiting a process, immobilizing any plutonium in a transportation mode, inhibiting remote handiing equipment, locking the doors, or some appropriate combination of these. Simultaneously, the arming of the next higher level of penalties could be authorized.

The initial set of possible penalties can be characterized as reversible. These penalties are designed to minimally impact restoration to normal operations. An example is the immobilization of transportation. The next step in 


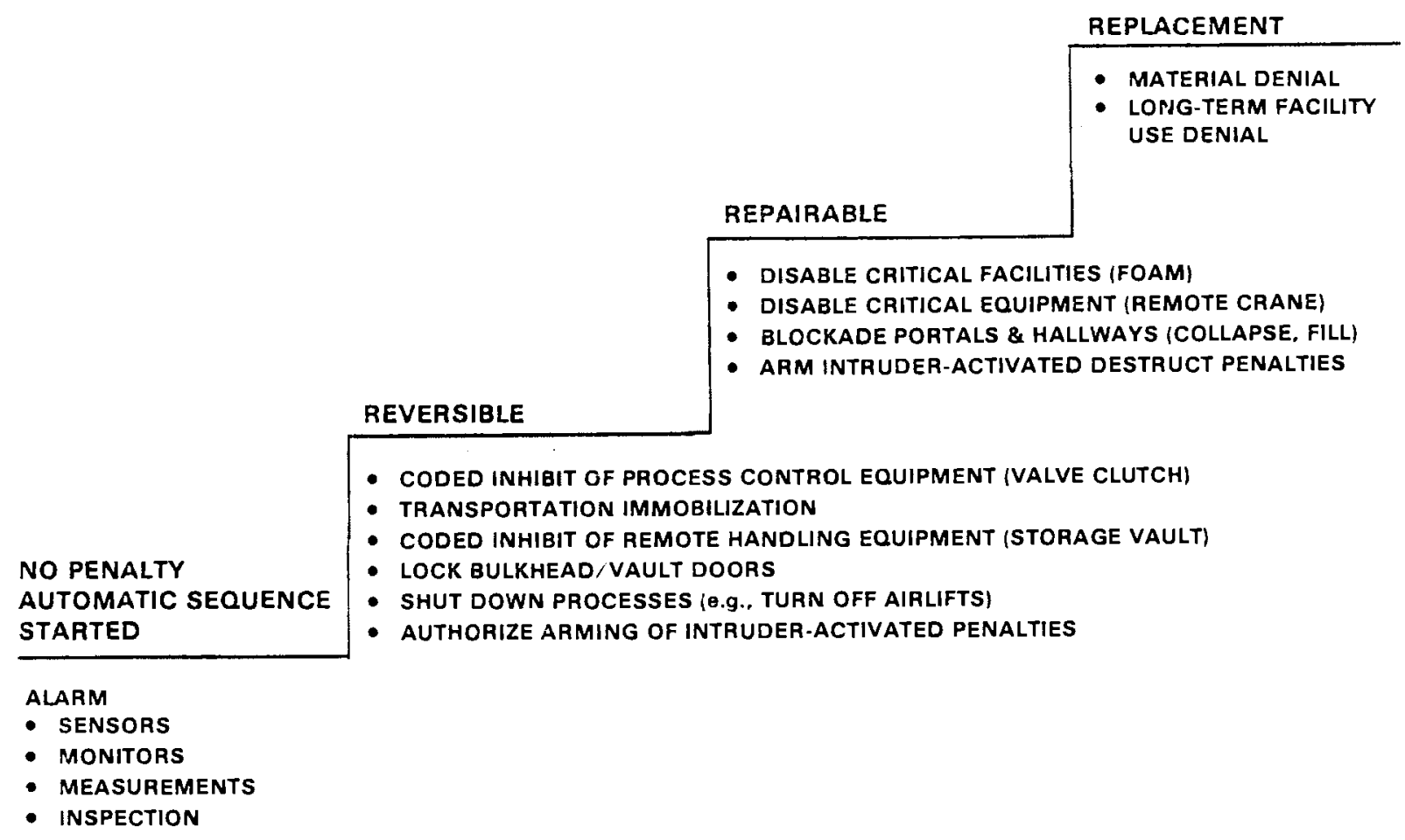

FIGURE 2.10. Graded Penal ty Response

increasingly severe penalties can be characterized as repairable. These penalties are not reversible by a simple change of code. Repair of some part of the equipment involved would require physical access to the penalty node site. Examples include placing an injectant in a process line, disabling the equipment (e.g., fracture a drive shaft), deactivating the remote crane with a coded signal (e.g., a power disconnect), and blocking the portals and hal1ways. The system could be designed to arm a severe penalty when an intruder tries to bypass a lesser penalty.

The severest penalties are characterized by the need for replacement. These penalties most likely would be intruder-activated. Examples are disruption of processes and equipment to the pcint that replacement is required in order to return the IFSC to normal operations. The facilities penalties could be severe enough that key portions of the facility are either abondoned or removed and replaced with new ones. Delay in restoring normal operations could be significant (months) in selected cases. 


\subsubsection{Impiementation.}

In order to assembie a working system one must determine the function of a denial penalty node. Figure 2.9 is an illustration of a multipenalty, graded-severity penaity node.

Penalty Node Operation

A penalty node must be able to receive, decode, authenticate, and store secure coded communications from the $c^{3}$ system. The proper disruptive response must be selected on a basis of either input data from $c^{3}$ or a preprogrammed, prioritized response. A large number of nodes might be distributed throughout the various facilities that make up an IFSC. These penalty nodes would have to be interconnected by means of the $\mathrm{c}^{3}$ system to properly coordinate a facility-wide penality response. The more complex penalty nodes might also include a tamper-proof sensor, sensor electronics, and a self-contained power supply to make sure that covert tampering does not subvert the system over tre life of the IFSC. All of this indicates the nesd for a highly sophisticated intelligence processor system physically located at each pena?ty node.

After all the sensor inputs have been evaluated and the nodal responses have been chosen, the arming interlock could be activated either on command from either an intruder-activated sensor or the $c^{3}$ system. An alternative might be to activate a nodal penaity response by means of an internal countiown timer started by a previous alarm input. At the proper time, the penalty would be invoked in the selected sequence. The penalty sequence at each penalty node wouid be a selected mix of reversible, repairable and replacement penalties chosen and timed to respond to the extent and seriousness of the intruder's progress.

The interconnected penalty nodes could interact with each other in such a way that a sequence of penaliy node resconses from one penalty node to the next could also provide a graded-severity, disruptive response. Finaliy, the most disruptive penalties could be set up to be intruder-activated so that, if the intruder continued to penetrate the IFSC, 
the responses would increase in severity as he proceeded toward a critical denial zone. As he penetrated into the critical denial zone, the severest of the disruptive responses would be activated.

\section{Reliability}

It is questionable whether a system as complex as that envisioned for an IFSC is adequately reliable and whether a sufficiently low system premature probability is achievable. A reliability of premature probability analysis has not been done because a design has not been developed. However, based on defense program-related designs and evaluations, we know that individual component reliabilities of 0.999 or better have been demonstrated and that warhead system reliabilities approaching unity are possible. This is not to say that these are the numbers that can be or need to be achieved for a proliferation resistance system. An analysis to determine the reliability requirements has not been done. Once the system reliability requirements are established, the next step is to analyze the design for a proposed system to determine if the desired performance is feasible. To put it another way, the kind of system reliabilities that are needed should be determined. Then, it should be determined which are possible for the established concepts. If these match, the design may be continued. If not, other design alternatives should be explored.

For defense programs, system premature probabilities of 1 in $10^{9}$ per system lifetime (typically 20 to 25 years) are required. These defense systems are fairly complex and their example lends credibility to a low premature probability per node in the proliferation resistance concept. Again, the system premature requirements have to be determined from analysis before deriving the premature probabilities for any proposed system. Only when all of this is done can it be said that needs for PREP system performance have been satisfied. 


\section{Remote Control}

Figure 2.11 shows a typical example of a remote controller. This illustration shows the proposed three-step control process--authorize, arm, and initiate. Authorization in this example is by the use of key lock switch. Arming is accomplished by unlocking the mechanical code switch. And finally, the initiate function occurs when the $T$ handle is pulled, causing the remote controller to send a coded signal down the line to the penalty node. This figure represents existing, developed hardware which could provide the basis for control of penalty nodes in a PRE concept.

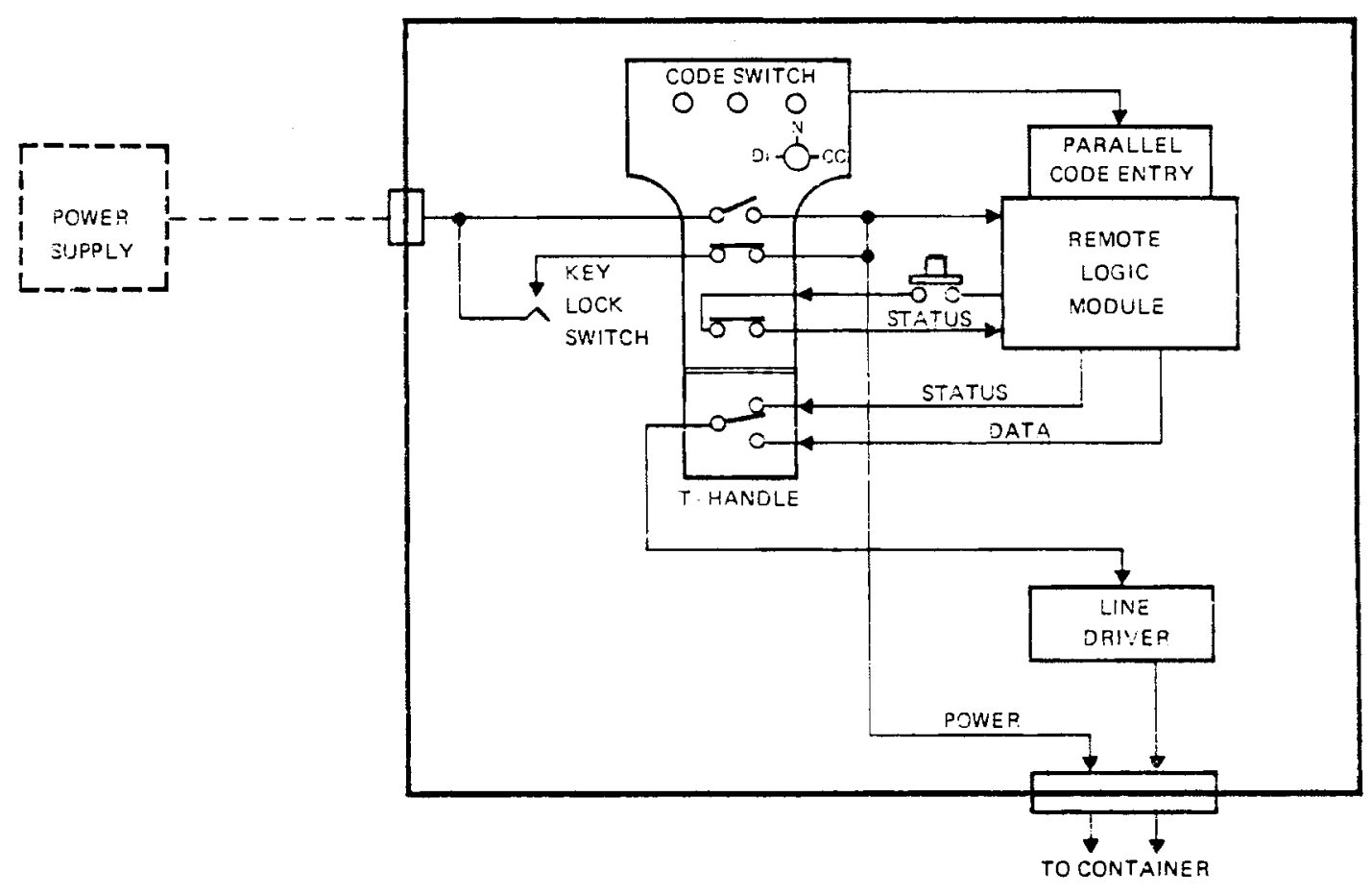

FIGURE 2.11. Remote Controlier 


\section{Safety}

Low premature probabilities indicate an acceptable safety level. The defense programs have achieved this in a hardware design by developing a safety philosophy that has resulted in the design of a component called a "strong link." Strong links are key elements in insuring acceptable low premature probability of a nuclear warhead system. The coded electromechanical switching device shown in Figure 2.12 represents a typical strong link. The code used to operate the device is not secure, but it cannot easily be duplicated during an accident that might cause power or other random-type signals to be applied to the penalty node input. With this type of component as part of a penalty node design, penalty initiation would be blocked, even if power or other signals did reach the node. Thus, a premature penalty actuation would be avoided (a required goal during normal operations at any facility).

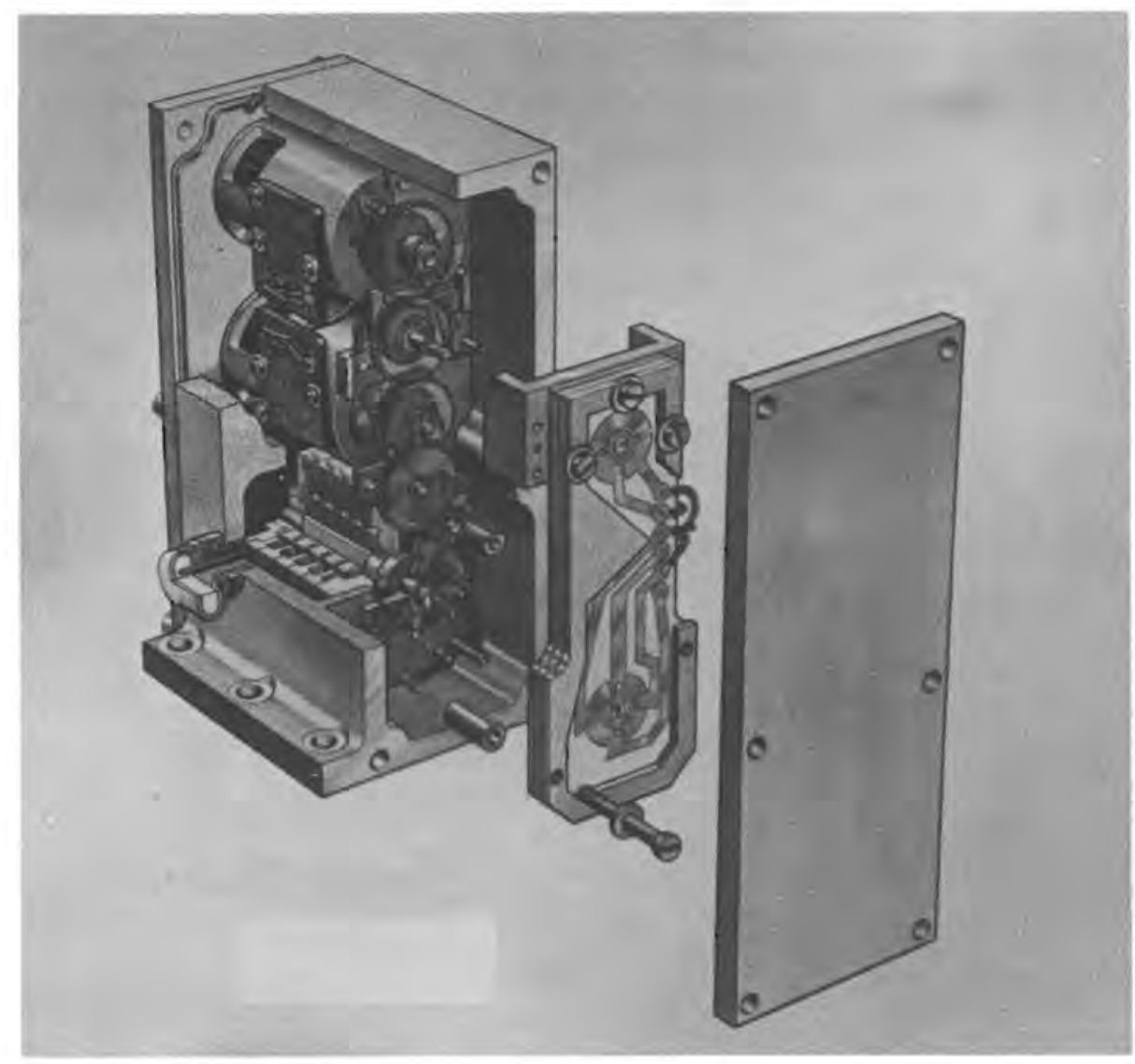

FIGURE 2.12. Coded Electromechanical Switching Service 
The denial penalty node itself may be damaged and have to be repaired. Some parts in the front end, the decoders and interrogators, could be damaged, but that may be an occasionally acceptable thing. If not, then another "strong link" could be placed at the nodal input to protect all of the nodes' electronic parts. Thus, there exists technology to guard against premature initiation of the penalty system, and to protect it from undesirable input signals.

The penalties may include pyrotechnics, explosive actuators, or final explosive shaped charges used to invoke some of the severest penalties. Because of unknown environmental effects or other aging processes, a concern is that the explosive charge might deteriorate chemically to the point of spontaneous premature detonation. Figure 2.13 shows another example of safety-related technology. This is a device that can be used to safely contain an explosive event. This explosive containment structure will contain all of the effects of a charge exploding internally. The case may expand a bit, but the outside reaction is basically nonviolent.

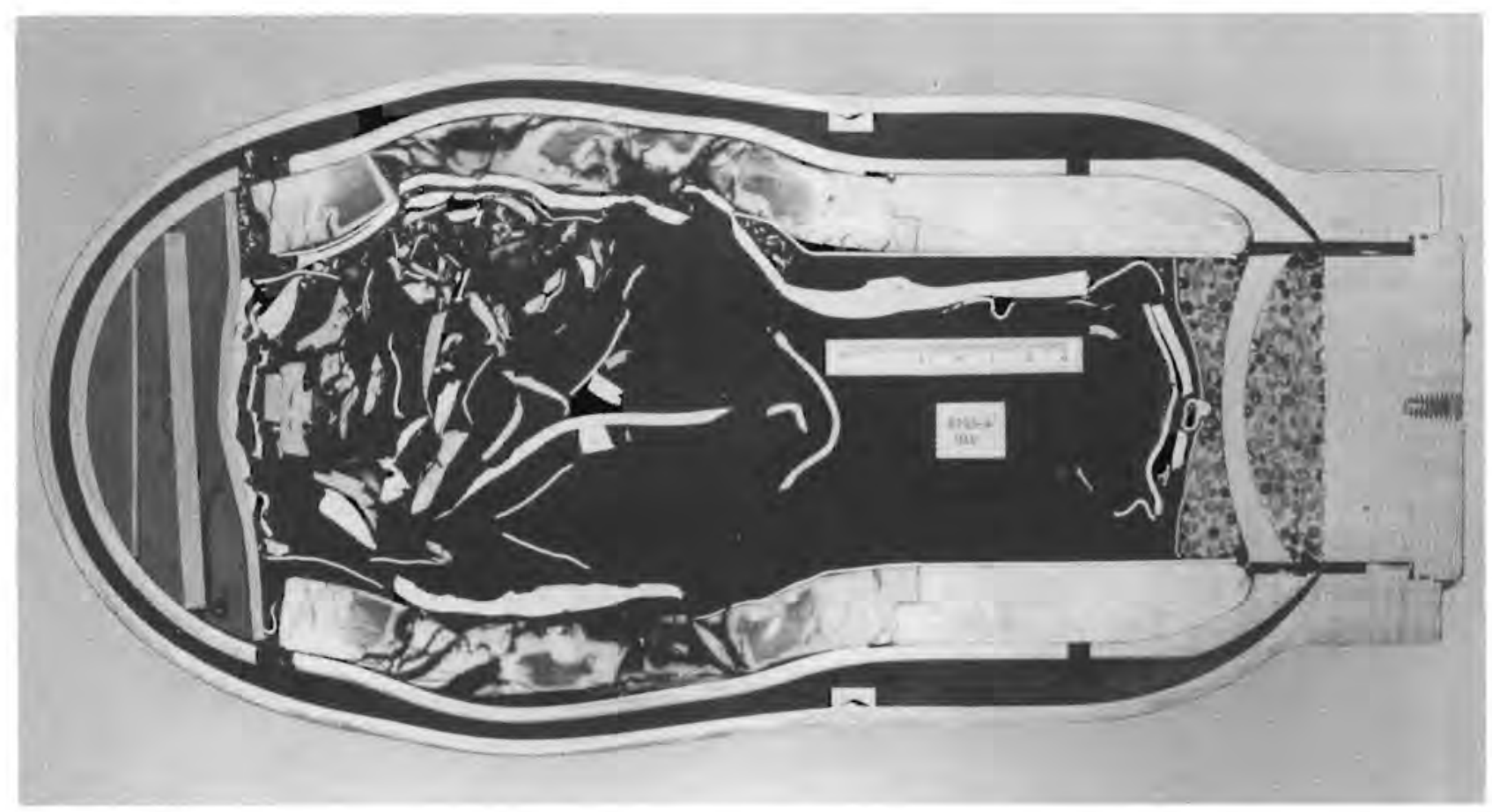

FIGURE 2.13. Device for Using Controlled Explosion 
To ease the uncertainty of chemical deterioration the explosive or pyrotechnic element of a penalty node might be stored inside one of these containers for the duration of its storage life. Whenever operation of that penalty was authorized, arming would be accomplished by mechanically removing the pyrotechnic device from its container and placing it in a functionally effective position. However, during most of its normal, unarmed shelf life, the explosive actuator would be kept in a contained status to essentially assure personnel safety.

Although it is uncertain whether pyrotechnics or explosive actuators will be required, the technology does exist to help insure safety during normal operations.

\subsubsection{Specific Hardware Examples}

For an idea of the number of sensors that could be used for PREP, review the examples given on page 2-46

\section{Sensors}

Figure 2.14 shows an example of a tamper-detecting sensor. Any attempt to by-pass this sensor could result in the immediate activation of a penalty. For tamper-safing application, the designer might be denied

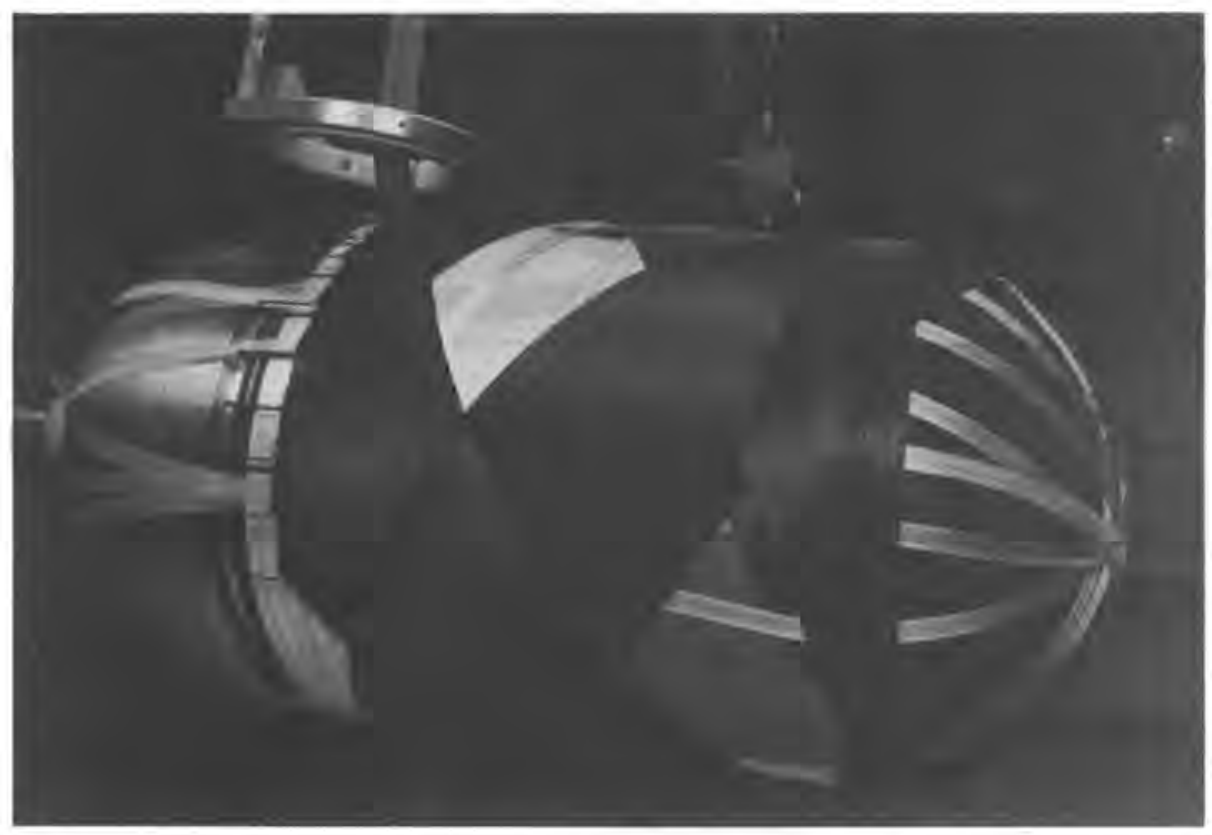

FIGURE 2.14. Tamper-detecting Sensor 
knowledge of a key interior part or code. Another penalty might be to alert the $\mathrm{C}^{3}$ system that a tamper attempt has been detected. It would be necessary to use such tamper-attempt sensors to insure that, over the long term, covert tampering did not subvert the PREP system. If larger areas were to be protected with intrusion detection sensors, something similar to wire mesh with the appropriate control electronics could be built into the walls of a room or process cell.

\section{Disruptive Actuators}

As Figure 2.8 illustrates, the sensors and the $c^{3}$ systems are connected with each other and with the array of disruption actuators which are.the ultimate source of any denial action. Examples of the wide range of possible disruptive actuators include: code-controlled motors which could be used for mechanical work, (these could be electric, pneumatic, or hydraulic in nature); high-pressure gas generators that can be very compact, and electrically-initiated ( a hot gas generator could generate high pressures on command); hydraulic devices such as pistons, could also be coupled with a hot gas generator for significant mechanical work (such a device could warp the rails of a remote crane); pyrotechnic devices that are electrically-or percussion-actuated, could be used in the design of a penalty node (torches or shaped charges could be used to damage large mechanical or structural components); and the ultimate disruptive actuators are the explosive options. Although these may or may not be in the final design, they certainly are on the list of technologies to be considered.

While there are a vast number of possible graded response disruption actuators, the final choice will be geared to the types of penalties chosen for the various facilities, the transportation modes selected, and SNM material involved in the definition of the PREP IFSC. 


\section{Penalty Node Examples}

An example of a penalty node concept is the controlled use of an important process control valve. Figure 2.15 shows a mockup of a part of the AGNS Barnwell facility at Sandia Laboratories. The loadout valves are controlled by magnetic clutches and require insertion of a code to be opened. This safeguards development is now underway. To extend this technology to proliferation resistance engineering a valve would be positioned behind the biological barrier on an extended shaft coupled with some sort of magnetic clutch to a manual control wheel that is outside the biological barrier. The valve could be manually operated with a proper authorization code. If a penalty were invoked, the valve would remain in the same state, but the control would be decoupled. An alternative would be to change the valve's state. Another severer penalty would be to permanently

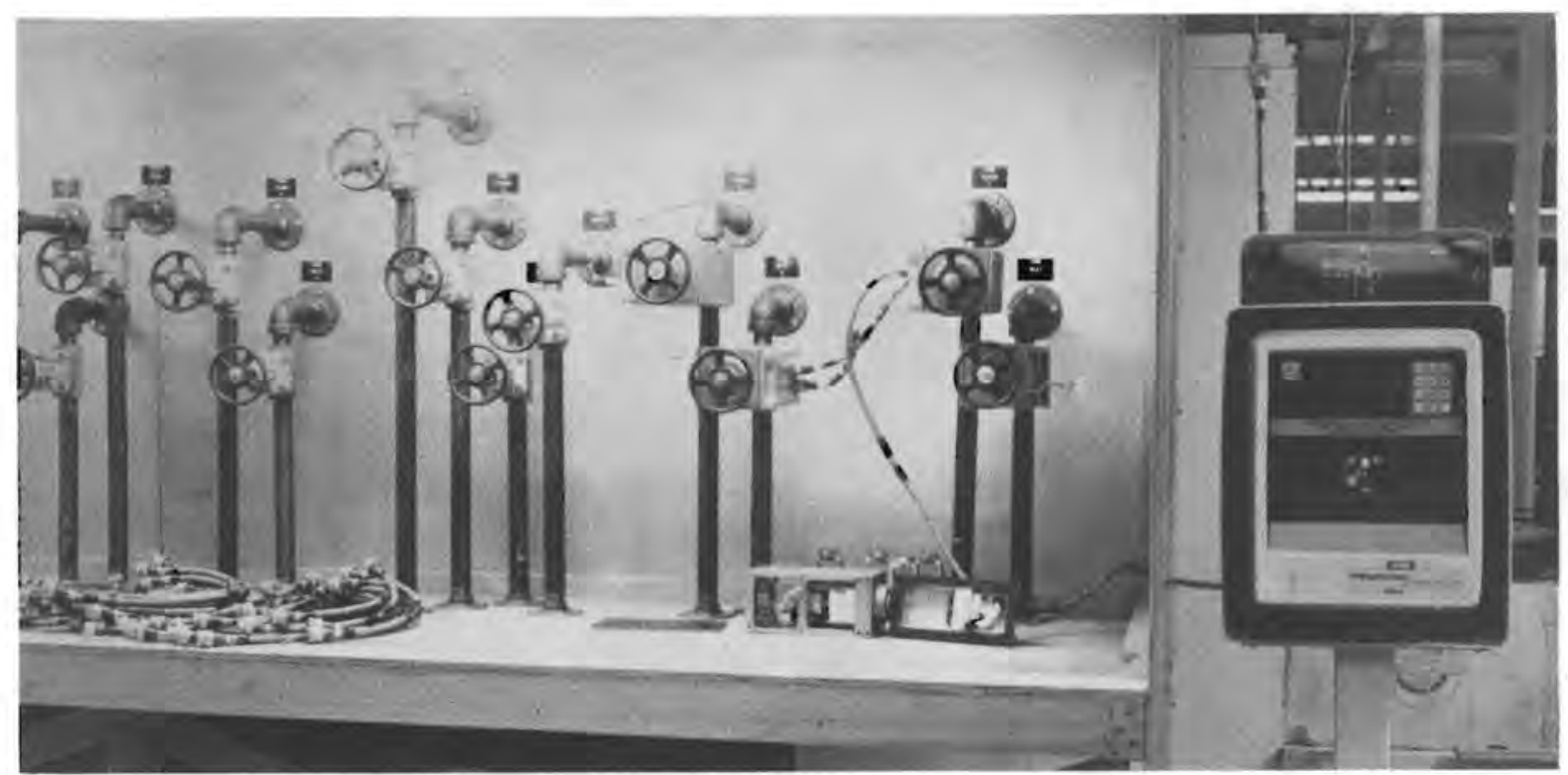

FIGURE 2.15, Loadout Valve Assembly With Use-Denial Capability 
decouple the control wheel and shaft from the valve, on command, by physically breaking the control shaft behind the biological barrier. This could assure that even if the proper code (obtained through coersion) is later transmitted, the state of that valve could not be changed without some physical repair. If attempts were made to bypass this valve or repair it, final action might feature a bypass attempt sensor that would trigger an even severer penalty. An example of such a penalty is injection of something (e.g., foam) into the process flow lines to permanently block them.

The use of foam for access denial has a foundation in defense programs. Figure 2.16 shows a weapons storage igloo. The foam system has been installed in the access door area. If this system were triggered, a foam would be released to delay access. This type of system has been designed, built, and tested. It could directly apply to the PREP concept if it were used to deny access to critical facilities or material.

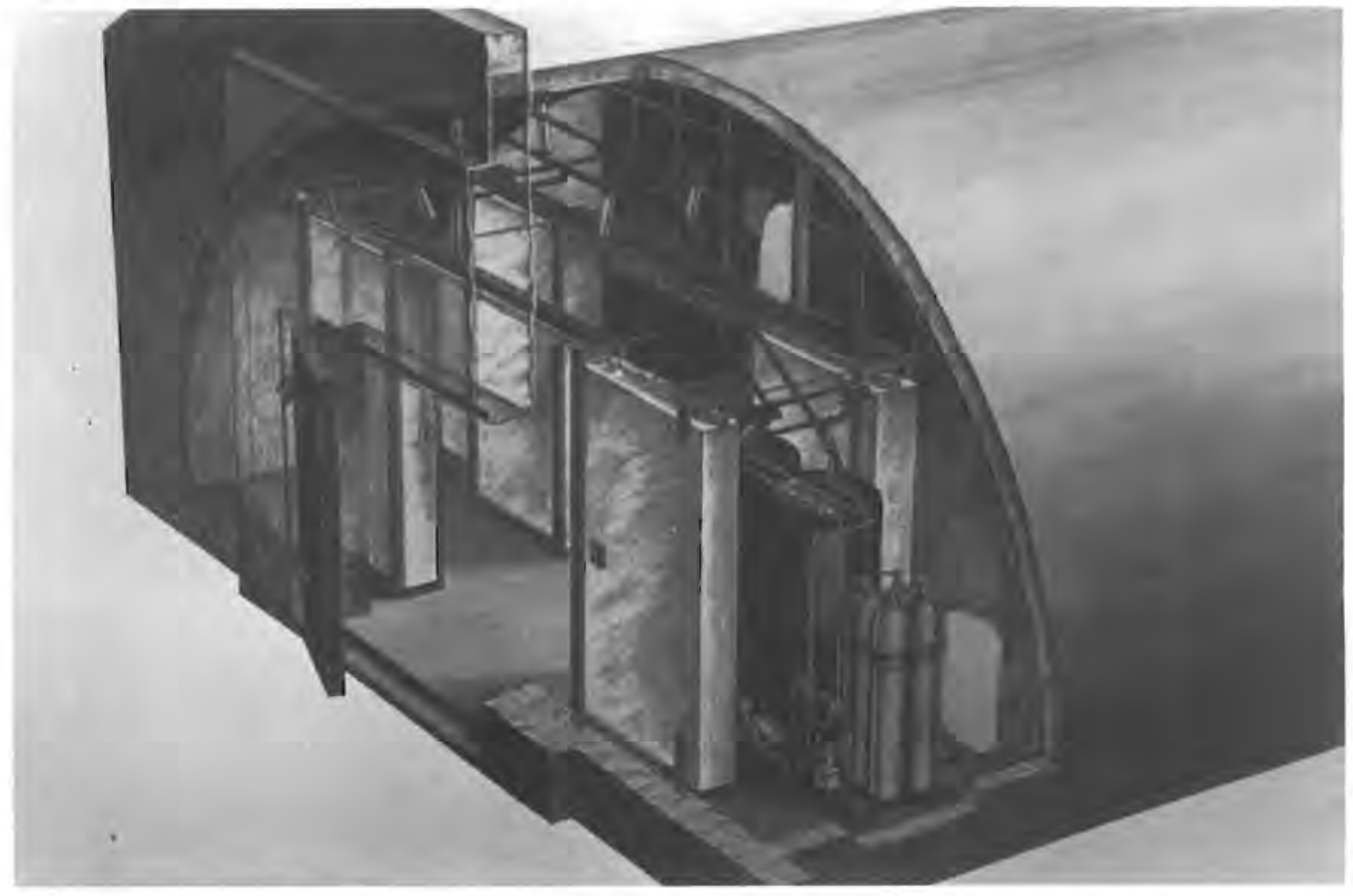

FIGURE 2.16. Storage Facility Using Access Denial Technology 

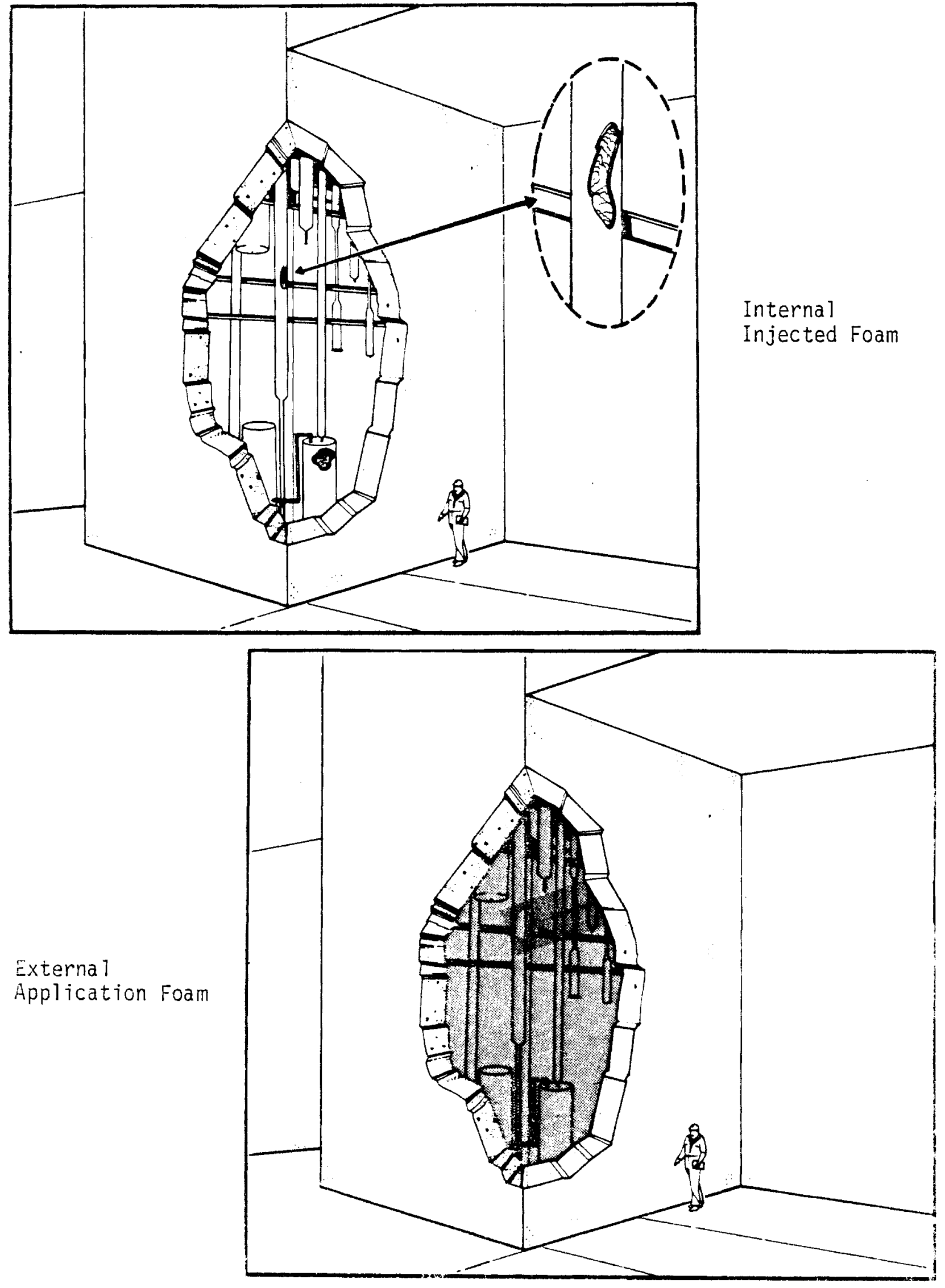

GQURE 2.17. Appitication of Foaming 
Figure 2.17 (top) shows now foam mignt be employed in proliferation resistance engineering. If an intruder attempts to gain access to this remote:processing cell, a material might be injected into the process tank, essentially halting the process and denying use of that process facility until the tank could be cleaned cut. Clean-up would be time consuming, although probably a relatively straightforward activity. In order to increase denial time, the next step (Figure 2.17, bottom) might be to inject something like foam into the cell itself to further delay the repair process by denying both physical and visual access to the damaged part. In various comoinations the deniaf technologies discussed so far, can increase both the severity of the penalty and the denial time.

\section{Transportation and Storage Mode}

In the transportation and storage mode, combinations of penalty actions are particularly appropriate. The time necessary to remove the material could be increased by employing physical restraints (for example, the SNi containers could be locked in place). This act by itself would not provide sufficient time for any kind of adequate international response to the intruders actions, but locking could provide time to assess the threat and make decisions before initiating material denial actions that would involve any higher cost. Of course, if the threat assessment and the $C^{3}$ system perceive that a threat exists, then the final denial step would be to chemically modify the target plutonium. Again, a number of different penalty actions have been coupled to provide a chance for threat assessment before the severer penalty is initiated, and to increase the time it would take the adversary to gain access to weaponsusable material. 
Figure 2.18 schematicaliy shows two trarsportation denial concepts-immobilization of the transportation vehicle and deny access to the containers carried inside.

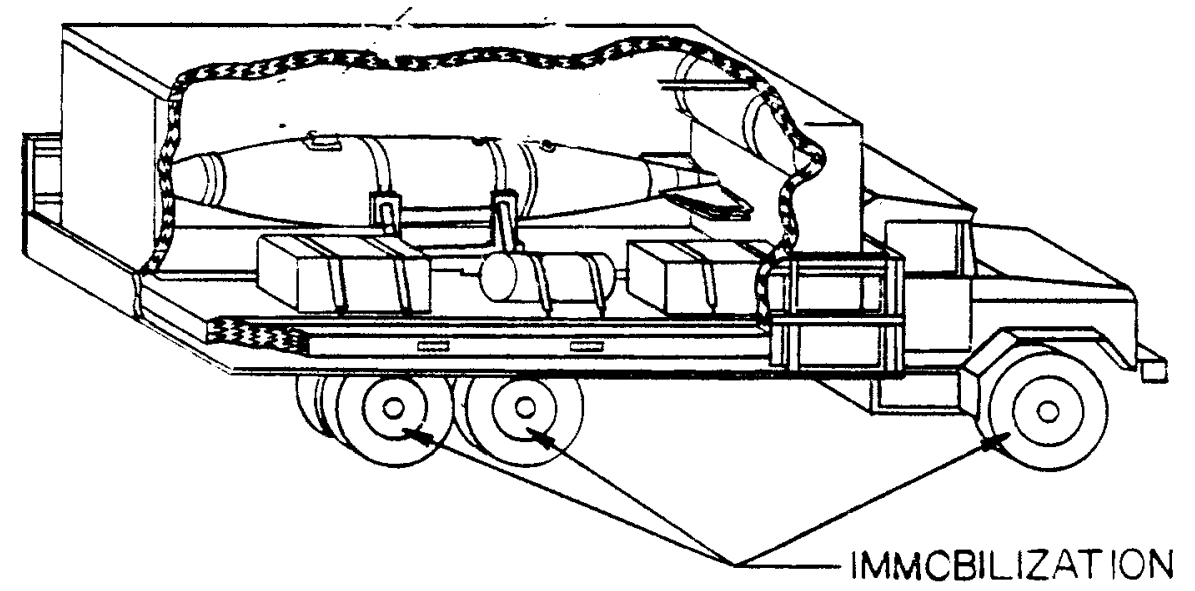

FIGURE 2.18. Application of Use Denial to Transport Vehicle 
Finally, Figure 2.19 shows the plutonium transfer vehicle (PTV). (a) The PTV would include penetration- and accident-resistant characteristics with code-controlled dead bolt locks. This would physically inhibit the removing of material to allow time to make a threat assessment before invoking a severer penalty.

(a) This concept was developed by Sandia under the safeguards program for transport of special nuclear material.

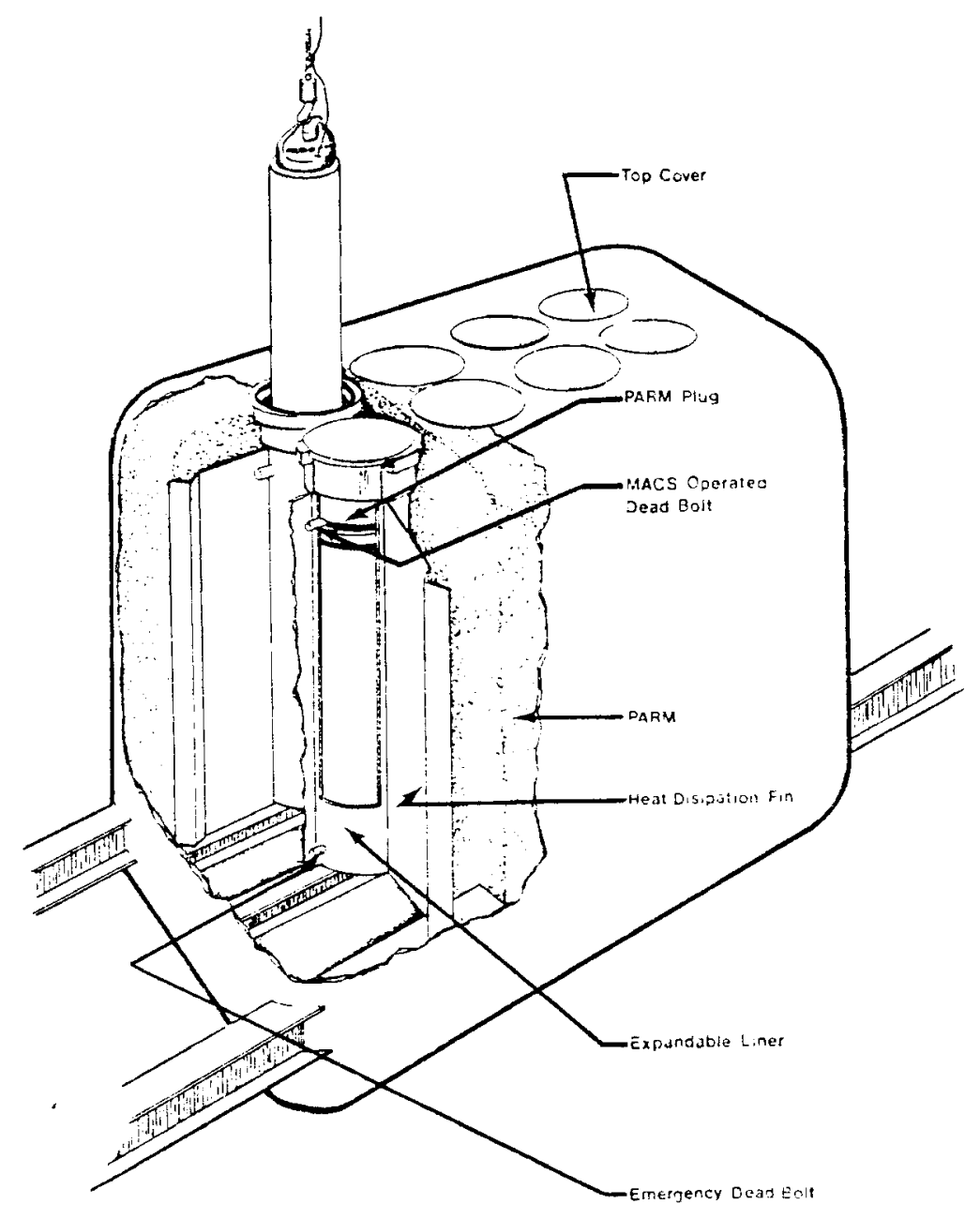

FIGURE 2.19. Plutonium Transfer Vehicle with Access-Denial Characteristics 


\section{Material Denial}

The goal for denying access to material is to increase the time and technological capability required for an adversary to utilize material taken from storage or transportation. The thermite SNM denial method (Figure 2.20) is basically the use of a thermite melting reaction where the material is surrounded by a thermite charge. On command, this charge is initiated and melts the SNM. During this process the material is mixed with the thermite and its additives and the product of the resulting reactor is similar to that shown in Figure 2.21. This product is not directly suitable for weapons use and also is very difficult to reprocess. Recovery of the denied material requires reprocessing steps which may be as complex as spent fue 1 reprocessing.

The form of the resultant mixture could be decided by choosing various combinations of thermite quantities and additives, deciding whether or not the mixture is a separate metal and slag phase or a slag and metal mixture and choosing how the plutonium will be diluted or dispersed through the product.

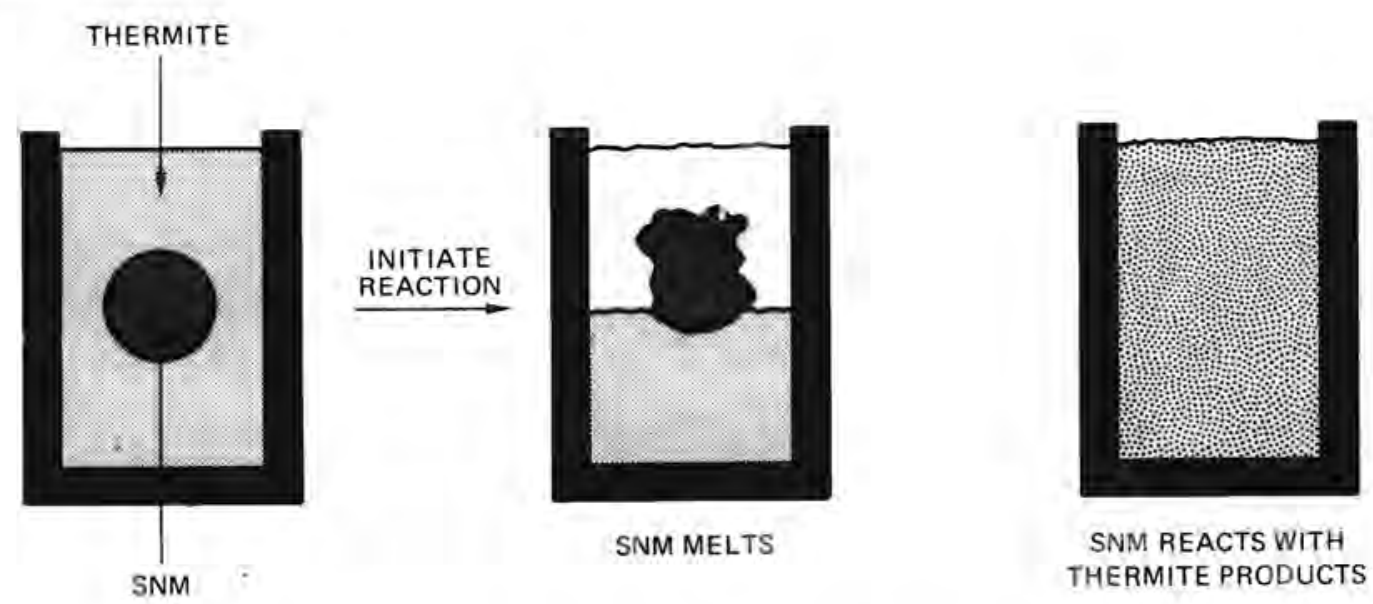

FIGURE 2.20. Thermite Plutonium Denial Concept 


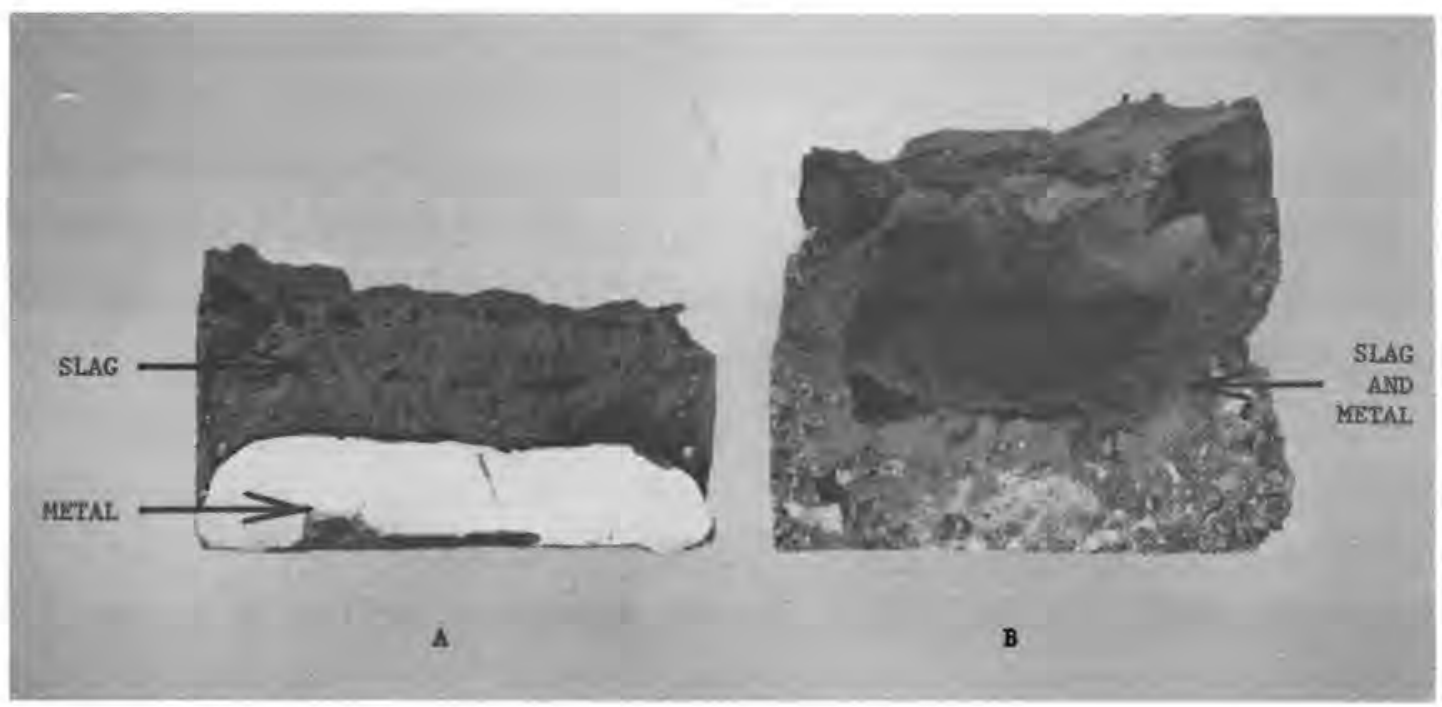

FIGURE 2.21. Thermite Reaction Product

(left) with consolidated metal phase

(right) with dispersal metal phase

Figure 2.22 shows a plutonium oxide shipping container which includes an aluminum jacketed thermite charge shown as the central core. The plutonium oxide occupies the annular region around the aluminum thermite canister. This canister would be connected to the $\mathrm{C}^{3}$ system through a penalty node control system. The intelligent penalty node control system would then operate on the proper $\mathrm{C}^{3}$ inputs to authorize, arm, and initiate the thermite system.

The end product of the thermite reaction is still being evaluated. Some things have been determined, however. First of a11, dissolution of the resulting product is very difficult, and although it can be dissolved, it takes a significant period of time. Also, the separation and recovery of the plutonium is not easy, even for experienced plutonium chemists. Although experience is important, there are still many chances for mistakes during the recovery operation. Of course, the chemistry of the thermite reaction can be tailored to the specific SNM material to be denied. 


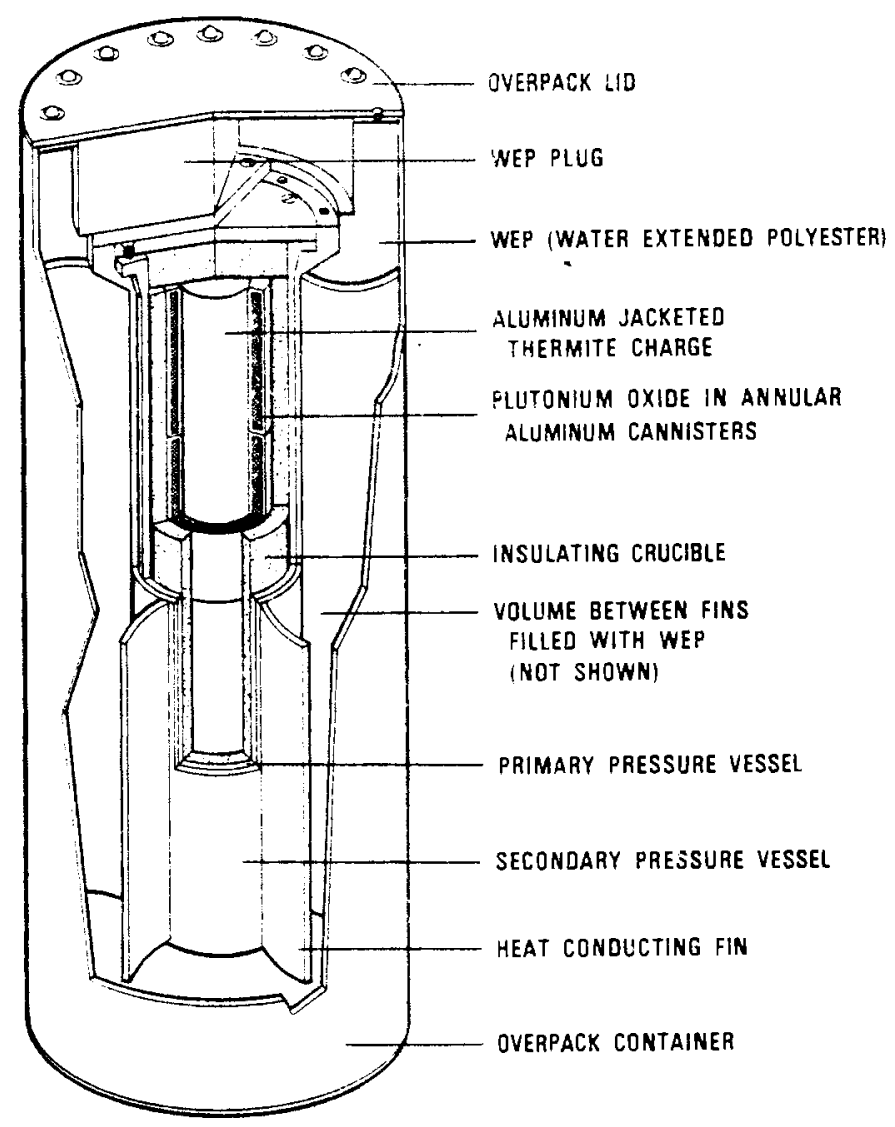

FIGURE 2.22. Plutonium Oxide Shipping Container With a Thermite Charge

Integrated Design Concept

It was mentioned previously that an integrated design concept would combine multiple penalty responses to maximize the denial time. One such possibility for material denial is to activate the thermite chemistry process. The melting phase of the reaction could be coupled with that to fix the material in place. The physical facilities could be designed to prevent easy accessibility to the melted product. Thus, extra time would be required for hands-on access to the material before chemical recovery could begin. This idea could be implemented in both the storage vault and the transportation mode. Thus area dispersai adds another element of delay to the time needed for final acquisition. 
The use of passive facilities design considerations to enhance some of the active denial penalties is attractive. For example, if storage or transportation is restricted to the use of an underground tram or rail system, or pneumatic transfer system, and if the access is very restricted, it is possible to delay access by using clocking techniques such as foam. This can mean additional time would be required to obtain weapons-usable materia1. One of the first actions taken might be to disable any portion of the transportation system, or to move it to the least accessible position.

Figure 2.23 illustrates the safeguards conceptual design for a mixed oxide fuel fabrication facility. This snows how the storage vault might be configured to minimize access to significant quantities of the special

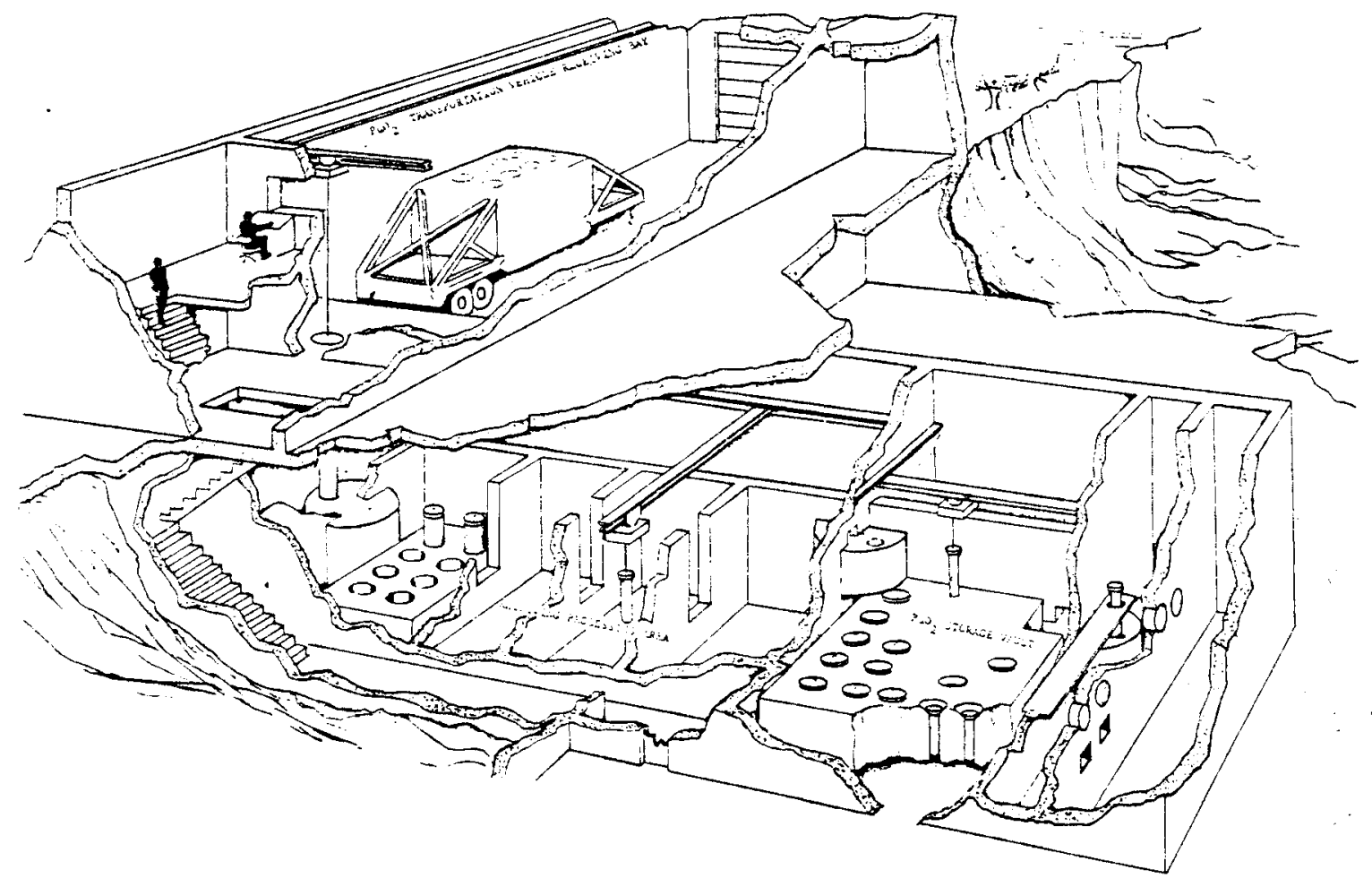

FIGURE 2.23. Fuel Fabrication Facility - Safeguards Conceptual Design 
nuclear material. It is visualized that stored canisters might be designed so that during the thermite melting process the molten thermite product would disperse into a holding area beneath the stcrage vault. A mining operation would then be required, again increasing the recovery time.

The examples given in this section illustrate some of the possible use-denial concepts for enhancing proliferation resistance based on today's state-of-the-art technology. This first step has been to collect ideas that may have merit. However, the technologies described have yet to be applied to a fully integrated and optimized facility or IFSC, the next step is to begin to form these ideas into an integrated design concept. 
. 


\subsection{BASELINE FACILITY DESCRIPTION}

The following sections briefly describe the six components in the reference fuel center and the safeguards systems. Section 1 of this report provides an overall introduction to the components in the fuel center. The appendices contain more detailed descriptions.

\subsection{THE FUEL REPROCESSING PLANT}

The process selected as the base case for fuels reprocessing is modeled after the Barnwell Nuclear Fuel Plant. The Barnwell plant was selected because it is fairly representative of conventional Purex technology and because the plant has been built and has undergone extensive testing. Proliferation resistance design concepts developed in this study can be applied to the Barnwell plant design and, because it already exists, there is the possibility for actual demonstration at the facility in the future.

The Barnwell plant is designed to receive, store and process light water reactor fuels. It can handle fuels with pre-irradiation concentration of $3.5 \% 235 \mathrm{U}$ or $29 \mathrm{Kg}$ of fissile plutonium per metric ton and average burnups up to 40,000 MWd/MTHM. The design capacity is 1500 metric tons annually.

The plant is not designed to process LMFBR fuels. Such fuels are typified by much higher Pu/U ratios than LWR fuels. The cladding, which is likely to be stainless steel rather than zirconium alloy and residual sodium metal coolant adhering to the surfaces is possible in the plenum, will require a different head end treatment than LWR fuels. The process for LMFBR fuels is not great?y different from LWR fuels. For this conceptual study, the Barnwel1 process is considered acceptable as a generic reprocessing case.

\subsubsection{Process Description}

The process, shown schematically in Figure 3.1 , consists of receipt and storage of irradiated fuel, chop-leach head end, separation and purification of plutonium and uranium and conversion of plutonium nitrate to oxide.

The spent fuel assemblies arriving in shielded casks by truck or rail are transferred from the cask to the fuel storage pool where they remain until added to the process. 


\subsection{BASELINE FACILITY DESCRIPTION}

The following sections briefly describe the six components in the reference fue 1 center and the safeguards systems. Section 1 of this report provides an overall introduction to the components in the fuel center. The appendices contain more detailed descriptions.

\subsection{THE FUEL REPROCESSING PLANT}

The process selected as the base case for fuels reprocessing is modeled after the Barnwe1l Nuclear Fuel Plant. The Barnwe11 plant was selected because it is fairly representative of conventional Purex technology and because the plant has been built and has undergone extensive testing. Proliferation resistance design concepts developed in this study can be applied to the Barnwell plant design and, because it already exists, there is the possibility for actual demonstration at the facility in the future.

The Barnwell plant is designed to receive, store and process light water reactor fuels. It can handle fueis with pre-irradiation concentration of $3.5 \% 235 \mathrm{U}$ or $29 \mathrm{~kg}$ of fissile plutonium per metric ton and average burnups up to 40,000 $\mathrm{MW}$ id/MTHM. The design capacity is 1500 metric tons annually.

The plant is not designed to process LMFBR fuels. Such fuels are typified by much higher Pu/U ratios than LWR fuels. The cladding, which is likely to be stainless steel rather than zirconium alloy and residual sodium metal coolant adhering to the surfaces is possible in the plenum, will require a different head end treatment than LWR fuels. The process for LMFBR fuels is not greatly different from LWR fuels. For this conceptual study, the Barnwell process is considered acceptable as a generic refrocessing case.

\subsubsection{Process Description}

The process, shown schematically in Figure 3.1 , consists of receipt and storage of irradiated fuel, chop-leach head end, separation and purification of plutonium and uranium and conversion of plutonium nitrate to oxide.

The spent fuel assemblies arriving in shielded casks by truck or rail are transferred from the cask to the fuel storage pool where they remain until added to the process. 


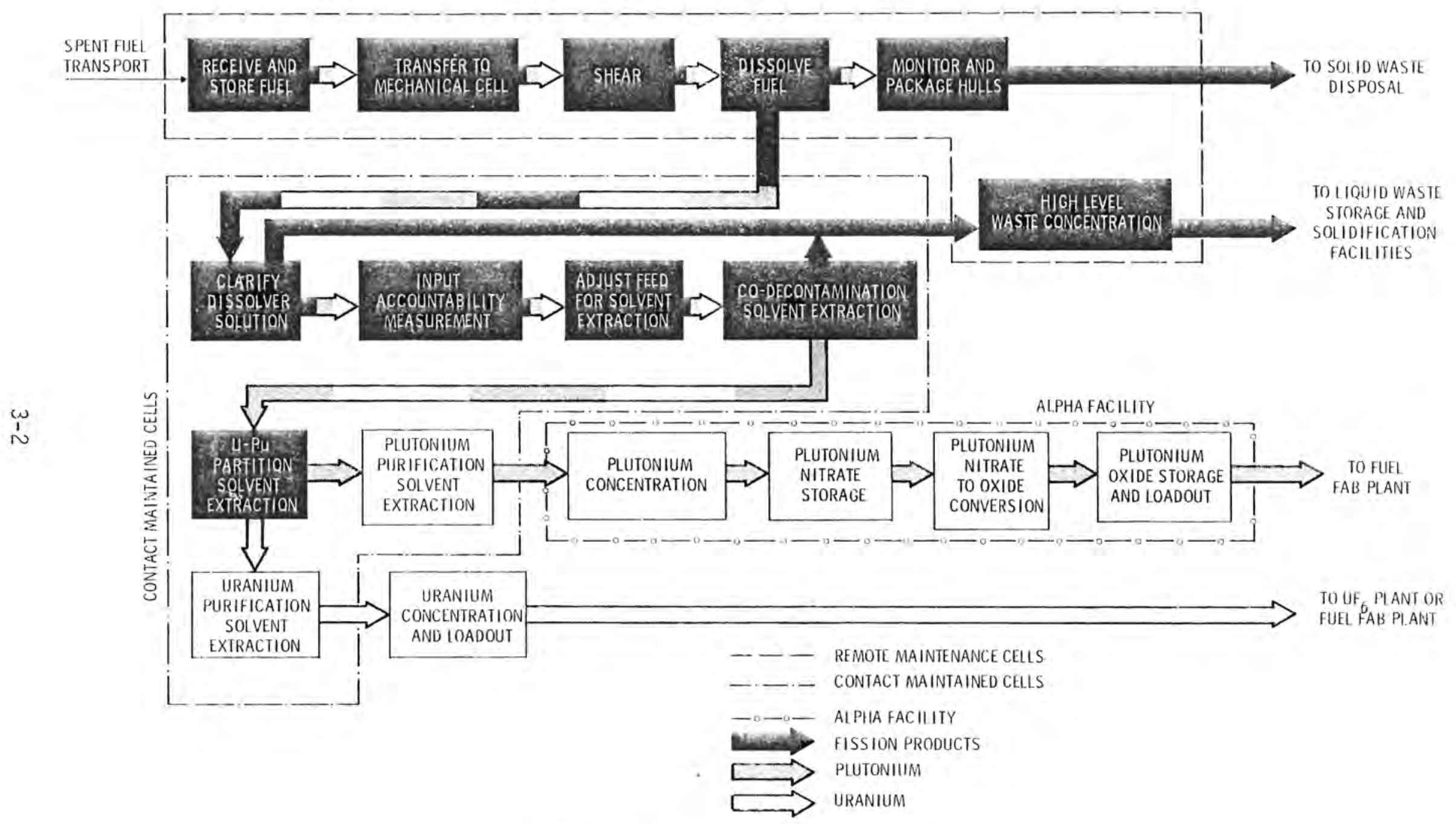

FIGURE 3.1. Fuel Reprocessing Flow Diagram 
The fuel assemblies are transferred from the fuel storage pool to the mechanical shear. The rods are chopped into short pieces which fall into the basket in the dissolver. The exposed fuel is dissolved by nitric acid containing gadolinium (which acts as a neutron poison to prevent nuclear criticality). The dissolved fuel is then transferred to an accountability tank where the volume is determined and samples are taken for $\mathrm{Pu}$ and $\mathrm{U}$ assay. The cladding, which is not dissolved in the leach step, is packaged and disposed of as solid waste.

The dissolved fuel is passed through a centrifuge to remove residual solids and the acid concentration is adjusted to 2-3M (appropriate for solvent extraction). The primary separation from fission products is achieved by co-extraction of uranium and plutonium in an organic phase of $30 \%$ tributyl phosphate in a hydrocarbon diluent in a multi-stage centrifugal contactor. The organic phase containing the uranium, plutonium and about $1 \%$ of the fission products is scrubbed in a pulse column with nitric acid to provide additional decontamination from fission products.

The plutonium and uranium in the organic stream are separated from each other in the partition cycle. The plutonium is reduced to the trivalent state and is preferentially stripped into an aqueous phase. The uranium remaining in the organic phase is stripped into dilute nitric acid, concentrated and then passed through a second solvent extraction cycle consisting of extraction scrub and strip. A final clean-up from fission product zirconium is achieved by contacting with silica ge?.

The plutonium in the aqueous phase from the partition cycle undergoes two additional solvent extraction cycles to complete the removal of fission products and uranium. The pure plutonium solution is concentrated by evaporation and stored as plutonium nitrate in critically safe tanks.

The Barnwell plant does not have the capability to prepare plutonium oxide. A large plutonium nitrate storage facility in the existing plant is intended to store $8000 \mathrm{~kg}$ Fu as a $250 \mathrm{~g} / \hat{x}$ solution. This concept is unattractive for noneroliferation. Thus, a conceptial conversion process has been selected for inclusion as part of tie reprocessing plant. The process is the 
plutonium III oxalate precipitation process used as a reference case in the coordinated safeguards studies carried out at LASL. In this process, plutonium is reduced to PU III with nydrazine and ascorbic acid. The plutonium is precipitated by adding oxalic acid and aigested to form a readily filterable plutonium III oxalate. The precipitate is collected on sintered metal filters built into filter boats. After washing with $0.3 \mathrm{M}$ oxalic acid and partialiy air-drying the precipitate, the filter boats are passed through tunnel furnaces where the plutonium oxalate is calcined to form $\mathrm{PuO}_{2}$. The product is then assayed and packaged for storage or insertion into the mixed oxide fuel refabrication process.

The aqueous wastes from the solvent extraction systems are concentrated either in the HAW (high activity waste) concentration or the LAW (low activity waste) concentrator depending on the level of radioactivity. The HAW originates primarily from the HA contractor raffinates. The overheads from the HAW concentrator are condensed and fed to the LAW concentrator. The bottoms are samples and, if the uranium and plutonium are acceptably low, are sent to a high level waste storage tank. Otherwise, the waste can be recycled.

Aqueous wastes from throughout the process that contain recoverable amounts of uranium or plutonium are processed through a solvent extraction column. The organic phase is routed to the HA contactor and the raffinate to the LAW concentrator. Various other very low plutonium and uranium bearing wastes are also fed to the LAW concentrator. The overheads from the LAW concentrator are sent to the acid recovery system; the bottoms are sent to the HAW concentrator.

Scrap and waste from the oxide conversion process are treated (dissolved if necessary) and recycled through the second and third plutonium purification cycles. 


\subsubsection{Reprocessing Plant Facility Descriotion}

The reference reprocessing facility is described briefly in this section.

The reprocessing plant description includes only the fuel receiving and storage station (FRSS) and the main process building. The actual plant includes other facilities such as a $U F_{6}$ conversion plant, auxiliary power plant water reservoir and administrative buildings. It also includes high and intermediate aqueous waste handling and storage facilities and a conceptual waste vitrification plant which are described in subsection 3.5. The plant also includes a plutonium nitrate to oxide conversion area. However, this conceptual facility has not yet been developed.

Fuel Storage and Receiving Station - The FRSS is designed to receive and store highly irradiated fuel from light water reactors. The building houses the cask and fuel handling equipment, cask unloading pools fuel storage pools, and the water treatment equipment. The main functional areas of the FRSS are listed in Table 3.1.

TABLE 3.i. Functional Areas in Fuel Receiving and Storage Station

$\underline{\text { Area }}$

Parking Area

Cask Unloading Bays

Tesi and Decontamination Pit

Jecontamination Pit

Cask Unloading Pool

Fuel Storage Pool

Fuel Transfer Pool
Function

Preiminary washing of vehicles and shipping casks

Unloading casks from truck or rail cars and preliminary cask decontamination

Prepare incoming casks for unloading and reasserible outgoing casks

Decontamination of casks after unloading Underwater unloading of fuei from casks Underwater storage of fuel assemblies Underwater handling of fuel for transfer to the ma in process building 
The FRSS is connected to the main process building by the fuel transfer conveyor tunnel. The fuel conveyor extends from the fuel transfer pool into the remote process cell, site of the fuel shear.

Process Building - The main process building consists of a series of heavily shielded process cells surrounded by galleries and operating stations. The process cells contain the process and support equipment that handle the highly radioactive materials. Personnel access to the cells is possible after extensive decontamination, but it is intended that entry will occur only when absolutely necessary. The galleries are limited access zones where operator entry is permitted under restricted conditions. These access zones are normally the closest to process equipment. They contain the process controls, piping, instrumentation and other support equipment. The stations are normal access work zones where routine process operations are carried out such as in-cell manipulator operations, chemical make-up, filter changes, etc. The stations at the remotely maintained cells include viewing windows, periscopes and manipulators, as well as controls for various in-cell equipment.

The process building contains five heavily shielded process ceils. The functions carried out in these cells are listed in Table 3.2.

The remote process cell is designed for remote maintenance and contains equipment likely to require routine maintenance and repair. It is equipped with viewing windows, TV and periscopes. The entire cell area is accessible by overhead bridge cranes and a power manipulator. Through-the-wali masterslave manipulators can reach parts of the cell. Maintenance is generally carried out in-cell, but equipment can be removed to other areas for repair, if necessary.

The high-, high intermediate- and intermediate-level cells; and the plutonium and uranium product cells are contact-maintained cells. In general, the equipment in these cells is designed to last the life of the plant and thus, no provisions are made for remote maintenance. Some failure-prone equipment such as the centrifuge and the HA contactor can be removed and replaced remotely. Other equipment items with mechanical parts such as pulsers are located outside the shielding walls where access is possible for repair. 
TABLE 3.2. Process Cel7s and Functions

\begin{tabular}{|c|c|}
\hline Cell & Process Functions \\
\hline Remote Process Ce11 (RPC) & $\begin{array}{l}\text { Fue } i \text { chop and leach high-level waste } \\
\text { concentration }\end{array}$ \\
\hline $\begin{array}{l}\text { Remote Maintenance and Scrap } \\
\text { Cel1 (FMSC) }\end{array}$ & $\begin{array}{l}\text { Solid waste handling maintenance of } \\
\text { highiy radioactive equipment }\end{array}$ \\
\hline High Level Cel1 (HLC) & $\begin{array}{l}\text { Preparation of feed for solvent ex- } \\
\text { extraction }\end{array}$ \\
\hline High Intermediate Level Ce11 (HILC) & $\begin{array}{l}\text { Co-decontamination and partition } \\
\text { cycle solvent extraction } \\
\text { Intermediate-level waste concentration } \\
\text { Dissolver off-gas treatment solvent } \\
\text { recovery }\end{array}$ \\
\hline Intermediate Level Cell (ILC) & $\begin{array}{l}\text { Acid recovery; Low-level waste concen- } \\
\text { tration; Vessel off-gas treatment; Used } \\
\text { solvent burning }\end{array}$ \\
\hline Uranium Product Cel1 (UPC) & $\begin{array}{l}\text { Second and third cycle uranium purifica- } \\
\text { tion solvent recovery }\end{array}$ \\
\hline Plutonium Product Cell (PPC) & $\begin{array}{l}\text { Second and third cycle plutonium purifi- } \\
\text { cation }\end{array}$ \\
\hline
\end{tabular}

Should a failure occur within a cell, it is necessary to decontaminate the cell and equipment to low enough radiation levels for human entry.

Remote sampling of various process streams and vessels is provided by the shielded analytical cells (SAC). These are a series of small shielded manipulator cells in which remote sampler heads are located. Samples can be drawn by means of air-lift from any sampling point in the process cells. The SAC facility also can be used to perform chemical analyses that require shielding, or for preparing dilutions of samples for the cold analytical laboratory.

A central control room houses process control instrumentation and the display and monitoring panels for safety-related instruments throughout the plant. This room serves as the communications center from which operations direct the performance of a11 manual functions. 


\subsection{THE REFERENCE FUEL REFABRICATION FACILITY}

The reference facility for this study is based on the WestinghouseAnderson mixed oxide recycle fueis plant (RFP). The RFP has a nominal capacity of 200 MT of mixed oxide per year. While the RFP is designed to fabricate only LWR fuels, the reference facility is assumed to be capable of producing either LWR of LMFBR fuel. The facility will use the pelletizing process incorporating a dry powder blending process for mixed oxide formation. The facility will maximize the use of automated and remote equipment.

The refabrication facility will be adjacent to or co-located with the reprocessing plant. A single structure will contain all silm associated with the facility.

The facility will receive dry plutonium and uranium oxide power. The material will be assayed and placed in secure buffer storage. The two oxide streams will be mechanically blended. The mixed oxide will undergo slugging, granulation and pressing to form green pellets. The green pellets will be sintered, ground to proper size and loaded into rods. The rods will than be welded closed, inspected, treated and assembled into bundles. The bundles are inspected and packed into shipping packages. Clean scrap material will be recycled internally within the plant. Other scrap will be returned to the reprocessing facility.

Alternate processing which could be used in the refabrication facility include co-precepitation followed by pelletizing and the sol-gel process with a vibratory compaction method of rod loading.

The reference facility is assumed to receive material with only the relatively low levels of radioactivity associated with recycled material. An alternate philosophy is to artificially enhance the radioactivity to very high levels. This renders the material lethal to handle without proper shielding, thereby improving proliferation resistance. 


\subsection{PLUTONIUM STORAGE AND TRANSPORTATION SYSTEMS}

The operation of an IFSC reprocessing, fabrication plant and reactors at a single site wili result in a significant quantity of plutonium, both in storage and transit. Assuming eight plutonium reactors, (see section 2.0), the quantity of plutonium in buffer storage will be in the range of metric tons (i.e., 5-10-20). Also, the quantity of material in transit between the individual facilities at the IFSC at any one time could be great enough to represent a target in a host nation takeover. The forms and nominal quantities of plutonium shown in Table 3.3 illustrate the magnitude of the problem.

TABLE 3.3. Forms and Quantities of Plutonium at an $\operatorname{IFSC}(a)$

\begin{tabular}{|c|c|c|c|c|}
\hline & $\begin{array}{l}\text { Spent } \\
\text { Fue } 1\end{array}$ & $\begin{array}{l}\text { Fresh } \\
\text { Fuel } \\
\end{array}$ & MOX & $\begin{array}{c}\text { Waste \& Scrap } \\
\text { Recycle }\end{array}$ \\
\hline Reprocessing & $x$ & & $x$ & $x$ \\
\hline Fabrication & & $x$ & $x$ & $x$ \\
\hline Reactor & $x$ & $x$ & & \\
\hline Material Transfer & $x$ & $x$ & & \\
\hline Waste Management & & & & $x$ \\
\hline $\begin{array}{l}\text { Approximate Annual } \\
\text { Flows, }\end{array}$ & $\begin{array}{l}11 \\
\text { LWR }\end{array}$ & $\begin{array}{c}14 \\
\text { LWR-MOX }\end{array}$ & $\begin{array}{l}29 \text { as } \\
\text { powder }\end{array}$ & $\begin{array}{c}0.1 \text { high-leve } 1 \\
\text { waste }\end{array}$ \\
\hline Metric ton $\mathrm{Pu}$ & $\begin{array}{l}18 \\
\text { LMFBR }\end{array}$ & $\begin{array}{l}14 \\
\text { LMFBR }\end{array}$ & & $\begin{array}{c}0.5 \text { recycle } \\
\text { scrap }\end{array}$ \\
\hline
\end{tabular}

(a) Based on an IFSC containing eight LMFBRs and one 1500 metric ton/yr reprocessing plant.

The material in storage will require protection from the adversary. To date, the idea is to use some form of thermite chemistry to render the material unusable. Thermite chemistry is envisioned as a reaction between the reactive thermite material and plutonium. The resulting slaglike substance is difficult to convert, back to a useful form of p? utonium 
useful for weapons (see section 2.3). This, coupled with dispersal, might provide the four to six weeks delay required before the plutonium could be returned to a usable form.

Material in storage might be more difficult to use-deny than material in the other components of the IFSC. Storage would require sophisticated containers armed with thermite and linked to the $\mathrm{C}^{3}$ system. The thermite can be activated either by the adversary himself while trying to penetrate the container or by a signal from the $c^{3}$. Where possible, physical dispersal can also be considered as a denial technique.

The thermite chemistry technique will be one of the first research and development items in the next phase of the project. Both MOX and plutonium nitrate solution will be examined. Oxide systems are already under development. Also to be considered are thermite reactions with fresh fuel rods and assemblies. The reaction concept appears to be plausible but development will be needed to prove feasibility and expand the technigue for larger items.

Part of the operational considerations will be to closely couple the facilities in order to minimize the quantity of material in storage. Since this is considered to be one of the most vulnerable points in an IFSC, other active and passive techniques must be fully explored in order to provide the required protection.

The internal transfers within the IFSC will be of two general types. First, the transit distances between the reprocessing, fabrication, storage and waste management, will be on the order of feet. Close-coupling results in a continuous process within a single building (see section 3.7.3). Secondly, the distance between the reactor and the fuel processing plants will be on the order of miles. Thus, two types of interfacility transportation systems are needed.

The first system will handle only some forms of MOX and waste and recycle material. The second system will transport fresh and spent fuel. Thus, these systems may be very different. Whatever the system used, it should be compatable with the input and output system to the IFSC. 
The types of systems to be considered for the proliferation-resistant IFSC may include:

- Above-ground transport

- roadbed - truck and trailer

- unique rail - e.g., monorail

- enclosed - pneumatic tubes

- Below-ground transport

- road

- rail

- pneumatic tube

- Air transport

- plane

- he licopter

Each of these systems has advantages and disadvantages. The system that is most resistant to host nation takeover may be dependent on operational considerations such as minimizing the quantities of material in transit at any one time. 


\subsection{THE REACTOR FACILITY}

The basic design will consist of a sodium-cooled reactor, containing a mixed plutonium-uranium oxide core surrounded by a depleted uranium oxide blanket designed for $2800 \mathrm{MW}(\mathrm{th})$ output, with associated heat transport and power conversion systems to produce a net electrical output of $900 \mathrm{MW}(e)$.

The system is designed to operate primarily as a base-load unit but with partload capabiitities down to $60 \%$ of its rating. Other operating features expected are:

- Refueling will be on an annual basis durina a nominal 20-day outaqe.

- During each refueling outage, $45 \%$ of the fue 1 assemb 7 ies, $30 \%$ of the blanket assemblies, a11 the control assemblies, and selected removable shield assemblies will be replaced.

- Selected blanket assemblies will be shuffled during each refueling.

- Spent fuel storage space in a sodium filled tank will be provided for a normal refueling load plus $10 \%$ of a normal refuelina load plus one full core load of core assemblies.

- Core components will be shipped in an as-removed condition.

- The design life of the facility is 40 years.

Figures 3.2 and 3.3 give some perspective on the size of these concepts and the configurations of the reactor facility.

\subsubsection{Core}

The reactor core consists of a group of replaceable core assemblies located inside a fixed radial shield and a core barrel. These assemblies consist of fuel, radial blanket, controi rods, and removable radial shielding. Each of the above assemblies are hexagonal in cross section and all are the same length so that the core is a close-fitting, compact array of these components (Figure 3.4).

The fuel rods in a fuel assembly consist of stainless steel cladding tubes with welded end caps and contain $\mathrm{PuO}_{2} / \mathrm{UO}_{2}$ fuel pellets, $\mathrm{UO}_{2}$ axial blanket fuel pellets above and below the fuel pellets, and space above and beiow the blanket pellets for the collection of fission product gas. The Pu enrichment in the fuel (central) section varies from about $16 \%$ to $13 \%$. 


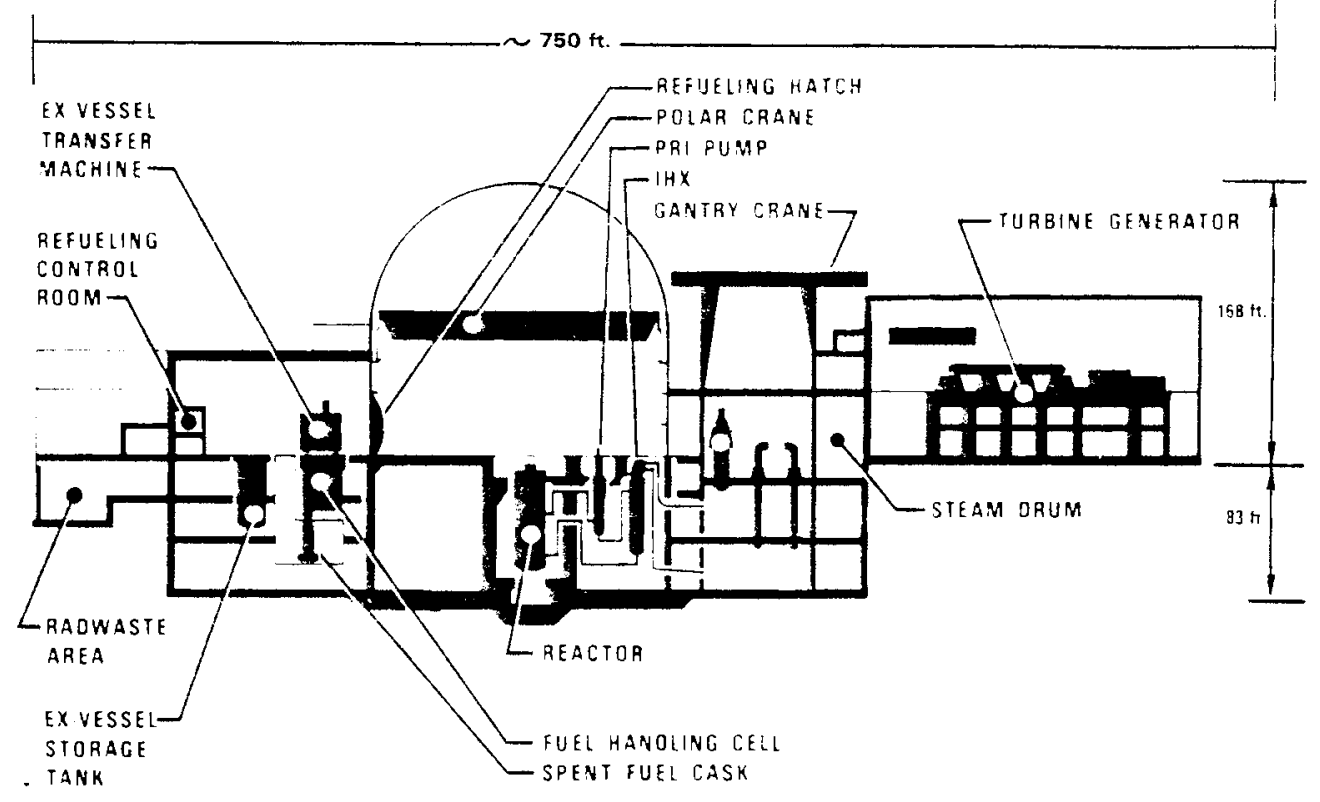

FIGURE 3.2. Section Elevation of the Plant

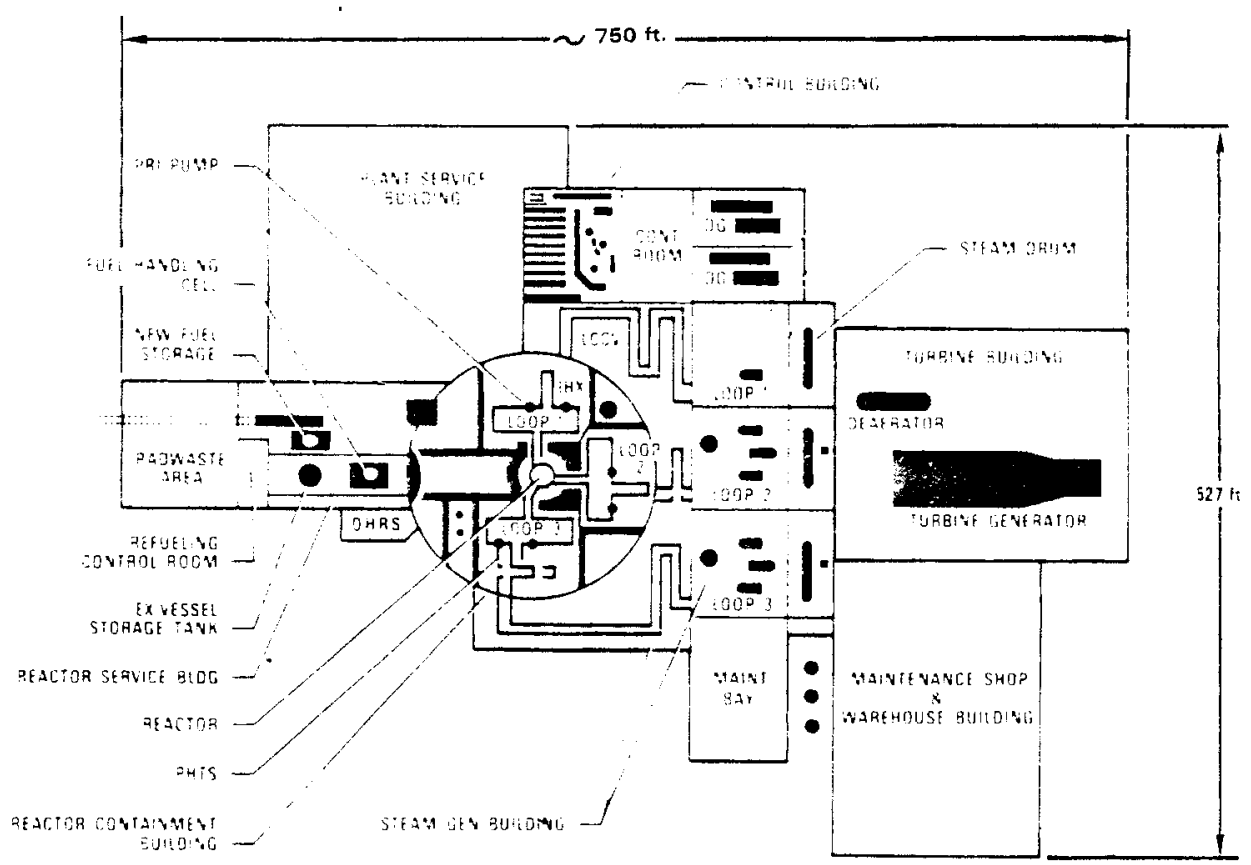

A section elevation of the CRBRP plant (above) and plan view of the plant layout illustrate the major design features incorporated in the reference design.

FIGURE 3.3. Plan View of the Plant 


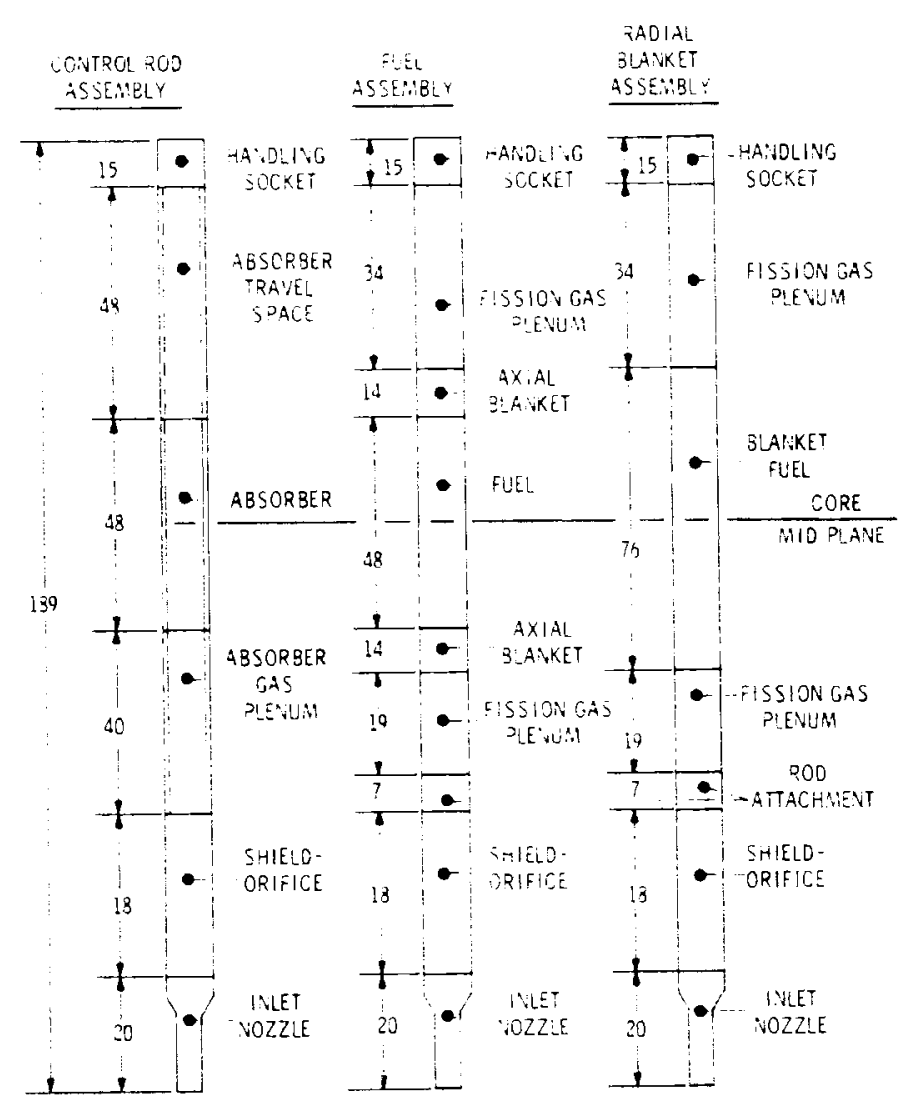

FIGURE 3.4. Reactor Core Assemblies

\subsubsection{Reactor Control System}

The reactivity control system is comprised of two independent, diverse systems (primary and secondary) including independent protection systems.

Both systems are core components containing a movable neutron absorbing material, enriched boron carbide $\left(B_{4} C\right)$, in the form of cylindrical ceramic pellets contained in stainless steel cladding tubes and arranged in a hexagonal form.

The secondary control rod system provides features diverse from those in the primary system and directed toward eliminating common mode system failure. In both systems, the absorber height is the same as the fuel assembly height and, when fully inserted, the two overlap completely thereby providing maximum shutdown capability. 


\subsubsection{Heat Transport System}

The heat transport system (HTS) couples the reactor system to the electrical generating system of the balance-of-plant. Primary, radioactive sodium flows in loops from the reactor vessel outlets through hot leg pumps to intermediate heat exchangers (IHS), through check valves and back to the reactor vessel at the inlet nozzles.

The IHX provides isolation of the radioactive reactor sodium and transfers heat to the non-radioactive intermediate sodium. The intermediate sodium in turn flows to steam generators.

Inert atmospheres help minimize the potential hazards of sodium fires. Within the reactor vessel and sodium pumps, argon gas is in contact with the sodium free surfaces. All primary sodium containing pipes are located in nitrogen atmosphere cells within containment. Intermediate system sodium piping is routed inside the HTS cells in containment until it exits through rigid containment penetrations. Thereafter, intermediate system piping and components are contained in hardened, air atmosphere cells or strictures.

Reactor decay heat following normal or emergency shutdown is transmitted to the steam generator system through the sodium heat transport system via pony motor flow or natural circulation. Relative elevations of the reactor core, IHX tube bundles and steam generator modules as well as sodium flow directions have been arranged to promote natural circulation of sodium coolant in the event of loss of all electrical power to the pumps.

\subsubsection{Auxiliary Systems}

Eight auxiliary systems support the principal reactor and heat transport system. An auxiliary fluid coolant system, which uses an organic fluid, provides for cooling equipment. The radioactive waste disposal system provides for collection, storage, monitoring, and the package and transfer of liquid and solid radioactive waste materials. Habitability, comfort cooling, and heat removal are accomplished by the heating, ventilation, and air conditioning system. 


\subsubsection{Reactor Refueling System}

Fuel movement from reactor to storage is accomplished with a heavily shielded ex-vessel transfer machine (EVTM) which is mounted on a gantry.

The refueling system consists of facilities and equipment necessary to accomplish the replacement of reactor core assemblies, including fuel, blanket, control and radial shield assemblies, as well as to perform other functions incident to handling of core assemblies.

Figure 3.5 of the fuel handling equipment and facilities shows the general arrangement of the system.

The sequence for handling fuel begins with receipt of new fuel on site. The fue 1 arrives by truck as a fully assembled element and is transported in lightly shielded, single assembly shipping containers. The number of containers per shipment will depend upon the use-denial procedures adopted for the facility. Each container is removed from the truck by the reactor service building crane and lowered into the new fuel storage cell. With an in-cell crane, the fuel is removed from the container and stored in separate tnimbles within the cell. The fuel assembly is normally inspected at this point for dimensional measurements, observation for damage and given a gas pressure drop test for determining potential flow blockage. These operations continue intermittently for about eight months out of the year until a complete refueling load has been received, inspected and stored. The new fuel storage cell can have a capacity for as many or as few assembiies as passive use-denial design strategies dictate.

The fuel assemblies are transferred from the storage cell to the exvessel storage tank by means of a special transfer mechanism. The machine is lightly shielded, handles a single assembly and changes the fuel assembly atmosphere from air to argon. The new fuel assembly is sent to a special preheat station in the storage tank where it is heated in argon to $400^{\circ} \mathrm{F}$ $\left(204^{\circ} \mathrm{C}\right)$. After preheat is complete the assembly is transferred to one of the storage positions by means of the transfer machine.

The ex-vessel storage tank is a large, two-tier sodium tank with multiple storage positions. The capacity is sufficierit to store two refueling loads 


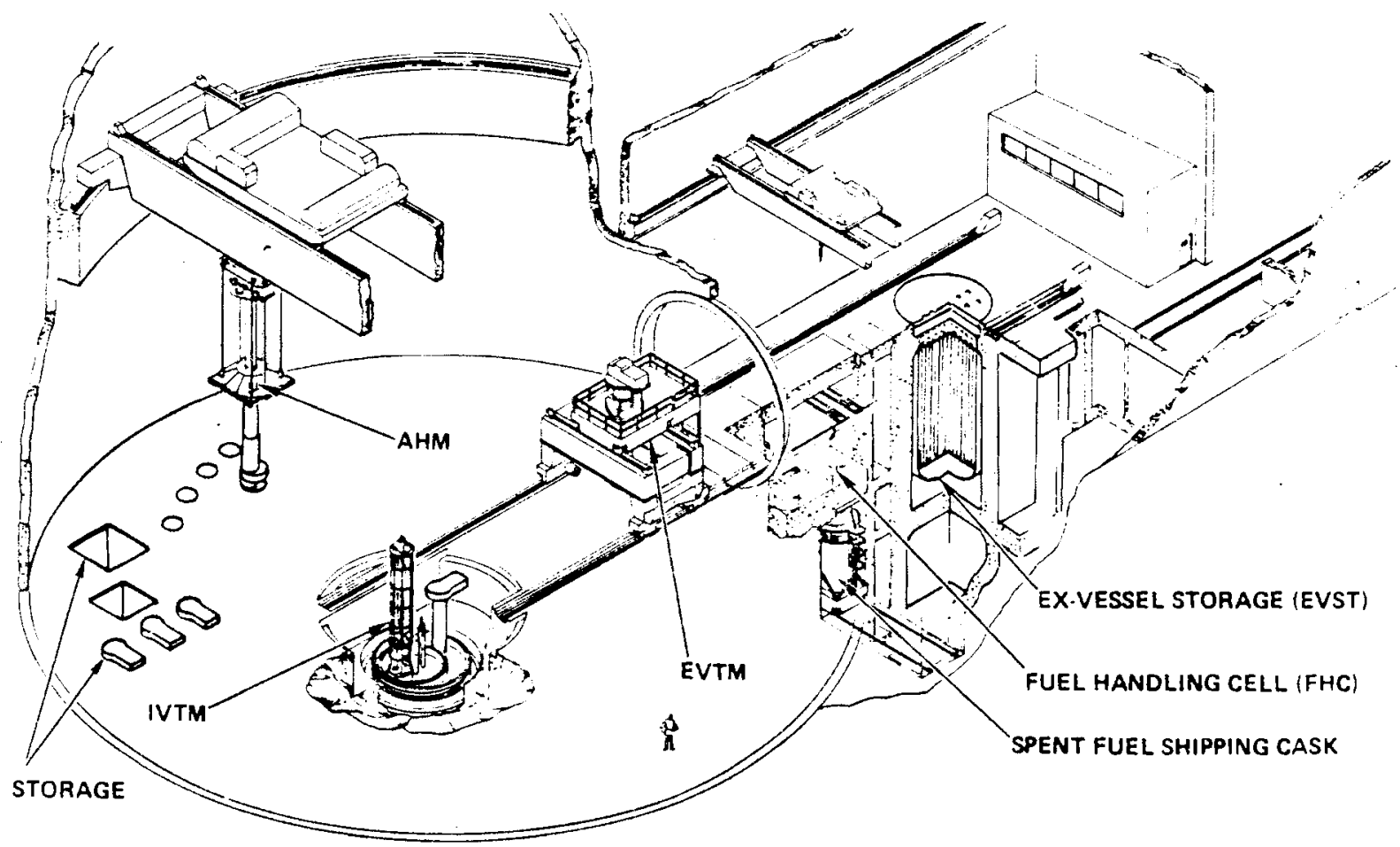

AHM - AUXILIARY HANDLING MACHINE

EVTM - EX-VESSEL TRANSFER MACHINE

IVTM - INTERNAL VESSEL TRANSFER MACHINE

\section{FIGURE 3.5. Reactor Refueling}

of heat producers and handle the heat producers from a complete core unloading. Non-heat producers (control and radial shield assemblies) are stored elsewhere under an argon atmosphere during a complete core unload situation.

Al1 fuel handied by the EVTM is done with the fuel in a sodium-filled thimble called a core component pot. This container is necessary to assure that the decay heat can be removed in the machine without allowing the fuel cladding to exceed maximum temperatures. The sodium, because of its good heat transfer properties, provides the medium to transfer the heat out of the fuel bundle to the pot wall and from there to radiate to the air. If the transfer is to be made by rails, spent fuel is allowed to decay for 100 days in the ex-vessel storage tank and a shipping cask is brought on-site by a special railroad car. Control, radial shield and some low-power blanket 
assemblies can be shipped off-site before the 100-day cooling period, but fuel and high-power blankets assemblies normally would be held until the decay to about $6 \mathrm{~kW}$ (Max.).

Fuel assemblies are transferred from the storage tank to the handling cell with the transfer machine and temporarily stored in a multi-position, sodium storage tank in the cell. The assemblies are removed, one at a time, from the storage tank by means of a gas-cooled grapple. They are dimensionally examined, residual sodium is removed by drainage and hot argon gas is forced over the assembly surfaces and then lcaded into the shipping cask. A cask can transport nine assemblies with a combined heat load of $26 \mathrm{~kW}$ by immersing the assemblies in liquid Dowtherm $A$ and allowing natural convection of air to flow over the cask body fins. The plant will have one or more casks and shipments will continue untii all spent fuel has been received by the reprocessor. 


\subsection{WASTE MANAGEMENT PROCESS}

The Barnwell plant does not have a liquid waste solidification facility. For the purposes of this study a conceptual waste vitrification plant ${ }^{(a)}$ was selected for inclusion as a reference facility.

The process is depicted in the flow diagram shown in Figure 3.5. The concentrated high- and intermediate-level wastes from the reprocessing plant are stored separately in large underground tanks. After temporary storage (up to five years) the wastes are solidified together in the waste solidification plant (WSP). This is a two-step process; calcination and vitrification. The mixed high- and intermediate-level liquid wastes are heated in the spray calciner and converted to a mixture of metal oxides. The calcine is mixed with a powdered glass frit. The mixture falls into a stainless steel canister which is heated to $21050^{\circ} \mathrm{C}$. The mixed calcine and frit melts and, on cooling, forms a glass-like monolith in the canister. The canister is welded closed, decontaminated, and transferred to interim storage. Interim storage can be in the spent fuel storage pool in the fuel receiving and storage station of the reprocessing plant. The canisters are eventualiy transported to a disposal site that as yet has not been defined.

The composition of 1 iquid wastes from reprocessing LWR and LMFBR fuels will be similar to that shown in Table 3.5. The concentration of plutonium in the waste is quite sma 11 and the fission product content is large. Plutonium recovery from the liquid waste appears to be a formidable task. Using vitrified waste would be even more difficult. Most certainly the adversary would need immense technical resources to achieve weapons capability if the wastes were his only source of plutonium.

(a) This plant was developed by Schneider et al. based on the spray calciner/ in-can melter under study at PNL. 
TABLE 3.5. Constituents of High-Leve? Liquid Wastes

Constituents

Grams/Metric Ton of Fuel Processed

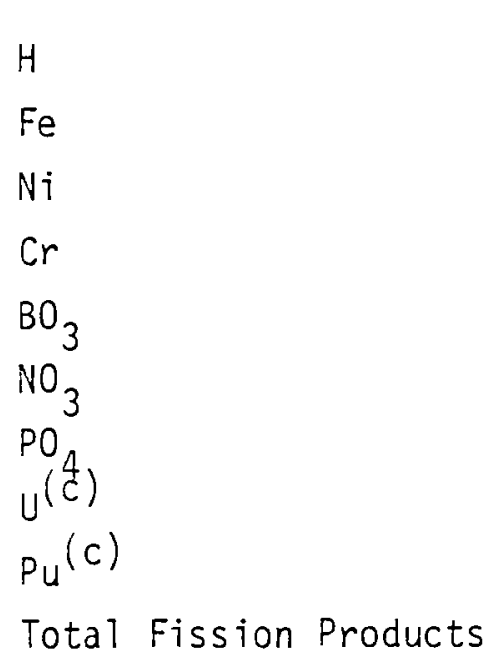

\begin{tabular}{c} 
LWR Fue I (a) \\
\hline 400 \\
1,150 \\
150 \\
200 \\
- \\
66,000 \\
900 \\
4,800 \\
45 \\
29,000
\end{tabular}

$\frac{\text { LMFBR Fue } 1 \text { (b) }}{1,300}$

26,000

3,300

6,950

98,000

244,000

4,300

480

33,000

(a) 33,000 MWd/MT, U-235 enriched fuel, 378 liters liquid waste/MT fuel.

(b) Mixed case and blanket, 1250-7iter liquid waste/MT fuel, boron used as a soluble poison, $10 \%$ of stainless steel cladding dissolved in the process.

(c) $0.5 \%$ product loss to waste. 


\subsection{ADVANCED SAFEGUARDS SYSTEM}

Each of the facilities in the fuel service center is assumed to be protected by a state-of-the-art safeguards system providing physical security and SSNM control and accountability. The operation of the saieguards system is under the control of the fuel service center management but the information generated by the system is available for use by the $c^{3}$ system. Management and operating personnel for the safeguards system can be a mix of host-nation citizens and multi-nationals.

\subsubsection{Advanced Safeguards System Description}

A safeguards system performs five basic functions:

- deterrence of potential adversary actions

- detection of unauthorized activities and discrepancies

- assessment of actions directed against the system

- delay of unauthorized activities until appropriate response can be made

- response to unathorized activities and discrepancies in an adequate and timely manner.

Two major independent, but interrelated, systems are required, namely, physical protection system and a materials measurement and accounting system. Physical protection controls the actions of people, protecting facilities and material. Materials measurement and accounting provides information on the locations and quantities of SNM in a facility. The physicai protection system is divided into access and operations control. Access control enables and monitors authorized movement of people and material across barriers, and prevents unauthorized movement of people, SNM, and contraband. Operations control, which is concerned with the operational interfaces among people, vital equipment, and SNM, enables and monitors authorized plant activities and seeks to prevent unauthorized actions that could result in theft or sabotage. These safeguards systems must be coordinated with normal plant operational systems to obtain a safeguards design that is effective, is cost effective, and has an acceptable operational impact. 


\subsubsection{Access and Operational Control}

An advanced safeguards system can be installed in the IFSC facilities based on currently available technology and using computer-based subsystems that provide continuous materials control, extensive physical protection, and automated personnel control. These subsystems are coordinated to provide an effective extension of the safeguards staff through the plant, encompassing the physical protection, materials control, and accountability functions. Emphasis is placed on improved containment of nuclear material by process monitoring. Added theft sensors give a means for detecting attempts to divert nuclear material in a timely manner. With a tested and operational ISS, improvements will be obtained in the areas of: timely theft indication, measurement data validation, and elimination of certain vulnerabilities.

In an inspected plant, the inspection staff must be supplied with the information needed to assure that special nuclear materials are not being diverted. The proposed system will provide information well beyond current requirements. Inspectors will have access to computer terminals enabling continuous monitoring of the movements and locations of nuclear materials throughout the plant. The structure of the safeguards system, providing for both information flow and control, is depicted in Figure 3.6

The proposed system meets the requirements for effective integrated safeguards control through:

- verification of materiai balance with improved timeliness (organic materials accounting) - Such verification provides the ability for the plant safeguards personnel and independent inspectors to observe and validate the collection of plant accountability data as it is obtained, including input from chemical measurements, nondestructive analysis, and plant-installed instrumentation.

- continuous monitoring of critical plant operations for the detection of diversion "signatures" - Data from existing and special additional instrumentation will continuously be collected and analyzed by a computer-based monitoring system providing a data base record accessible at any time for inspection purposes.

- remote alarm indications - When improper operations or diversion "signatures" are detected, remote alarm sionais will be displayed at 


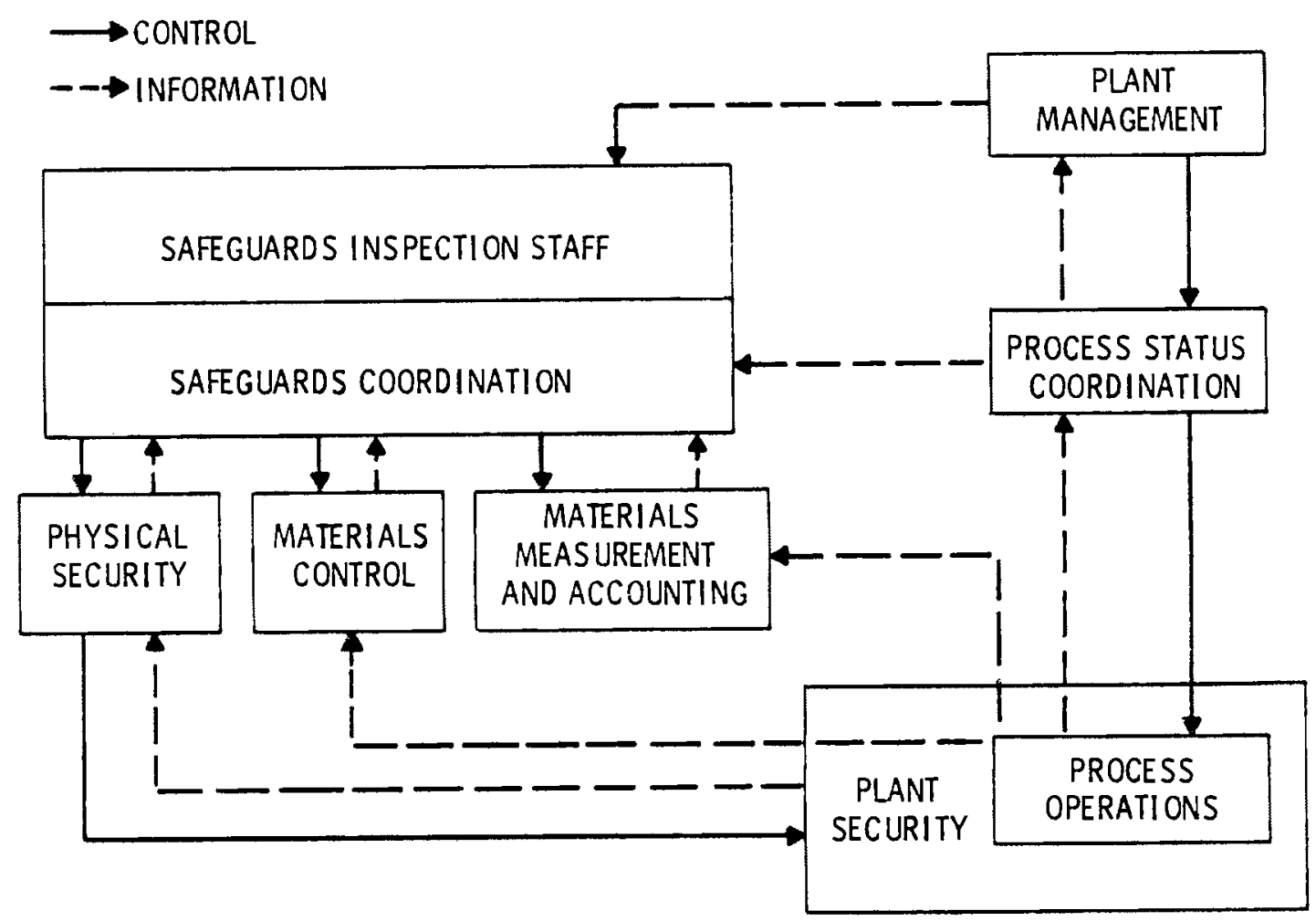

FIGURE 3.6. Safeguards Structure

the inspector's location. This feature will allow the inspector to investigate suspect operations immediately.

- monitoring of nonroutine access to sensitive areas - Significant improvements in timely and comprehensive personnel access monitoring can be implemented to both discourage and to immediately detect access to process equipment that is not permitted by administrative and operational procedures.

The computerized instrumentation and monitoring system design employs current software security, self-checking, and hardening technology. The inspectors have cognizance of instrument maintenance, calibration, and substitution, and may inspect operator instrument installations for cause, or as indicated by the built-in self-testing functions. The inspectors are assisted in monitoring material transfers by a computer-based system that continualiy observes process operations, and anticipates routine sequences associated with an authorized transfer. In this way, normally disallowed 
activities are immediately brought to the attention of the inspectors and are automatically documented for subsequent review.

This overall safeguards monitoring by the inspection team is not intended to replace the traditional physical protection, materials control, and accountability functions required of the plant operator. More correctly, the automated system supplements the inspector's traditional sampling and analysis overlay and improves the timeliness with which normal operations are verified and questionable activities are detected. The process monitoring thef $t$ detection system records provides a timely way of verifying that no loss has occurred. This lends great support to the present methods of verification. Validation of measurement data is provided by supplemental and backup information that strengthens and confirms the material balance conclusions.

A key feature of the ISS is close monitoring of vital areas, activities, and process areas, that greatly extends the period of time it would take to draw off a significant quantity of material. This raises the time of exposure of the diversion activity, which increases to near certainty the probability of detection for monitored actions. This may reduce those vulnerabilities associated with collusion of several plant employees to falsify data or conceal material.

\subsubsection{Dynamic Material Accounting}

The materials measurement and accounting system (MMAS) performs two safeguards functions:

- "single theft" detection where material balance calculations are made on a near-real-time basis

- "long-term diversion" detection based on trends in material balances.

Conventional safeguards inventory control of bulk material consists of complete inventories conducted during periodic plant shutdowns, with numerous accounting and administrative procedures for interim operating periods. The classical material balance associated with this system is drawn around the entire facility or a large portion of the process, and is formed by 
adding all measured receipts to the initial measured inventory and subtracting a 11 measured removals from the final measured inventory.

Recently developed nondestructive analys is technology, state-of-theart conventional measurement methods, special in-plant sensors, plant instrumentation signals, and the effective statistical data-analysis techniques combined with supportive computer and database-management technology allow timely assessment of the containment of material within a facility. This information provides quantitative evidence that measures taken to prevent and detect diversion have been effective. In addition, conventional materials accounting can be augmented by on-line measurements and material sensors to achieve a highly effective safeguards system. To implement this approach, the facility is partitioned into discrete accounting envelopes, called process accounting areas. Unit processes are defined on the basis of function and the ability to draw a material balance around the contained portion of the process. Material balances drawn around unit processes are called dynamic material balances to distinguish them from balances drawn after cleanout and physical inventory. A dynamic material balance is based on measurements of significant material transfers into and out of the unit process during its material-balanced period. Quantities of material much smaller than the total plant inventory can be controlled by partitioning a facility into unit processes and measuring appropriate materiā flows. Furthermore, because shutdown and cleanout are not required, dynamic materials accounting can provide a timely indication of possible theft. Balance periods of less than one day are practicable. Finally, any discrefancies are localized to that portion of the process contained in the unit process accounting area.

The materials control system collects rapidly obtainable database information, specifically designed to detect a theft in progress, form a limited set of on-line measurement equipment, plant-grade instrumentation, and cther simple, reliable process-monitoring devices. The system makes use of plant instrumentation and standard plant operating procedures whereever possible. Data from the plant instrumentation is used for rough material balances on transfers between tanks and across columns. In a similar 
manner, an overall plutonium balance can be maintained. This near real-time material accounting sacrifices some accounting accuracy for timeliness and continuity of data.

The system also uses an array of sensors to provide information on the status of the process valves: presence or absence of liquid in the process, sampler lines, and decontamination lines; status of valves supplying sample or transfer jets, and pressure in instrument lines. These sensors are a 11 simple, rugged, and relatively inexpensive.

A safeguards system of this type would use a hardened, dedicated computer system to assist in the collection and analysis of safeguards-related data, to generate timely and accurate storage, and report the results. As much of the instrumentation as possible is interfaced directly to the computer system so that speed of data collection is increased and the possibility for human error is reduced. In addition, the entire data collection system (both hardware and software) is hardened with respect to security and reliability.

Instrumentation of such a design concept is best done as part of the initial facility design. Incorporation of this instrumentation during plant construction would:

- allow installation and test of NDA equipment, in-line monitors, realtime data processing, and analytical computer systems

- permit greater latitude and efficiency in inspector training including exercises in material-diversion path and analys is

- allow greater freedom and opportunity to examine plant design, equipment and characteristics, and operations made under nonradioactive active conditions

- allow confirmatory evaluation of plant equipment, instrumentation installation, and anticipated process performance under simulated conditions of flow, temperature, and pressure

- allow modification to the facility to accommodate alterations to facility and equipment design, if necessary. 
Considerable safeguards emphasis is usually placed on spent fuel reprocessing, but all of the IFSC facilities, including the reactors, fuel storage, waste handling fuel fabrication, and conversion would be instrumented to give integrated protection system monitoring. 


\subsection{POSSIBLE METHODS FOR RESISTING PROLIFERATION}

At present, proliferation resistance is merely a concept. However, during development of the concept, several mears have been determined through which the resistance of a facility can be enhanced:

- utilizing the most appropriate processing alternative

- varying the physical structures

- closely compiling the facilities

- laying out process equipment

- maintaining the facility by the most proliferation resistant means

- using process controls that are inherentiy proliferation resistant

- controlling the process instrumentation

\subsubsection{Processing Alternatives}

In the reference process, uranium and plutonium are separated from the fission products and from each other and the plutonium is converted to pure plutonium oxide. The oxide is blended into appropriately large batches and transferred to the fuel fabrication plant where it is mixed with uranium and fabricated into mixed oxide fuel. This results in relatively large inventories.

Two reprocessing alternatives that have been proposed may increase the difficulty in obtaining weapons-usable plutonium from the plutonium fuel cycle. These are:

- limiting the plutonium output from the reprocessing plant to a uraniumplutonium mixture, and

- adding high energy gamma-emitting isotopes to provide a high dose rate ("spiking").

The first alternative can be achieved by coprocessing or by blending uranium with the plutonium after separation and prior to its transfer to the fliel fabrication plant. Coprocessing is a concept in which plutonium is never 
completely separated from uranium at any point. In one separation technique, coprocessing involves modifying the partition cycle so that a fraction of the uranium follows the plutonium. Blending uranium with the plutonium can be done conveniently by adding uranyl nitrate solution to the product from the plutonium purification cycle or by mixing uranium dioxide with plutonium dioxide after the oxide conversion step.

The spiking alternative includes high energy gamma emitters in the plutonium. This can be achieved by modifying the separation process in such a way that the decontamination efficiency is greatiy reduced and a small fraction (2-5\%) of the fission products follows the plutonium. A separated gamma emitter can also be added to the plutonium at some strategic point in the process.

The radioactivity level necessary to deter the diversion of plutonium and to delay its use in weapons is very high, perhaps thousands of $\mathrm{k} / \mathrm{hr}$ per $\mathrm{Kg}$ at 1 or $2 \mathrm{ft}$ from the source. Heavily shielded facilities for conversion and fuel fabrication are necessary. The fresh fuel must be transported in shielded casks, and handied remotely at the reactor.

Spiking combined with coprocessing or blending of uranium in the reprocessing plant is another potential alternative for the plutonium fuel cycle. The highly publicized CIVEX concept utilizes partial decontamination and coprocessing for production of a mixed oxide suitable for LMFBR fuel. The concept also includes facility design features that inhibit process modifications for the purpose of obtaining pure plutonium. These features prevent back cycle and replace the uranium purification solvent extraction system with a volatility sys tem.

A partial listing of the various other options and combinations of the two reprocessing alternatives that can be devised is given below. Fiçures 3.7 to 3.12 are generalized flow sheets which correspond to this list: 
Case 1 Reference process (Figure 3.7)

Case 2 Coprocessing with high decontamination (Figure 3.8)

Case 3 Coprocessing with partial decontamination (Figure 3.9)

Case 4 Same as reference case, but radioactive spike added after plutonium purification (Figure 3.10)

Case 5 Same as reference case but with uranium plutonium blending after plutonium purification (Figure 3.11)

Case 6 Coprocessing with spike addition (Figure 3.12)

Cases 2, 3, and 6 are incompatible with the reference Pu conversion process. Cases 4 and 5 can use the conversion process only if the spike (Case 4 ) or the uranium (Case 5 ) is added after the conversion step.

Conversion processes which are compatible with all the cases can be based on direct denitration or coprecipitation of the mixed plutonium-uranium-spike solutions. Figure 3.13 is an example of a flow sheet for direct denitration. This conceptual process utilizes a fluid bed calciner to convert the solution to a mixed oxide solid. Figure 3.14 is a schematic example of coprecipitation-the Coprecai concept. 


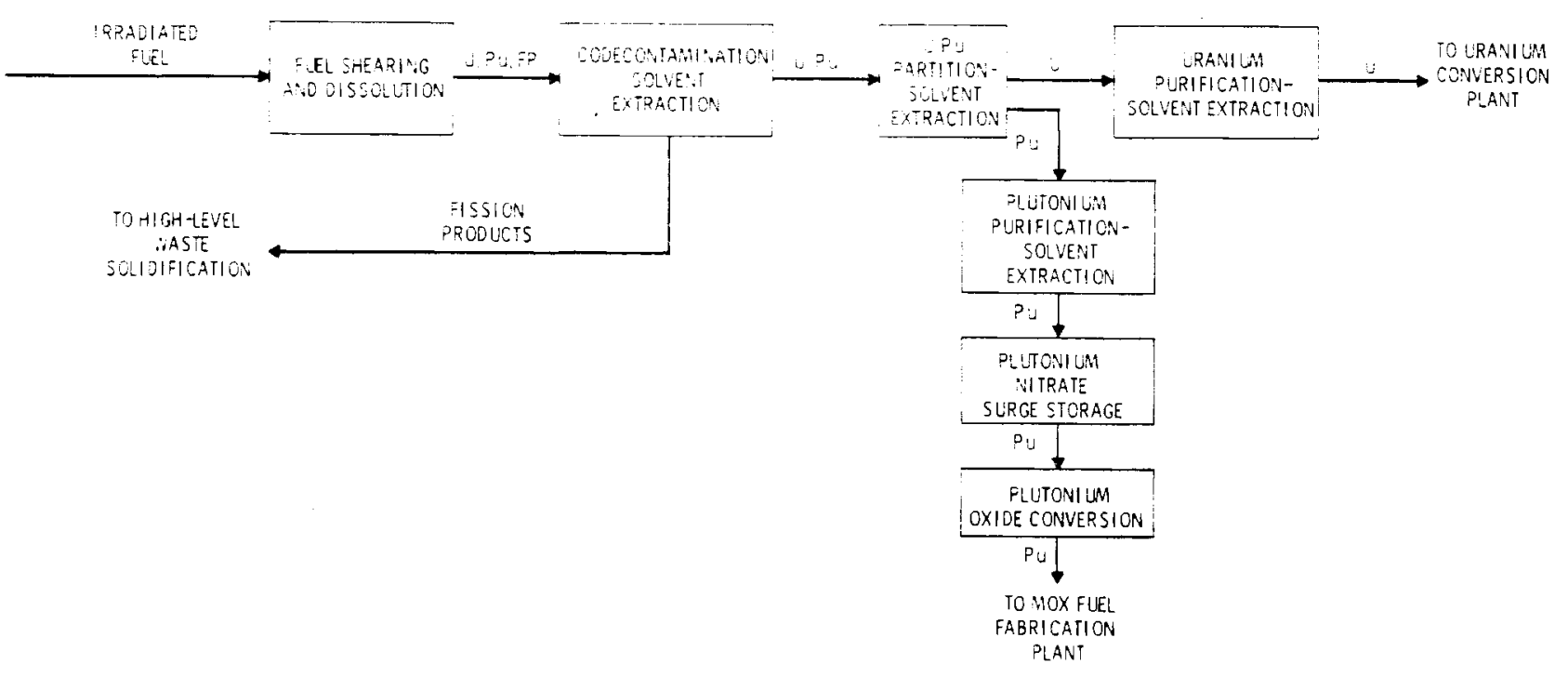

FIGURE 3.7. Reference Process Case
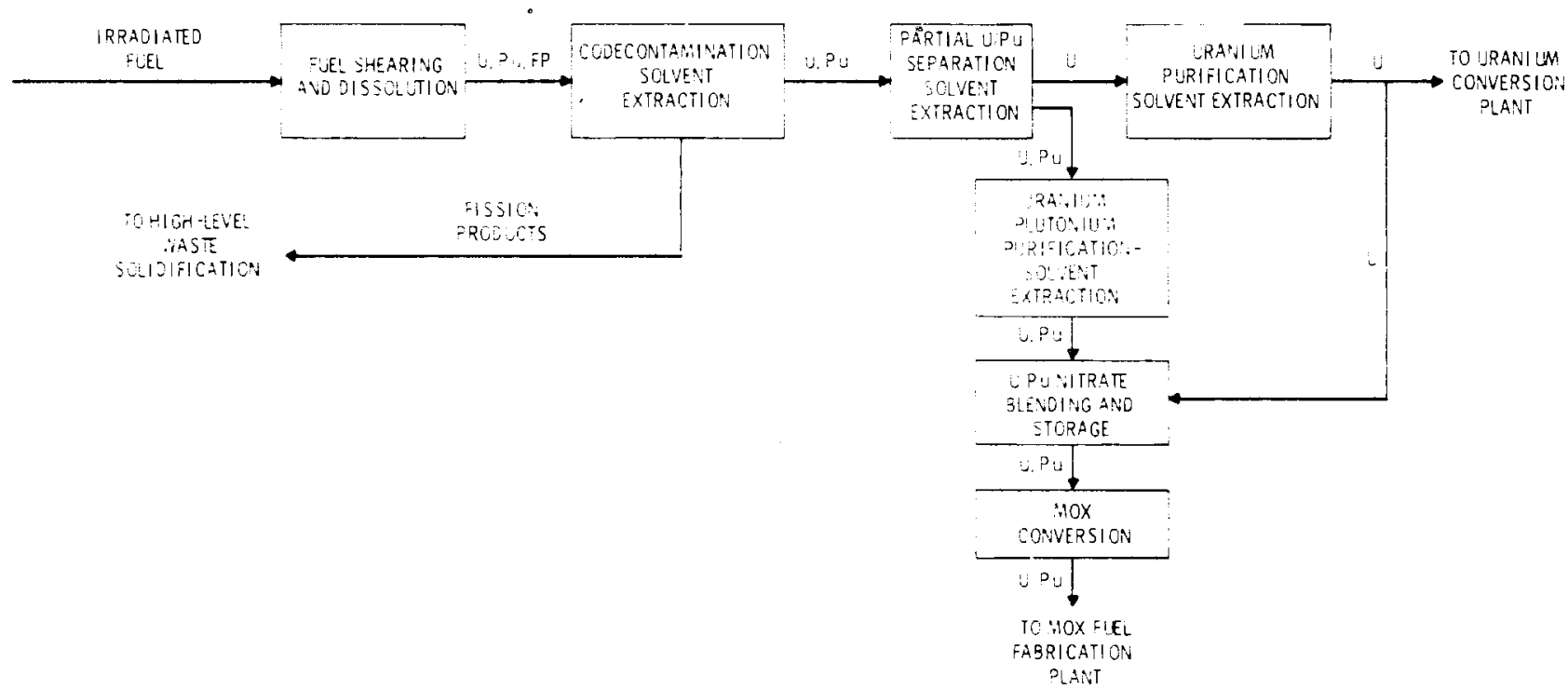

\section{FIGURE 3.8. Coprocessing With High Decontamination}




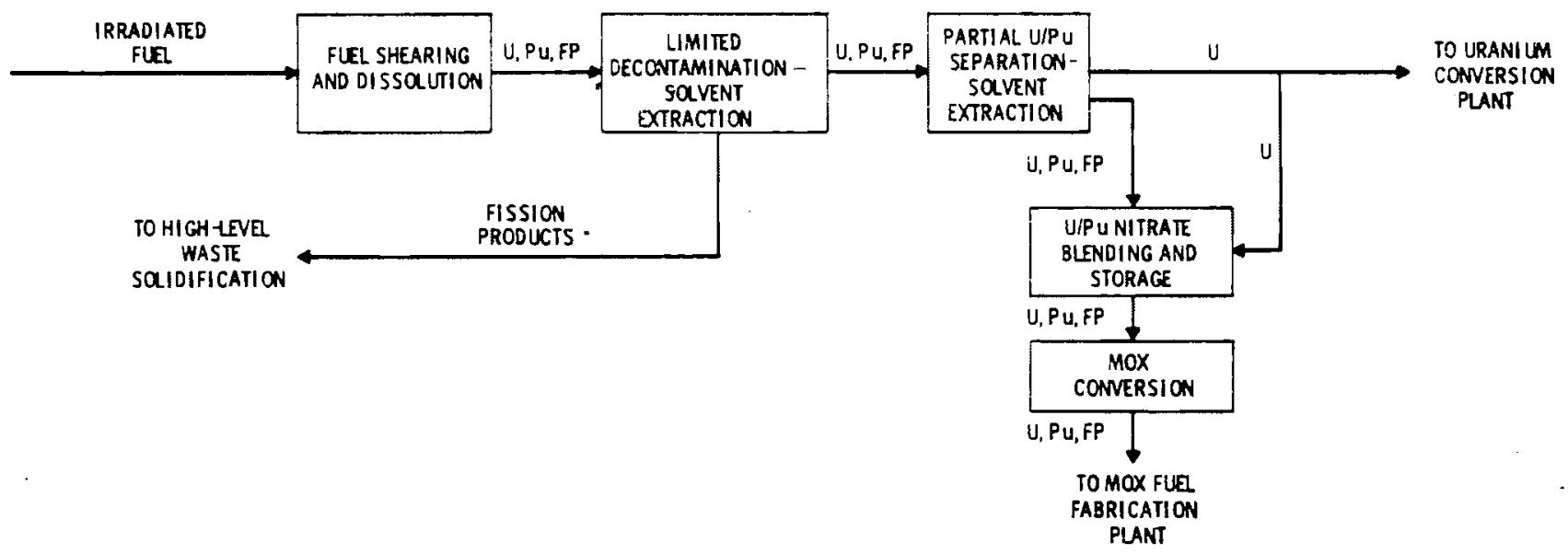

FIGURE 3.9. Coprocessing with Partial Decontamination
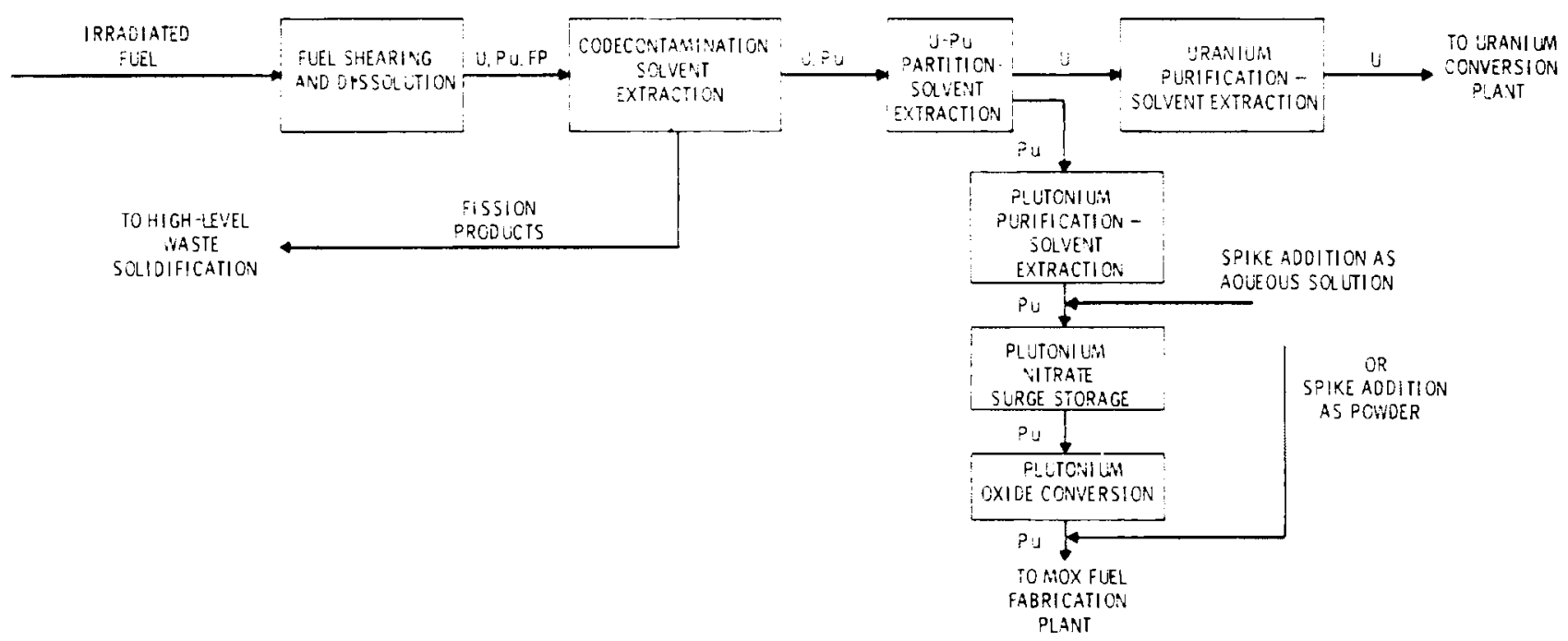

FIGURE 3.10. Reference Process Case, But With Spike Addition 


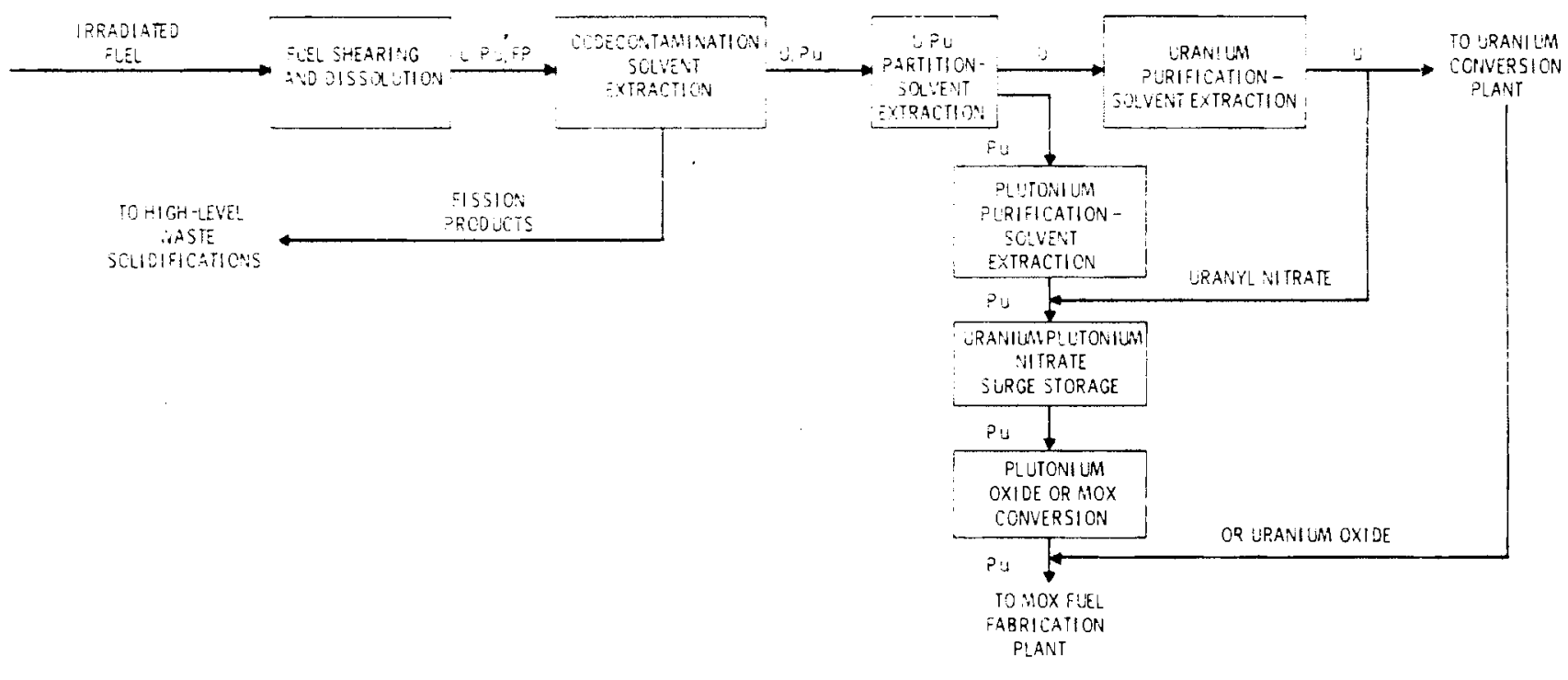

\section{FIGURE 3.11. Reference Process Case, But With U/Pu Blending}

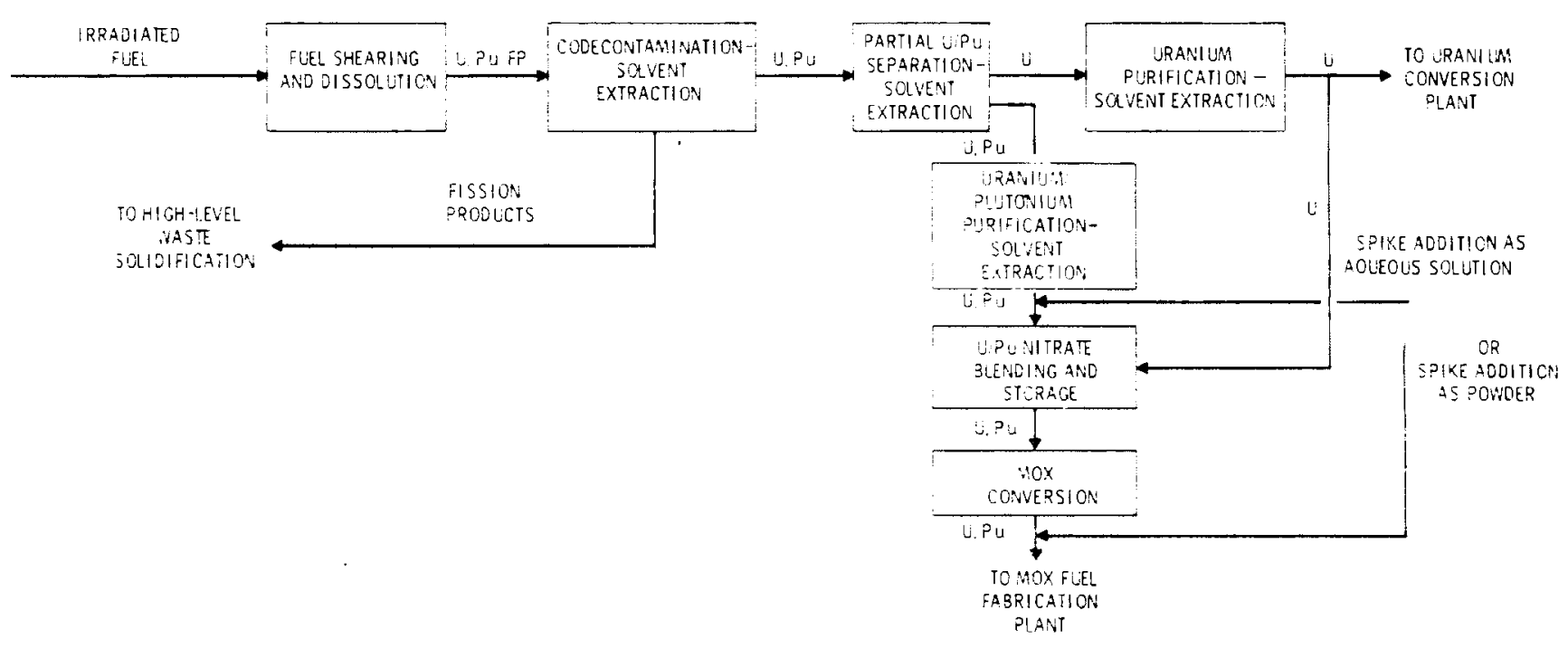

FIGURE 3.12. Coprocessing with Spike Addition 
In this process, the nitrate solution is created with ammonia to form a thixotropic slurry. The slurry is fed to a fluid bed calciner where it is converted to a mixed oxide powder. The powder is treated with $\mathrm{N}_{2}-\mathrm{H}_{2}$ and then with $\mathrm{CO}_{2}$ to form a stabilized oxide suitable for fuel fabrication.

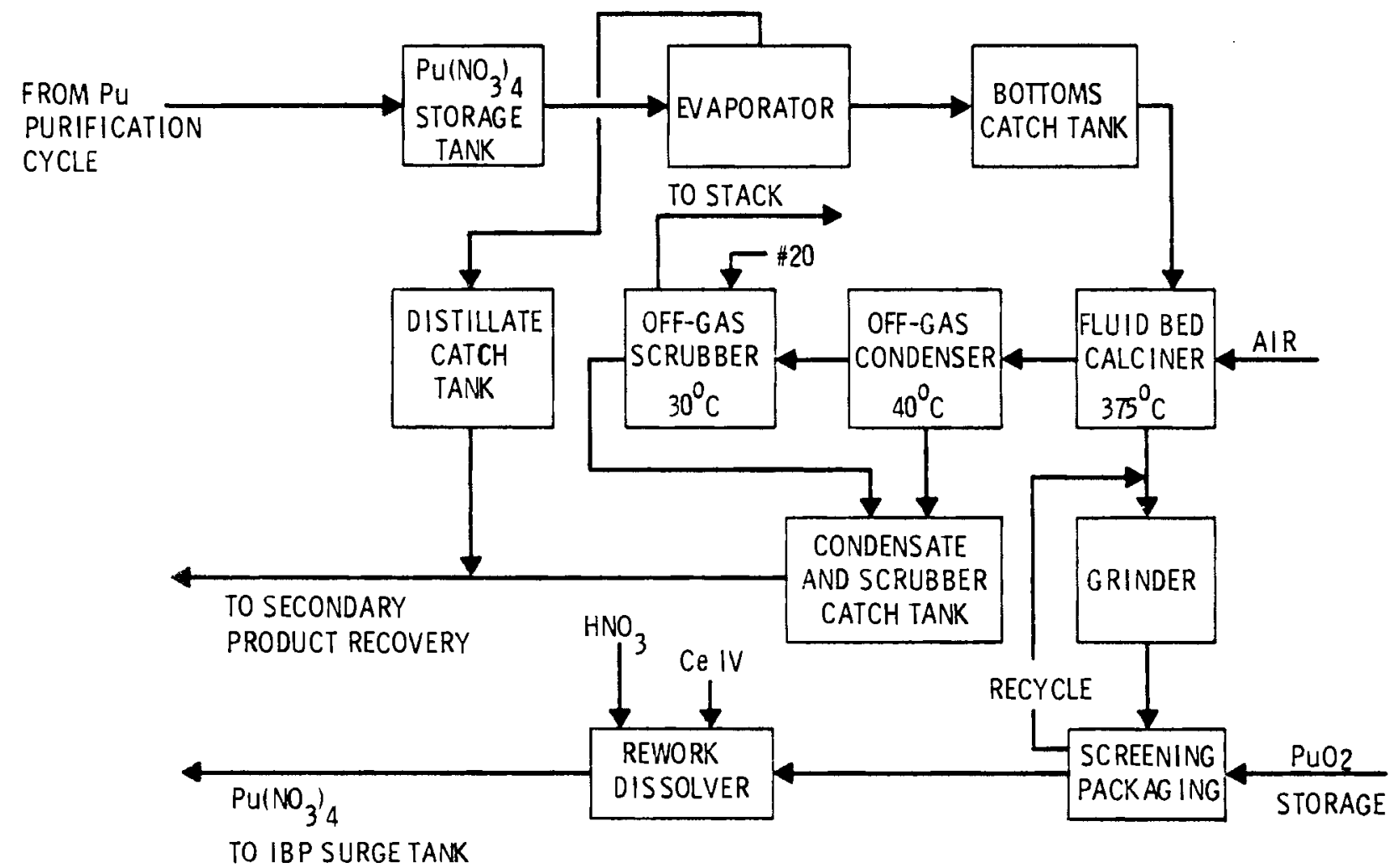

FIGURE 3.13. Oxide Conversion by Direct Denitration 


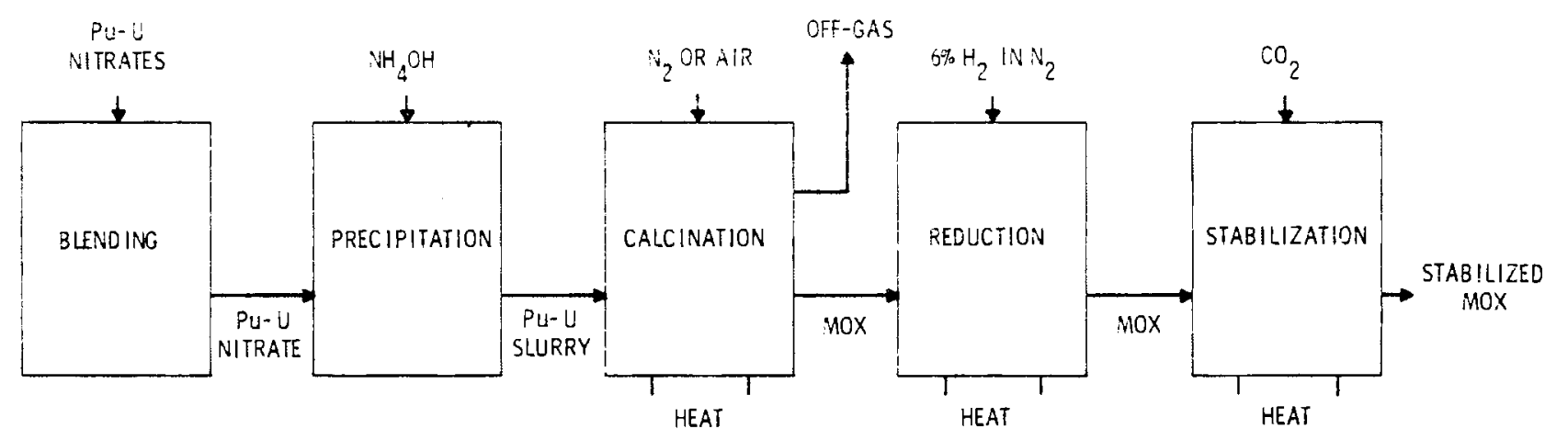

FIGURE 3.14. Oxide Conversion by Coprecipitation

The perceived proliferation resistance of the reprocessing alternatives adds a measure of difficulty to an adversary's plan to fabricate weapons from the reprocessing plant output. Mixtures of uranium and plutonium require a chemical separation prior to making conventional nuclear weapons. The processing concepts involving spiking will necessitate biological shielding and remote handling operations for the weapons fabrication facility and any subsequent handling of the weapons. The adversary is more likely to perform a chemical separation of the spike and the plutonium than use shielded fabrication facilities but this also must be done within shielding. Separation will be required, in any case, for spiked uranium-plutonium mixtures.

The reprocessing alternatives may present a degree of deterrence or delay to a subnational adversary or to a national adversary who has very limited technical resources. Quantitative assessment of the deterrence or delay has not been performed and considerab?e disagraement still exists on the amount of delay time that is introduced by the aitarnatives.

The technology for separating plutonium from uranium or any combination of spiking materials is well known. Any developed nation is highly likely to have the physical resources and technical compatance to perform the separation. Separation of plutonium from uranium in the absence of gamma activity can be done in lightly shielded facilities and the time delay to weaponsusable material is short; requiring only one additional operation in the sequence of steps leading to plutonium metal. The process for separation of plutonium from cobalt, ruthenium, zirconium, cerium, cesium or any other 
spiking material is also relatively simple and not very time consuming. The major differences between it and uranium separation is that piutonium separation cannot be done in unshielded facilities; its operations are more complex and the probability for failure is greater. However, successful performance of the separation requires no more time than does a plutonium-uranium separation.

It is premature to speculate as to whether coprocessing or spiking adds significantly to proliferation resistance. It is clear, however, that it is not as difficult to circumvent either alternative as it is to recover plutonium from spent fuel (the baseline for establishing proliferation resistance in this study). For this reason it is concluded that the reprocessing alternatives alone are insufficient to deny use of plutonium in process or storage.

\subsubsection{Physical Structures}

The physical design of the processing or storage facility structures can play a significant role in the proliferation resistance of the fuel cycle. The actual process cells or canyons provide barriers that constrain the material to defined locations and restrict personnel access to materials or strategic process equipment.

The structural designs should include the configuration or layout of the process cells so as to optimize the utilization of radiation barriers. This is particularly true for the reprocessing plant. Plutonium in the reprocessing plant ranges in composition from that of spent fue? to pure plutonium nitrate or oxide. The levels of penetrating radiation likewise range from extremely high to relatively innocuous levels from the beginning to the end of the process (if the spiking alternative is not used). Proliferation resistance can be enhanced by using process cell or canyon configurations that distribute highlevel radiation throughout all processing areas. Such an approach permits establishment of radiation barriers around the plutonium purification cycle, conversion, and product storage locations which are not protected in conventional designs. The radiation can prevent access to the plutonium vital equipment and instrumentation and process controls which may be part of an active use-denial mechanism or device. 
Structural configurations can be used to maximize the difficulty in modifying a process or adding equipment to perform illicit plutonium separations or conversion of plutonium to metal. Space restrictions and cell entry hatch sizes can delay the adversary from adding or removing larger pieces of process equipment for the purposes of repairing or replacing equipinent damaged by the active use-denial systems.

Another consideration for structural designs is the control of the movement of plant personnel within the facility. Appropriate design can make operating stations, galleries, and access portals more amenable to easy inspection or electronic surveillance. Restraints on the movements of people can be built in the structure, particularly for stressful conditions (when a takeover threat is evident). An example is remotely operated gates. This may be necessary to provide the time to activate penalty systems without interference by the plant forces or outside forces.

The structural designs must be coordinated with the integrated safeguards system designs to assure that the detectability of covert diversion is not compromised. Certain factors must be included in the design criteria; minimizing holdup in intercell piping, surveillance of points of egress of plutonium from the process or storage, and ease of detecting piping changes which would allow covert diversion.

\subsubsection{Close Coupling of Facilities}

From a proliferation point of view, one of the most vulnerable parts of the IFSC is the large quantity of material in buffer storage. Denying use of these large quantities of materials will be both difficult and costly. Of all the elements of the IFSC the smallest achievable denial time with PREP concepts will undoubtedly be in the buffer storage.

As indicated in Subsection 3.3, the amount of material in an IFSC will be very large. Based on the size and number of facilities in the IFSC, the quantity of plutonium at any one time will be in the range of metric tons. From a proliferation point of view there is no difference between 10, 20, and 30 metric tons of plutonium. 
An IFSC probably provides the ultimate benefit achievable by close association of fuel cycle facilities. When considering only the national threat, however, the IFSC provides an attractive target to the nation who wants a large quantity of material. Thus, close-coupling of certain facilities in the IFSC is an important consideration in any proliferation resistance study of such a center. A future phase of this study will investigate closely coupled facilities or minimized buffer storage.

Traditionally, operation management has wanted very large quantities of material in reserve inventory as a hedge against possible interruptions in their supply of raw material. Thus, passive proliferation engineering that minimizes inventories will be resisted by traditional fuel cycle people.

There has already been a change in the back end of the fuel cycle which, if continued, will benefit the concept of close coupling. All existing reprocessing and fabrication plants are based on plutonium nitrate as the interface product (shown in the top portion of the figure). The evolution (illustrated in Figure 3.15) began when plutonium nitrate shipments were discontinued.

The plutonium conversion operation for facilities now being designed must be located with the reprocessing plant. Thus, the interface product will be oxide. This is illustrated in the middle portion of the figure.

The next generation of facilities may resemble the bottom area of figure 3.15. With this concept, spent fuel is received and fresh fuel is snipped from a single facility. The process would involve continuous units coupled together within the facility. This concept would enhance the use-denial sys tems.

\subsubsection{Process Equipment Layout}

In conventional reprocessing plants design criteria for process equipment, piping, controls and instrumentation are based upon operational objectives that provide the following:

- maximum on-line plant availability

- high degree of plant fiexibility

- very high product decontamination

- minimum loss due to waste. 


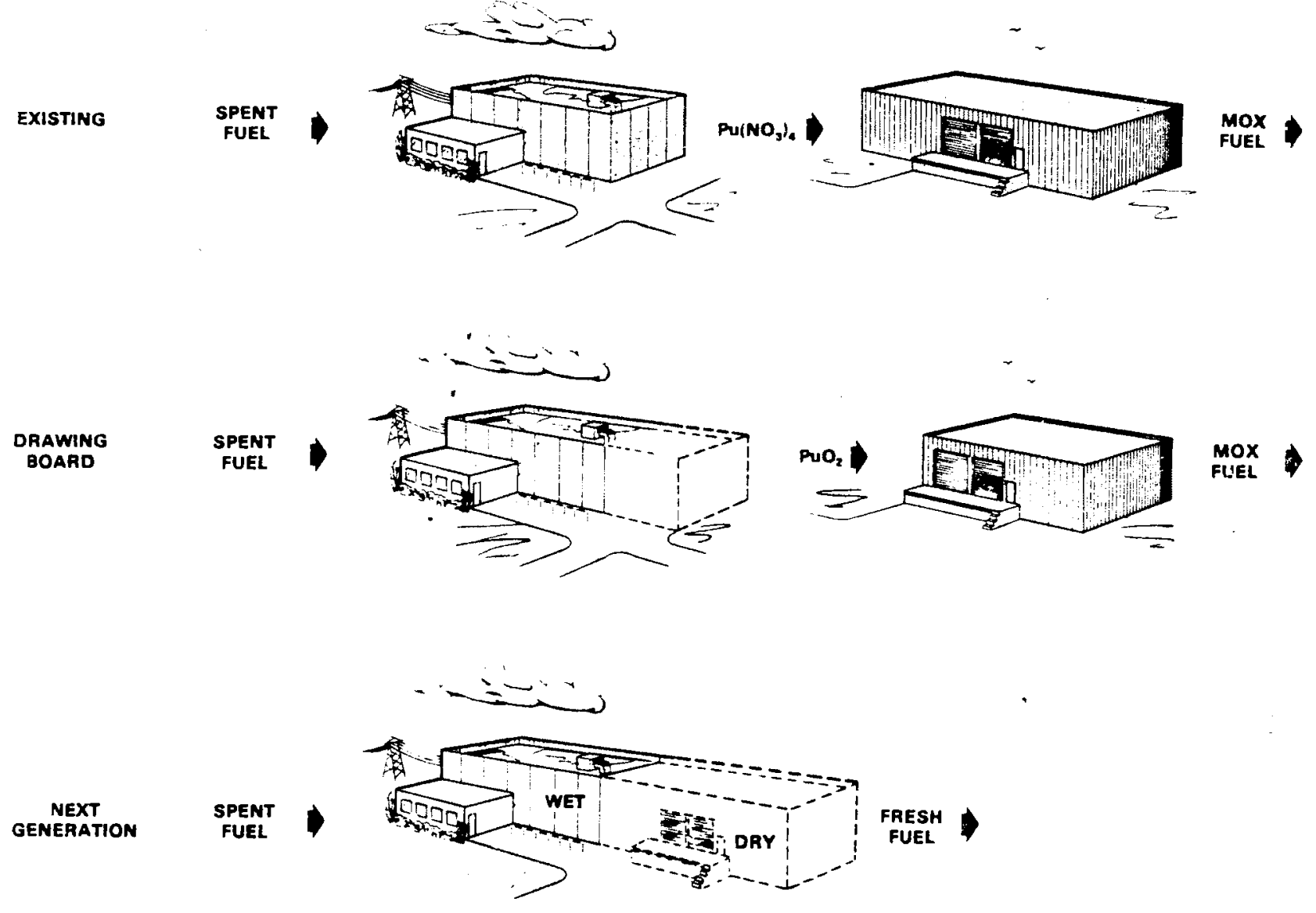

FIGURE 3.15. Close Coupling of Reprocessing and Fuel Fabrication Plants

The complexity of the reprocessing operation, particularly the solvent extraction cycle, calls for certain design provisions: surge capacity between stages, redundancy of routings, spare process lines and the inclusion of extra or spare space in the operating cells. These provisions give the flexibi?ity needed during startup and process upsets, and permit routing for the recyciing of off-specification product and the recovery of plutonium and uranium from waste streams. The extra space in the process cells permits modification of the process as new technology and new process requirements arise.

The equipment and piping layout is guided to a large extent by expected future maintenance requirements. The positioning of the equipment in the cells permits performance of maintenance work with a minimum of disruption tc neighboring equipment. Faijure-prone equipment items are given pricrity for accessibility. Contäct-maintained equipment requires space for workmen to 
stand while remotely maintained equipment requires access by cranes and manipulators and visibility through viewing windows, periscopes, or television cameras. Maintenance considerations are discussed more fully in the following section.

In general, the process equipment wili be physicaliy separated into zones based on the level of radioactivity involved and on the expected frequency of repairs. The Barnwell plant, for example, is divided into process cells more or less dedicated to specific process steps. The mechanical processing, dissolution and high-level waste concentration are located in a remotely maintained cell because these operations require the use of high-maintenance equipment. The remainder of the process is in contact-maintained cells. The co-decontamination and partition steps are very highly radioactive and are separated from the relatively low activity plutonium and uranium purification cycles. In the Barnwell configuration, access to the plutonium purification cell or the uranium purification cell is relatively easy because of the lower radiation dose levels.

The design philosophy for a proliferation-resistant plant with regard to process equipment layout will be markedly different from the conventional design. The major areas of proliferation resistance which must be considered are:

- limit access to strategic equipment

- limit spare space

- distribution of radioactivity to eliminate "cold" zones

- restriction on backcycle capability

- minimization of transfer routes

The objectives of these considerations are to prevent the operator from circumventing process interruptions by quickly repairing equipment that has been disabled by a use-denial penalty or from modifying a proliferationresistant process, such as coprocessing or spiking, to allow production of pure plutonium.

Another consideration in the layout of the equipment need is the implementation of use-denial actions. In example is the del iberate contamination of 
pure plutonium with radioactive waste. The process vessels and piping layoui must be designed to accomplish this action with minimum delay and with a high probability of successful completion. Close proximity of the waste vessel facilitates the action. Transfer by gravity fiow rather than steam jets, air lifts or mechanical pumps increases the probability for success and may reduce the adversary's opportunities to prevent the action. To be successful, other denial actions require special designs related to the hydraulic systems. Such actions include deliberately plugging process transfer lines, filling vessels with foam or other material and disrupting steam jets, or using air iifts to prevent transfers of material.

Where radiation is used to deter illicit facility repair, modification or plutonium removal, additional design features can delay removal of the radiation barriers. Conventional designs indicate the desirability of rapid decontamination, and vessel designs include spray rings to improve flushing efficiencies. Sloped bottoms and smooth surfaces improve vessel drainage. Special installation of piping eliminates low points which detain liquids. The proliferation-resistant design may require elimination of decontamination spray rings in some vessels and built-in hold-up in vessels and lines to increase the time needed for decontamination.

Material movement in the reprocessing plant conceivably can be restricted by the use of localized nuclear criticality. But reliance on criticaity appears to be of doubtful value for proliferation resistance since the consequences are unpredictable and may be difficult to control. The release of short-lived fission products, particularly ${ }^{131}$ I, as a result of nuclear excursion may overtax the plant off-gas control system, causing dangerous releases to the surrounding area.

A conventional reprocessing plant design does little to restrict access to plutonium. For example, the plutonium nitrate solution in the plutonium purification cycle may be readily removed by way of interceil piping, pump maintenance galleries or sampling/instrument 1 ines. The solutions are relatively free of penetrating radiation and couid be transferred in kilogram quantities to containers with little or no shielding. The proliferationresistaint design could reduce the number of'access points (posicibly by 
eliminating mechanical pumps through the use of jets or air 1 ifts and vacuum transfers). Other designs that could be developed are innovative instrument and sampler designs that limit the flow rates in the lines or the total volume that could be transferred at a given time. The use of more extensive in-line measurements for process control can eliminate the need for some of the sampling points, thereby reducing the number of active use-denial locations that are required.

\subsubsection{Maintenance Philosophy and Use-Denial}

Two maintenance philosophies have been utilized for highly radioactive nuclear processing facilities. The first, remote maintenance, is epitomized in the design of the Hanford Purex Plant. The remote maintenance concept is characterized by plant designs that permit quick repairs or replacement of equipment without in-celi decontamination and prolonged facility shutdown. The second, contact maintenance, is used extensively at the Idaho Chemical Plant. Contact maintenance is based on the use of simple, ruggedized in-cell equipment that is designed for long operating lifetimes. It also utilizes designs which place mechanical equipment that is subject to breakdown outside the main biological shielding barriers. Contact maintenance assumes personnel will enter into the high-level cells and, therefore, requires the capability to decontaminate the facility when breakdowns occur.

A third philosophy, that of no maintenance, is an extension of the contact-maintenance strategy. It was used at the British reprocessing plant at Windscale. This plant was designed on the principle that there would never be maintenance or modification to the equipment inside the hot cells. Some redundant equipment items such as a spare dissolver were placed in the facility just in case of failure. The no-maintenance philosophy was successful and the second generation reprocessing plant was designed on the same basis.

The reference reprocessing plant combines remote maintenance and contact maintenance and, therefore, provides examples of use-denial techniques applicable to both philosophies. The remotely maintained portion of the reference plant is confined to the head-end operations (consisting of the chop leach and dissolution operations), the high-level waste concentrator and solid waste 
handling. These operations are carried out in cells equipped with master/s?ave manipuiators, power manipulator and overhead cranes. Viewing windows and periscopes are provided to facilitate maintenance operations. Equipment design and placement in the cell considered the ultimate capability for repair, disconnect, removal and replacement.

The contact-maintained zones of the reference plant include the solvent extraction separations, acid recovery, solvent treatment, and aqueous waste and off-gas treatment. The designs of the cells and equipment for these operations are characterized by simplicity, welded connections, use of airlifts for liquid transfer and placement of mechanical components outside the main shield. Some concessions to contact maintenance were made. For example, the HA contactor and the centrifuge for clarifying the dissolver solution are removable and replaceable by remote means. Also pumps are used for liquid transfer in the plutonium process cell (second and third plutonium purification cycles). These pumps are placed in shielded niches and accessible for replacement without entering the cell.

The contact maintenance cells in the reference plant are designed to run for extended periods without repairs or routine in-cell maintenance. Required maintenance is anticipated, however, and special equipment has been included to reduce the decontamination time. Spray heads are strategically located to enable wasning of the interior cell surfaces and both interior and exterior surfaces of the process vessels and piping.

The proliferation resistance designs for highly radioactive facilities can utilize the radiation as an effective barrier against use of the plant or material or modification of the plant to produce weapons-usable plutonium. The maintenance philosophy used in the plant design has a profound influence on the effectiveness of the radiation barrier. Repairs of damage that mignt result from an active use-denial penalty can generally be done more rapidly on remotely maintained parts of the plant than on parts requiring contact maintenance. Also, entire equipment modules can be removed and roplaced quickiy without decontamination. Thus, the strategy for use-deniai must focus on the manipulators, cranes, viewing windows, or other devices installed in the piant for maintenance; or on passive use-denial designs that limit maintenance or replacement to less strategic equipment and leave key equipment unreachable. 
The radiation barriers inherent to the parts of the plant that require contact maintenance can retain their integrity only so long as decontamination can be prevented or delayed. Therefore, to be effective, any in-cell usedenial action must have a secondary use-denial of the decontamination capability or use of passive use-denial design features that increases the decontamination time requirement to achieve the required delay. The passive use-denial features could include eliminating decontamination spray heads, increasing the heel volumes of vessels (to increase the volume of flush solutions), and strategically intermixing highly radioactive process vessels with intermediate- or low-activity process vessels.

Basically, contact-maintained facilities are conservatively designed, and, by nature, are more inflexible than remotely maintained facilities. This lends additional proliferation resistance to processes that are constrained to produce plutonium mixed with uranium and/or fission products such as envisioned in the CIVEX concept.

\subsubsection{Process Control}

Many steps of the process in the reactors, reprocessing plant, and waste management facility are remotely controlled because of high levels of radiation in would-be work areas. Inherent in their design are proliferationresistant features; namely, the inaccessioility of process equipment, transfer lines and control equipment. The addition of use-denial technology under $c^{3}$ control essentially means these steps of the process control include considerable passive features to complete the proliferation resistance design. Other process steps in these and other facilities in the fuel service center, however, must include features not normally required in their design such as isolation; remote, monitored operation, and use-denial technology.

Several examples of use-deniai technology applied in various sections of IFSC facilities are:

Plutonium Load Operations in the Reprocessing Plant.

This includes that section of the plant from final purification of the plutonium through the evaporator, solution storage, denttration, and ioadout 
as a solid. The sensors include level instruments on storage tanks, transfer valve sensors, sample sensors, flow transducers, concentration sensors, and load cells. The work requires remote operations isolation, containment status of the cell, and rigid control of transfers. In the case of severe use-denial penalties, auxiliary transfer equipment may be required to recycle plutonium to high-level waste storage tanks. For use-deniai needs, instrument impulse lines and sample lines may be equipped to become inoperative on demand.

\section{Vault Protection}

This section includes the plutonium storage vaults. Module sensors include those advanced technology devices encompassing motion sensors, optical monitors, personnel identification sensors, and storage position indicators. The sensors involved provide information necessary to control access, monitor operations, and locate and track material within the vault. Use-denial penalty modes could include deep underground installations and sprays to fill storage sections with foam, making recovery an extensive mining operation.

\section{Dissolution Operations}

Dissolution operations include the dissolver, makeup tanks, adjustment tanks, and the plant input tanks with associated equipment. Sensors here will include tank level, density sensors, sampler usage sensors, fuel ID sensors, and transfer and mixing operations sensors.

The proliferation-resistant technology here will monitor the input measurements, validate their accuracy, and insure that improper operations do not compromise the inventory caiculations.

Use-denial technology may include additional transfer capability to mix dissolver solutions with concentrated plutonium streams or vessels, in ultimate penal ty modes.

\section{Aqueous Waste Section}

This section covers the measurement and monitoring of plant process waste streams. The sensors included in the module will be: tank level, sampler 
usage, sample I.D., on-line or off-line analytical sensors, transfer and valve sensors, radiation sensors, and mixing status sensors. This section will keep track of waste transfers and will insure that the waste systems are not used in a diversion attempt.

Auxiliary equipment may mix liquid plutonium-bearing inventories with this waste to involve severe penalty modes in use-denial technology.

\section{Separations Operations}

This section covers the extraction operations area within the plant. The sensors here include transfer flow and valve position sensors, sample usage sensors, radiation monitors or other devices needed to detect improper process solutions, sensors to detect improper use of instrument lines (liquidon-line sensors or vacuum switches) pump usage sensors and line pressure switches. Data from sensors in this section will indicate if plant lines are used to bypass SNM measurement points, or to divert material from the usual jlant streams.

Techniques to make sensors and line and valve position indicators inoperaive may include nethods for denying information about the operations of this jection.

\section{Fuel Management}

This section is concerned with transfer and storage of both unused and irradiated fuel. The task of this section will inciude tests of on-line fuel transfer monitoring, fuel element identification, and on-line descriptions of stored fuel. The objective is to track the location and identity of stored fuel. Components to be installed as part of this module include data terminal operation, fuel inspection devices, rack occupancy sensors, and transfer operations sensors. Fuel analysis instrumentation will be included. This data will be required for operational needs and for surveillance $\left(c^{3}\right)$ and independent auditing.

Use-denial technology in these facilities may include simultaneously collapsing fuel racks with small sections of storage areas, spray foaming the storage volumes, and making the fue? transfer mechanisms inoperative. 


\section{Standardization}

Each facility in the IFSC would have equipment used to calibrate and test the system sensors. This mociule will be oriented towards computer-operated components to aliow rapid on-line test of the operating group. A computercontrolled pressure source for on-line calibration of plant level sensors is an example of the desired equipment. Using it, calibration frequency, results, and operator response would be fed to the $\mathrm{C}^{3}$ system.

Security Related Sections

The communications control design provides methods and equipment to move the output of both process/physical sensors and instrumentation to the monitoring computers/users. Security and reliability are principal considerations. This is primarily an engineering task whose objective is to select specific equipment and communications protocols for an integrated safeguards system.

The personnel access and location module that is dedicated to physical security will also input to $\mathrm{C}^{3}$.

This concept is concerned with the identification of workers requesting access to plant areas. Devices to be installed could include new approaches for. personnel identification, door access, instrument operation monitoring, and, if feasible, remote location. The function of the section will be to ensure that only authorized persons enter controlled areas and vaults, operate certain equipment or computer terminals, permit certain equipment or computer terminals, or permit certain transfers.

For a successful $c^{3}$ mission the installed equipment must provide the methods, procedures, and computer algorithms that will interpret the data produced by the various modules and alarms by ana?yzing them and then generating an appropriate response. Applied mathematics and computer programming are involved in meeting the objective, namely the development of software with the necessary adaptability and reliability to give very high assurance that the SNM is contained in approved time-dependerit locations.

The development of software to recognize patterns of personnel and equipment performarice must be accomplished with sufficient reliability to include decision-naking steps in the graded use-wenial actions software. 
Efforts must be made to provide protection of data and programs in safeguard system computers and provide against unauthorized modification or access. Software structure, programming, and special hardware devices will be specified and tested. Engineering design includes the selection of procedures, specification of hardware, computer architecture, or security techniques capable of providing the necessary software security.

\subsubsection{Process Instrumentation}

The designs of scme of the process instrumentaticn may be directly affected by proliferation-resistant technology. Limited reaciout and coritrol capability could be built into scme instruments and controllers on key steps in the process. For example, specific operating and process conditions cculd. be forced by the spacs of these instrument readouts to cover only operation that is performed in an acceptable manner. Changes in flows, levels, material feed rates and others that would alter the process would not be possible as instrument readouts for these conditions would not be available. The instrument would essentially be pegged at other than normal ranges for the process. Operating in other than normal modes would be a blind operation. Calibration methods for many different kinds of instruments can be automated and centrally directed. The test signals can be computer controlled, coded where appropriate, and the results monitored by the $c^{3}$ computer. This feature may be a routine operating requirement of an advanced type, but its availability could contribute to proliferation-resistant instrumentation. Here, the staff of the $c^{3}$ system would have some assurance of the validity and integrity of the plant operating information.

For every instrument where use-denial techniques are needed, a method (hardware) could be included in the design to deny the normal availability of its output on demand. Each such instrument would have essentially an electronic switch in series essentially controlled only by the $c^{3}$ system. It would be dormant during all operations not requiring active responses by the $\mathrm{C}^{3}$ system. Al1 key instrument systems to be utilized in use-denial technology would require tamper safing and tamper indicating features. This may include some isolation of 7 ines and hardening of individual components. 
Some key instrument systems may have an li timate penalty feature asscciated with them. For example, some sampler or signal line impulse may have the capability to be parted from its system and be in essentially unrecoverable locations such as extremely high radiation zones or within thick concrete walls. The penetration through thick shielding walls essentially may be permanently denied.

Special techniques will be necessary to make some of the above methods reliable and unavailable for malevolent operation. These techniques will include using the computer as a monitor and decision maker, and using rugged instruments and redundancy of equipment.

On-line instrumentation may have to be accepted in some locations without the capability to routinely sample some process streams. Redundancy of equipment, special disconnects and other features to permit reasonatie maintenance can be expected to make these concepts consistent with other nonproliferation features. 


\subsection{INTERFACES BETWEEN THE FACILITIES AND THE $C^{3}$ SYSTEM}

Most of the interfaces between the facilities and the $c^{3}$ system can be included in two categories.

One kind of interface supplies information about the facility that is largely of a safeguards nature, including a significant amount relating to the status of the processes and the equipment. From this interface, the $c^{3}$ functions in continuous surveillance and data acquisition modes.

The other type of interface permits the $c^{3}$ system to intervene in the control of processes and equipment, including safeguards systems. This interface couples the $c^{3}$ system with the penalty nodes in the usedenial technology included in the design.

Figure 3.16 illustrates how the computer-based system in the $c^{3}$ center is coupled to the plant facilities.

Both interfaces, while requiring special designs and unique application of hardware at some interface points, become part of the over-all use-denial technology that overlays the normal functioning of the fuel cycle center. The interfaces and use-denial techniques, including hardware, must be designed for generally low visibility and extremely low probability of any interference with routine operations, except on demand.

\subsubsection{Proposed Systems Within the $C^{3}$ Concept}

The heart of the system within the $c^{3}$ concept, which guides the application of use-denial technology is a computer, dedicated to $C^{3}$ activities. As presently conceived, its function would be to interface with (monitor) many selected key signals normally available from the process, routine plant operations, the plant physical security system, safeguards, accountability, and from other parameters, as needed. It would utilize existing instrumentation, equipment and hardware installed for normal plant operation. 


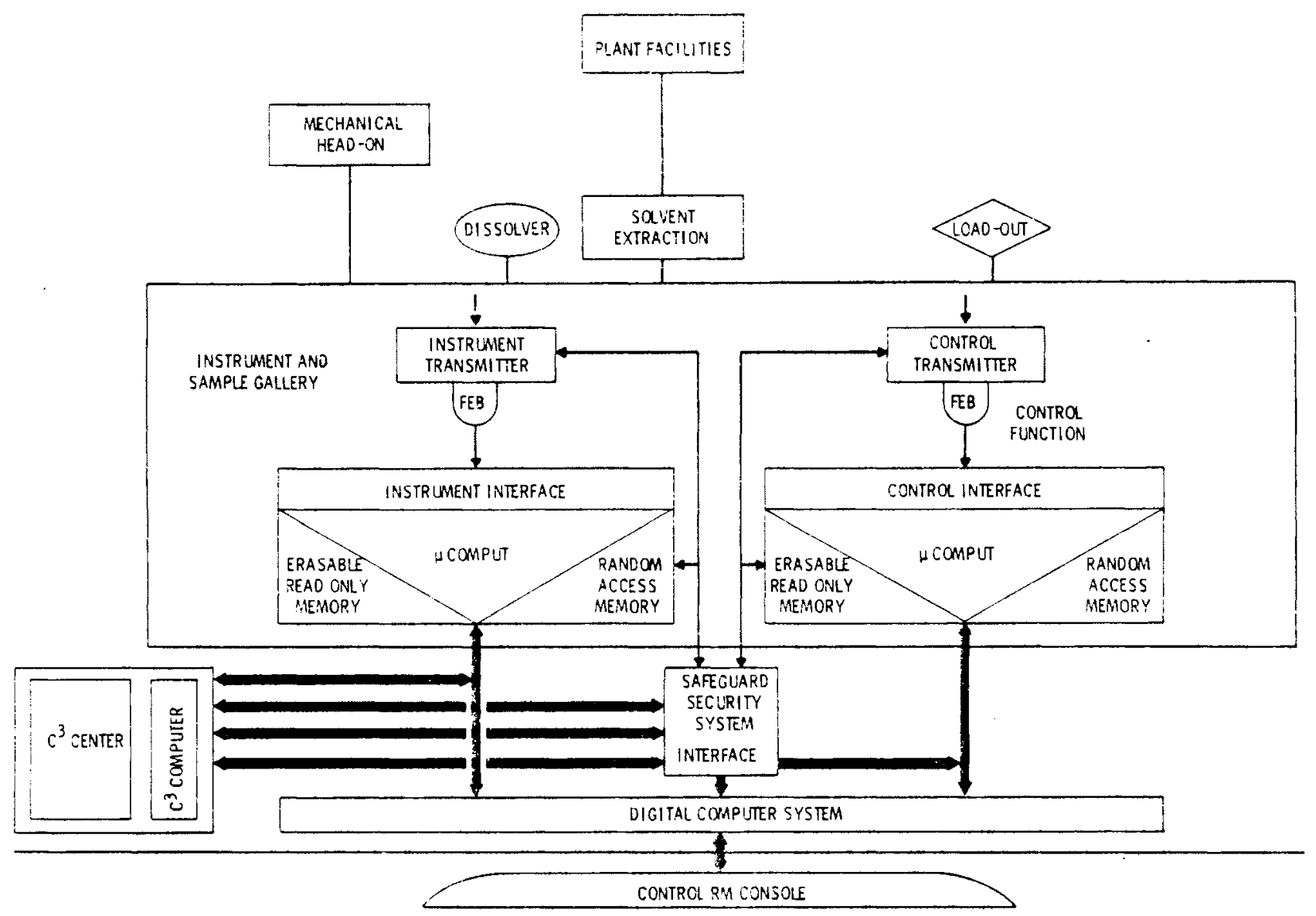

FIGURE 3.16. Generalized System Diagram Showing the Interfaces with the $\mathrm{C}^{3}$ system

On certain key process systems, special equipment would be installed for active use-denial procedures or to call upon passive design features. This equipment would be an interface in addition to, and typicaliy located in, series with the normal systems designed for generic modern fuel cycle facilities.

For the covert threat, the extensive data handiing capability and software development potential of computer technology would provide a sophisticated engineered safeguards system (ESS) within the IFSC. It would be used to monitor material transfers, processing and storage; to monitor vital areas, equipment, and operations involving special nuclear material in quantity; to note movement of personnel, and follow 
maintenance activities. The $\mathrm{C}^{3}$ system would monitor selected parts of the ESS but, more importantly, it could examine various combinations of these. Some combinations of information in the categories mentioned may be provocative and indicative of activities that could signal attempts to defeat the use-denial concepts. The computer would monitor the obvious as well as the devious on a 24-hour-a-day basis.

For the overt threat, the computer-based system of the $c^{3}$ can be expected to monitor, as in the covert case, for signs of surreptitious activity underway. These signs expose activities that would lead to rapid takeover of the facility and seemingly ready access to inventories of SNM.

The main function of the computer-based system of the $c^{3}$ in the overt threat case however, is expected to be in the application of the graded usedenial and access to the process, the selection of the enable/disable modes; and the automatic initiation of procedures including the remote, unaccessible and perhaps ultimately irreversible automatic procedures to defeat the hostage threat.

Any system designed to manage the overt threat must assume that the host nation will, at some time, attempt an overt takeover. It must also be designed to defeat this eventuality, or appear formidable enough that other sources for SNM will be considered more attractive. The $c^{3}$ directed system must be designed to assure through graded application of the use-denial technology, a delay of eight weeks to materials and/or processes accessibility.

\subsubsection{Interface Within the Plant}

During development of these concepts, it was assumed that plants with modern instrumentation and control technology would be in place in an IFSC. Process automation may range from merely preprogrammed automatic data-taking of process parameters to full closed-loop process control. The level of automation for operational needs will be determined by the operating needs, cost restraints and nature of the process. It is expected that there will be closed loop control of 
most of the process steps in the FRP. Similarly in reactor operation (including the entire refueling operation), current technology emphasizes closed-loop or essentially closed-loop contro?.

While the possibility of extended closed-loop control seems unlikely in other facilities and processes at a fuels service center, some subsystems and processes may be highly automated. For example, at the fuel fabrication facility only certain sections of the process can be expected to be automated.

The automated $C^{3}$ system can interface properly with any level of automation and closed-loop control of processes at a fuels service center. In general, the more automated the process and material control system the simpler the interface requirements between the process systems and the $C^{3}$ system. More interfacing hardware may be required for the ieast automated process control, inaterial control and physical protection systems. But the $c^{3}$ computer system can be interfaced to effectively overlay the process instrument and control systems in any of these instances.

\section{Process Instrumentation}

Information from process instrumentation, status of equipment, materials accounting and physical protection features will be available to the $c^{3}$ system and will require a minimum of interfacing hardware. Design attention will be directed primarily to signal compatibility and reliability. This data will be the primary source for $c^{3}$ software programs to monitor, alert, make decisions and initiate action.

Some process instrumentation by the computer may be designed to yield data over a limited range. This important technique will be used on key steps in the process. For example, specific operating and process conditions would be forced by the 1 imited span of these instrument readouts that cover only operation in an acceptable manner. Changes in flows, levels, material feed rates and other parameters that would alter the process, would not be possible because instrument readouts for these conditions would not be availabie. The instrument would essentially be pegged at other than norma? 
ranges for the process. Operating in modes other than normal would be a blind operation. The interface to $\mathrm{C}^{3}$ system here would monitor for tampering to assure that this special design feature was not compromised. An interface with the calibration of some instrumentation will be appropriate. Calibration methods for many different kinds of instruments will normally be automated and centrally directed. The test signals will be computer-controlled and coded where appropriate. The results will be monitored by the $c^{3}$ computer. This feature may be a routine operating requirement of a modern type of process instrumentation system, but its availability could be a contribution to proliferation-resistant instrumentation. Here, the staff of the $\mathrm{C}^{3}$ system would be somewhat assured of the validity and integrity of the plant operating information coming to them via instrumentation.

Permitting the $\mathrm{C}^{3}$ system to interface back to the instrumentation on the process, equipment, and physical security features in order to place usedenial teciniques in operation would directly affect the designs of instrumentation in some systems. For some of the preliminary use-denial steps, total process information may be denied to the operating staff. The design would include an interface between the instrument readout and the $\mathrm{c}^{3}$ system. The interface would be a hardware item to deny the normal output as the $c^{3}$ system demands. Each such instrument would have an electronic switch in series that is essentially under the control of only the $c^{3}$ system. It would be dormant during all operations not requiring active responses by the $C^{3}$ system. The concept is illustrated in Figure 3.17. Here, functional electronic blocks (FEBs) under the demand and control of the $c^{3}$ system would maintain or interrupt the signal. In other instances some key instrument systems may utilize an installed FEB interface to initiate an ultimate penalty feature associated with the instrument. For example, some sampler, impulse, or signal lines may have the capability to be parted from their systems with the break occurring in essentialiy unrecoverable locations such as extremely high radiation zones or within thick concrete walls, causing denial of this signal for an extended period. 


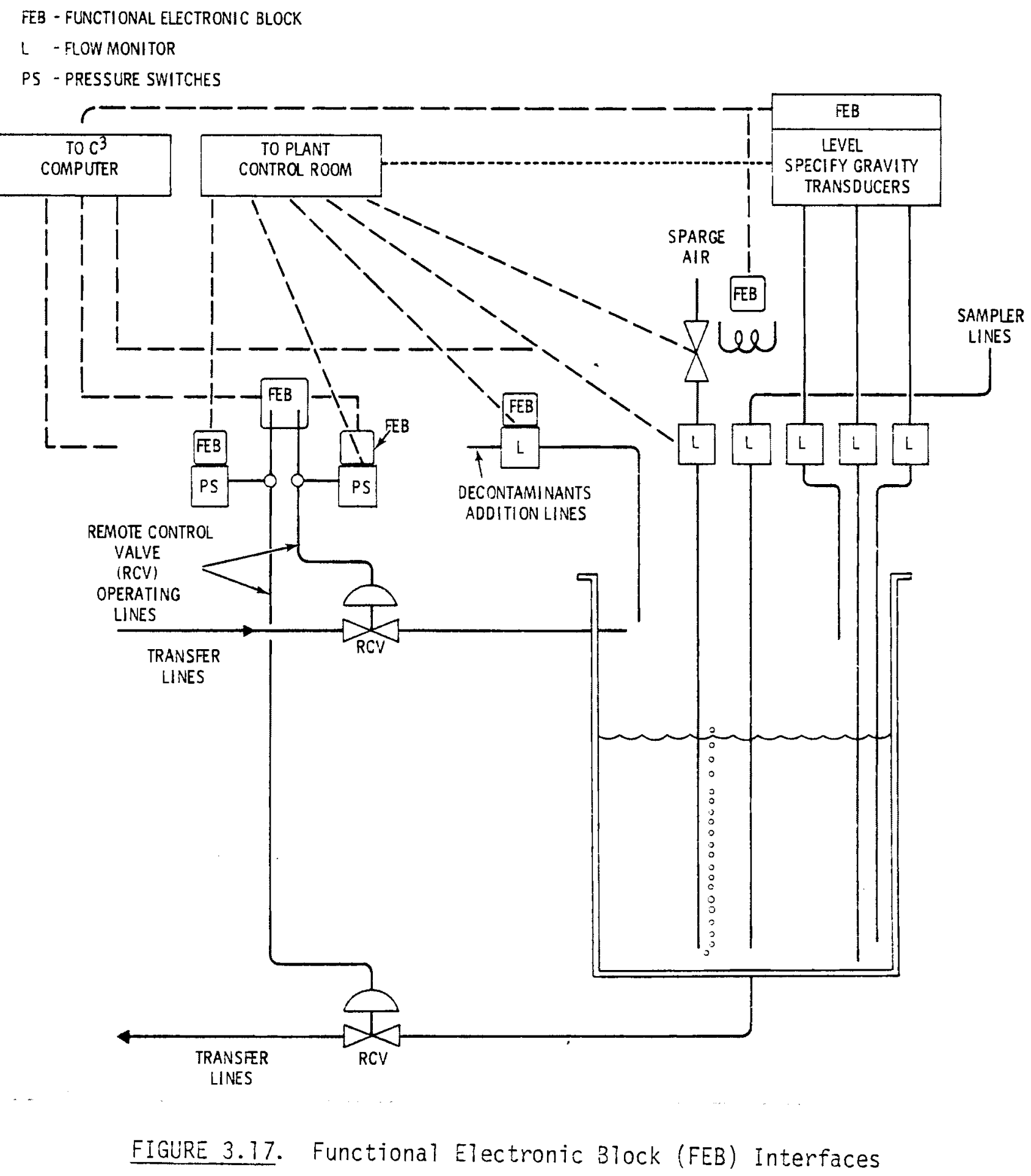


Added capabilities for the $\mathrm{C}^{3}$ system at the interfaces would result from using micro-computers for distributed processing essentially at the interface of the $\mathrm{C}^{3}$ system with plant hardware. Redundant circuits self-auditing features, tamper-indicating data, data coding, and erasable electronics, all available at the interface would provide securer, more reliable systems with fewer demands on the central $c^{3}$ system.

\section{Process Control}

The interface with the $c^{3}$ system and process controller would provide the $\mathrm{c}^{3}$ system with the capability to intervene in the operation of the process, the storage areas and some physical protection features. Intervention would occur when sufficient data was received by $\mathrm{C}^{3}$ to warrant the response. The interface between the $C^{3}$ and the various processes and other plant systems would permit the $\mathrm{C}^{3}$ system to initiate the appropriate steps to deny use. Direct control of some equipment would pass to the $C^{3}$ system, permitting various penalties to be invoked such as shutting the process down, denying al1 transfers of material by process lines or forcing some streams to secure locations. Figure 3.18 illustrates this concept. In a demand situation, the $C^{3}$ would control the position of the valve shown. Proliferation resistance features included in the design would activate various penalty steps resulting in denial of material, and perhaps equipment use. The severity of some penalties requires a reliable system. The integrity of the systems can be significantly enhanced by the level of security developed at the interface including, for example, hardening the control links. As above, it is possible to incorporate many desirable features by utilizing microcomputers for distributed processing. These features include self-checking, coded signals, tampering indicators, and redundant circuits without placing added demands on the central computer in the $c^{3}$ system.

\section{Engineered Safeguards Systems}

It is assumed that an ESS will be in place at the IFSC. It may consist of several parts serving the different facilities separately; or as a consolidated safeguards system for the whole IFSC. The option will be available 


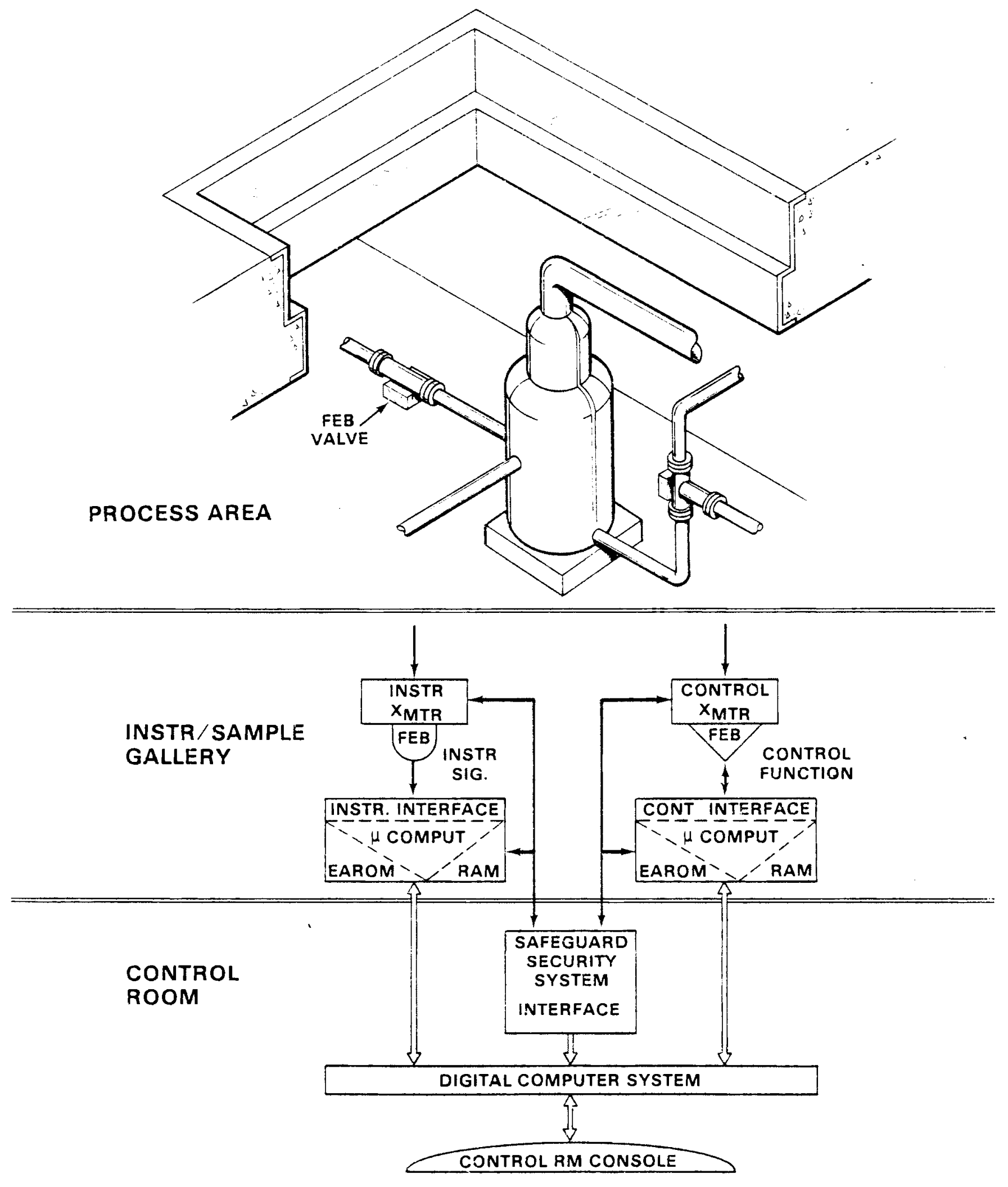

FIGURE 3.18. Use-DeniaT--Liquid Transfer 
to the PRE designer to recognize and organize the inputs from all the IFSC safeguards systems into a single data base for the $c^{3}$ concept.

Most information from the emergency safeguards system within the IFSC wi11 be used to guide the management (operators) in countering a covert threat. The primary objective of this overall study is to address the overt threat to the IFSC, namely, a host-nation takeover. But much of the information normaliy considered only of interest in countering a covert threat may also be of direct interest in an overt situation. This is primarily true regarding the $c^{3}$ capability to recognize an initial development of the overt threat.

Currently available technology for such a system indicates the kinds of interfacing expected of PRE design. This will include computer-based subsystems providing extensive physical protection, automated personnel control and continuous materials accountability.

Presumabiy, the physical protection system would inciude the zone or access control systems to assist in the protection of SNM. Zone operations control is concerned with the operational interfaces among people, vital equipment, and SNM. Working in conjunction with the access control subsystem, it enables and monitors authorized plant activities, allowing activities of only those persons who are authorized, thereby recognizing unauthorized actions that could lead to theft or sabotage.

The information base to the $C^{3}$ system will consider the total FSC and each facility through division into zones. These zones are defined by combining contiguous material access or vital areas that have common protection requirements. Only personnel essential to operations within a zone are authorized to enter. The $c^{3}$ system would be aware of both exemptions and vioiations. Access control enables and monitors authorized movements of people and SNM across barriers and regulates unauthorized movement of people, SNM, and contraband. $C^{3}$ would be interfaced to these parts of the physical security system for instant preliminary alert to a 11 breeches of security and unauthorized activities within the IFSC. Similarly, through an interface with parts of the materials measurement and accounting system, $c^{3}$ would be apprised of significant discrepancies in material salance. 
The appropriate measurement equipment in each area and a computerized data processing system would enable calculation of material balances at frequent intervals to permit rapid detection of discrepancies. Ali or as much of the above information as seems warranted, would be available to the $C^{3}$ system. For example, sensors capable of direct measurement of plutonium concentrations in plant streams will have two important functions in the integrated piant SiM control system. The first function is input for the SNM accountability data base. The second function is as input to those on-line calculations of SNM flows by the plant model to provide indication of theft or improper operating conditions. As a part of the interface with PRE, only information from the second function, for example, would be provided to the $C^{3}$ system.

In addition to inputs from instrumentation, the software programs in the $C^{3}$ system would also incorporate the required procedures and expected responses of the facility operating group to unauthorized activity. As $C^{3}$ personnei would know the status at all times of both key physical protection and significant material accounting systems, they would also be somewhat aware of proper operator response to off-normal situations.

As above, information from these kinds of interfaces with the IFSC safeguards system would be utilized primarily by the $C^{3}$ system. It utilizes this information in evaluating actions being initiated as part of the host-nation takeover of the IFSC to defeat the use-denial systems overlaying the IFSC. 


\subsection{APPLICATION OF FROLIFEPATION}

\subsection{APPLYING DELAY TECHNOLOGY}

Use-denial technology is intenced to be considered and applied in the initial planning and designing of facilities in a nuclear fuel center. In this manner both passive and transient ${ }^{(a)}$ features for delay techrology will receive a more thorough and baianced review.

Passive delay technology delays access to use of the process or to materials in a facility by virtue of static features such as thick shielding walls and isolation of process equipment and components. These features force remote control of the operation and remote (hands-off) maintenance. This passive delay technology is normally inherent to some extent in many steps in the nuclear fuel cycle.

Passive delay measures encompass a broad spectrum of techniques and methods ranging from facility structural designs to instrument/equipment operational features. It is proposed here that facility design features that limit access to material, control or limit flows of process streams, and isolate material from neople fit the definition of passive measures. The concept of passive features has been extended in this report to include elements requiring some initiating act, which generates nondestructive, reversible actions resulting in the requisite time delay. Included in this definition are:

- erasible codes for computer-controlled instruments and equipment,

- irmobilizing key access doors by use of fail-safe locking mechanisms,

- automated process shutdown,

- integrated safeguards system that alerts system to malevolent acts (and diversion attempts) and that gives timely alarms, and

- software programs.

Alternative processes offering passive delay features are also being investigated. For the most part, these concepts eliminate pure piutonium from the fuel cycle by paritial separation of uranium (coprocessing and/or

(a) Transient in this context is used in preference to active. 
by assuring that the products contain radiologically hazardous components that severely restrict or prevent direct handiing of the material.

It is proposed that passive features be considered in facility planning for their delay capability. It is likely that additionai and perhaps different designs may result when passive delay techniques are considered during the development of a facility design. Some of these changes may result from the need to supplement transient delay designs as these techniques are considered in the design process. Transient delay techniques, which cover a broad spectrum of results, affect mostly instrumentation, controls, or process equipment to effect delay to access to process or material. These techniques may be reversible, repairable, or replaceable to recover to normal operation.

\subsection{GENERAL CRITERIA}

General guidelines or criteria must be established and followed to properly identify and design appropriate passive and transient delay features. First, the safety of the operating staff must not be adversely affected by any delay designs. Any delay technology resulting in on-the-job hazards greater than those which a worker is normaliy exposed to cannot be expected to be acceptable. Further, any additional exposures to routine hazards of the job as a result of delay technology must be commensurate with the gain in security to be expected.

Second, any impact on the environment that could result specificaliy from applying delay technology is not acceptable. This would include both short- and long-term effects.

Third, the impact of applying delay technology on plant operations must be minimal. Passive features, where applied in delay technology, must result in a fully operable plant. It seems conceivable that some flexibility in plant operation may be traded for a more secure system in that some recycle, recovery, or bypass features may be 1 imited. Some effect on overali plant operations may result and any such features must be weighed against the gain in security.

Fourth, the designs installed for transient delay steps must be unobtrusive and not interfere with normal operation of the plant. These features must remain, as far as possible, essentialiy invisible during routire operation. 
Fifth, plant maintainatility is not to be adversely affected by designs to accomplish either passive or transient delay. It may be expected that routine testing and possibly preventative maintenance of some transient delay equipment wili add to the maintenance load. It is interided, however, that transient delay features will be inciuded in the automated calibration and self-checking capability to be included with the computer-based system installed as a part of plant operating and control systems.

Sixth, engineered safeguards and security (ESS) features normaliy in place throughout the facilities must not be adversely affected by delay technology. Equipment or changes in plant layout resulting from installing delay capability cannot downgrade the ESS designs. Information from some parts of the ESS system may be coupied to the $c^{3}$ concept, and delay techniques may also ultimately be involved with physical security features, but only to complement the expected responses from the ESS system.

In general, design goals for delay should encourage the inclusion of passive features, must provide for extremely low visibility in plant of the transient delay techniques, and assure reliable interfaces between plant operations and the transient delay features. Normally the latter interface couples the $\mathrm{C}^{3}$ system to the piant processes and information systems.

\subsection{TECHNICAL CRITERIA}

In developing technical criteria for delay measures, the concept of identifying key nodes in the process is proposed. Delay features would then be considered for installation at these key nodes. Characterizing the overal1 process in several different ways will develop sufficient information to identify several key nodes. Some of these ways are:

- Determine the steps in processing significant concentrations of strategic material:

(a) Identify a? 1 points or steps involving significant quantities of SNM such as holding tanks, weighing vessels, and storage vessels.

(b) Identify all stream flows containing significant concentrations of SiNM.

- Identify and describe key items of equipment. 
- Locate all alternative flow paths that normaliy may be utilized for bypassing, material recovery, or recyciing.

- Describe the design penetrations and normal access to strategic materials.

- Identify key measurement and essential control features.

In assembling and analyzing this information, some places in the processes wi1l appear to have higher concentrations or simply greater amounts of SNM with varying levels of vulnerability. Similarly with process flows, equipment and measurement parameters, some wi11 appear more strategic than others. From these data an ordering of nodes relative to the likely effectiveness of the application of delay strategies can be developed.

\subsection{DEVELOPMENT OF DELAY STRATEGIES}

Delay strategies are developed around key nodes. When the concept of delay is available at the initial design stage, consideration of both passive and transient delay measures at each node is possible. For some nodes mostiy passive delay features may be relied upon, whereas for other nodes transient techniques may provide the only practical application of delay.

A basic performance criteria to establish at each node must be to determine the delay wanted, namely, process interruption, material denial, or both.

\subsection{TRANSIENT STRATEGIES}

After the passive delay features for a facility have been established, an orderly application of transient delay techniques at each node follows. A primary performance criterion for the transient technique to satisfy is the time intervals that the process or the materials are to be denied. To achieve this it must be decided if the technique, when imposed, is to be reversible, i.e., with essentialiy an automatic recovery to normal status, or will the use-denial technique result in equipment failure that must be repaired or maintained to resume operation, or will the transient effect desired result in the replacement of equipment to recover. 
Even in the simplest or briefest applisation of delay technology that may result from false information or aborted attempts, some operating time may be lost, which is always expensive. In other applications, interruptions from days to several weeks may be achieved, which would be the goal of the delay technology. A well-designed delay system would utilize reversible steps up to imposing the step that results in long-term use-denial of a process or denial of access to material.

Developing the logic to implement delay techniques at the few nodes selected in a facility will require significant effort. In general, it is proposed that each step toward delay or material isolation always include a three-step process. These steps can be defined as 1) authorize, 2) arm, and 3) initiate. Each step requires some level of data input from the system to proceed to the next. These three steps may well be imposed more than once in a series, if the analysis warrants it, prior to actualiy initiating some act of transient delay.

An essential development process at each node will require selection of a logic scheme to implement the delay strategy. The delay techniques used must be viable under abnormal as well as normal conditions. Basic methods to cope with abnomal and normal conditions would include enabling logic circuits that remain inactive until properly authorized; disabling logic circuits that require a continuous input, becoming disab?ed upon its loss; and appropriate combinations of these. The development of the logic at this step can be somewhat general. It is expected that redundant circuits would be used both to increase the reliability and enhance the logic.

Following the development of the logic to implement the transient delay strategy, identifying the interface with the $c^{3}$ system becomes essentially automatic. Normally the actual interface between the $c^{3}$ system and a transient delay technique will occur at a single point, although the $c^{3}$ may have several data input channeis capable of defining concitions at that node.

Finally, some measure of the reliability of delay techniques at each node must be quantified. This analysis should include the demands on the system imposed by the six general criteria given in Section 4.2.

The utilization of solid state circuitry, erasable electronics, and districuted processing as described earlier is assumed. 


\subsection{DELAY EXAMPLES}

A set of nodes has been proposed for a fuels reprocessing facility (FRP), at each of which some transient delay techniques can be applied. This preliminary set is developed to illustrate where and how transient delay techniques may be used. No attempt will be made to discuss each node in any detail or to assess the effectiveness of the delay techniques that have been selected.

The first node selected at an FRP is the first decontamination cycle and the goal would be to deny on demand the use of the pulse columns for extraction of uranium and plutonium from the process stream. Table 4-1 below lists several possible denial points at the extraction node in an FRP.

\section{TABLE 4.1. Possible Use-Denial Steps at Extraction Node}

\section{HA Contractor \\ HS Column \\ IB Electropulse Column \\ 2D column}

Control HCF Airlift

Control Airlift Input

Control Airlift Input

Control Airlift Input

Delay would be effected by removing control of the airlift pumps from the plant operator, thus establishing the potential to temporarily interrupt and delay the process operation. Assuming that a graded response would be a part of the delay concept, control could be restored to the operator with no interruption or delay in the process up to the time when the step to delay the operation for four to six weeks would be initiated. In the latter case, control over air sources to the columns would be erased at the miniprocessor and radiation levels in the celi would prevent installing bypass lines. The actual delay step would be intruder activated.

Similarly, SNM material in process tanks at the purification node can be temporarily denied to the operator. Control over tank levels can be included in designs for transient delay at a plutonium purification node by

(a) Intruder activated is intended to inclucie actions to obtain SNM material or operate the facilities during or following an overt take-over. The capability to back out of this special condition would reside off-site and some delays to recover can be expected. 
removing sensing and fluid transfer capabilities. Table 4-2 shows the process steps in the purification node at which delay techniques may be applied.

\title{
TABLE 4.2. Possible Delay Steps at Purification Node
}

\author{
IB Surge Tank \\ 2A Column \\ 3A Column \\ Pu Catch Tank \\ Pu Sample Tank \\ Pu Storage Tank(s) \\ Pu Rework Tank \\ Is Column
}

Quick Drain to HWW Catch Tank Control 2AF Line Airlift Control 2BP Line Airlift Code Controlled Input/Output Valves

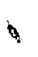

Quick Drain to HLW Tanks

Control ISF Airlift

The potential exists for longer term material denial by dumping SNM material into high level waste tanks as the most severe step in a graded response. This could be intruder activated. This is shown in Figure 4.1 Here the vessel could depict a tank for storage of a plutonium solution and the valve labeled FEB (for Functional Electronic Block) illustrates a quick drain valve under control only of the PROC. If the need arose, this valve could be activated (i.e., intruder activated) to permit the solution to drain to a high-level waste tank to effect a four to six week delay in the recovery of the plutonium.

At a SNM storage node, denial of ready access to material may be accomplished on demand of the $c^{3}$ system by establishing preset barriers or by forcing recovery of the stored material into a four to six week mining operation. The storage enclosure may be a deep underground vault, perhaps normally only remotely viewed and operated. Continuous surveillance could be maintained by tamper-proof detectors, for activities predetermined to be unauthorized, with essentially instantly reversible graded response protective actions indicated by an enable/disable FED. A delay period of four to six weeks as a last step (i.e., intruder activated) could be achieved by the use of foam as shown in Figure 2.17. 


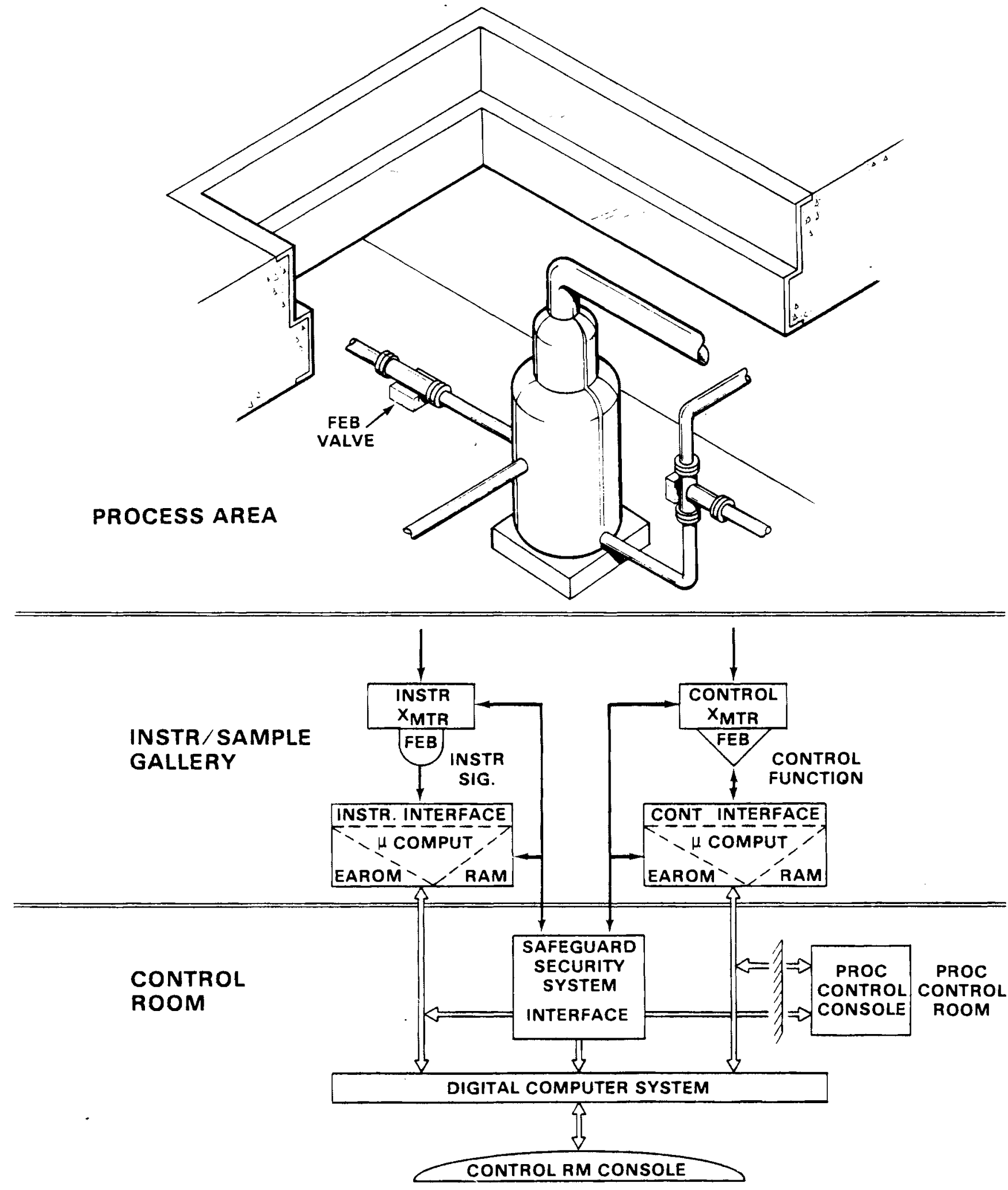

FIGURE 4.1. Graded Response: Dumping SNM into High Level Waste 


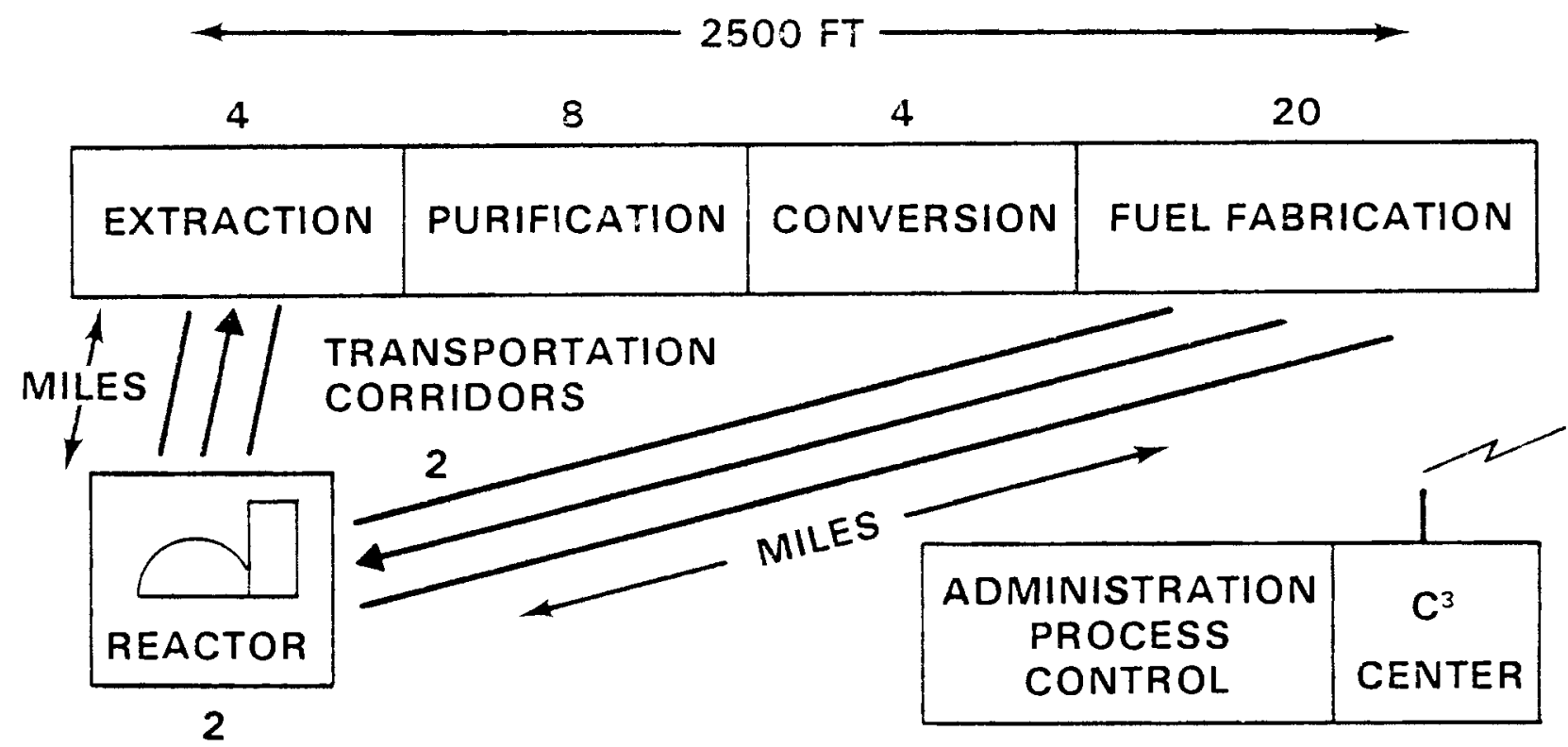

FIGURE 4.2. Distributed Penalty Nodes

Similar node selections would be made at other parts of the fuel cycle at an IFSC. Figure 4.2 proposes one concept of layout of the steps in the fuel cycle. Note that co-iocation of several steps in the cycle is suggested. The numbers above each step in the figure indicate a likely number of nodes available to implement use-denial techniques at each of these steps in the fuel cycle.

\subsection{ASSESSMENT OF THE SELECTED USE-DENIAL STRATEGIES}

A categorization of the delay techniques that are proposed is essentiai. In this assessment, the attempt should result in establishing priorities among the nodes selected. This additional screening will result in firmly identifying those nodes where transient delay should be implemented and eliminating the less useful. In this final review process, each node with its delay strategy should be assessed relative to meeting the six general criteria given in Section 4.2. In addition, the review should assess the delay strategies at each node relative to their meeting the general goals of the use-denial concept. Each node with its delay techniques should be rated and compared using standards applied equaliy to each and relative to:

- a level of effectiveness in providing delay, 
- the expected reliability in quantified terms, i.e., using failure rate data, redundant components or systems, etc.,

- its compatibility with the operation of the process, including measurements and control, and

- its expected acceptability among operating staff. 


\subsection{POLITICAL AND INSTITUTIONAL ISSUES IN PROVIDING PROLIFERATICN RESISTANCE \\ FOR AN INTERNATIONAL FUEL \\ SERVICE CENTER}

\subsection{GENERAL CONCLUSIONS}

There are three major sets of political and institutional issues involved in providing proliferation resistance for an International Fuel Service Center (IFSC). These are:

- political acceptability of introducing proliferation resistant technology in an IFSC, with specific emphas is on assessing differences in acceptability of passive or active use-denial technologies;

- value of multinational presence in enhancing or reducing IFSC, proliferation resistance;

- issues of organization, management, and operation of a proliferation resistant IFSC.

The general conclusions of this analys is may be summarized as follows:

From a political perspective, the proliferation resistant IFSC concept appears generally unfeasible since it is extremely unlikely that any nonweapons state harboring weapons ambitions would consider hosting such an installation. The major reasons for this conclusion are:

- Proliferation resistance features which are perceived as discriminating against the host nation will almost certainly not be acceptable to nearly all potential host countries.

- Active use-denial features which are designed to exclude the host nation from positions of authority or control are unlikely to be acceptable to any host nation.

- Passive use-denial features are likely to be unacceptable to host nations, and other IFSC partners, unless they have been demonsirated to be environmentally safe and have a modest and predictable impact on the economic efficiency of the center. 
- Multinational presence in an IFSC is likely to create management and security problems due to lack of a common language among the work force, and the likely necessity of insuring that all operating partners are treated equitably.

The IFSC concept without proliferation resistance technology may be politically acceptable to a variety of hosts and participants, and therefore merits further consideration. On political grounds, multinational presence in such an IFSC would seem to make an IFSC a less attractive target for host nation take-over than would facilities owned by only one other foreign nation.

\subsubsection{Proliferation Resistant Technology}

Proliferation resistant technology refers to a set of devices and technical process modifications which may be applied to nuclear fuel cycle facilities to delay the unauthorized diversion or conversion of plutonium into weapons usable form.

Conceptually, there are two types of use-denial technologies: passive and active. It should be emphasized that at this time there are no systems of either type which have actually been built except in classified weapons systems. Passive designs are principally theoretical and represent judgments about what may be technicaliy feasible operating systems. Active use-denial devices have been used in military applications for some time. Application of active use-denial technology to protect reactor fuel cycles remains purely conceptual.

Passive use-denial technology inheres in the basic reprocessing design: no detection or response to attempts to divert weapons-grade materials is required. An example of such a system is the CIVEX concept. In passive systems, the reprocessing plant and other facilities would be designed to prevent weapons-usable material from existing in process streams. Unfissioned plutonium and uranium would be left together thus making process material of 1 imited value for direct conversion to weapons. Process streams would be radiologically hazardous throughout all operations, thus requiring shielding for all reprocessing, fuel fabrication, and storage operations. To separate weapons-usable plutonium from a passive 
system, diverted materials wou?d have to undergo separate reprocessing operations in order to remove the materiais that render the fuel material useless for weapons.

Another passive design contrives to build reprocessing facilities so that the plant's operation could not be altered to perform the additional reprocessing needed to yield weapons material. It should be noted that no proven passive design concepts for reprocessing plants exist now. Indeed, there appears to be no way of building a totally passive system that is completely proliferation resistant. Additional active use-denial measures are apparently needed even in "passive" systems.

Utilization of active use-denial involves adding detection devices and remotely controlled penalty nodes to existing facility designs. Active use-denial implies the automatic detection of unauthorized diversion and the remote invocation of a prohibitive response. These actions are aimed at isolating weapons-grade material in storage or in process, and/or rendering key facilities unusable by adversaries wishing to divert materials. The active use-denial system would require an accurate Command, Control, and Communications $\left(C^{3}\right)$ systen enabling security personnel to monitor detection systems, and to remotely invoke use-denial actions.

\subsubsection{Goals of Proliferation Resistant Technology}

There are two major goals of proliferation resistant technology which must be integrated into an IFSC. The first goal is making an IFSC invuinerabie to covert diversion and unattractive for host nation takeover. A second goal is to design a proliferation resistant technology that would provide a flexible response to external threats. Achieving these goals would buy time for the IFSC participants and their governinents to determine what diplomatic or mijitary actions ought to be taken to counter any unauthorized activity. 
The deterrence value of proliferation resistant technology is based on the presumption that if passive and active use-denial features work properly, then unauthorized use or diversion of materials would have grave technical problems in:

- attempting any undetected diversion of nuclear material;

- gaining access to storage areas;

- extracting weapons-usable plutonium from any fuel or other material which they might acquire;

- utilizing the reprocessing plant for extracting weapons material; and

- making modifications to the reprocessing plant and other equipment so that weapons-grade plutonium might be extracted.

The presence of proliferation resistant technology provides owner/ operators with a far more flexible response to external threats than would a multinational facility without proliferation resistance features. With proliferation resistant technology in place, the following options and responses to external threats would be available:

- Suspending a 11 processing operations and "arming" penalty nodes which would only be activated if an intruder tampers with them. If the threat passes, all operations could be returned to normal.

- Remotely disabling the IFSC's operational capability from an off-site location inaccessible to those attempting unauthorized diversion (e.g., location in another country).

- Isolating strategic materials through the use of remotely controlled use-denial devices.

It should be emphasized that these use-denial practices and procedures would not be available in an IFSC without proliferation resistance technology. In such facilities, the only measures of protection come from traditional security devices provided by the owners and by conventional IAEA safeguards and inspections. These would be of little retardant value to determined diversion efforts.

\subsubsection{Institutional Definitions}

Effective analysis requires a working defirition of "multinational presence" in this context. The following definitions and associated assumptions are those of the alithors, not those of the NASAP program. 
Multinational presence refers to the ownership, control, and operation of the fuel service facility in question. At a minimum, the multinational owners will include the host nation, the United States, and at least one other country.

Control refers to setting basic policies of the IFSC, including the appointment of management. The owner states will exercise control through the vote of their designated representatives at what would be considered stockholder meetings or some similar form of directorship. (If there were more than three owner states, some countries might function as silent partners, say in routine management policy-making.) The facility will be operated by personnel from the owner states with the bulk of the work force (perhaps $80 \%$ or more) being drawn from the host nation. Administrators from non-host nations will serve in sensitive management and supervisory positions, while workers from all owner states will be involved in most plant hands-on operations.

It is presumed that IFSC's would be established by forma 1 negotiated agreements among governments of member nations. Such agreements might involve treaties, or they might involve some lesser form of collaborative arrangement. Although private companies might operate the facilities, IFSC's will not be established on a purely private company operating basis. 


\subsection{POLITICAL ACCEPTABILITY OF FROLIFERATION RESISTANT IFSC DESIGNS}

\subsubsection{Definition of the Acceptability Problem}

No passive or active use-denial feature can contribute to the proliferation resistance of an IFSC unless the states involved consent to its installation. Therefore the political acceptability of such technology to each of the participants is critical. Early anaiysis of this issue is important for two reasons: 1) to guide the design of proliferation resistant IFSC's so as to enhance their political acceptability, and 2) to assess the overall promise of proliferation resistant IFSC concepts.

Put starkly, an IFSC design is "acceptable" if the design does not cause a nation to refuse participation (or to condition participation on concessions that are unacceptable to other IFSC participants). Acceptability will be expressed as an authoritative governmental decision to sign (or not to sign) "on the bottom line."

A complete analysis of political acceptability must proceed along two dimensions. The first refers to the acceptability of a particuiar IFSC option--i.e., it asks: acceptability of what? For simplicity, we consider three possibilities: 1) an IFSC subject simply to IAEA safeguards, 2) an IFSC with passive use-denial, and 3) an IFSC with active use-denial. The threshold category of an IFSC with only safeguards is necessary as a baseline against which to gauge the marginal impact on the acceptability of alternatives.

The second dimension refers to the roies of the IFSC participants--i.e., it asks: acceptability to whom? We consider three basic categories: 1) supplier participants (if other than the United States), 2) host participants, and 3) other participants. This distinction is critical for the obvious reason that in order to reach operation a proliferation resistant IFSC must be acceptable to at least one supplier, one host, and one other participant.

In this section we first identify generic factors common to determining the acceptability of each of the three basic IFSC options to each of three categories of participants. This discussion should serve to isolate those substantive concerns which seem most likely to decide the fate of proliferation resistant IFSC's. Then after noting tre importance of governmental picesses 
in translating substantive concerns into political outcomes, we extend the analysis to case studies of actual candidates for IFSC participation.

\subsubsection{Domestic Policy Issues}

The very label "International Fuel Service Center" connotes matters of global importance as does "proliferation resistance." Nonetheless, as many thoughtful observers note, arms control begins at home. A variety of sometimes mundane domestic policy issues are likely to have a major influence in determining the political acceptability of proliferation resistant IFSC's to suppliers, hosts, and other participants. Here we identify some of those issues.

\subsubsection{Sovereignty Issues: For Potential Hosts}

That hosting an IFSC be consistent with the host nation's conception of sovereignty appears essential. Hosting any form of IFSC may raise serious issues of sovereignty for some countries. For others, sovereignty may be implicated only if the IFSC contains use-denial technology. For still others, a proliferation resistant IFSC might be fully consistent with conceptions of sovereignty.

of primary importance is the constitutionality of such a proposal. The most general question is whether a nation can legally accept an IFSC regulated by international law or by multilateral treaty arrangements. For example, the constitution of the Federal Republic of Germany authorizes participation in multinational institutions under international law.

A related issue involves the conditions under which extraterritorial status for an IFSC might be negotiated by treaty. This would involve the ceding of territory to a multinational body controlling a center. There is some precedence for the establishment of a multinational center which could be run either under IAEA auspices or an agency of the United Nations. An example is the status accorded the United Nations grounds in New York City. Embassy and legation offices are also granted extraterritorial status in host countries.

Since roughly $80 \%$ of the work force will be host nation personnel and the territory on which the IFSC rests will at least originally have been host nation territory, major concern of a host nation is likely to be resolution of the issues surrounding exercise of sovereign control over the national territory 
and the nationals involved in the IFSC. Some of those issues may be quite removed from proliferation resistance. They have to do with the maintenance of law and order, taxation, housekeeping, and the role which national police have in pursuing law breakers on extraterritorial grounds.

The presence of proliferation resistance technology raises further sovereignty issues. In particular, the presence of proliferation resistance measures, especially those of an active nature, are likely to raise serious issues regarding the exercise of sovereign control over the facilities, which, unless granted extraterritorial status, would be legally subject to police control by the host nation. It is doubtful that active use-denial components would be consistent with the basic laws of most nations.

In addition, some side effects of proliferation resistance technology may come into conflict with other national laws of the host country. In particular there should be concern over the impact of proliferation measures on environment and safety laws, laws governing the transportation of nuclear materials, laws and regulations covering nuclear waste management and finally, the national requirements for nuclear safeguards which may be at variance with IAEA standards or those of the nonproliferation treaty.

The presence of proliferation resistance technology may also offend the host nation's political sensitivities. Active use-denial systems are especially likely to be viewed by any potential host as highly intrusive and characteristic of unequal treatment in the international arena. In addition, measures which may be required in an IFSC to provent a host nation take-over may unacceptably curtail the civil liberties of the host nation personnei. Yet another intrusive impact of the IFSC is that many nations likely to host such an installation are pursuing a policy of energy independence. To the extent an IFSC is controlled by outsiders, the host nation may be required to abdicate control over their energy sources in a politically unacceptable way.

\subsubsection{Sovereignty Issues: Partner Nations}

There are six issue areas that impinge upon and conflict with the sovereignty of nations participating in an IFSC. These issue areas are:

- the possible use of multilateral security forces;

- response of host nation take-over; 
- conflict with nätionai law;

- national regulation of the use of nuclear materials;

- national energy independence; and

- civil liberties.

Because of its international character, an IFSC with nonproliferation safeguards will require some form of multilateral security force drawn from the participating nations. If such a security force were to take action in dealing with irregularities in the operation of the IFSC, it is likely that conflict might be generated with domestic security forces. Given the nature of national sovereignty and the emotions that sovereign rights tend to elicit, the importance of such potential conflicts ought not to be underestimated in negotiating IFSC arrangements.

Multilateral security forces would be immediately involved in the case of a host nation attempting to take control of an IFSC. Responding to a host nation take-over would in effect mean grave conflict between a sovereign nation and an international organization (the IFSC). This type of situation is bound to be ambiguous and demanding of the personnel faced with on-site decision making. This would be the case in extremis should there be a change of government producing a new political leadership dedicated to either taking over an IFSC or renegotiating the terms of its continued operation.

Partner nations may also find that the establishment of an IFSC initially will produce conflicts with existing national laws. Regulations covering the export of strategic nuciear material and the export of MOX fuel are likely to become major issues associated with the establishment of an IFSC. Similarly, national nuclear safeguards requirements which are different and sometimes more stringent than those required by the IAEA may also come into conflict with the IFSC arrangement. France, for example, imposes, in their view, somewhat stricter safeguards requirements on material shipments than do either the United States or the IAEA. It may be anticipated that in the years to come various nations will choose to impose increasingly more stringent national safeguards requirements on the movements of nuclear materia?. 
Another area where national laws cculd conflict with the IFSC proposals is that which applies to the transportation of nuclear material. The movement of spent fuel and fresh fuel as well as the movement of nuclear waste from fuel reprocessing may become the subject of substantial concern to partner nations participating in IFSC ventures. The mere establishment of an IFSC may in fact create severe difficulties in the transportation of materials which might not be occasioned by developing strictly national facilities.

Sovereignty as an issue of national politics may impinge upon the issue of energy independence as it relates to the acceptability or operation of an IFSC. The international controls implied by the IFSC concept may run counter to policies directed toward the national control of energy resources. Since the idea of sovereignty includes the notion of governmental control over all matters within the borders of a nation, the IFSC may be viewed as a "foreign object" that is incompatible or becomes inconsistent with priority policy issues such as energy independence. Should such a conflict arise between sovereignty and energy independence on one side and the IFSC on the other, it is overwhelmingly likely that the resolution will favor the national interest.

Finaliy, proliferation resistance features and the security measures likely to be imposed in proliferation resistant IFSC may pose a threat to civil liberties in both the host nations and partner nations. This issue is hardly trivial given the extent civil liberty issues are a source of international political contention. Recent exchanges at the highest level over the fate of Soviet political dissidents and the United States civil righis resisters such as the "Wilmington 10" indicate that civil liberties questions regarding participation in IFSC may be important.

\subsubsection{Economics}

Both partner and host nations are likely to have a number of substantial reservations about participation in proliferation resistant IFSC's based on solely economic grounds. Proliferation resistance technologies have implications both for the added costs of construction, operation, and for the relative economic competitiveness of IFSC fuel services.

At the present time there is littie information avajlable on the extent to which proliferation resistance fea wres would add to the cost of constructing an IFSC. Parametric estimates developed by System Planning 
Corporation (SPC) indicate that the added costs involved in construction may in fact be low. However, these figures have been questioned by Sandia Laboratories personnel who indicate that such estimates may be off by at least one order of magnitude. For any IFSC it is unclear to what extent the United States' experience, on which SPC estimates are based, is valid for projecting costs of construction in foreign countries where the highly skilled work forces necessary to complete such projects may be difficult and costly to assemble.

For an IFSC with passive use-denial technology, this uncertainty is compounded by the fact that no operational design for such a facility exists. The first design which is built will probably involve a number of engineering and operational problems which will have to be resolved on the basis of experience.

The added costs imposed by the installation of active use-denial technology with the associated Command, Control, and Communication center $\left(C^{3}\right)$ are perhaps even more difficult to estimate. The two major sources of error are the cost of materials and labor necessary for building the use-denial system, and the cost of communications equipment which must be implemented in order to make the system operate effectively.

The added costs of proliferation resistance features which occur during routine operations are also difficult to project. SPC has estimated that the principal costs of operation are likely to be personnel costs. These estimates are also questionable in that there is presently no way of estimating the impact that passive features will have on the economics of the IFSC's or the extent to which active features will interrupt or interdict process operations making the IFSC's industrial output uneven and uncompetitive. The economic impact of false alarms, jury rigging, and bypassing of $\mathrm{C}^{3}$ systems and on-site inspection must also be estimated for any IFSC system. It is clear that the proliferation resistance features of IFSC's are likely to impose substantial costs on operations during the early phases of startup and shakedown. What costs will be imposed on routine operations are in the rea $1 \mathrm{~m}$ of speculation at this time.

The impact of these highly uncertain increments in cost on the willingness of hosts and partners to participate in proifferation resistant IFSC's will depend on tradeoffs. The balance struck will depend on the relative value 
placed on the domestic and foreign policy goals implicated by participation, and on the attractiveness of alternatives such as developing indigenous fuel cycle technology or purchasing foreign services.

\subsubsection{Status of Domestic Energy Programs: Energy Independence}

The need for nuclear power over the next 20 to 50 years and the avai1ability of alternatives to nuclear power will be particularly important in determining the extent to which even undesirable aspects of a proliferation resistant IFSC become acceptable.

In a host nation, paramount considerations are those of assured energy supply and determination of the role which nuclear power is going to play in the national economic development over the next 20 to 50 years. In a realistic development scenario one cannot imagine siting an IFSC in a location where the host nation would not be a customer for a sizeable amount for the center's reprocessed fuel and energy output. Given this, we may assume that the greatest likelihood for any IFSC with or without proliferation resistance features will be in a host country which is heavily industrialized and committed to nuclear energy as a major energy source. For nonhost participants, the key consideration is apt to be the need for reprocessing or other back-end fuel cycle services. Unless the participant is located near the IFSC, the participant is unlikely to make use of the nuclear power generated. Thus, nonhost participant power needs are not directly relevant.

For potential hosts and other participants which have reasonably priced alternatives, cooperation in an IFSC may be regarded as too costly. However, where those alternatives are limited or where the prices of alternatives are high, the desirability of participating in an IFSC may outweigh either the short-term economic costs or the political problems introduced by the presence of proliferation resistance features. For example, the Japanese, with few alternatives, face the prospect of continuing foreign energy dependence if they are not able to rapidly develop an indigenous nuclear generating capacity.

The energy RD \& D programs presently underway in the major supplier states will likely have a strong impact on the arrangements which those states will find agreeable or acceptable from both an economic and political viewpoint. In Westerr. Europe, there is a strong comri; tment to the nuciear opicion with particular emphasis in France, West Germany, and Britain on the breeder 
reactor. The extent to which a proliferation resistant IFSC makes the breeder a more attractive commercial option, it may be anticipated that the western European nations would tend to support the concept. A further aspect of commercial attractiveness is the extent to which French, German, or British breeder technology would be employed in the projected IFSC's.

Precisely whose technology is employed in the centers is likely to become a major issue surrounding the institution of IFSC's. Substantial economic advantages can be anticipated for those nations which are able to establish their own technology as the basis for the first IFSC. The advantage will arise from the likelihood that subsequent IFSC's will employ the same technology if it is proved successful and commercially viable. In view of the difficulties that can be expected in starting the first IFSC, it is unlikely that partners in further ventures would want to participate in an IFSC based on unproven technology.

Concomitant with this is the extent to which participating partners or supplier states have developed full commitments to plutonium recycle or other reprocessing alternatives and the extent to which they have been able to successfuliy cope with their nuclear waste disposal problems. If an IFSC presents an alternative to the domestic disposal of high-level nuclear wastes, the attractiveness of such a facility may be considerably enhanced.

Energy independence concerns have been alluded to throughout this section. Commitment to an IFSC by a major industrial nation will of necessity involve making judgments about the extent to which participation in this venture leaves the nation vulnerable to foreign interdiction of fuel supplies and the extent to which the nation would find acceptable the possible interruption of such a fuel supply. Each nation will have to decide the extent to which it will commit its energy future to foreign nuclear fuel services, whether these services are under international control or under contract with another government. It would appear unlikely that nations such as Japan, which are especially vulnerable to an interruption of external services or supplies, would be willing to stake their future on sources which may be interrupted by the vicissitudes of international politics. 


\subsubsection{Environmental and Safety Considerations}

Of particular concern to hosi nations wili be those proliferation resistance features which have environmental and safety impacts. These include direct environmental effects related to operating the facility, worker safety considerations, and general peril to third pariies. Participating partner states are likely to have concerns about liability for damages resulting from a malfunction in an IFSC with proliferation resistance features.

Direct environmental impacts of operating IFSC facilities with proliferation resistance technology can be categorized as those affecting air quality, water quality, ambient radiation releases, and the potential for accident situations affecting work force personnel. The standards that will be applied for air and water discharges are likely to be no higher than the discharges permitted during the operating of nuclear power planis in any one of the major industrial nations.

of particular concern will be the potential which proliferation resistance technology creates for additional accidents on the site. For example, should a malfunction occur crippling equipment, it is quite possible that a messy cleanup procedure, a local facility contamination, or an inadvertent contamination of personnel may result. The determination of what constitutes an acceptable risk level will be a key consideration in negotiating environmental safety agreements.

Passive use-denial designs pose other prodlems. They apparently create fundamentaly different process streams with quite different safety problems from any systems which have been built and operated to date. Since the purpose of the passive system is to create a process stream of material which is highly radioactive and thus dangerous to manage, it could well be that by using this stream, additional environmental problems are created throughout the IFSC. By necessitating different handling procedures in an additional number of steps where heavy shielding and the transport of extremely hot materials is required, one can presume that there is an increment of potential danger posed which may become the subject of discussion on the acceptability of passive designs. 
The issue of third party liatility is also likely to become a major point of discussion. Of special concern are the risks members of the genera? public may be exposed to in the movement of either spent fuel to the IFSC or highly spiked fresh fuel from the IFSC. Also, the extent to which passive designs pose risks for operating personnel and for third parties will be a consideration. It can be expected that there will be substantial discussion over the ways in which liability claims are to be prepared and who is to pay for them.

5.2.2.5.1 Waste Management Issues. There are major unresolved technical, institutional, and political problems in the management of nuclear wastes. At present, none of the countries actively developing commercial nuclear power has been able to establish workable programs for the final disposal of nuclear wastes from power reactors or military weapons programs. Until the major suppliers of nuclear technology are able to demonstrate that they have workable and effective solutions to the waste management problem, $i \tau$ is unlikely that non-nuclear countries will be receptive to housing large nuclear installations on their territory.

\subsection{Decommissioning Nuciear Facilities. An issue closely allied} with waste management concerns is that of decommissioning plans and provisions for an IFSC. A full-scale IFSC will involve many component buildings, reactors, and other facilities which will have to be replaced, removed, or decommissioned during the lifetime of the IFSC. At present, the major nuclear supplier states have not developed workable programs for the decommissioning of large nuclear installations or of nuclear waste disposal sites. Intil such time as effective programs for decommissioning are devised and proven, one may anticipate that potential host countries will be reluctant to accept àn IFSC.

\subsubsection{Domestic Political Opposition}

Domestic opposition to the concept of the IFSC may come from several sources. These include political groupings, economic interests, and interest groups concerned with ecological issues. It should be emphasized that in almost any country there are many groups and interests of widely varying political views which might have powerful motivations to try and prevent their nation from participating in an IFSC venture. 
One major group of potential opponents is economic interests backing competing energy tecinnologies which have a reasonable opportunity to capture the share of a iation's energy market which might be otherwise dominated by the IFSC's reactor output or services. Since the major purpose of the IFSC is to suppiy energy and fuel services, those parts of the economy with a stake in alternative energy sources may seek out supportive political allies in attempting to scuttle any serious plans for an IFSC. Specifically, coal producers, corporations with a major interest in solar, geothermal, or hydro power may be vigorous opponents of an IFSC regardless of its otherwise desirable proliferation resistance features.

Strong opposition to the nation paricicipating in an IFSC venture, or hosting a facility, may also arise from within the country's nuclear power interests. As discussed briefly above, a major policy issue which will arise concerning an IFSC proposal is, whose technology will be utilized in the center? For example, reactor vendors in the United States are likely to oppose IFSC's using French breeder reactor technology.

Domestic opposition to proliferation resistant IFSC's stemming from conservative political groupings can also be expected. If an IFSC arrangement curtails any nation's sovereign control in a significant manner, nationalistic forces can be expected to register severe opposition. The nationalist will not want to see "their" country "give away" any decision-making authority. Nationalists are particularly unlikely to approve of the idea of $\mathrm{C}^{3}$ having the authority to shut down or cripple an IFSC. The presence of foreigners in control would, in itself, be grounds for condemning the IFSC concept. The vigorous debate which occurred both in the United States and Panama over the new Panama Canal Treaty is an example of this form of political opposition.

If there are reasons to believe that "right wing" nationalistic groups may vigorously oppose an IFSC, there are few indications that the political groupings of the left will tend to support the IFSC. To the extent that the political parties of the left are increasingly coming to feel the influence of environmentalists, one may expect growing cpposition from such sources.

A major source of domestic opposition to IFSC is likely to come from environmental groups, many of which are already mobilized in opposition to nuclear power ano the plutonium economy. Environmental groups are working 
within most mainstream political parties in major countries across a broad range of the ideological spectrum. In many parties these environmental activities are gaining strength. This was clearly demonstrated recently in West Germany in the party conferences of the governing coalition partners, the Social Democrats, and the (1iberal) Free Democrats. In both cases, the rankand-file came close to revoking the leadership's commitment to nuclear energy. Similar developments are taking place elsewhere.

In addition to the established parties, environmentalists in many countries are forming single issue interest groups aimed at specific targets of concern. These groups are challenging the established political parties to take favorable stands on "their" issues. Moreover, they are gaining in numbers of supporters, organizational sophistication, and financial backing. All three factors speak the basic language of politics. To the extent that the political system is or becomes responsive to these interests, opposition to the IFSC idea is likely to grow.

If all three sources of domestic opposition--economic, political, and specialized interest groupings--combine or coalesce, the chances of pro-IFSC policy decision in many countries becomes disappearingly smal1. Current trends in most of the industrialized nations indicate that domestic opposition to nuclear power is on the rise. What cannot be determined with surety is the extent to which the rising trend will continue. The other sources of opposition in the economy and among nationalistic groups are probably relatively permanent features of the domestic political landscape.

\subsubsection{Foreign Policy Issues}

Foreign policy issues are the second broad set of concerns that could affect the willingness of suppliers, hosts, and others to participate in proliferation resistant IFSC's. As with domestic policy issues, the impact of foreign policy concerns on the acceptability of IFSC's will depend critically on the nature of alternative energy sources avaijable to participants and the domestic issues which are influencing their poititical decisions. Here we identify seven major foreign policy issues determining whether or not a nation might participate in an IFSC. 


\subsubsection{Attitude Towards Participation in Multinational Organizations}

The reasons for a national aversion to participation in multinational organizations are obvious. First, participation could involve some sacrifice of prestige: why be required to join with others to do that which you should be capable of yourself? Second, participation could be inefficient if it were possible for a nation to do the same thing alone and reap greater rewards. Third, and perhaps most important, nations are often reluctant to have their actions constrained by the votes of others in crisis situations.

Some nations, however, might find similar considerations favoring participation. Participating in a grand adventure with other nations could be a source of prestige as, for example, the concorde Project. Similarly, international cooperation may offer some nations an opportunity to do things they could not undertake alone such as developing a high-technology sector of their economy. In these circumstances, the sacrifice of being constrained by partners in a crisis situation might be an acceptable cost. In determining how any given nation might view these circumstances, that nation's current experiences in multinational ventures should be examined. For example, has the nation under consideration recently been willing to enter into cooperative international undertakings? Has the experience been favorable? These questions can be developed to account for varying national attitudes towards international organizations.

The broad implications for IFSC participation are fairly straightforward. The IFSC with safeguards alone seems substantially analogous to any joint business enterprise, except perhaps for the importance of the commodity involved. Therefore, the willingness of nations to host or participate in an IFSC may correspond roughly to its willingness to host or participate in joint business ventures. An IFSC with passive use-denial does not involve much additional concession of autonomy and therefore is likely to be roughly as acceptable or unacceptable as an IFSC with safeguards alone. In contrast, an IFSC with active use-denial represents a major increment in the concession of national autonomy and flexibility. Indeed, such a facility is rather akin to a military alliance in that the participants are bound by group decisions in a crisis--decisions which cold result in major sacrifice by a dissenting 
participant. Therefore, the acceptability of an actively proliferation resistant IFSC will likely depend on generous participant attitudes towards participation in multinational organizations.

\subsubsection{Antecedent Relations with Partners}

Whereas the preceding concerned generalized attitudes toward cooperation, this section is concerned with past experience with the partners proposed to participate in an IFSC. Some nations, such as the United States and Great Britain, have long records of trust and cooperation in a variety of enterprises. Other nations, such as Brazil and Argentina, have analogous records of mistrust and antagonism. Still other nations, perhaps such as France and the Federal Republic of Germany, have histories of mistrust but now find it useful to cooperate, in part to reduce levels of mistrust. Still other categories of nations cooperate economically, while remaining aloof or opposed in the military and political spheres.

On balance, a record of trust and cooperation in similar undertakings among potential supplier, host, and other participants is likely to enhance the willingness of each to join in an IFSC. Previous instances of discord or hostility are likely to raise major barriers among nations contemplating joint participation in an IFSC. These generalizations hold for IFSC's with either active or passive use-denial.

\subsubsection{Regional Military Conditions}

The regional military balance in the area of the host nation will likely affect the way in which IFSC designs are viewed by other regional participants, by the host, and by the supplier. Because construction of an IFSC of any type gives the host a potential source of indigenous weapons material, it could destabilize the military balance in the region. Potential participants in the region are thus likely to disapprove of such a facility, but with two possible exceptions: First, if the alternative were a national fuel center for the host, rival nations are likely to prefer an IFSC; second, even if they strongly disapprove of locating an IFSC on the host's soil, they may nonetheless find their participation preferable to nonparticipation should construction of the facility be inevitable. 
For the host itself, the impact of military conditions on acceptability is difficult to predict. Constructing an IFSC with use-denial technology is likely to reassure neighbors of the nost's benign intentions. However, the military utility of reassuring neighbors depends on the host's military strategy. If the host nation practices a "studied ambiguity" about nuclear weapons capability (as does Israel), reassurance is unnecessary. For such states, military considerations are unijkely to enhance and might even detract from the acceptability of an IFSC over a national facility. If the host forthrightiy relies on conventional weapons alone, reassurance of neighbors should serve to head off pressures for them to acquire nuclear or additional conventional weapons. In this instance, military considerations are likely to favor an IFSC instead of a national facility.

The impact of military considerations on acceptability to the supplier state will depend on the supplier's interest in and conception of military stability in the region being considered.

\subsubsection{Commitment to the Goals of the NPT}

The greater their commitment to the goal of nonproliferation, the greater the willingness of potential participants to cooperate in an IFSC. Such commitment should have a corresponding impact on the acceptability of participating in an IFSC.

It should be noted that different naticns have varying conceptions of nonproliferation and of measures which can further nonproliferation goals. For example, in contrast to the official United States' view, some nations believe that the commercial nuclear fuel cycle is an unlikely path to national weapons proliferation. They point out that in comparison to alternative paths, host nation take-over of commercial fuel cycle facilities is the most perilous, cosity, and time-consuming way of achieving a nuclear weapons capability. For natiors holding this view, the substitution of an IFSC for a national fuel center will make little contribution to the goal of nonproliferation. The willingness of nations not concerned with commercial routes to proliferation to participate in IFSC's is likely to hinge on other factors. 


\subsubsection{Nuclear Weapons Ambitions and Alternative Paths to Nuclear Capability}

This section concerns IFSC participants who may desire a nuclear weapons option and for whom access to commercial fuel cycle facilities would be helpful. Primarily, these are nations that are poor in raw materials, nuclear technology, or both. It could also include nations that for reasons of domestic or international politics cannot pursue a dedicated weapons option, but desire the de facto option that access to a nuclear fuel center provides.

For prospective host nations in this category, participation in an IFSC is less desirable than acquisition of a national facility. Participation in an IFSC is even less desirable because of its use-denial features. The marginal impact on acceptability in this situation is especially sensitive to the availability of alternatives. The IFSC option may be preferable to no domestic fuel cycle facility at all. Therefore, if the choice is between a proliferation resistant IFSC or nothing, a potential host desperate for a domestic facility may be willing to participate (or to base its decision on considerations other than weapons ambitions).

Nonhost nations desiring a domestically located fuel cycle center to acquire nuclear weapons would tend to resist IFSC participation, since partnership in an IFSC eliminates the justification for a national facility. Such a nation may participate nonetheless if suppliers clearly denied it the capacity to establish a domestic fuel service facility. The technology transfer value of IFSC participation may then be viewed as a possible contribution to national weapons ambitions. The presence of active or passive use-denial is likely to have little impact on the willingness of nations in this category to participate in an IFSC because they lack the capability to take over and run a facility as complex as an IFSC.

\subsubsection{Importance of Good Alliance Relations}

Alliance relations affect hosts, partners, and suppliers alike with respect to IFSC participation. The allies of a potential participant may, for a variety of reasons, desire strongly that nation join in an IFSC. The impact of such desires on the willingness of a potential participant to comply will depend on the firmness of the allies and the willingness of the desired participant to accede to or resist the allies' demands. 
Predictions concerning the effect of alliance relations require careful attention to the entire context of alliance patterns among the specific countries being considered. In general, IFSC participation is such a basic issue, tied as it is to fundamental national conceptions of sovereignty and independence, that even a very large and important ally--or group of allies-may find it difficult to work its wiil on even a small and dependent potential participant if that nation is strongly opposed. Indeed, alliance pressures may have a negative impact on an ambivalent potential participant if greater rewards are anticipated from asserting independence than from complying with alliance partners.

\subsubsection{International Economics}

Several international economic considerations are of importance to national decision making on IFSC participation. Al1 participants must assess the balance of payments effects. A participating supplier is unlikely to reap the full benefits otherwise obtainable from exporting technology or seling services independently. Conversely, the host and nonsupplier participants are likely to improve their balance of payments by participating in an IFSC rather than importing foreign technology or purchasing fuel cycle services from abroad. The impact of use-denial will be limited to the marginal incremental effect on balance of payments resulting from the added cost of the use-denial technology or its impact on the competitive efficiency of the IFSC.

Nations supplying fuel cycle technology to an IFSC may anticipate additional negative economic implications. First, the total market for fuel cycle technology may be reduced below that available from several national centers. Second, if proliferation resistant technology were used on an IFSC, this would likely require supplier design cooperation with the United States. Such cooperation would dilute the supplier's share of the profits for the immediate fuel service center. In addition, the IFSC supplier's fuel cycle technology might become so intertwined with that of the United States that the supplier would have to share profits on all further IFSC technoiogy. 


\subsubsection{The Importance of Political Processes: Introduction to Case Studies}

We have stated several factors that could affect the acceptability of the three basic IFSC approaches to potential suppliers, hosts, and other participants. Many cast doubt on the viability of proliferation-resistant IFSC's, especially with active use-denial. Obviously, however, the actual prospects for proliferation-resistant IFSC's hinge on how real-world participants would respond to these considerations in determining whether or not to participate.

The way acceptability issues are perceived and the way in which authoritative national policies are made reflect the action of national political processes. These processes, in simplified form, are made up of actors, groups, and interestswithin a country which seek to promote and influence specific policy goals or outcomes. Generally, no single voice speaks for "the nation." However, on issues of major national and international importance for a nation, the most critical policy decisions are usually made at the highest level of government.

In seeking to assess the policy a country might adopt toward IFSC participation, it is necessary to understand the decision-making structure within that country on nuclear issues. Decision-making structures may be pluralistic, technocratic, centralist, or dictatorial. These terms refer principally to the actors, groups, or interests within a country that are able to participate in decision-making on issues affecting a nation's participation in an IFSC. Generally, since many of these decisions are technical in nature, the role played by technocrats and technical people within the government bureaucracy is likely to be significant.

Political decisions in most countries are arrived at through a process of bargaining and negotiation among actors, groups, and specific interests. Actors can be thought of as prominent individuals who may have a specific policy orientation on an issue. Groups are unofficially constituted segments of the general public or of governmental actors who have a particular policy position or persuasion. Groups exercise influence on the decision-making process by virtue of their relative political strength in terms of numbers, organization, or economic importarce. 
In assessing likely policy outcomes on specific issues, it is first necessary to determine the significant actors, groups, and interests in a system and second, what their policy positions or preferences may be on a particular issue. Next, it is important to assess the relative power of the actors, groups, or interests and eventuaily determine the likely policy output of the political system.

In relating the current policy preferences of actors, groups, and interests in a given political system to an assessment of future national policy, it is necessary to gauge the stability of that political system. This is particularly important if policies developed at the present time were to have any resilience. Political systems having a long tradition of stability, such as Britain and the United States, are likely to have policies which are generally stable for at least a 10-to 15-year period. Other political systems, such as Iraq or Libya, may show an unstable pattern in their policy choices. Making the long-term projection in these latter cases is clearly impossible.

A usable assessment of IFSC acceptability requires identifying plausible sets of participants, specifying their relative concerns as translated into decisions by their political processes, and applying these "political objective functions" to hypothetical IFSC alternatives. This is done in the subsequent sections. The resulting assessment is subject to uncertainty--due bot'h to the limitations of analysis and to the sensitivity of the conclusions or assumptions about the technology and about the domestic and international political context in which the IFSC options are introduced. However, this range of uncertainty is substantially narrower than would prevail if the analysis did not refer to specific countries at a 71 .

Our particular choice of countries for case analysis demands some explanation. As suppliers we have chosen France and the Federal Republic of Germany. France and the FRG are critical to the fate of proliferation resistant IFSC's for two reasons. Both stem from their roles as the principal exporters of fuel cycle technology, along with the United States. On the one hand, unless the United States decides to supply proliferation resistant IFSS hardware itself (which would require a major policy reversal), France and the FRG are virtually the only logical suppliers. On the other hand, the willingness of $n^{\text {th }}$ countries to participate in proliferation resistant IFSC's will 
depend on whether France and the FRG offer to supply fuel cycle technology or services on a bilateral basis.

As potential participants, we have choseri Brazil, Argentina, Mexico, Pakistan, Iran, Japan, the Republic of China and the Republic of Korea. This selection results from two criteria. First, we are interested in states for which national fuel cycle centers increase proliferation risks; i.e., countries which may wish to acquire a nuclear weapons option and for which domestic commercial reprocessing facilities would ease this task. (Unless some such nations join, there is no reason to build proliferation resistant IFSC's other than to counteract terrorism.) Second, we are interested in states whose projected spent fuel production over the next few decades could possibly justify a pilotscale commercial reprocessing plant. We assume that the fuel cycle aspirations of countries unable to make this justification can be thwarted without resort to cffering or demanding IFSC participation. Six nations meet both criteria: Argentina, Brazil, Iran, Pakistan, the Republic of Korea and the Republic of China. Two cases do not meet the first criterion: neither Mexico nor Japan appear to have weapons ambitions, and additionally, Japan would not require commercial reprocessing facilities to fulfill weapons ambitions should they develop. We include them because they are potentially attractive hosts in regions with several nations that do fulfill other criteria as cotert: $a$ ? : $=00$ participants.

\subsubsection{Case Study: France}

French cooperation is important for successful implementation of a global program of proliferation resistant spent fuel reprocessing. Since they operate the world's only commercial reprocessing plant, French firms are a potential source of technology and commercial experience for an IFSC. At the same time, French manufacturers could handicap an international approach by selling reprocessing plants to developing nations on a bilateral basis. In addition, the French commercial program for reprocessing foreign spent fuels establishes a second alternative to an international effort.

The French Foreign Ministry initiated a policy review of multinational and proliferation resistant approaches to the nuclear fuel cycle during the summer of 1978. This self-generated exercise indicates that alternatives to national reprocessing are receiving a favorable, or at least a sympathetic, 
hearing. Possibly the French are preparing to propose alternative institutional frameworks to administer spent fiel reprocessing.

The likelihood of French participation in an IFSC appears to bear on three sets of factors:

- the characteristics of the French nuclear energy program;

- the central factors which policy makers will consider in determining the desirability of participation; and

- the specific nature of the IFSC and the French role as a host, participant, or supplier.

These factors will be presented in detail and analyzed in the next three sections.

Characteristics of the French Nuclear Energy Program. The central features of the nuclear program which will affect the likelihood of French participation in an IFSC can be summarized as follows:

- The nuclear energy program is highly centralized at the national level.

- The political and technical leadership are strongly committed to the commercial development of the plutonium breeder fuel cycle.

- There has been a shift in French attitudes favoring strong measures to insure nuclear nonproi iferation.

- French participation in internationai project of any sort is limited by their desire to safeguard national sovereignty.

French Nuclear Energy--A Centralized Program. The three main tasks of setting and executing nuclear policy are all performed at high levels of the central government.

- Domestic energy planning is performed by federal agencies with virtually no input from municipal or regional officials.

- The national nuclear energy plan is implemented by a group of public and quasi-public corporations under the direction of the Commissariat a l'Energie Atomique (CEA).

- A small group of ministers meet as the External Nuclear Policy Council to set nuclear export poicicies. 
This centralization has allowed a relatively few individuals, responsible for both planning and implementation, to direct France's nuclear program. The nuclear program has thereby been largely insulated from effective criticism, redirection, and public accountability.

Since its inception, the CEA has enjoyed the support of French presidents. The "nuclear bureaucracy" has been able to take advantage of this support and the French penchant for centralized planning to consolidate its role and avoid seeking formal approval for the nuclear program from the electorate or from local officials.

The CEA was founded in 1945 and given full responsibility for promoting and coordinating every aspect of French nuclear energy development. The Commissariat employs some 28,000 people and has been directed in the recent past by members of the elite group of public managers trained in the Ecole Polytechnique. The organization is responsible for advising the president on nuclear policy, management of industrial assets (especially in the nuclear fuel cycle), pursuit of a11 necessary research and development, and transfer of nuclear technology to private users, particularly to Electricite de France, the national electrical utility.

In 1976, the CEA transferred its fuel cycle activities to Cogema, a subsidiary. Although 100\% government owned, Cogema has private legal status. This organization is charged with maintaining a strong market position to guarantee adequate fuel supplies ard services for domestic needs and for export. Cogema owns and operates the reprocessing plants at Marcoule and La Hague.

The External Nuclear Policy Council was formed in September 1975 and reflects the French government's new sensitivity to the problem of nuclear proliferation. The Council is composed of the President, ministers concerned with nuclear exports (including the Ministers of Industry, Foreign Affairs, and Defense), and the Chairman of the CEA. In this forum, political considerations have dominated commercial and technical interests. President Giscard d'Estaing has used this setting to exert his personal influence and to direct an increasingly important international policy. The Council established a French policy endorsing restrictions on the export of sensitive technology and set a noratorium on the expcrt of Erench reprocessing plants effective December 1976. 
The centralized nature of the French nuclear industry has thus far protected it from domestic critics, but makes it sensitive to new direction from the chief executives of the Republic and the CEA. Therefore, if Giscard can be convinced that the IFSC concept is the most effective tool for controlling nuclear proliferation, he can cause the nuclear energy bureaucracy to be responsive to this program.

Commitment to the Plutonium Cycle. French policy makers are committed to achieving energy independence and believe that nuclear development is the only viable route toward that goal. In 1976, total French energy consumption was 7.35 Quads. Domestic production measures only 1.68 Quads. Thus, France had a $77 \%$ dependence on energy imports. Government officials perceive this dependence as a tremendous vulnerability and the cause of the disequilibrium in international balance of payments. (The French $0 i 1$ bill in 1977 totaled more than 3\% of the Gross Domestic Product.) The French believe that because their country is deficient in sources of energy and is concerned over economic independence, atomic energy is basic to long-term economic developrient.

In the wake of the 1973 Arab oil embargo, the French dedicated themselves to increase the pace of nuclear growth. Pompideau made a decision for "toute nucleaire"--all French electricity would soon be generated by atomic power. Government officials now hope that by 1985 nuclear plants will provide $70 \%$ of French electricity. In 1976, nuclear facilities provided less than 10\% of French electricity. It is not likely that the French wi1l achieve the 1985 goal, but they are making progress and are committing themselves to further nuclear development.

In order to avoid a future fuel shortage, the French technocracy combined the toute nucleaire decision with a commitment to breeder reactor deveiopment. France's uranium reserves are estimated at 100,000 tonnes. This reserve is sufficient to fuel less than half of the LWR's that France intends to operate. It is estimated that through the use of breeder reactors this uranium can produce 2,100 Quad which would be equivalent of al1 Middle East oil reserves.

The French have indicated intentions to market their breeder technology abroad, both to undemurite the domestic development program and to generate foreign capital. Toward this end, they have signed accords facilitating international cooperation in breeder commercializaticn. One agreement arranges 
for the exchange of French technology in return for German capital investment. Another agreement estabiished Serene (Societe Europeene pour la Promotion des Systems de Reacteurs Rapides a Sodium), involving the French, as majority shareholders with German, Dutch, Belgian, and Italian interests. This company will support commercial production of the breeder and arrange licensing agreements among the reactor manufacturers in each country. Commenting on the goals of Serene, Andre Girard, then Chairman of the CEA, said that the first objective of Serene would be to build fast breeders in a competitive way in the five countries. The Serene plan could lead to exports abroad in the next 10 to 15 years.

In anticipation of breeder development, and a further sign of their commitment to the plutonium cycle, the French are reprocessing their own commercial fuel at La Hague. The UPS-2 reprocessing plant is now completing its second commercial campaign. Plans are set for construction of an $800 \mathrm{Mtu}$ UPS-3 plant to reprocess foreign fuel from European and Japanese utilities beginning in 1985 .

The economic benefit from reprocessing spent fuel from the current generation of LWR's is not proven. The French have four goals in reprocessing at this time. They hope to:

- Reduce the need for fresh uranium ore by $30 \%$, thereby decreasing their dependence on foreign energy supplies and "stretching" their domestic reserves.

- Offer services to other colintries on a cost-plus-fee basis. Some trade journals have called the French terms "tough."

- Demonstrate the viability of reprocessing and waste disposal as part of their breeder development program.

- Discourage other countries from developing a domestic reprocessing capability. (This will be discussed further in the section on French attitudes toward nonproliferation.)

There is strong political support for commitment to the plutonium fuel cycle and rapid commercialization of breecer technology. The only opposition among the major parties comes from the Socialists and their associated trade union, the Confederation Francaise Democratique du Travail (CFDT). These groups call for a three-year moratorium on LWR construction and fast breeder 
development coupled with a program of public information on the dangers of nuclear power. In light of their defeat in the last elections, the Socialists are reported to have moderated their position and can be expected to call for "go-slow" approach to nuclear development.

There has been opposition to nuclear deveiopment from the French ecology movements and the Breton separatist movements. Neither of these groups was successful during the last election and their support seems to be waning. They are likely to challenge further nuclear development through judicial appeals. These actions will slow the pace of development, but probably not significantly alter the goals of nuclear development.

Not surprisingly, the French technical community is strongly dedicated to plutonium fueled reactor development. The French research development and demonstration effort is smaller and more focused than similar efforts in the United States. French scientists are concentrating their efforts on breeder development and diversifying the application of existing nuclear technologies. There is virtually no research work underway in France exploring alternative fuel cycles and proliferation resistant reprocessing technology.

The French are strongly committed to the plutonium cycle as a means for achieving a guaranteed domestic fuel supply. They are therefore unlikely to participate in an IFSC if that means abandoning domestic development projects or domestic energy independence. The highly focused character of the RD \& $D$ effort will make it difficult for French engineers and manufacturers to participate in construction of a passive proliferation resistant IFSC. Nevertheless, as plans for export of the fast breeder begin to materialize, the French may find the IFSC approach to reprocessing a desirable means for dealing with the problems of proliferation.

Shift in Nonproliferation Policy. In December of 1976, the French government announced that until further notice it would withhold authorization for the signature of bilateral contracts that cover the sale of industrial installations for the reprocessing of irradiated fuels. This announcement reflects a new French position vis-a-vis nonproliferation, that certain sensitive technologies should be exported. It has been widely reported that 
this new position was adopted as the result of the personal effort by President Giscard d'Estaing. His dedication to nonproliferation has been compared to that of American President Carter and characterized as "religious."

Prior to the December announcement, the French maintained that nuclear transfers should not be inhibited. They argued that strict application of international safeguards was sufficient to prevent weapons proliferation. The French suggested that limiting transfer of certain sensitive technologies would call into question both the credibility of the safeguards and the integrity of the proposed recipients. Agreements to provide reprocessing plants to Pakistan and the Republic of Korea reflected that French position. (Since that time, the Republic of Koreans were pressured by the United States to cancel their request for a reprocessing plant. The French have tried to force the Pakistanis to back out of their agreement. Informed observers report that al though the Pakistani order is still on the books, the reprocessing technology will not be delivered.)

The French now agree with the United States that it is undesirable for developing countries to build national reprocessing plants. However, they do not believe that this can be prevented by denying the developing countries access to the technology.

First, the French continue to advocate the principles of free trade and national sovereignty. Andre Girard, Minister of Industry and former head of the CEA, sajd in Tokyo, March 1978, that it must be kept in mind that nuclear energy is necessary to world peace. Every nation has the right to maintain its dignity and to construct its energy policy. Therefore, no restrictions can be decided on the transfer of fissile materials, equipment, and technical know-how. Science and knowledge cannot be reserved for a few.

Second, the alternative proposed by the United States, spent fuel storage, is not acceptable. The French and other Europeans argue that this prospect is potentially more dangerous than national reprocessing plants. A policy of using thermal reactors alone in the once-through cycle is not a satisfactory nonproliferation policy. Every fuel storage facility, wherever it is placed becomes a "plutonium mine;" the plutonium in that mine becomes steadily more accessible with the passage of time. 
Third, the technology cat is out of the bag. Reprocessing has been thoroughly described in the open literature. Well-trained engineers in most countries could build a crude plant within a reasonable time.

French nonproliferation and commercial representatives argue that countries are interested in nuclear development, including reprocessing, for the economic benefit it offers them. The only way to effectively discourage them from constructing national reprocessing facilities is by offering alternatives that are economically more attractive. This can be best achieved by allowing all nations to buy nuclear fuel services from the most developed countries. In order to assure that the client states availability of services at a fair price, there must be multiple sources of service. The United States should, therefore, not discourage French and British efforts to develop commercial reprocessing, but should follow suit and offer its services on the world market.

French leaders have privately mentioned another reason for selling fuel cycle services. They feel that it is important to try to maintain a separation between a developing country's nuclear power programs and the military. If the legitimate (civilian) nuclear needs of a country can be met by purchase of either equipment or services, there will be no motivation for the civilian policy makers to associate their program with the military's nuclear aspirations. If on the other hand, the civilian technocrats need to argue for the allocation of significant funds for the development of a national reprocessing capability, they are likely to take advantage of their natural allies--the military. It is likely that any facility built by this alliance would serve both civilian and military nuclear programs.

Giscard d'Estaing encountered only limited opposition from the nuclear industry to his desire to shift the nonproliferation policy. The rew policy to sell services rather than equipment coincides well with the marketing plans of the CEA and Cogema.

The industrial leadership believes that the way to best exploit the international nuclear fuel cycle market is to sell services rather than equipment. The French predict that there are significant economies of scale in fuel reprocessing, and that they can provide services more cheaply than the cost of domestic reprocessing in many councries. In addition, some developed countries' nuclear programs are running into strong opposition from the 
environmentalist movements. These nations are most anxious to export their irradiated fuel for reprocessing and waste treatment.

French industry officials hope to exploit fuel service fees to underwrite their own research and domestic development programs. The domestic enrichment capability was funded in part by foreign utilities consolidated by Eurodif. Similarly, the agreements for breeder development mentioned above will alleviate some of the financial pressures of breeder development and commercialization. The UPS-3 reprocessing will be funded almost exclusively through foreign capital.

The new French commitment to nonproliferation and the policy review now underway suggest that an IFSC proposal will receive a serious hearing in the government. Their "providing services" approach to the problem of technology transfer makes France a good potential host nation for an IFSC. It is likely that industrial advocates of supplying services would oniy accept an international program like Eurodif in which French management and technology play the dominant role.

Limited Appeal of International Programs. French participation in the international programs, ranging from security alliances to cooperative research and development, reflects policy makers' desire to protect national sovereignty. To the French, sovereignty is reflected by a nation's ability to chart its own political and economic course unconstrained by alliances or dependency relationships. Pursuit of sovereignty has led the French to withdraw from full participation in NATO and to develop domestic uranium enrichment facilities. The French are willing to associate themselves with international organizations but will not abdicate their right to make autonomous national decisions.

Recent French participation in multinational industrial ventures is one means that has been employed to enhance their sovereignty. These joint efforts can be characterized as arrangements which improve the economic viability of French industries. In order to maintain a high technology aircraft industry, French companies have been cooperating with American and European manufacturers in design and production. To aid the smooth commercialization of breeder technology, the French have signed agreements with European reactor manufacturers. Foreign utilities were invited to invest in Eurodif to offset the significant costs of establishing a domestic French source of enriched uranium. ihe French 
feel that raising the economic viability of domestic interests without forfeiting technical and managerial control of the projects supports the goal of sovereignty.

The French have tried to expioit their position of technical leadership among the European nuclear industries. They have limited multinational cooperation to:

- foreign investment in French technology controlled by French management;

- market-sharing licensing arrangements with competitors whom the French cannot or prefer not to force from the market; and

- scientific exchange of basic nuclear research.

These agreements improve the French commercial position without sacrificing autonomy.

Eurodif is a good example of foreign investment in French technology controlled by French management. Shares in this company are held by government and private entities in France, Belgium, Italy, Spain, and Iran. The international character of the company is reflected by representation of all participants on the corporate supervisory board. However, the French own a controlling share in the company. There has been virtually no technology transfer to the other participants. The management of the plant will be almost exclusively French. The other nations do have an input in determining company policy, a guaranteed source of enriched uranium, and an interest in corporate profits. Nevertheless, they are better characterized as shareholders rather than partners in Eurodif.

The United Reprocessors Group is a French, German, and British marketsharing agreement designed to control the development of European reprocessing capabilities during the next decade. This organization does not involve significant technological transfers or interface between national operations. It is simply a paper organization design to protect European industries from overextending themselves too quickly in a recently commercialized field.

The limited appeal of international ventures need not rule out French participation in an IFSC. A center could, for instance, be constructed in France and managed like Eurodif. This would achieve the nonproliferation goals and enhance the French market position. The French might join a foreign IFSC 
if there were some market-sharing agreement which would protect French commercial interests in La Hague.

Active use-denial technologies would prove a more difficult block to French participation. If a faciitity were built outside France, the participants would have to agree to a joint response should the host try to take over the facility or divert fissile material. The French will probably not be willing to commit themselves to a course of action a priori. If the plant were built in France, the concept of a $c^{3}$ system without French participation would be totally unacceptable. This would represent a serious abdication of sovereignty with regard to their territory and citizens.

Acceptability of an IFSC. French policy makers will judge the acceptability of participating in a proposed IFSC largely on four criteria:

- Will the proposed center jeopardize French commercial interests?

- Is the proposed center an effective means to pursue nonproliferation?

- Is the project economically viable?

- How will French participation affect her relationships with other countries?

In discussions about the general prospects for an IFSC, French representatives to the Nuclear Supplier's Group stated that France would on Ty consider participation in an economically viable project. The French are likely to prefer proven technologies. A safeguarded Purex plant would be the preferable use-denial plant. The passive design might simply not work on a commercial scale. The active system might keep the reprocessing plant shut down for long periods as a result of false alarms and other malfunctions.

The French may perceive that their early participation in an IFSC could jeopardize their relationships with developing nations. It is easy, for instance, to imagine that developing countries would be alienated by a developed country's attempt to locate an IFSC with active use-denial features in a developing nation. Louis de Giringaud, the architect of the North-South dialogue, will try to prevent any French action which might harm her relationship with developing states. In this respect, the active use-denial facility is much less acceptable than a passive use-denial or Purex plant. 
Conclusions. The foregoing analysis indicates that no single approach to an IFSC and role is the most acceptable to France. It is difficult to forecast exactly what an IFSC will look like, the specific nature of national roles, and how competing interests will bargain as participation in an IFSC is considered. Nevertheless, we can extrapolate from the work above about the acceptability of active versus passive use-denia? technology.

Nonproliferationists are likely to favor the passive use-denial system. This approach will allow the establishment of an IFSC with fewer problems than if an active system were used. It would avoid problems with developing nations and seems more consistent with French foreign policy goals.

Commercial interests are likely to prefer an active system which would allow France to participate more fully in the design, construction, and management of the IFSC. They would support any innovation, however, that does not seriously endanger the French nuclear industry and furthers the prospects for the breeder economy.

Predictions about French response to an IFSC proposal should be made in light of their current policy. Both commercial interests and nonproliferationists are committed to a program of providing services rather than technology. Until this approach is proven unworkable, as less than optimal, it is unlikely that French advocates for an IFSC will emerge.

\subsubsection{Characteristics of the West German Nuclear Program.}

The Federal Republic of Germany (FRG or West Germany) has been active in the commercial applications of nuclear energy since 1955, when post-war restrictions were 1 ifted. Its activities have grown rapidly in the intervening years and now the FRG is a major nuclear vendor and an important international actor in the nuclear field.

West German attitudes towards an IFSC with proliferation resistance technology will be conditioned by the following factors:

1. The organization of the FRG nuclear energy program, which has both central government and federal (state) elements. These elements are not always in narmony when it comes to nuclear policy making.

2. The West German commitment to nuclear development, which is strong in terms of goverrmestal policy and strongly supported by business and labor leaders. 
3. FRG attitudes toward nuclear nonproliferation. The West German government has become increasingly concerned with the potential dangers of weapons proliferation, but remains committed to the export of nuclear technology including reprocessing and enrichment technologies, as well as the development of the breeder reactor.

4. West German commitment to the plutonium economy. Although the FRG is firmly committed to a breeder program, it is moving forward slowly because of environmentalist-inspired legal problems.

5. Internal opposition from antinuclear groups. An IFSC located in the FRG will be a likely target for the substantial and growing antinuclear groups in the FRG. West German IFSC participation per se will probably not attract the attention of the antinuclear protest movement, except as it may bolster the domestic nuclear program.

6. Finaliy, sovereignty issues will affect potential West German participation in an IFSC. Although the FRG is a participant in multinational organizations--some of which involve the partial forfeiture of sovereignty--it is doubtful that the FRG would now host or otherwise participate in an IFSC requiring sacrifice of sovereignty.

5.2.4.2.1 The Organization of the FRG Nuclear Energy Program. The West German nuclear program rests on three bases: the federal government, the states, and private industry, including the electrical utilities. There is no centralized direction such as was found in the French case, largely as a result of allied policies in the post-war era which mandated decentralized elements in the structure of the FRG.

The central government responsibility for the FRG nuclear program is divided among several ministries. Most important in the nuclear field is the Federal Ministry for Research and Technology (FMRT). The FMRT is responsible for allocating major research and development support in the area of nuclear energy. Federal funds support about $90 \%$ of the research done at the two principal research facilities at Karlsruhe (Gesellschaft fuer Kernforschung) and Juelich (Kernforschungsanlage Juelich). The other $10 \%$ of the budgets of the research facilities comes from the state hosting the facility. 
The direction of the FMRT has taken in the energy area has been distinctiy pronuclear. In 1972, the relationship of nuciear to non-nuclear energy research was 78.9 (excluding fusion). By 1978, this proportion was to have been reduced to 27.1 . While this represents a significant shift in emphasis, it must be stressed that almost three times the effort is going into nuclear research compared to all other energy sources (Federal Ministry for Research and Technology 1977a, p. 158).

In the second redrafting of its energy program, the present FRG government downgraded the nuclear effort in terms of priorities to fourth place behind increased energy efficiency, reduced emphasis on petroleum, and increased use of lignite and coal (Federal Ministry for Research and Technology 1977b, p. 5). This shift in priority may be partly for political reasons in response to growing domestic opposition to nuclear development. Nonetheless, it is clear that a gradual change in attitude away from nuclear energy is beginning to take shape in the FMRT.

The new minister, Volker Hauff, appointed in January 1978, brought to the FMRT a personal history of opposition to the nuclear establishment. Although he has stressed continuity in the FRG energy program, he has systematically raised questions about all aspects of the West German nuciear commitment, including the breeder reactors (Bergdol1 1978, p. 6). The FMRT's traditionally firm commitment to nuclear research and development is now accompanied by shifts that may signal a moderation of that commitment.

The Economics Ministry is also involved in central government policy making affecting nuclear interests in the FRG. The Economics Minisiry has been, and continues to be, highty supportive of the nuclear industry. The former Economics Minister, Hans Friedrichs, emphasized this in his comments in the Mannheim Reactor Congress in 1977, where he stressed the need for the FRG nuclear industry to develop new markets, implying that the United States was inhibiting West German nuclear exports (Nuclear News 1977, p. 56). Economics Ministry support for nuclear development comes from its traditionaliy ciose ties to west German industry. The ministry is concerned about jobs in the nuclear field as well as with guarantees for nuclear exports, guarantees that are a virtual necessity to make foreign sales possible. Moreover, the 
Economic Ministry is closely tied to the utility companies which play a large role in financing nuclear construction in the FRG.

The goals of the FMRT and the Economic Ministry are not always the same where nuclear programs are concerned. FMRT tends to lean toward the basic research aspects that might be incorporated into the nuclear industry, while the Economic Ministry is more intimately concerned with the needs of the utilities.

There are two more federal ministries that play a role in the West German nuclear program: the Interior Ministry and the Foreign Office. The Interior Ministry is involved in the increasingly litigious process of licensing nuclear facilities (along with the state governments). The licensing of new nuclear facilities has been suspended in the FRG until the waste management problem has been solved by the center at Gorleben, which is very much the subject of controversy and is far from completion.

The Foreign Office is involved in questions of nuclear export. Since the matter of nuclear exports rates a high priority in the West German nuclear industry, the say of the Foreign Ministry has from time to time had an impact. The Foreign Ministry has taken a go-slow attitude on nuclear exports, thus coming into conflict with economic interests. Generally its views have not prevailed.

It is clear that the organization of the West German nuclear program at the central government level is divided and sometimes conflicting. This causes grave problems of coordination, particularly when differing interests and personalities are involved in policy making affecting the nuclear program.

The federal aspect of the organization of the FRG involves the states (Laender) which have important administrative and legislative powers. Administratively, they are responsible for the execution of a large share of central government legislation. And, legislatively, they have a say in the formulation of FRG policy through the Bundesrat or upper chamber of the national legislature where the states are represented (Conradt 1978, pp. 135-139).

The West German states play an important role in the licensing of nuclear facilities. Much of the litigation and controversy surrounding the future siting of the disposal facility at Gorleben and the breeder reactor at Kalkar are the responsibility of the siate governments. Since state governments are 
often controlled by parties different from those constituting the central government, there is a great potential for conflict.

The state governments are aiso in a cosition of having to deal with more narrowly focused issues at their level of government. Thus, protests that might be neglected at the central level may loom large in the political calculations of the individual states.

Overall, then, the policy making elements of affecting the FRG nuclear program are disparate and sometimes in conflicting disarray. A major implication of this for the acceptability of an IFSC is that any decision committing the FRG to such an important policy must come from the very top of the governmental hierarchy, at the level of the Chancellor's office. And, in addition, the Chancellor must have broad support from various and varied governmental agencies.

\subsection{The West German Commitment to Nuclear Development. In the} previous section some reference was made to levels of commitment to nuclear development. As a general rule, the leaders of governmental policy making along with the leaders of business and labor interests have been strongly supportive of an active program of nuclear development in the FRG. Although there are indications that shifts in priorities are taking place, the basic commitment of the leadership remains steadfast.

This commitment was dramatically demonstrated in 1977 when the government coalition parties, the Social Democratic Party of Germany (SPD), and Free Democratic Party (FDP) held their annual meetings. Both parties have undergone considerable soul-searching on nuclear issues. In generai, the parliamentary delegations and the party leaderships of the SPD and FDP support a go-ahead policy on nuclear construction while the rank-and-file party members favor a go-slow attitude or even a moratorium on the domestic expansion of nuclear capability.

At an interim convention of the FDP in the summer of 1977 , the rank-andfile overrode the party leadership and endorsed a moratorium of at least three years on the construction of new nuclear facilities. They also supported the suspension of licenses for added facilities until the problem of nuclear wastes has been solved. Last fall the formal party congress revised FDF policy over considerable internal opposition. Essentially the FDP stands for completion of 
nuclear power plants currently under construction. At the same time, the party declaration holds that no new 1 icenses should be issued until waste storage and disposal problems have been handled.

The SPD faced a somewhat different situation. The rank-and-file of the SPD, along with the left wing of the party, were strongly opposed to nuclear development in 1976 and the spring of 1977. During the spring of 1977, the trade unions marshalled their influential forces within the councils of the SPD. The unions argued that a moratorium on nuclear construction would cost at least 170,000 to 200,000 jobs in the nuclear and nuclear-related industries. The nuclear industry and the utilities added their voices to those of the unions prior to the SPD party congress in November 1977.

At the November congress, the SPD leadership prevailed and appeals for an outright moratorium on nuclear construction were rejected. The party stand, as reflected in its policy statement, came out for a stop to approving new reactors until 1981 unless construction of an integrated waste disposal system had been approved or a satisfactory interim waste storage system could be arranged.

The government political parties--with varying enthusiasm--support the continuation of the installation of nuclear plants and the developnent of riuclear technology (Conradt 1978, pp. 135-139).

The West German nuclear industry, represented by the Kraftwerk Union (KWU) has been very active in its own behalf. The argument that the KWU makes is an economic one, defending the large investment in terms of money and national prestige that has gone into the nuclear industry since the mid-1950s. KivU Board Chairman, Klaus Barthelt, has indicated that a backlog of about 40 reactors is needed for the full utilization of KiN productive capacities. At the end of 1977, KWU had a backlog of 25 reactors on its books, a sufficient volume to hold together a team of engineers and highly skilled workers in a total KWU work force of some 14,000 employees (not including those employed in subcontracting companies which account for about $75 \%$ of the total contract for a reactor) (Die Zeit 1977, p. 12).

The KWU is in a holding pattern that cannot continue indefinitely. Aided by the considerable resources of Siemens, KWU's parent concern and the second largest corporazion in the FRG, the bearer of west Germany's nuclear hopes is 
engaging in an increasingly sophisticated campaign of public education and persuasion at home while trying to open foreign markets.

Organized labor has joined industry in defense of the nuclear program of the FRG. The Mining and Energy Union under the leadership of Adolf Schmidt has been particularly concerned about public involvement in opposition to nuclear development. Schmidt and his colleagues feel that the nuclear protest movement threatens the health and even existence of the nuclear industry in the FRG.

The leaders of the labor unions and the governing parties are united in their dread of the combined effects of inflation and unemployment. Deeply ingrained in the political culture of the FRG is an insecurity bred by the collective memory of the 1920s, when inflation and unemployment were instrumental in bringing down the Weimar Republic and clearing a path for the Nazis. By identifying the health of the nuclear industry with the health of the West German polity, labor and industry are hoping to broaden their base of support.

In summary, in spite of some moderating tendencies noted in Section 5.2.4.2.1 the leaders of the governing parties, industry, and organized labor are strongly behind the nuclear development program of the FRG. The idea cf an IFSC may well be attractive to these people if FRG participation meant increased support for the nuclear industry, more jobs, and enhanced political support.

5.2.4.2.3 FRG Attitudes Toward Nuclear Nonproliferation. The SPD-FDP coalition, shortly after coming into power in 1969, indicated its willingness to accept the NPT. This represented a considerable policy change from the previous Grand Coalition government, which had viewed the NPT as too restrictive of West German nuclear interests.

The FRG acceded to the NPT with certain specific expectations. Among these was that worldwide research on the commercial use of peaceful nuclear energy would proceed without restraints, that a high priority be given to general disarmament, that the security of the FRG be guaranteed, and that European integration would not be prejudiced (Wilker 1978, p. 3). The first point was especially important: the West Germans wanted an NPT that would place no inhibitions on the development and growth of the FRG nuclear industry. 
It is one of the ironies of international politics that the FRG deposited its NPT ratification documents two days after having closed its celebrated nuclear deal with Brazil in the spring of 1975. The FRG government saw no contradiction between the NPT and the Brazilian deal, which would transfer enrichment and reprocessing technology to a Third Norld country which was not an NPT signatory, and which was involved in regional power struggles with its neighbors.

As a general matter of perception and policy, the government of the $F R G$ has taken a formalistic approach to the NPT. Thereby, the inconvenient implications of their export policies have been avoided--or at least were avoided until the Ford and, later, the nascent Carter administrations forcefully brought the matter to Chancellor Schmidt's attention by threatening the supply of enriched uranium to the FRG LWR Program--a threat that was more implied than explicit, but nonetheless effective.

The matter of nuclear transfer policies under the NPT and in relation to the United States' objections has not been a part of the "public nuclear debate" in the FRG. Rather, the matter has been generally confined to the highest levels of the government and administration--along with the lobbies of the West German nuclear industry. Indeed, government officials often publish their views in the industry journal atomwirschaft/atomtechnik. The consensus favors the view that NPT concerns are little more than a veiled threat to the competitive capacity of the FRG nuclear industry.

Despite a skeptical view of United States' intentions, the FRG government has shown increased sensitivity toward NPT concerns since United States' criticism of the Brazilian deal began in June 1975. Indeed, official government statements have made much of the support for (narrowly interpreted) NPT regulations, have pointed with pride to the observance of IAEA safeguards in export agreements, have emphasized participation in the Supplier Club and the acceptance of its principles, and have stressed FRG cooperation with the International Fuel Cycle Evaluation.

FRG policy on nonproliferation can be summed up in four points:

1. Each country supplied with nuclear technology must be the subject of a specific program. 
2. The exported program must be in tune with the IPT.

3. Consultations among suppliers must guarantee nondiscrimination in nonproliferation.

4. The effectiveness of nonproliferation policies depends on the number of participating countries (Bulletin des Pressund 1977, p. 331).

A1 though the West German government decided in June 1977 to stop further exports of reprocessing and enrichment technologies, it is keeping its options open in this area. In fact, the June 1977 decision, which came after a similar policy change by the French, is viewed as a gesture toward the Carter administration rather than as a basic shift in policy. This gesture plus the participation in INFCE bought the FRG goverrment time to develop policy options.

FRG nonproliferation policy options are likely to arise from a fundamental disagreement with the United States' approach, which is basically one of denying technology to those who do not possess it. The IFSC concept is entirely consistent with this policy and is bound to be viewed critically by the present West German leadership who take the position that the denial of technology only hastens efforts to acquire the means that lead to the acquisition of weapons materials among presently have-not countries. The West Germans maintain that controls and safeguards cannot function without the consent and cooperation of the recipient nations.

In addition, the West Germans place great emphasis on the role of the IAEA in any safeguards programs. This came out at the INFCE conference in the fall of 1977 and holds as well for regional fuel centers and measures directed toward the physical protection of nuclear materials that might be converted into weapons. This view, including a strong role for the IAEA, was incorporated into the final communique of the INFCE organizing conference (DOE 1977).

In summary, the FRG stand on nonproliferation is one that strongly represents harmonized West German government and industry views regarding what is good for the West German nuclear program. What is good for the FRG nuclear program is what enhances the competitive position of the industry and this competitiveness is, in turn, enhanced by West German ability to export ali aspects of nuclear technology with safeguards that are considered appropriate 
but which fall far short of the controls demanded by the Carter administration. Thus, the FRG might accept the concept of an IFSC provided, that it is under truly international control rather than the ultimate authority of the United States.

\subsection{West German Commitment to the Plutonium Economy. The FRG} government is fully committed to the sodium-cooled fast breeder reactor. The West Germans are actively cooperating with Belgium, France, Italy, and the Netherlands in technical and basic science research and development. Given the logic of the West German stand on nonproliferation, it is doubtful that long-term denial of the export of plutonium-based technology is probable. Sooner or later the reprocessing and use of plutonium, with its proliferation implications, will be part of Europe-based unilateral or multinational export programs.

The time frame for West German breeder development leaves some time for policy adjustments. The demonstration breeder reactor at kalkar is not due on line before 1983 and is the object of considerable controversy. The current minister of the FMRT has stated that no go-ahead decision for the breeder will come prior to 1990, following a thorough national and international discussion about the pros and cons of a plutonium-based nuclear program. Meanwhile the West Germans, French, Belgians, and Dutch have combined in a series of arrangements to move forward with the breeder development. In the summer of 1977 the French Atomic Energy Association (CEA) signed an agreement with Interatom, a Siemens subsidiary, and the GFK, the West German state atomic research company, to spend $\$ 200$ million per year for the next three years on joint development projects. In addition, the French have joined the West Germans, Belgians, and Dutch in a joint breeder marketing company named Serena. Cooperation and commitment have not diminished in the past year (The Economist 1977, p. 116).

The West German government argues that breeder technology is essential given the fact of insecure uranium supplies. Ninety percent of West Germany's enriched uranium comes from the United States and there is little inclination to trade foreign oil dependence for dependence on foreign uranium spplies.

The problem of steeply increasing costs for the breeder is countered by the argument that anticipated efficiences in fuel consumption will make up for the current escalation in investment costs. Also, avoiding any future uranium shortage will be worth the price now being paid. 
Finally, implied in much of the argument between the FRG and the United States over the plutonium economy issue, is the riational pride, not onily of the West Germans, but of Europeans generally. They--the Europeans--tend to see in the Carter policy an abdication of the future unworthy of a Great Power. Thus the idea of European pre-eminence in an important field of technology acts as a spur to urge on the breeder program.

Summarizing, the West German government's continuing commitment to the breeder program within its overall energy policy keeps the FRG on a collision course with the United States. Moreover, the FRG view seems to be gaining the upper hand in the INFCE discussions, which have been seen to be heading toward an endorsement of the view that national breeder programs can proceed and that technological transfers may be made provided safeguards are observed-safeguards that fall far short of what is proposed in the IFSC concept.

5.2.4.2.5 Internal Opposition from Antinuclear Groups. Most of what has gone before has been a discussion of official FRG government policy and the position of various leadership groups in West Germany, particularly industry and labor. Mention was also made of disquiet in the rank-and-file of the governing parties of the FRG and the need for concerted action on the part of the government to assert itself in the fact of vigorous antinuclear opposition in certain sectors of the FRG polity and society.

The rank-and-file opponents to nuclear development within the SPD and FDP reflect the antinuclear movement in the FRG. Public debate over nuclear issues has grown increasingly heated since the fall of 1976 . As the Vietnam issue has faded and as the politicized West German universities have quieted down, the nuclear debate engaging broad segments of the public has warmed up. Large-scale protest movements at the grass roots have turred out tens of thousands of protestors to the sites of nuclear construction such as Brockdorf and the breeder reactor at Kalkar. Public involvement and protest has created political tension between the official establishment and those members of the general public who feel threatened by nuclear development.

Relations between critics of the FRG nuclear program and the government were made difficult by a lack of knowledge on both sides. Critics knew little about what they were criticizing and the government knew 7 ittle about the concerns the critics were trying to articulate as they scught to participate 
in decisions affecting them (Galland 1978). Questions and protests directed at the FMRT were turned aside with a curt "We do not build reactors!" as a response. Incidents of this sort did nothing to ease communication.

Public involvement has many sources and organizations. They range from radical organizations bent on revolutionary upheaval to groups of concerned citizens. The latter category has become increasingly organized. The Confederation of Citizen's Initiatives for the Protection of the Environment (BBU) is the umbrella organization for some 1,000 groups and has been in operation for about four years. The BBU claims to represent about 300,000 members and collected dues and contributions at the rate of DM 200,000 per year. The BBU is a steadily growing organization (Henkel 1977, p. 3). (A counter organization called the European Energy Association with international headquarters in Denmark was just recently organized to support nuclear projects.)

A poll done early in 1977 for the magazine Der Spiegel and based on a national sample showed that the public in the FRG is, in fact, fairly evenly divided on nuclear construction. On the question of whether they were in favor of or opposed to more nuclear plants, in spite of possible dangers, 53\% were in favor of construction while 43\% were opposed. When asked how they would feel about having a plant constructed nearby, 57\% expressed concern, 14\% were favorably inclined, and $28 \%$ did not care. On what people would actually do should a plant be constructed near them, $13 \%$ said they would work for construction, $50 \%$ said they would do nothing, $22 \%$ would sign protest petitions, $12 \%$ would join a citizen's initiative against construction, and $2 \%$ would participate in an occlipation of the construction site (Relay from Bonn 1977, p. 2).

Relative to the previous discussion on nonproliferation and mulitilateral commitment to the breeder reactor, it is of particular interest to note that virtually none of the public debate on nuclear issues involves the exportation of nuclear technology or the international implications of the West German nuclear program. The policy of exportation and possible proliferation has either escaped the attention of the participants in the debate or they simply do not care as long as they do not feel directly involved. In any case, it appears that the "attentive publics" active in the nuclear question in the FRG are not opposed to the exportation of nuclear technology to any significant extent. 
Projecting the nuclear debate to the issue of the acceptability of an IFSC on the part of the FRG as either a host or participant does not produce a clear picture. Some contours do present themselves. If the IFSC were located abroad, public opinion would most likely not be aroused. It would be a matter for another country. FRG responsibilities and ilabilities would be remote and, consequently, of little interest.

Further, it is quite clear that an IFSC on West German soi1, representing a major installation that could be seen, feared, and marched upon, a significant amount of opposition could be expected. The presence of an international installation may well have the effect of directing the antinuclear debate toward the international implications of the West German program, thus escalating this confrontation.

The strength of the West German antinuclear movement is not to be underestimated. It has become sophisticated in its techniques and refined in its use of dissenting scientists, legal lines of attack, and pubiic sentiment.

The total impact of the antinuclear movement has been to cause significant delays in the construction of nuclear facilities and to create massive lega 1 snarls about the complex issues surrounding the siting of nuclear facilities, such as the waste facility at Gorleben. As indicated above, the future of new construction of nuclear reactors depends heavily on solving the waste disposal problem. This was the price that the government leadership paid to get the support of the party dissenters in the SPD and FDP in the fal1 of 1977. The Gorleben facility must be licensed by the State of Lower Saxony. The ministerpresident of Lower Saxony has shown little enthusiasm to rush ahead with the licensing process. Moreover, he is faced with local dissidents who are taking every possible step to block development of the waste storage and reprocessing plant. Its future looks uncertain at this time.

The big question is: Can the antinuclear movement block nuclear development in the FRG? Probably not, although it has imposed significant penalties on the West German nuclear program. It may also cause major delays in the breeder program. To this extent the antinuclear movement aids the policies of the Carter administration and buys time for those who would slow down the spread of the breeder economy. Similariy, it could be argued that domestic nuclear opposition will drive the West German nuciear industry to hurry and expand its export efforts. 
In summary, the West German antinuclear movement is a potent force in West German politics and may well become more powerful with the establishment of the "Green Action Front," an organization calculated to challenge the major parties to attend to environmental and antinuclear concerns. Yet there is too much invested in the nuclear program, too much of a commitment by the government to nuclear development for the anti-front to prevail. Delays may eventually exact unacceptable penalties, but even that is not certain.

With regard to the IFSC, the antinuclear movement will only be a factor if the installation is placed in the FRG. The nuclear debate has yet to go international and an international facility placed in another country may attract little public attention.

\subsection{Sovereignty Issue Affecting West German Participation in an}

IFSC. The Basic Law or constitution of the FRG specifically placed international above domestic law. This provision has made possible the participation of the FRG in international organizations even when that participation has involved a partial loss of national sovereignty. An example of this has been the important role the FRG played in the European Coal and Steel Community and the later European Economic Community.

In formal principle, there would be no specific barrier to West German participation in an IFSC. In terms of practical politics there may be some problems.

One such problem might emerge from the political right in West German politics. Nationalistic groups make much of the self-determination of the German nation. The IFSC would merely be another example of ceding of German authority. To the extent that these groups can assert themselves in FRG government circles, they might be a factor. It is doubtful that they would be a major source of opposition in the FRG.

A more serious concern involves the question of energy independence or, stated otherwise, foreign control over energy sources. In a resource-poor country such as the FRG, governments view it as essential that they have maximum control over energy supplies. Since the IFSC concept involves a decisive measure of outside control, it is unijkely that the present government would care to participate. This is all the more the case in view of the fact that the FRG can move to a breeder economy together with its European allies 
without United States participation. Since the United States would apparently want to control a technology it does not possess, IFSC participation would be absurd.

5.2.4.2.7 Summary and Conclusions. There is a strong top-ievel commitment to nuclear development in the FRG. This commitment includes the principal decision makers in government as well as the leaders of industry and labor. This commitment is solid in spite of what appear to be changing priorities in the ministries related to the political and economic decisions affecting nuciear programs.

The West German commitment to nuclear development includes moving to the breeder reactor and exporting nuclear technology. The breeder option is supported as a means of easing FRG dependence on foreign sources of energy (particularly 0i1). In order for the breeder and the rest of the West German nuclear industry to be economically sound, exports must be relied upon. The export of reprocessing and enrichment technology to Brazil is symptomatic of the need felt for foreign sales to support domestic programs.

Countering leadership cominitment to nuciear development is the strong and growing grass roots opposition to the domestic nuclear program of the FRG. The antinuclear movement in West Germany has gained in momentum and organizational sophistication during the past two years. The antinuclear movement has tended to neglect the international aspects of the nuclear debate relating to weapons proliferation. At this time--and in spite of activities ranging from demonstrations to legal action--the antinuclear movement in the FRG is not yet strong enough to block the West German nuclear program.

The conclusions to be drawn for enhancing the acceptability of an IFSC involving the FRG can be made in five points:

1. The FRG might be included to favor an IFSC if it couid be demonstrated that participation would strengthen and support the West German nuclear industry. That is, if IFSC participation gave the FRG nuclear industry benefits as great or greater than those expected from current export contracts, the probability of participation would be enhanced. 
2. West German participation in an IFSC would be more attractive if that participation would contribute to the leadership image of the FRG in international nuclear affairs. Prestige is an elusive and unquantifiable quality that has played an important role in the controversy surrounding United States' nuclear export policies. If the IFSC were viewed as a means of restoring West German initiative threatened by the Carter policies, the chances for FRG cooperation would be substantially improved.

3. FRG support for the IFSC concept would be improved to the extent that the IFSC is truly multinational in character. There was some sentiment among the FRG leadership that the West Germans were being singled out as "baddies" because of the Brazilian deal. This feeling could be assuaged by truly international cooperation among sovereign equals.

4. West German involvement in an IFSC would be more probable if the IFSC were located in another country than the FRG. Location elsewhere would avoid domestic opposition.

5. Finally, FRG participation would be substantially enhanced if that involvement would assure energy supplies. Greater energy independence is a goal of the FRG government. Whether or not this could be achieved through an IFSC in the case of the FRG has to be assessed against the current state of unease in relations between the United States and West Germany. The United States' leadership position has suffered greatly because of the difficulty the Carter administration has had in adopting an energy program. Moreover, there are lingering bad feelings in the FRG that the Carter nonproliferation policy is aimed at helping the United States' nuclear industry at the expense of West German firms. These considerations, along with the advantage that the West Germans and their European partners enjoy in breeder technology, may make the IFSC superfluous as well as difficult. 


\subsubsection{Brazil}

This case study assesses the willingness of Brazil to host a LatinAmerican IFSC, to participate in an IFSC hosted by Argentina, and to participate in an IFSC hosted by Mexico. Each of these three Brazilian roles could serve the goal of nonproliferation. An IFSC hosted by Brazil would be less vulnerable to conversion for nuclear weapons materials production than a national facility, a proliferation resistant IFSC stili less vulnerable. Moreover, if Argentina participated in such a facility, Argentina would not need to build its own national facility, and would have less reason to fear Brazilian development of nuclear weapons--thus reducing the incentive for Argentina to develop nuclear weapons. Brazilian participation in an IFSC hosted by Argentina or Mexico would further impede the development of nuclear weapons in Brazil by removing commercial reprocessing facilities from Brazilian soil altogether, aithough at the cost of placing such a facility on the soil of Argentina or Mexico.

The governmental process for making decisions concerning the acceptability of Brazilian participation in any of these IFSC options is a relatively closed one. The country is governed by a military regime; in practice, a small circle of officers and technocrats make the important decisions. The military is the single most important group in this process. Many influential officers favor a nuclear weapons option. Second in importance are the technocrats charged with charting Brazil's economic development. These include pianners and economists, as well as the operators of the organizations directly involved in the nuclear area: CNEN, NUCLEBRAS, and ELECTROBRAS. The technocrats are mainty concerned with developing Brazil's place in the sun economically and are thus highly sensitive to Brazilian actions that could offend the allies and investors that are essential to Brazil's economic growth. In addition, some technocrats fear that excessive cooperation with West Germany in nuclear matters could undercut Brazil's nuclear independence.

On balance, these decision-makers seem unlikely to scuttle the GermanBrazilian deal in favor of hosting or participating in an IFSC. A few factors do favor hosting or participating in an IFSC. In terms of econcmics, Brazil's current nuclear program is very ambitious. Current plans call for spending an estimated $\$ 185$ miliion per year by 1985 , $\$ 550$ mi1iion by 1990 , and $\$ 1.25$ bition by 1995. Brazil can certainty amass these sums, but not without severe drains on its resources. 
In military terms, an IFSC might enhance Brazil's security. Brazil's primary military rival is Argentina. At the moment, this threat is latent, and actual military confrontation between Brazil and Argentina appears unlikely. Since both countries have the capability to develop nuclear weapons, but not assured second-strike capabilities, it is probably in the interest of both to reassure each other that neither is building nuclear weapons. Brazil could increase Argentina's confidence in its benign intentions by allowing Argentina to participate in an IFSC on Brazilian soil, or even better from this standpoint, joining with Argentina to participate in an IFSC on neutral ground such as Mexico's. In terms of alliance politics, Brazil has some interest in maintaining (or reacquiring) good relations with the United States, a principal ally and investor. Abandoning its indigenous reprocessing facility in favor of hosting or participating in an IFSC would greatly improve Brazilian-IJnited States relations.

More weighty factors weigh against Brazilian IFSC participation, however. First, the offense to national pride in abandoning the much touted Germansupplied reprocessing facility in favor of nosting an IFSC, or still worse participating in an IFSC abroad, would be overwhelming. Second, Brazil has made a national commitment to develop the full nuclear fuel cycle as a means of attaining energy independence. A Brazilian-hosted IFSC would substantially undercut this goal, participation in a foreign IFSC still more so. Third, although it may actualiy be in Brazil's security interests to cooperate with Argentina, the record of hostility between the two countries, including current rivalry over the River Plate Basin, probably precludes close cooperation between the two nations. This hostility would especially impede Brazil's hosting an IFSC in which Argentina participated, or participating in an IFSC hosted by Argentina. Joint participation in an IFSC hosted by Mexico might be more acceptable. Fourth, at least some segments of Brazil's military do wish to maintain a weapons option. Foreign ministry officials and others have interest in developing PNE's. (Brazil holds the view that the Tlateloco treaty, with which Brazil has pledged to comply, does not apply to PNE's.) Although conversion of a commercial reprocessing facility would probably not be the preferred path should Brazil choose to develop nuclear explosives, this path cannot be ruled out. Moreover, the technology transfer provided by an indigenous 
reprocessing faciitty would be invaluable to the development of a weapons capability. Although an IFSC would provide some technology transfer as weil, an IFSC on Brazilian soil would be politically very difficult to expropriate for weapons purposes, and participation in an IFSC elsewhere would remove this possibility entirely.

Thus, it is not surprising that Brazil has rejected United States' proposals that Brazil invest in a multinational facility in some third country in exchange for cancellation of the enrichment and reprocessing porticns of the German-Brazilian transaction, and has also rejected a proposal by United States Secretary of State Cyrus Vance that the Brazilian reprocessing plant be organized to serve as a regional facility.

The presence of proliferation resistance technology could have some marginal impact on the willingness of Brazil to host or participate in an IFSC. Although it seems plain that Brazil would find hosting an IFSC unacceptable, the presence of proliferation resistance technology would make such a venture even more unacceptable. This result stems mainly from Brazilian conceptions of national pride. Passive proliferation resistance technology would likely seem an unfair burden placed on Brazilian nuclear facilities by the United States. Active use-denial technology would likely seem to intrude severely on Brazilian sovereignty. The presence of proliferation resistance technology might make participation in a foreign IFSC less unacceptabie-especially if the host were Argentina, which Brazil mistrusts.

\subsubsection{Argentina}

This section assesses the willingness of Argentina to host an IFSC (in which Brazil might be one of the participants) or to participate in an IFSC hosted by Brazil or Mexico. The nonproliferation benefits of these options are slightly complicated, depending upon the likelihood that Argentina would otherwise develop indigenous commercial reprocessing facilities and on the likelihood that Argentina would use such reprocessing facilities as a source of plutonium should it decide to develop nuclear weapons. Assuming Argentina is otherwise unlikely to develop indigenous commercial reprocessing facilities, the nonproliferation benefit of an Argentine-hosted IFSC hinges on the villingness of Brazil to participate: if Brazil were wiling to participate, such a 
facility would serve to eliminate the justification for the planned national Brazilian facility. The nonproliferation cost would be placing a reprocessing facility on Argentina's soil, the magnitude of such cost depending upon Argentina's needs for such a facility in the event it decided to develop nuclear weapons. Assuming Argentina would otherwise develop an indigenous reprocessing facility, an additional nonproliferation benefit would be replacing such a facility with an international facility less vulnerable to conversion to weapons purposes. Here the incremental nonproliferation benefit depends on one's assessment of Argentina's need for commercial reprocessing facilities for weapons purposes.

The nonproliferation benefit of Argentine participation in an IFSC located in Brazil or Mexico is threefold: removing the justification for an indigenous reprocessing facility, reassuring Brazil of Argentina's benign intentions (and thus reducing the incentive for Brazil to acquire nuclear weapons), and providing participation needed to establish an IFSC.

The decision process in Argentina that would determine the acceptability of such options is pernaps even more closed than that in Brazil. Argentina is now riled by a military junta that ousted the widow of Juan Perron, who succeeded to power on the death of her husband. Argentina is highly unstable politically, undergoing roughly a half dozen coups d'etat in the past two decades. Despite this political instability, the Argentine nuclear program managed by the Comision de Energia Atomica (CNEA) has maintained a degree of continuity under the guidance of the navy, which has provided the nuclear program some insulation from politics. Both the CNEA and the Foreign Ministry favor nuclear cooperation with Brazil.

Argentina appears more likely than Brazil to finding, hosting, or participating in an IFSC politically acceptable. The reasons are several. First, unlike Brazil, Argentina has not contracted for and thus irrevocably committed itself to a domestically located, nationaliy operated reprocessing facility. Thus, participation in an IFSC would involve less of a concession on the part of Argentina, and not be such a wound to national pride. Second, Argentina is in relatively straightened financial circumstances, with a very high inflation rate, and thus could be attracted to the economic savings generated by IFSC participation. Third, al though Argentina has the most advanced nuclear power 
program in Latin America (based on CANDU technology) and desires a complete fuel cycle for energy independence, Argentina's nuclear pre-eminence and independence goals are in jeopardy. The German-Brazilian deal raises the prospect of Brazil surpassing Argentina in nuclear capability. And although Argentina has a laboratory-scale spent-fuel reprocessing unit, it has been rebuffed in its efforts to obtain a commercial-scale reprocessing facility. (Argentina can probably develop such a facility indigenously, but this route will be timeconsuming and expensive.) At some cost in energy independence, hosting or participating in an IFSC would provide Argentina with access to the back end of the fuel cycle, as well as commercial parity in this area with Brazil. Fourth, Argentina has some interest in assuring Brazil that Argentina is not developing nuclear weapons, and in reassuring itself that Brazil is likewise refraining. Joint participation in an IFSC, whether on Argentine soil, or that of Brazil, or best of all in a neutral country such as Mexico, would serve to provide such reassurances. Fifth, Argentina probably has the capability to develop nuclear weapons overtly or covertly without making use of commercial reprocessing facilities. So, to the extent Argentina has weapons ambitions, it is probably not sacrificing very much by utilizing an IFSC for fuel cycle services. (of course, if this is the case, the utility of Argentine participation in an IFSC in terms of forging Argentine proliferation is somewhat limited.) Sixth, Argentina has actually expressed some interest in joint efforts in the nuclear area. Despite tensions with Brazil, the two have cooperated in the Plate Basin group established in 1969 to promote hydroelectric power in the region. Economic relationships between Argentina and Brazil are growing. Both the CNEA and the Foreign Ministry have specifically called for cooperation in the nuclear field, the CNEA having launched the Reunion de Autoridades Nucleares de America Latina (RANDAL) for nuclear cooperation in Latin America. In January of 1977, at Argentina's initiative, the two countries issued a joint communique stressing nuclear cooperation. All this suggests that Argentina in particular might find cooperation with the Brazilians in an IFSC not un thinkable.

The marginal impact of proliferation resistance technology would depend upon the context. The Argentines might find passive use-denial technology acceptále in an Argentira-hosted IFSC if such technology did not impose 
excessive cost or operating penalites. The Argentinians would likely find active use-denial technology too intrusive. The presence of use-denial technology in a Brazilian-hosted IFSC would probably se attractive to the Argentinians; however, the absence of use-denial technology might actually further encourage the Argentinians to participate. The presence or absence of use-denial technoiogy in a facility hosted in Mexico would probably have little marginal impact on acceptability, unless such technology imposed severe cost or operating penalties, in which case it would have a negative affect on acceptability.

\subsubsection{Mexico}

This section assesses the willingness of Mexico to host an IFSC (with Brazil and/or Argentina as participants) or to participate in an IFSC hosted by Brazil or Argentina. A Mexican-hosted IFSC would contribute to nonproliferation by internationalizing the back end of Brazil's and/or Argentina's fuel cycle, thereby forestailing the opportunity for either country to divert national facilities to nuclear weapons development. Because Mexico appears to have no weapons ambitions, a Mexican-hosted IFSC probably could not be justified on the basis of 'its contribution to preventing Mexico from joining the nuclear club. Therefore, without the participation of Srazil and/or Argentina, the primary nonproliferation rationale for placing an IFSC in Mexico would be to test and legitimize the concept. Similariy, participation by Mexico in an IFSC hosted by Brazil or Argentina would contribute to nonproliferation primarily by providing support for those facilities and thus helping to forestall nuclear weapons development in Argentina and/or Brazil. For like reasons, the primary nonproliferation benefits of utilizing use-denial technology in a Mexican hosted IFSC lies in creating a precedent for the concept and enhancing its legitimacy.

Nominally, the national decision-making process in Mexico is a democratic one, with an elected president and legislature. In practice, howevar, this democracy is of a one-party sort, so that the will of the current political elite generally prevails. (There are exceptions to this rule. In attempting to develop foreign markets for Mexican oil, the current administration has run into great resistance from the Mexican legislature.) Significantly, President Lopez Portillo is a former director of the National Electric Utility (CFE), 
enharcing the likelihood that Mexico's nuclear program will have strong support and attention at the highest levels. Of additional significance is that the organization charged with managing Mexico's nuclear activities, the Instituto Nacional de Energia Nuclear (INEN) is directed by civilians and not greatly bound up with national security activities.

Relative to the other $n^{\text {th }}$ countries studied for this report, Mexico seems more likely than most to be willing to host or participate in an IFSC. This degree of political acceptability stems from a variety of factors. First, an IFSC seems reasonably consistent with Mexican conceptions of sovereignty. Mexico amended its constitution in 1974 to limit the use of nuciear energy to peaceful purposes. Mexico is the only country in the world to request that the IAEA apply safeguards to all Mexican nuclear activities. The presence of an IFSC is not likely to seem greatly more intrusive. In this connection, however, it should be noted that Mexico is highly sensitive to any arrangements that smack of imperialism, especially on the part of the United States. These sensitivities date at least to the experience with America in $0 i 1$ interests in the 1930s, culminating in the Cardenas expropriations of 1938 and Mexico's Declaration of Economic Independence. Therefore, a low profile on the part of the United States would appear to be essential. Second, as already mentioned, Mexico has no ascertainable nuclear weapons ambitions, in spite its status as the only Latin American state besides Brazil and Argentina with a nuclear program having significant military potential in the next several years. Militarily, Mexico has a defensive orientation, no particular security threats, and no aspirations to world power status or regional hegemony. Mexico spearheaded the Treaty of Tlateloco, to which it is a full party. Mexico is also a full party and strong supporter of the Nonproliferation Treaty. Thus, Mexico is sufficiently dedicated to the principle of nonproliferation that hosting or participating in an IFSC would not likely pose unacceptable constraints on Mexico's nuclear program, and would be fully consistent with Mexico's commitment to reduce the prospects for nuclear weapons proliferation elsewnere, as in Brazil and Argentina.

Third, Mexico would have use for a fuel center either on its own soil or elsewhere as a means of handling the back end of its fuel cycle. Although recent discoveries of vast oil reserves may change Mexico's long-term energy 
plans, the current program calls for a capacity of 15,000 WWe in United Statessupplied light water reactors by 1995, and a capacity of 18,000 MWe by 2000 . Although Mexico has adequate domestic uranium supplies, indeed, perhaps a large surplus, the nation has a serious interest in developing a reprocessing facility in order to reduce dependence on foreign fuel sources, especially the United States. A major study is presently under way to determine the feasibility of an industrial-scale reprocessing facility. (A small pilot reprocessing plant is already under construction with IAEA assistance.) An IFSC located in Mexico, or elsewhere in Latin America, could serve the same purposes. Fourth, Mexico's oil wealth makes the country less dependent on foreign energy sources than most other Latin American states, and thus less in need of independent nuclear facilities. Fifth, and most important, Mexican officials have expressed interest in the multinational fuel center concept. Representatives of the Mexican National Electric Commission have proposed creation of multinational nuclear energy companies for peaceful purposes within the framework of the Laitin American economic system (SELA). These proposals have specifically included multinational enrichment facilities and facilities for the back end of the fuel cycle. Other Mexican spokesmen have stated that Mexico should "join with other parties to form a regional [nuclear energy] company in which the large countries in Latin America would seem likely partners" (Redick 1978, p. 188).

The impact of proliferation resistance technology on the willingness of Mexico to participate in such a venture is not clear. However, Mexico is probably at least as likely as any state to find use-denial technology acceptable. As a host, Mexico would probably be willing to accept passive use-denial technology if it did not impose excessive cost or operating penalties. Indeed, such features would be consistent with Mexico's commitment to setting a nonproliferation example. As for hosting an IFSC with active use-denial technology, Mexico just might be willing to go along with this feature--particularly if the $C^{3}$ were controlled by an international body such as the IAEA. As a participant, Mexico would probably not have major objections to either active or passive use-denial technology. 


\subsubsection{Pakistan}

This section assesses the wilingness of Pakistan to host an IFSC with Iran and one other state (such as France) as participants in an IFSC hosted by Iran. A Pakistani-hosted IFSC would serve the goal of nonproliferation by replacing the currently planned French-suppiied reprocessing center with a facility less vulnerable to conversion for weapons production. Pakistan's participation in an IFSC hosted by Iran would further complicate Pakistani proliferation by removing a 11 commercial reprocessing facilities from Pakistan's soil. If Iran were not committed to acquiring a reprocessing facility of its own (and currently it is not), however, this nonproliferation benefit would come at the nonproliferation cost of placing a reprocessing facility on Iranian soil.

Pakistan's decisions are made by the ruling military junta that overthrew President Bhutto in the wake of disturbances following Bhutto's 1977 re-election. Although the regime is dictatorial, it probably cannot afford to severely offend the Pakistani Alliance--i.e., the anti-Bhutto coalition that enabled the regime to take power.

The point of departure for any discussion of the willingness of the Pakistanis to host or participate in an IFSC is the 1976 commitment of France to supply Pakistan with 100 tons per year reprocessing facility. The French agreed to supply the facility before acquiring religion on nonproliferation, and now appear regretful that they do so. (The French have subsequently cancelled their deal with the Pakistanis.) The French have repeatedly and unsuccessfully attempted to persuade Pakistan to abandon plans for the facility or at least to incorporate a new coprocessing design that would make the facility less vulnerable to weapons use. Presently the French have walked off the job-site at Chasma pending resolution of this dispute. Unless the French refuse to complete the facility, the prospects for Pakistan's accepting an IFSC instead are probably nil. There are two basic reasons. First is the issue of sovereignty. Former President Bhutto said while in office that the reprocessing plant is of fundamental importance to Pakistani sovereignty, that the reprocessing issue is a test of national independence. It is true that the current regime was origirially reported to be not so committed to the facility as was Bhutto. Indeed, the regime seems to regret that Bhutto did not accede 
to Secretary of State Kissinger's offer to take 100 A7 figiters instead of the reprocessing plant. Nonetheless, the new government has remained just as adamant on the issue as Bhutto. Second, Pakistan seems committed to the development of a nuclear weapons option. Pakistan faces a precarious and deterioriting regional security situation. The chief threat is India with which it shares a history of hostile relations, including two major wars in the past decade and a half, and to whom $i \dot{i}$ has iost parity in conventional arms not to mention India's demonstrated nuclear capability. In addition, Pakistan faces a threat from the Soviet Union via Afghanistan. In this context, Pakistan's inability to secure international guarantees of aid from other nuclear powers in the event Pakistan is subjected to nuclear blackmail, and its inability to purchase conventional arms, especially from the United States, push Pakistan inexorably toward nuclear weapons. Indeed, following the Indian detonation of 1974, Bhutto said Pakistan will "eat grass, but produce the bomb" (Tahir-kheli 1978, p. 307). Because Pakistan lacks significant uranium deposits, as well as any enrichment or reprocessing capabilities, Pakistan would be hard pressed to develop a nuclear capability without obtaining an indigenous reprocessing facility. Therefore, Pakistan seems likely to cling tenaciously to the French commitment to supply a national reprocessing facility. If the French reneged on their commitment, the Pakistanis might be amenable to accepting an IFSC. However, in this instance, the nonproliferation rationale for encouraging Pakistan's participation would be unclear, inasmuch as a sufficient consensus has probably developed to deprive Pakistan of a reprocessing facility from any other source.

Because the political acceptability of hosting or participating in an IFSC instead of going ahead with the national facility is virtually nil, the marginal impact of proliferation resistance technology on Pakistan's willingness to participate is largely irrelevant.

There are reasons to suppose that Pakistan might abandon its national facility in favor of an IFSC. The government faces severe economic difficulties. Per capita income is declining, Pakistan's trade deficit is high, and its external debt is rising. Indeed some have said Pakistan is almost "bankrupt." Moreover, Pakistan's need for reprocessing facilities for commercial purposes is not great. Pakistan's integrated plan for acquiring 24 reactors of 600 megawatts each by the year 2000 would not support an economic reprocessing 
facility. Given Pakistan's financially strained circumstances, the leadership may well decide to utilize cheaper and available hydroelectric power for its energy needs. Finally, Pakistan is in desperate need of good relations with the United States. Pakistan considers CENTO the key to its defense, and the military leadership would be greatly bolstered by additional United States' conventional arms. Pakistan is now quite susceptible to financial pressure, which the United States has been exerting by cutting military aid, slashing economic aid, and encouraging others to do likewise. Replacing the national French facility with an IFSC could ameliorate all these problems. However, that course seems unlikely.

\subsubsection{Iran}

This section assesses the willingness of Iran to host an IFSC with the participation of Pakistan and some other countries such as France and to participate in an IFSC hosted by Pakistan. The primary nonproliferation goal to be served by an Iranian-hosted IFSC would be as a means of thwarting a national reprocessing facility in Pakistan. Because this option would have a nonproliferation cost--namely, placing reprocessing facilities on Iranian soil--it is perhaps not worthwhile unless it becomes apparent that Iran wolid also otherwise acquire indigenous reprocessing capabilities. The nonproliferation benefit from Iranian participation in an IFSC elsewhere would be to forestall Iranian demands for an indigenous facility. If the host were Pakistan, Iranian participation would serve the goal of nonproliferation by providing support for such a facility.

The decision process in Iran is not difficult to specify. Basically it consists of the Shah. Indeed, at least one observer has identified Iran as the one state in the world that corresponds to the "unitary national actor" model of political decision making. Apparently, both in the military sphere and in the nuclear energy sphere, what the Shah says goes.

Currently, Iran appears moderately amenable to hosting or participating in an IFSC. Iran presently has a very ambitious plan for developing 70,000 megawatts of installed generating capacity by 1994, 23,000 megawatts of this capacity to be supplied by nuclear energy in the form of light water reactors. This goal is all the more remarkable given shat total present eiect:ic power 
consumption is about 14,000 megawatts. Iran plans to obtain enriched uranium from Eurodif and Coredif participation. (Iran ras no known indigenous supplies of uranium.) Iran has some interest in obtaining reprocessing facilities, but it has made no actual request and knows the current views of suppliers. Although a case for reprocessing cannot be easily made in the foreseeable future, Iran will have obvious needs for back-end fuel cycle services over the next several decades, which needs could be fulfilled by hosting or participating in an IFSC. In addition, Iran could replace some of its planned national nuclear power plants with the power output of an Iran-hosted IFSC and thereby sidestep some technical barriers to developing so much capacity on a turnkey basis. Presently, Iran appears not to have nuclear weapons ambitions. It is meeting its principal security threats--the Soviet Union to the north, Iraq to the west, and internal guerilla threats--by acquiring substantial conventional military capabilities. Indeed, Iran is presently the dominant military power in the Persian Gulf. Nuclear weapons seem more likely to decrease than increase Iran's security. Iran is a party to the Nonproliferation Treaty, and has proposed a nuclear-free zone for the Persian Gulf, and supports Pakistan's proposed nuclear-free zone for South Asia. Thus, when after the Indian nuclear explosion, the Shah was quoted as saying Iran might soon follow suit, the denial that immediately followed seems reasonably convincing. A desire to acquire nuciear weapons would appear not to stand in the way of Iranian participation in an IFSC. In addition, Iran seems amenable to participation in multinational nuclear ventures in principle. As previously mentioned, Iran is a partner with France, Italy, Spain, and Belgium in Eurodif. Although his enthusiasm has recently cooled somewhat, the Shah agreed during Secretary of State Kissinger's August 1976 visit that if reprocessing were necessary in the region, it would be done on a multinational basis. In terms of cooperation with Pakistan in particular, Iran's special relationship with Pakistan appears to ensure that such cooperation would be acceptable.

Proliferation resistance technology could have some affect on acceptability. The effect of passive use-denial technology, in an IFSC either hosted by Iran or participated in by Iran, is likely to hinge on cost and operating penalties: the Shah is relatively hard-headed on these matters. Given Iran's historic 
mistrust of foreigners, active use-denial technology which excludes Iran from participation in the $\mathrm{C}^{3}$ is unlikely to be acceptable for an IFSC hosted by Iran.

\subsubsection{Japan}

This section assesses the willingness of Japan to host an IFSC with participation by the Republic of Korea and/or the Republic of China. Because Japan lacks weapons ambitions, and because Japan could more conveniently develop nuclear weapons by other means than through commercial fuel cycle facilities, the nonproliferation benefits of an IFSC hosted by Japan derive from thwarting domestic reprocessing capabilities in the Republic of Korea and the Republic of China. Similarly, the nonproliferation rationale for including use-denial technology in such a center hinges principally on establishing the feasibility and legitmacy of technology, rather than on denying Japan access to weapons materials.

The decision process in Japan depends perhaps as much on matters of culture as it does on the formal structure of government. Formally, Japan is ruled by a prime minister and cabinet and bicameral legislature, the Diet. Since the inception of Japan's current form of government following World War II, the ruling party has been the relatively conservative Liberal Democratic Party. However, the LDP is increasingly under challenge by the nationalist Komeito party, as well as the communists and other leitist groups. The LDP itself is hardly monolithic, and consists of a variety of shifting factions. The executive deparments have strong and continuing relations with Japanese business and other technocractic interests. Consensus is a key cultural concept running through Japanese society and government. As a consequence, policy shifts are slow and deliberate. The formal authority of the Prime Minister and the will of the majority of the legislature are necessary but not sufficient conditions for governmental decisions and actions.

The willingness of Japan to host an IFSC is difficult to predict. There are factors both for and against participation. Several strong considerations would appear to militate in favor of participation. First, uapan has a need for services relating to the back end of the nuclear $f: \equiv 1$ cycle. Japan has 
taken a strong position in favor of nuclear power and the breeder. This position stems from Japan's high dependence on foreign energy supplies, including both oil and uranium. Prime Minister Fukuda has called atomic power "the only feasible alternative [energy] source." International Trade and Industry Vice-Minister Toshinobu Wada has said reprocessing is a "matter of Japan's very economic survival" (Dixon 1978, p. 341).

Currently, Japan has two basic options for these services. First, Japan may develop its own indigenous reprocessing facility. It already has a pilot version of such a facility in the 220-ton per-year unit at Tokaimura. This plant went operational in September 1977. Under United States' pressure, the Japanese reluctantly agreed to relegate this facility to experimental status for two years. The plant will be used as a test bed for coprocessing and other advanced reprocessing techniques. The plutonium nitrate produced will be stored rather than converted to plutonium oxide. Following the two-year period, the Japanese could convert Tokaimura to commercial reprocessing (on a small scale) by adding the additional oxide conversion step, or they could develop an additional and larger plant. The Japanese also have obtained contracts with the French Cogema reprocessing operation and with British Nuclear Fuels Limited (BNFL) to transport and reprocess spent fuel from Japanese reactors, presumably pending development of indigenous Japanese facilities, or possibly in place of them. However, the United States may stand in the way of these plans. Under the Nuclear Nonproliferation Act of 1978, the United States has the right to disapprove the retransfers to Cogema and BNFL, and to disapprove of indigenous reprocessing as well--inasmuch as the uranium involved originally comes from the United States. The United States has not presently committed itself to such approvals and has said it will consider requests for retransfer on a case-by-case basis. Thus, the United States is in a relatively good position to insist that Japan host an IFSC to handle its own spent fuel and that of other nations.

Second, Japan has a relatively strong commitment to nonproliferation. Its "nuclear allergy" is well known, and Japan has signed and (belatedly) ratified the NPT. Moreover, Japan's atomic energy basic law prohibits nuclear weapons according to three non-nuclear principies, frequently reiterated by Japanese officials: 1) not to acquire nuciear weapons, 2j not to manufacture 
nuclear weapons, and 3) not to allow foreign powers to introduce nuciear weapons into Japan. Japanese pubitic opinion is also strongiy opposed to the acquisition of nuclear weapons. Hosting an IFSC could underscore japanese commitment to nonproliferation by helping to thwart paths to proliferation in the Republic of Korea and the Republic of China. Third, Japan is highly dependent on maintaining good relations with the United States. If the United States strongly stressed the importance of Japan's hosting an IFSC, this insistence would strongly favor participation, unless the insistence were poorly managed.

There are, however, considerations cutting against Japan's hosting an IFSC. First, Japan is highly sensitive about its sovereignty. Insistence that Japan involve other nations in the reprocessing of its nuclear fuel on lapanese soil could offend that sensitivity. Second, there is strong public concern with environmental and safety issues arising out of nuclear power, especially involving the back end of the nuclear fuel cycle. Therefore, strong public pressures for Japan to export its spent fuel for reprocessing elsewhere may be expected. Not only would an IFSC require Japan to retain its spent fuel, the concept would require that the Japanese accept spent fuel from others. It could therefore be expected to attract public opposition. Third, there is the problem of the specific partners envisioned. Although the Japarese might be willing and able to participate in an IFSC with the Republic of Koreans as a means of thwarting reprocessing by the Republic of Koreans, Japan's relationsilip with the Peoples Republic of China precludes partnership with the Republic of China in such a venture.

In light of the rough balance between factors for and against participation, Japan's ultimate willingness to go along with an IFSC is likely to depend on the skill of the United States in advancing the concept and on the skill of the Japanese administration in securing a consensus in favor of participátion.

Passive and active use-denial technology would likely have differing effects on acceptability. Because the Japanese are aiready experimenting with a passive use-denial technique--coprocessing--in the Tokaimura faci i ity, Japan appears a relatively good candicate for incorporation of passive use-denial technology. On the other hand, Japan's extrene sersitivity to intrusions on 
its sovereignty makes Japan quite unlikely to accept active use-denial technology, especially if Japan is excluded from $c^{3}$ participation.

\subsubsection{Republic of China}

This section examines the willingness of the Republic of China to participate in an IFSC hosted by Japan. The nonproliferation rationale is to eliminate the justification for commercial reprocessing facilities on the Republic of China.

The Republic of China is ruled through a president who governs through a premier and cabinet. The Republic of China has a representative body called the Legislative Yuan, some of whose members are elected and some of whose members hold office for life. Either the premier or the president can exercise effective power depending on the political and military following of the particular individuals involved, although not without some attentiveness to public opinion.

The prospects for Republic of China participation in a Japanese-hosted IFSC appear reasonably favorable, at least from the Republic of China point of view. Participation would appear to fit in well with the Republic of China energy program. The Republic of China, the most prosperous nation in Asia outside Japan, will have six light water reactors on line by the mid-1980s. All will be United States supplied (by Generai Electric and Westinghouse). The fuel is to be supplied by the United States as well, and a 11 reactors subject to IAEA safeguards. Thus, the Republic of China will be generating a significant quantity of spent fuel, but not enough to justify an economically viable indigenous reprocessing facility. The Republic of China once had a laboratory scale reprocessing facility under construction, but, under pressure from the United States, disassembled it and stated that the Republic of China does not plan commercial reprocessing of its spent fuel. Thus, the Republic of China will need to dispose of its spent fuel in some fashion, and an IFSC located elsewhere could appear an attractive option. The Republic of China is tied to the United States for military support, and is therefore highly sensitive to taking actions that could disrupt good alliance relations with the United States. Therefore, American insistence that the Repubiic of China participate in an IFSC and refrain from incigenous reprocessing is ijkely to 
carry great weight. Cutting against participation in an IFSC (and in favor of developing an indigenous reprocessing capability) is the possible incination of the Republic of China to develop nuclear weapons. The Republic of China is a party to the NPT. And as recently as 1976 in a note to the United States, the Republic of China has stated that "the government of the Republic of China has no intention whatsoever to cevelop nuclear weapons or a nuclear explosive device ..." (Chinese Government Information Office 1976). However, the military balance vis-a-vis the Peoples Republic of China is shifting. The Republic of China is increasingly isolated internationally, and its long-term security prospects are open to question. Therefore, the Republic of China may desire to obtain a nuclear weapons capability sometime in the future. However, since the Repubiic of China possesses all the basic technology for nuclear weapons development, including the technology for plutonium reprocessing, having a commercial reprocessing facility does not greatly enhance the Republic of China's ability to develop nuclear weapons.

The marginal impact of proliferation resistance technology on the Republic of China's willingness to participate in an IFSC hosted by Japan is likely to be confined to the cost and operating penalties thereby imposed.

\subsubsection{Republic of Korea}

This section assesses the willingness of the Republic of Korea to participate in an IFSC hosted by Japan. The nonproliferation rationale is the same as that for attempting to secure Republic of China participation in an IFSC, except that the nonproliferation dividends would be higher, inasmuch as the Republic of Korea would have greater difficulty developing an indigenous plutonium reprocessing capability than would the Republic of China.

The Republic of Korea is governed by an elected president who rules through a premier and cabinet with the assent of a national assembly, most but not all of whose members are associated with the President's Democratic Republic Party. In practice, any policy adopted by the President will gerieraliy be implemented by the buraucracy and military, which respond readily to the President's wishes.

The Republic of Korea appears likely to be willing to participate in an IFSC hosted by Japar. :t could use the services provided. The Republic of Korea's long-range plans call for nine power reactors totalling 6,000 megawatts 
by 1986, and 25 reactors by 2000. Like the Republic of China, it will have need for services relating to the back end of the fuel cycle, but will lack the spent fuel production capacity that would justify an economically optimal reprocessing facility. The principal reason that the Republic of Korea might resist participation in an IFSC is that this course would eliminate the justification for an indigenous commercial reprocessing facility. Such a facility could prove useful to the Republic of Korea in developing a nuclear weapons option. Although the Republic of Korea has signed the Nonproliferation Treaty, it faces a very difficult security situation arising from the problem of the two Koreas. The Republic of Korea must constantly fear a Chinese or Sovietbacked invasion by North Korea. Republic of Koreans widely assume that planned withdrawal of United States' ground forces will result in precisely such an invasion. Nuclear weapons might provide a last-ditch means of fending off such an invasion in the absence of credible United States' security guarantees. An indigenous reprocessing capability could make a substantial contribution to such an option because the Republic of Korea would require 5 to 10 years to develop nuclear weapons if forced to develop plutonium reprocessing facilities from scratch. Moreover, it would be difficult for the Republic of Korea to initiate a clandestine weapons program given its dependence on foreign equipment and material supplies, and with the presence of United States' military forces likely to detect any such activity. (On the other hand, United States presence would also make it reasonably easy for the United States to prevent Republic of Korea conversion of a commercial facility to weapons uses.) For the foreseeable future, however, the Republic of Korea's heavy dependence on good relations with the United States is likely to mean that if the United States does not want the Republic of Korea to develop an indigenous reprocessing capability, the Republic of Korea will refrain. The ability of the United States to force the Republic of Korea inco cancelling its order for a pilot reprocessing facility from the French underscores the point. The prospect of participation in a Japanese IFSC would likely make this job even easier. Finally, the Republic of Korea has close trade relations with Japan, which would make participation in a japanese-hosted IFSC a natural extension of current practices. 
The presence or absence of proliferation resistant technology in such a facility is Tikely to have little impact on the acceptability of participation to Republic of Koreans. Even cost or operating penalties would likely have small effect, especially if the United States subsidized the effort. 



\subsection{ISSUES OF ORGANIZATION, MANAGEMENT, AND OPERATION}

If a number of countries agree in principle to establish an IFSC with a variety of proliferation resistance features, many organizational, managerial, and operational issues must be resclved. Among the most critical problems for evaluation are those which relate to the effective operation of the proliferation resistance features of the faciitities.

\subsubsection{Political and Institutional Issues Involved in Passive Use-Denial Systems}

The major issue in passive use-denial appears to be initiation of the passive system, particularly the acceptance of the specific conditions imposed by the system on IFSC partners and hosts. There are, however, a number of serious issues involved in the passive use-denial case: environmental and safety concerns, the impact of passive system design on IFSC cost and profitability, and the host's view of its acceptability.

Passive design impact on environmental and safety questions will be of paramount concern to the host nation. Without a detailed reference design, it is impossible to specify environmental and safety considerations. However, it is apparent that the host nation will be very concerned about the potontial impact of passive use-denial systems on both worker safety and the local environment.

The economic impact of utilizing passive use-denial designs will be important to both the host nation and other partners in the enterprise. As previously stated, there may be unusual economic burdens in construction, personnel, and operating costs.

A further economic impact which may characterize passive use-denial designs is a penalty in operating efficiency which may negatively affect the center output. It is not yet ciear how much the passive system might reduce efficiency, economics of scale, flexibility of operation, and other factors influencing the financial performance of the IFSC. If economic considerations in the use of passive designs are less favorable than hoped, it could mean reluctance on the part of many potential investors to become involved in an IFSC.

Convincing potential host nations and potantia? IFSC partiners that passive designs do not impose major economic penalties requires a denonstration 
project. Partners in IFSC ventures will likely demand proven technology in the center. The present ambiguity of fuei reprocessing economics is sufficient to cause potential investors to doubt the wisdom of investing in unproven plant designs. There seems to be less doubt about the ultimate value of reprocessing, either for extending the life of the LWR fuel cycle or moving to a breeder based energy source. However, in the near term (10 to 15 years), the efficiency of reprocessing operations will be evaluated against the cost of competing fuels. Through such comparisons, excessive reprocessing costs can become a source of major concern.

Another consideration is the degree to which the host nation perceives passive use-denial as an intrusion on national prerogatives. If standard passive use-denial technology is applied in all IFSC's, the host is less likely to regard it as an intrusion or affront. If, however, the application of these designs is not uniform, or United States' policy implies a need for selective use, severe resistance to its implementation may resuit.

In summary, the major issues likely to arise in connection with passive use-denial technology are: the cost impact on the IFSC's, the host nation's assessment of the system, and the impact on environmental and safety considerations.

\subsubsection{Political and Institutional Issues in Active Use-Denial Acceptability Issues}

As has been discussed above, placing active use-denial technology in an IFSC will be quite controversial. The first installation of active use-denial systems on a real IFSC is likely to engender a substantial amount of disagreement and bargaining. Issues regarding the political acceptability of various aspects of proliferation resistance technology are most applicable to the acceptability of active use-denial systems. The host nation's control over facilities located within its border are effectively removed through the presence of an on-site command, control, and communication $\left(\mathrm{C}^{3}\right)$ system which is designed to use-deny the center if the host nation or other force attempts to take control of the IFSC.

The $\mathrm{C}^{3}$ system forms the central core of the active use-denial technology. Conceptual studies envision an on-site $C^{3}$ center which monitors all operation and inspection functions under normal conditions. An off-site $c^{3}$ center, 
perhaps in another country, would take control of use-denial actions if the center were threatened by a host nation take-over. It is likely that only the off-site $\mathrm{C}^{3}$ center will be able to invoke the most extreme use-denial actions (those which destroy equipment or otherwise render process equipment inoperable).

The effectiveness of the $c^{3}$ system in achieving the desired degree of proliferation resistance will largely depend on two factors. These are careful institutional design and sensitivity to the weaknesses inherent in the concept of the $\mathrm{C}^{3}$ system.

\subsubsection{Institutional Design for the Exercise of $C^{3}$ Functions}

The most extreme threat which the $c^{3}$ system must be designed to meet is that of host nation take-over. The assumption is that the most extreme threat which the $\mathrm{C}^{3}$ system must be able to meet is a coordinated covert and overt take-over attempt initiated by the host country or by a parallel force within the host country. In this threat scenario, the families of the $c^{3}$ operators are taken hostage along with other multinationals on the site. In contemplating the institutional design of a $c^{3}$ capable of meeting this threat, several fairly difficult political problems become apparent.

The first of these problems concerns the role of host nationals in $\mathrm{c}^{3}$ cperations. Given the level of risk which they might pose if a coordinated take-over were initiated, it is important that host nationals not be placed in a position where they couid frustrate the operation of $c^{3}$ functions during a crisis. The host must instead accept a $c^{3}$ system run by foreigners and operating within their borders. However, as noted earlier, this is generaliy unacceptable to the eight key nations we have studied in this assessment.

A second major institutional problem in active use-denial is that IFSC partners must reach detailed agreements on responses to all predictable nonstandard situations, particularly crises. Virtualiy automatic responses to various threat levels must be detailed well in advance of implementation. Reaching these agreements will not be easy since the partners are iike nave divergent opinions on proper responses to given situations. Also, the differences in partners' responses in the event hostages are taken are like?y to be sizable. Nonetheless, it appears absolutely necessary that the partners agnee in detail on how resporises are to be made in crisis cituations. This 
should prevent the $C^{3}$ functions from being sutverted by indecision or arguments among partners over strategy in the event of a crisis.

There are also likely to be serious issues raised by the problem of hostage-taking. No matter where the families of the $c^{3}$ operators and the consortium executive reside, it should be stressed that they will be vuinerable to kidnapping either by host nation adversaries or by agents of a parallel force, or by revolutionary forces. Innocent parties are also likely hostage targets by terrorists, political extremists, or agents of a host nation-led conspiracy. Preparations must be made for the possible event of a take-over attempt. These preparations should include attempts to physicaliy isolate $\mathrm{C}^{3}$ operators from hostage threats and agreement among partners to take certain action during crisis situations.

As in the case of the passive use-denial designs, the active systems will give rise to environmental and safety concerns both to the host nation and to the partners. The potential impact of active use-denial procedures on the plant environment is likely to be perceived as extreme if demonstration facility tests are not provided beforehand.

Similarly, the IFSC partners will be concerned about the potential impact of active systems on the operational economics of the center. A demonstration project might provide operating data on how such devices might slow or interrupt processing operations. In the absence of such a project, it remains to be seen how potential investors and partners will respond to the presence of technology which, at worst, could seriously damage the center or, at least, frustrate the efficient operation of the center.

As presently envisioned, the $\mathrm{C}^{3}$ system which monitors and controls routine operations will be physically located on the IFSC site. To be insulated from the maximum threat conditions, there would also be a duplicate $C^{3}$ command post off the IFSC site, probabiy in another country. This $c^{3}$ command center would have override authority over the on-site $\mathrm{C}^{3}$ post, and would be where control over active use-denial devices would be transferred if a serious threat to the IFSC developed. 


\subsubsection{Extreme Case--Host Nation Take-Over with Multinational Hostages}

If the active use-denial devices are to be considered adequate, they must be designed to meet the most extreme threat which might be mounted against: an IFSC. That threat could be a highiy-coordinated overt and covert take-over attempt by the host nation. Agents inside the IFSC would move to neutralize the on-site $\mathrm{C}^{3}$ operator, while forces outside the facility would take hostages and move to take over the IFSC physical plant.

The IFSC would be built with devices for destroying key points in the processes incorporated in the basic design. It is therefore possible that the $C^{3}$ use-denial system might be used as a mechanism for sabotaging the IFSC. A series of hostile actions might be initiated against the facility which would result in use-denial actions being taken. Such actions could effectively cripple the IFSC for a long period of time, and result in huge monetary losses for the partners.

A kidnapping of $C^{3}$ personnel and families before active use-denial actions could be initiated within the $C^{3}$ system (on-site or off-site) could, in theory, circumvent many of the defenses presented by that system. This scenario is plausible if, for example, the $C^{3}$ watch commander's family were taken hostage prior to any overt moves against the facility: the $c^{3}$ watch commander, informed privately that his family is in custody, can insure their safety by "ignoring" some danger signals which might otherwise arm some usedenial systems in the plant. The adversaries then isolate a significant amount of fissionable material in one process operation for availability when the overt take-over begins. This action paves the way for the aggressor to accomplish the principal objective, even if all use-denial actions are invoked.

One problem which must be worked out in great detail is that of reducing the number of ways in which the $c^{3}$ system could be effectively circumvented, or neutralized, by taking hostages. Generally, as long as any fail-safe systems or use-denial controls can be overriden by a $c^{3}$ operator's command, the entire $c^{3}$ could be circumvented by taking hostages. There are ways of reducing the pressures generated by kidnapping; there is almost no way to eliminate them.

Some measure of protection against the occurrence of a hostage scenaric can be gained hy building "inevitable" responses into proliferation resistance technologies. In these cases, automatic time clocks would be put on some 
use-denial nodes. This would make it impossible to disarm various use-denial devices once they had been armed for a period of time, perhaps as long as three weeks. All use-denial devices would only be activated by an intruder tampering with the specific node. The presence of these time clock devices might insulate individuals in the $c^{3}$ control center from the full pressure posed in the event hostages were taken. The operators would not have the discretionary power of disarming the system. Building self-destruct devices into a plant which is under control of a $\mathrm{C}^{3}$ operator is a two-edged sword. If the adversaries' objective is to close down the facility rather than take it over, they might take hostages to coerce the $\mathrm{C}^{3}$ operators into activating use-denial systems. It is also possible that hostages could be taken solely for the purpose of forcing plant shutdown.

Clearly, there is a need to analyze the ways in which an aggressor might cover or use $C^{3}$ operations to circumvent the security an active use-denial system would provide. There is also a need for the major partners in the multinational enterprise to be committed to courses of action, and to prearrange the responses they will make to predefined and developing threats. For example, the partners need to determine what course of action will be taken in such a way that they can respond expeditiously to rapidly emerging and developing threats. These include a host nation take-over due to a change in its government or a problem arising out of internal revolutionary activity.

\subsubsection{Issues of Management Control and Organization}

Although the central concern of this analysis is with proliferation resistance features of fuel centers, if an IFSC is to be established, there are iikely to be many issues which arise concerning the relationship between management of proliferation operations and the purely business operations of the center.

One of the major areas where some tension is likely to occur is in establishing the control priorities between business and security operations. Those analysts and politicians concerned with proliferation control will tend to place security concerns above business priorities. In principle, no one is likely to argue with such an arrangement. In practice, reasonable people are likely to disagree about the need for such prioritizing if the host country was 
considered "safe" enough to permit safe estabiishment of the IFSC in the first place; and perhaps the reed to adhere to extreme security precautions when no tangible or manifest threat exists.

A major issue which is likely to attend the establishment of an IFSC is the form of its incorporation. Clearly the initial decision to establish an IFSC with proliferation resistant features will represent the decisions of heads of state. However, the actual operational form of the IFSC may be quite different. The United States has exhibited a clear preference for governmentrun operations, incorporated through governments and financed and supported through governments. The Germans and the French have expressed strong sentiments in favor of private operation with government backing. The articles of incorporation are especially important for the way they will lay down the basic decision-making structure for both business operation and management of the center, and the exercise of the proliferation resistance technology.

Along with incorporation, the ownership of the IFSC must be considered. There is a range of possibilities beginning with purely private ownership, a private contractor running a government-owned facility, public ownership (ownership by owner governments), and finally ownership by the IAEA. Each of these forms of ownership would involve the actions of one partner, nor will the malfunctioning of the center cause them serious difficulty.

Establishing an IFSC for the first time is likely to raise significant issues regarding what will be done with existing nationally-owned fue? cycle facilities. Secondly, the question is likely to be raised as to whether the proliferation resistant design of the first IFSC is to be used in all further installations or only in some. Related to this is the question of wnat should be done with existing national facilities as far as retrofitting them with proliferation resistance features.

There appear to be no ready answers to this other than to suggest that if an IFSC with proliferation resistance features is proposed it will be more Generally acceptable to participants and to host nations if it is offered as a standardized design which is to be utilized in all applications rather than in just selected ones. The principle of fairness is central to this notion. It is unlikely that a proliferation resistance design would be acceptabie if it were only used in those countries deemed irresponsible or high risk areas. 


\subsection{MULTINATIONAL PRESENCE IS A FACTOR IV RETARDING OR ENHANCING THE PROLIFERATION RESISTANCE OF AN IFSC}

Multinational presence probably increases the proliferation resistance of an IFSC. This increment would be greater than proliferation resistance afforded to facilities owned by one country. The amount of increase is lncertain and will depend on the host country and the specific arrangements made regarding the role of multinationals in inspecting or operating the facility. It should also be noted that there are problems created by a multinational presence which may reduce the general proliferation resistance of a fuel service center. This section will briefly examine multinational presence as a factor in both retarding and enhancing the proliferation resistance of an IFSC.

\subsubsection{Multinational Factors Tending to Reduce the Overall Proliferation Resistance of IFSC's}

There are four major factors which would act to reduce the overail level of proliferation resistance of a multinational IFSC. They are:

- language problems

- ethnicity problems

- personnel recruitment of foreigners

- personnel recruitment of the host nationals

- technology transfer to host nationals.

ilost of these factors occur at the working level. They are manifested as problems which arise or are likely to arise in the daily operations of the facility. United States' personnel are likely to encounter greater difficulty in carrying out supervisory and inspection duties which require them to use a working language other than English. Presumabiy, the bulk of the IFSC work force will speak the language of the host country.

The language problem tends to reduce the general level of proliferation resistance in that it becomes much more difficult for the inspectors and supervisors to detect plots developing within the plant, to communicate effectively with host-nation personnel, and to interpret ambiguous situations which may emerje during crises. 
It is highly unlikely that a condition of employment in the work force of the plant will be to iearn a foreign language. Thus, the adminstrative and supervisory personnel must be able to communicate in the host's native language. If this language is French, Spanish, German, or possibiy Portuguese, any learning difficulty United States' personnel are likely to have would appear to be surmountable. However, if the working language is a non-European language, such as Arabic, Japanese, or Turkish, it is likely that United States' personnel attempting to gain a degree of proficiency necessary for supervision and inspection will experience great difficulty. It is unclear to what degree language will present a problem to other IFSC partners, since many nations outside of the United States have a more deeply ingrained tradition of learning foreign languages. It may be anticipated that Europeans will also have difficulty with the Oriental and Middle Eastern languages, but perhaps not as much as Americans.

Ethnicity problems which may prevail in the host country have substantial potential for creating volatile situations among the host country's work force. Religious, racial, and subnational political conflicts which occur in the host country may well be carried over to the IFSC. Characteristically, hostile relations which would possibly have a profound effect on the overall security of an IFSC would be: the England-Northern Ireland disputes; the growing tensions between Conversative Moslems and those committed to more modern ways; the separatist movements in Spain, Canada, or France; and racial tensions between blacks and whites.

Ethnic conflicts can have an impact on the general level of security in an IFSC by affecting the relationships which the work force and the security force have with each other. Conflicts in the work force could lead to poor quality control, sabotage of plant facilities, conflict between workers and supervisors, and creation of a siege mentality among the foreign nationals working in the plant. It is also conceivable that some of the more fanatic actors in ethnic conflicts might choose to use the active use-denial features to harm their opponents (e.g., purposely arm a penalty node, then entice IFSC staff to unknowingly activate it). Fanatics might also attempt to divert nuclear material (either for weapons or for contamination purposes) for use against their enemies. 
The array of possibilities for severe ethnic and religious conflict is quite broad. The extent to which such factors might actualiy weaken the proi iferation resistance of an IFSC will depend on its location. Suffice to say that such conflicts have the potential for undermining the security of an IFSC.

Another working-level prodlem which would tend to reduce the general level of proliferation resistance concerns personnei recruitment by the IFSC's foreign partners. It may prove to be quite difficult for the foreign partners to continualiy recruit a highly-qualified staff if the center is located in remote or undesirable country. This is particularly true if the IFSC is competing with domestic industry and business for highly-qualified technical personnel. It also appears likely that a staff member who puts in two to three years or more in an IFSC as an inspector/supervisor with extensive language skills, may be recruited away by private companies because of these valuable skills.

The stationing, particularly of Americans and Europeans, in remote, isolated, or inhospitable national settings is an insurmountable problem. Frequently pay and compensation can be attractive enough to bring people to work in isolated and even hazardous conditions. The experiences of manning oilwell drilling and pipeline construction operations in Alaska and the Middle East might be taken as relevant examples. However, it should be recalled that these examples do not equate fully with the IFSC since the Americans and Europeans who have manned these operations have existed essentially in smail national colonies and have not been required to routinely interact with hostnation personnel as part of their jobs. Thus, the language and cultural interface has not been particularly critical in some of these other situations. Also, the level of performance required on some of these jobs has been very low compared to that needed in an IFSC.

The fact that host-nation personnel will constitute roughly $80 \%$ of the total work force at the IFSC again may present a sizable problem the further it is from countries with a tradition of industrial work. Again, problems are likely to arise in the quality of the work force. In nonindustrial cultures, a recurring problem is that work forces do not readily respond to the United States' types of incentives for higher quality such as higher pay and fringe benefits. Rather, the people characteristically work one to two days per week, getting only enougn pay to acquire a few more goucs, and generally avoid 
managerial positions. Problems of this sort could result in such things as a greater false alarm rate, a laxity in on-site monitoring, a high degree of frustration by multinational supervisors, and perhaps a generally negative impact on the cost and efficiency of the center's operation.

Technology transfer is frequently mentioned as a factor in attempts to curb proliferation. If an IFSC is placed in a nonweapons state and staffed principally with host-nation personnel, over a period of years enough highly skilled technicians will be trained to provide the host nation with personnel capable of developing a clandestine weapons project. Because of this, it may be necessary to carefully track key host-nation personnel after they leave IFSC employment if they have held a critical position. The extent to which and how foreign employees should be tracked also should be determined.

In summary, at the working level there appears to be some features of a multinational operation which might tend to reduce both the general effectiveness of the work force and the anticipated level of proliferation resistance.

\subsubsection{Factors Which Tend to Enhance the Overall Proliferation Resistance of Multinational IFSC's}

Although a number of features might tend to retard proliferation resistance, multinational presence may also create working-level conditions that may generally enhance it.

Multinational presence may legitimize very strict international inspection of processes and operations. Involvement of multinationals in the ownership and management of a fuel center operation might legitimize a degree of on-site inspection which would come much closer to actual regulation. This would replace the present annual accounting inspection done by IAEA personnel.

At the present time most nuclear facilities are owned by the host nation, even in cases where there are multinational consortia. As yet, no provision or precedent has been established which would permit strict on-site inspection on a continuing basis by international groups. However, if such inspection criteria are established for the first IFSC, possibly subsequent IFSC's could be closely inspected and regulated by an international agency such as the IAEA.

The diverse national loyalties of the multinationals and the host nation personnel reduce the opportunity for internai conspiracies to develop within the plant. As noted earlier, the maximum threat of host nation take-over with 
such a sophisticated, highly technical passive and active use-denial system would of necessity involve a siriultaneous overt and covert action by the perpetrator. Multinational presence in this situation could effectively reduce the opportunity for development of internal conspiratorial portion of this threat.

Multinational presence is likely to reduce the inclination to cover up mistakes and errors. These are the types of mistakes which could ?ead to unexplained differences in material balance or other mistakes and failures in plant operation which could cause difficulty from a proliferation resistance standpoint. In a plant operated wholly by host nationals, there might be an inclination to cover up such mistakes.

5.4.3 Multinational Presence as a Factor in Reducing the Attractiveness of an IFSC for Potential Host-Nation Take-Over

A number of major political factors would tend to make a multinational IFSC less attractive to host nation take-over regardless of its internal political situation. Because the center would be a multinational facility established by participating governments expressly for the purpose of limiting nuclear proliferation, any take-over act by a host would be a major international action bordering on war. Thus, a host nation take-over, even in a revolutionary situation, would have to be regarded by leaders of that political movement as an extremely high risk venture. Characteristically, the tendency of foreign governments is to take a hands-off policy toward the internal affairs of most countries (with notable exceptions). However, an attempted IFSC take-over by a host-nation revolutionary force might invite swift and massive retaliation by IFSC partners.

Another factor making a multinational IFSC less attractive for potential host nation take-over is the prospect of multiple sanctions as opposed to sanctions imposed by only one government. Several nations can bring more intense economic and political pressure to bear on a host than one country acting alone. Potential adversaries would also tend to avoid the prospect of multiple military sanctions.

Multinational presence may also justify extraterritoriality for the IFSC. This international legal arrangement may provide an added increment of political insurance against host nation take-over. As international property, the center's take-over or such an attempt would constitute a grave act. 
Multinational presence may also present greater obstacles to legalizing a host nation taking over a fuel center through expropriation of the property. Host countries have been expropriating foreign property for some time. If the IFSC is a multinational facility subject to treaty among a number of partners, then it becomes much harder to legally justify expropriation of the IFSC. This is particularly true if the initial objective of the treaty were to insure multinational control of the facility for the purpose of reducing nuclear weapons proliferation.

Multinational presence may also indirectly affect proliferation by reducing neighboring states' suspicions toward the operations of the IFSC. A multinational center with strict proliferation resistance procedures and sophisticated technology for monitoring fissionable materials can help reduce the fears neighboring states might otherwise have that weapons development could be occurring within the host nation. Because of this, neighboring states may not feel pressures to undertake nuclear weapons development programs of their own, being reassured about the use of fissionable material in the IFSC. 


\subsection{SUMMARY AND CONCLUSIOIS}

Section 5.0 has considered three major sets of issues concerning the national acceptability of IFSC's with use-denial features:

- the political acceptability of active and passive use-denial tecinologies,

- issues of organization, management, and operation of a proliferation resistant IFSC, and

- the value of a multinational presence in affecting IFSC proliferation resistance.

Nations contemplating partnership in an IFSC venture are faced with the immediate issue of use-denial as a constituent part of the IFSC. Two types of IFSC use-denial technology are planned: active and passive. Active systems intervene directly in the functioning of an IFSC in a manner intended to interdict attempts to divert weapons-grade materials from the facility and to impose penalties on such diversions. Active use-denial systemis involve both human decision making and automated technologies managed by a command, control, and communication $\left(C^{3}\right)$ system.

Passive use-denial inheres in the processes of the IFSC. These processes function in a manner that precludes any production of weapons-grade materials. Passive use-denial concepts are as yet untested and exist only as concepts. Even as concepts, passive production flows yield products that can be converted into weapons-grade materials by outsiders willing to pay the necessary costs in time and risk. It appears that passive use-denial designs can at best buy time for IFSC partners to intervene should a determined effort be mounted to divert and produce weapons grade nuclear materials.

The intrusive nature of active use-denial raises many issues of acceptability by nation states. Nations, by definition, are sovereign in international law. That is, countries control what goes on within their territorial limits. Since the logic of the IFSC with use-denial removes major areas of concern-weapons and energy--from the control of national decision makers, an intrusion upon national sovereignty is inevitable.

Since national sovereignty is a sensitive issue in terms of national pride, honor, and self-image, IFSC acceptability will be intimately related to the way in which national policies anc policy makers respond to the cradeoff 
between sacrifices in sovereign control and gains in assured energy supplies and nuclear fuel services. This tradeoff is not trivial because IFSC participation, particularly as host of such a facility, means that important decisions will be beyond national control. Energy independence may be threatened and military relations affected by accepting an IFSC.

The domestic and international politics of sovereignty indicate that the less obtrusive use-denial aspects of an IFSC, the greater the chances of national acceptability. This clearly argues in favor of unproven passive IFSC use-denial concepts.

There are other acceptability factors than sovereignty issues that may be of similar importance:

- Economics. Any use-denial features are bound to add to the costs of nuclear power. Only the magnitude of the cost increment is at issue.

- Energy Program. Domestic energy needs and possible commitment to energy independence can influence acceptability. If energy needs can be secured through an IFSC, participation will be encouraged. If, however, the international aspect is viewed as a threat to controlled energy supplies, the likelihood of participation will decline.

- Domestic Political Concerns. Domestic political issues will have a strong impact on IFSC acceptability. Antinuclear and environmental movements are factors in the political systems of the industrialized nations to the extent that IFSC participation is perceived as consistent or conflicting with the goals of these interests will be an acceptability factor relative to their power and influence.

- International Politics. Beyond domestic factors, international affairs play a fundamental role in influencing IFSC acceptability. Several international concerns are apparent in terms of attitudes toward international organizations, relations with regional powers, cormitment to the NPT, and nuclear weapons ambitions. Generally, the more secure and satisfied a nation is in international affairs, the more inclined it would be to accept the implication of IFSC participation. 
All of the foregoing factors are reflected in the national case studies, which assess probable national responses to IFSC participation. In sum, the case studies lead to the conclusion that IFSC participation will be decided as a matter of national interest. To the extent that national interests and the proliferation resistant aspects of the IFSC concept are in agreement, participation is a possibility. The general trend must be seen moving contrary to acceptance, in good measure because the idea of the IFSC is not yet fully developed.

Issues of organization, management, and operation of a proliferation resistant IFSC relate mainly to effectiveness. In terms of passive use-denial systems, there are major concerns of environmental and safety considerations, economic costs and benefits, and political implications.

Some conceptions of passive systems require high-level radioactivity to assure the security of potentially weapons materials. To the extent that this results in added hazards, acceptability is bound to decline, particularly since enhanced hazards are likely to add to the costs of operation. The economic issues surrounding participation in undemonstrated and unproven technologies are bound to inhibit willingness to participate.

The political factor is relevant to institutional, operation, and management concerns because of the international character of the fuel service centers. Passive (and active) use-denial features must be perceived as nonprejudicial in character. That is, all countries musi be treated the same with respect to the proliferation resistant features of IFSC's, whether passive or active.

Active use-denial systems, because of their inherently intrusive and destructive nature, require special attention in the area of management and operation. In fact, active systems may be misused to achieve political ends unrelated to the purpose of an IFSC. Thus, extreme care must be taken in designing and executing $\mathrm{C}^{3}$ and associated systems with the awareness that probably no foolproof active system can be devised.

A further management problem relates to the international terms of operation and ownership of an IFSC. The roles of governments and private corporations must be negotiated, along with the status of existing national facilities. As the case studies indicated, countries are likely to have such 
divergent views in these matters that they may we 11 become major factors confounding acceptability.

Finally, the value of multinational presence in enhancing or reducing IFSC proliferation resistance must be viewed in two aspects. Complications of cultural and ethnic diversity are bound to complicate either active or passive use-denial efforts. The intrusion of rivalries or conspiracies into the operations of an IFSC would generally reduce the effectiveness, especially of active use-denial systems.

At the same time it can be argued that multinational participation may enhance the inspection and enforcement aspects of an IFSC. International presence, if successful, can act to legitimatize the role of agencies such as IAEA. Moreover, the presence of a number of nations improves the chances of coalition formation to counter host-nation take-over attempts. On balance, institutionalized multinational involvement will be a favorable factor in achieving IFSC goals, both in terms of operations and nonproliferation. 


\subsection{COST IMPACT ON THE IFSC RESULTING FROM PROLIFERATION RESISTANCE ENGINEERING}

The incremental costs imposed on the design, construction and operation of an IFSC by including the PRE concepts can only be tentatively estimated at this stage of the study. PNL and SPC have both made preliminary estimates based on our current perceptions of the $\mathrm{C}^{3}$ system, the passive and active use-denial technology, and the need for a multinational presence. The estimates are, of necessity, based on preliminary concepts, and as a result, will have to be updated as firmer analysis becomes available.

\subsection{SUMMARY OF THE PNL ESTIMATE}

The cost of applying PRE concepts in an IFSC will include research and development for the required use-denial technology. This involves the active systems for process interruption, material denial and the $\mathrm{C}^{3}$ system. The design and fabrication (or construction) costs for incorporating passive design features are assumed to be negligible. The incorporation of active use-denial technology in the facility and the construction of the dispersed $\mathrm{C}^{3}$ system are significant cost elements, as are the operating costs for the $\mathrm{C}^{3}$ system. Another major cost increment is the additional labor costs incurred as a result of the need for multinational presence. The added implementation and operation costs over and above those of a similar IFSC without PRE are summarized below.

\begin{tabular}{|c|c|}
\hline 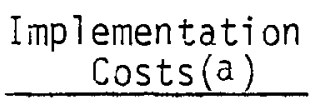 & $\begin{array}{c}\text { Annua } 1 \text { Operating } \\
\text { Costs (a) }\end{array}$ \\
\hline$\$ 30 \mathrm{M}$ & -- \\
\hline $30 \mathrm{M}$ & --- \\
\hline 0 & 0 \\
\hline $50 \mathrm{M}$ & 0 \\
\hline $60 \mathrm{M}$ & $\$ 2 M$ \\
\hline--- & $70 \mathrm{M}$ \\
\hline
\end{tabular}

(a) Stated costs are incremental to a similar facility without PRE. 
If these estimates are correct within a factor of 10, it appears the economic impact of PRE will not be an overriding element on its acceptability.

\subsection{COST ESTIMATE PREPARED BY SPC}

\subsubsection{Facility Model for Costing}

The conceptual model IFSC used for cost estimates purposes consists of:

- A fuel handling activity, made up of

- a reprocessing facility

- a LMFBR fuel fabrication facility

- a LWR fuel fabrication facility

- a storage facility for all but spent fuel

- A spent fuel storage activity

- A waste management and storage activity

- A power generation activity employing LMFBR reactors

- Seven $C^{3}$ centers comprising

- four individual activity $c^{3}$ centers

- one on-site $c^{3}$ master facility

- one off-site $c^{3}$ headquarters

- one consortium $C^{3}$ headquarters.

The scale of the conceptual IFSC is defined by the reprocessing facility which has a nominal capacity of 1,500 metric tons of heavy metals per year. An idea of the acquisition cost of an IFSC centered on this reprocessing facility follows from the estimate of $\$ 6.3$ billion that has been made for the West German 1,400 mt facility at Gorleben. $(a, b)$ The

(a) Rippon, Simon. 1978. "Prospects Look Good for Gorleben Center." Nuclear News. 21(2): 48-53.

(b) The estimate shown by Rippon is \$4.5-6.8 billion to be raised by commercial interests and $\$ 680$ million provided by the German federal government. These estimates were "figured after the preliminary study in 1976." Taking the mean of the range to be raised by commercial interests ( $\$ 5.6$ billion) and adding the government contribution ( $\$ 680$ million) leads to a total of $\$ 6.3$ billion. 
Gorleben facility includes a!1 IFSC activities except the power generating activity and the $C^{3}$ centers. Given the uncertainties associated with the configuration of the IFSC, $(a)$ and with cost estimates in general, it is likely that the acquisition cost of an IFSC will be more than $\$ 5$ billion and less than $\$ 20$ billion. For this purpose, a median value of $\$ 10$ billion will be used.

\subsubsection{Cost Impact of Equipment for Prol iferation Resistance Design}

The incremental costs of proliferation resistance design and operation by a consortium as compared to the same center designed and operated as a national facility is being sought. The incremental cost components identified are associated with changes in facility design and construction, special $\mathrm{C}^{3}$ and denial equipment, and personnel, both numbers and types.

Basic Facility Cost Increment. The acquisition costs for the basic facility would likely be no different for an IFSC than for a national facility. The use of inherently simpler processes such as CIVEX rather than PUREX could actually lead to less costly facilities. Some aspects of the facilities are likely to be more expensive. For example, the storage vaults used for plutonium are likely to be more complex than those in a national facility. Without detailed design and cost data to argue that the acquisition cost of an IFSC would markedly differ from than of a national facility, there appears to be no gross first order indication of such differences. Therefore, assuming the costs are the same, a baseline cost of $\$ 10$ billion for both a national facility and an IFSC will be used.

$\mathrm{c}^{3}$ and Denial Equipment Costs. The additional special equipment associated with the $\mathrm{C}^{3}$ system and denial actions includes special equipment at the denial nodes, special computers, control and displays at the $c^{3}$ centers and special communications.

The special equipment at a denial node inciudes devices such as communications terminals, membranes, (b) coded switches, ard actual denial implementation elements such as thermite charges or one-time mechanical actuators. Sandia Livermore Laboratories conservatively estimated the average cost of this equipment at $\$ 100,000$. Each type of facility will have a number of denial nodes.

(a) Some IFSCs may have no on-site electric power generating capability.

(b) A membrane is a special kind of envelope (intrusion sensor) that produces a signal when it is penetrated. 
A reasonable range for most facilities appears to be $\$ 10,000$ to $\$ 100,000$. For the present purpose, an average of 50 nodes per facility has been assumed for all but the storage facility and storage areas within other facilities. If four LMFBR reactors are assumed, then there is a total of 10 facilities containing denial nodes within the IFSC.

Using a total of 10 facilities, 50 denial nodes per facility (exclusive of material storage areas), and a cost at each denial node of $\$ 100,000$ leads to a total cost of $\$ 50$ million for special denial equipment at the denial nodes (other than storage areas).

Plutonium output buffer storage at the reprocessing facility and input buffer storage at the LMFBR and LWR fuel fabrication facilities represent special cases. PNL has estimated that a total of 5,800 to $7,800 \mathrm{~kg}$ of plutonium may be in storage at these locations. (a) (The plutonium in storage elsewhere is in a form covered by the more general denial nodes already discussed.) If the material in the buffer storage areas is in the form of plutonium oxide, it will be stored in canisters whose capacity is $8 \mathrm{~kg}$. Thus, in round numbers, PNL's estimate of 5,800 to $7,800 \mathrm{~kg}$ of plutonium will lead to 1,000 storage canisters that constitute denial nodes. (b)

If the material in these buffer storage areas is stored in the form of mixed oxides rather than plutonium oxide, it can be stored in larger containers. PNL has estimated a range of 29 to 39 metric tons of mixed oxides corresponding to its previous estimate. Thus, if mixed oxides were stored in canisters whose capacity is approximately $40 \mathrm{~kg}$, the total number of nodes represented by this storage would again be 1,000.

The number of denial nodes associated with storage canisters is thus taken to be 1,000 regardless of whether the material in the canisters is plutonium oxide or mixed oxide.

If there are 1,000 substanially identical canisters to be equipped as denial nodes, it seems likely that the special equipment cost associated with each node could be reduced from $\$ 100,000$ to perhaps $\$ 50,000$. This would lead to a total of $1,000 \times \$ 50,000=\$ 50$ million in special denial equipment associated with storage canisters.

(a) Sorenson, R., et a1. 1978. Proliferation Resistant Design of a Plutonium Cycle. Draft report. Pacific Northwest Laboratory, Richland, WA 99352.

(b) The weight difference between plutonium and plutonium oxide is neglected here. 
The reduction for the cost of the speciai denial equipment associated with a canister is plausible on two scores. A large fraction of the $\$ 100,000$ estimate is associated with the membrane which could likely be simplified for this application. Further, the economies of scale that would result from the development and production of equipment for such a large number of canisters will significantly reduce the cost. (a)

$\mathrm{C}^{3}$ Computers, Controls, and Displays

Computers, special control equipment, and status displays will be needed at each of the three $\mathrm{C}^{3}$ centers and the four individual activity centers. The cost of hardware for each of these computers (including the necessary backup equipment) is an estimated $\$ 2$ milition, (b) for a total of $\$ 14$ million in computer hardware. The cost of secure software for these computers is assumed to be twice that of the total hardware, ${ }^{(c)}$ i.e., $\$ 28$ million. Special control equipment and status displays driven by the computers are estimated to cost the same as the computer hardware, $i . e ., \$ 14 \mathrm{mili}$ ion. The total estimate for computer hardware and software, and special controls and displays is therefore $\$ 56$ miliion.

Communications

Communications are required to support the $C^{3}$ system within the IFSC, the on-site $\mathrm{C}^{3}$ master facility, and the two off-site headquarters. Compared to the other communications costs, the costs of the communications channels within the IFSC are negligible.

(a) The potential for this reduction becomes apparent if, for example, the log-linear average cost formula used by the Army is applied with the learning curve of 0.9 commonly used for equipment of the general kind under consideration here. Applying this formula to a procurement of 1,000 items whose first unit cost is $\$ 100,000$, leads to an average cost for the 1,000 items of $\$ 35,000$.

(b) This estimate is based upon the $\$ 1.9 \mathrm{M}$ estimated hardware cost of the Manufacturing Information and Control System (MICS) at the GE-Wiimingtor low-enriched uranium fuel fabrication operation.* MICS provides safeguards and inventory management functions.

* See footnote $c$ below.

(c) Fagan, J.F., G. L. Atkinson, F. L. Adelman, and C. L. Herrir. 1977. Options for Supporting Non-Safeguards Functions with the Concoptual Safeguards Computer System for a Generic Mixed-0xide Fuel Fabrication Facility. Report 329, System Planning Corporation. 
Communications costs within and between the on-site master $\mathrm{C}^{3}$ facility, the off-site $\mathrm{C}^{3}$ headquarters and the consortium $\mathrm{C}^{3}$ headquarters can be estimated. This can be done by letting the communications between any two of these be a link (three links are required). One link would consist of a pair of dedicated satellite voice channels, cne for digital data and one for voice. This pair should be replicated three times over different paths to assure reliability. Where readily feasible in terms of cost (i.e., where long submarine cables are not required), these six satellite channels would be backed up by six dedicated parallel land lines. Now, a dedicated satellite voice channel between two points (e.g., both in Europe; or one in Europe and one in the United States) costs $\$ 120,000$ per year. (a) The six satellite channels required for a link will therefore cost $\$ 720,000$ per year. The cost of a dedicated land 1 ine is $\$ 6$ per mile per year for representative maximum distances of 2,000 miles. (b)

The satelitite communications cost for the three required links are thus $3 \times \$ 720,000=\$ 2.2$ million per year. Costs associated with land lines, if any, will be bypassed. In the material that follows, this annual cost is shown in some cases as an equivalent one-time cost of $\$ 21$ miliion. This is a reflection of 30 years' operating 1 ife and a $10 \%$ interest rate. (c)

\section{Equipment Cost Summary}

The equipment cost impact of proliferation resistance design can be summarized as shown in Table 6.1. Note that the estimated total cost impact of the proliferation resistance design is $\$ 177$ milition, or less than $2 \%$ of the estimated $\$ 10$ billion cost of the base-line national facility.

\subsubsection{Personnel Costs}

The impact of multinational operation of the IFSC on personnel costs is shown in Table 6.2. The burdened labor cost for host nationals is computed using an average rate of $\$ 17,000$ per year plus a $125 \%$ burden

(a) COMSAT Corporation, private communication, 17 February 1978.

(b) American Telephone and Telegraph Company, private communication, 17 February 1978.

(c) The $10 \%$ rate is mandated for most United States Soverment activities in circular No. A-76, Bureau of the Budget, XXX YY, 1977. 
TABLE 6.1. Equipment cost Impact

$$
\begin{aligned}
& \text { Baseline } \\
& \text { National } \\
& \text { Facility } \\
& \text { \$Billions } \\
& \hline
\end{aligned}
$$

Basic Facility

Denial Nodes

- General

- Storage Canisters

$c^{3}$ Computers, Software, Controls, Displays

$\mathrm{C}^{3}$ Communications

Total Equipment Acquisition Cost Increment
10

0

0

0

0

10
Proliferation

Resistant

Design

Increment

SMillions

0

50

50

56

21

177

TABLE 6.2. Labor Costs

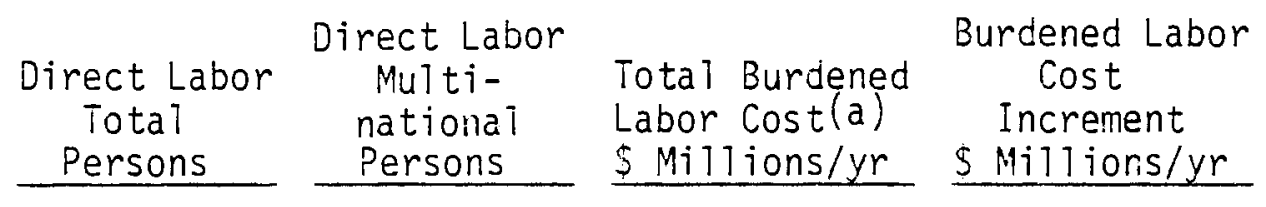

IFSC as National

Facility

4010

0

153

0

IFSC With Minimum Acceptable Muttinational Personnel

4695

860

212

59

IFSC with Reasonable

Maximum Multi-

national Personnel

4695

1950

254

101

(a) See text. 
for a total of $\$ 38,250$ per year. (a) The average rate assumed for multinationals is $\$ 34,000$ per year, to which $125 \%$ burden is applied for a total of $\$ 75,500$ per year. The rate difference reflects a generally nigher average skill level and various types of premiums ordinarily paid to people working outside their home country under this kind of circumstances.

The last column of Tabie 6.2 shows an increment in the annual burdened labor cost of $\$ 59 \mathrm{million}$ above the $\$ 153$ million baseline. This increment appears when a transition is made from an IFSC operacea as a national facility to an IFSC operated as a multinational tacility (using additonal ceople and the minimum acceptable number of multinationals). The increment becomes \$101 milition above the \$153 million baseline when the total number of people remains the same as in the earlier multinational case, but the number of multinationais is increased from the ninimum acceptable to a reasonabie maximum.

These labor costs, both baseiine and increments, may appear to be large, but they are not. The next section will show that an IFSC is an extrame?y capital intensive activity, and that the iabor costs, baseline or increment, represent only a small fraction of the annual operating costs.

\subsubsection{Cost Overview}

The total cost impact of proliferation resistance design can now be assessed on an absoiute and relative basis lising the data shown in iable 6.3. Costs in the tacle all reflect acuuisition time. Annual people costs are translated to acquisition time on the assumption of 30 years operating 1 i ie at an interest rate of $10 \%$.

As previously noted, in going from a nationai facility to an IFSC, the cost impact of facility design changes and additionai equipment is small. The first column shows the change from $\$ 10$ billion to $\$ i 0.2$ billion in facility acquisition cost. The extreme range of total people

(a) Eegional Nuclear Fuel Cjcie Cencres. 1977. Basic Studies, 977 report. The IAEA Study Project. Voi. iI. International Atomic Energy Agency, Vienna, p. 188. 
TABLE 6.3. Cost Summary

10

10.2

10.2

IFSC as National

Facility

IFSC with Minimum

Multinational

IFSC with Maximum

Multinational

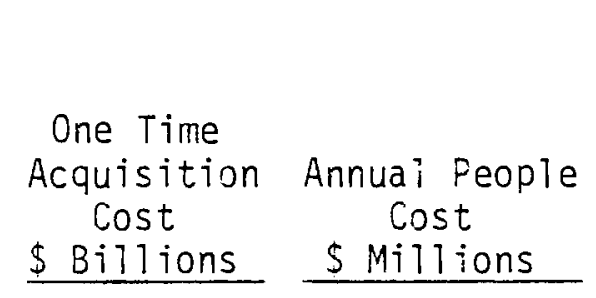

People Cost Refiected

to Acquisition Time

As Percent

of Facility

Acquisition

$\$$ Billions Cost

Per Million Production Workers

Primary Metal Industry

Motor Vehicle Industry

$83^{(b)}$

157

1.5

15

Petroleum Industry

$$
\begin{aligned}
& 38,250(c) \\
& 38,250(c) \\
& 38,250(c)
\end{aligned}
$$

361

435

282

$511^{(b)}$

361

361

71

costs for the 30-year operating period extends from $\$ 1.5$ billion for $15 \%$ of facility acquisition cost) to $\$ 2.4$ billion (or $24 \%$ of facility acquisition cost). The difference is less than $\$ 1$ billion, again over the total 30 -year period, or less than $10 \%$ of the facility acquisition cost.

To a first approximation, a business judgment about al ternative, based upon costs stated on a common basis, is indifferent to the fraction of the costs represented by things and people. Thus, if acquisition

(a) For 30 years at 10\%. Ten percent specified in Bureau of the Budget Circular No. A-76.

(b) U.S. Bureau of the Census. 1976. Statistical Abstract or the United States. 97th ed. Washingtor. DC. 1976 and 1972 datc have teen updated to 1977 by wholesale price index $(1972=119.7,1977=194.2)$.

(c) Computed at $\$ 17,000$ per man year $+125 \%$ burden $=\$ 38,250$ per man year. 
costs and people costs are aggregated at acquisition time, the comparison between the IFSC as a national facility and the IFSC with maximum multinationals is a comparison betiveen $\$ 11.5$ billions (i.e., $10+1.5$ ) and $\$ 12.6$ billions (i.e., 10.2+2.4). A determination as to whether having an IFSC as a multinational facility is desirable must flow from other considerations. It is not plausible that this determination could be made from a comparison of $\$ 11.5$ billion and $\$ 12.6$ billion. The difference is too small-- approximately $10 \%$.

The assertion that the cost differences between a national and multinational facility, which are primarily people costs, cannot dominate a decision stems from the fact that the people costs are smal1, and an IFSC is capital intensive. This is persuasively shown by the comparison of the IFSC with the data shown for three representative ordinary U.S. heavy industries. Note that the petroleum industry is the most capital intensive ordinary industry in the U.S. The data in the last column of Table 6.3 show that an IFSC, with maximum multinationals, is three times as capital intensive as the petroleum industry and 18 times as capital intensive as the primary metals industry. Given this level of capital intensiveness, it is unlikely that any increment in people cost, even a fairly large one, could significantly change the assessment of an IFSC as a commercial enterprise. 


\subsection{REFERENCES}

Bergdo11, Udo. 1978. "Hauff Promises Greater Scrutiny of Technology." The German Tribune. 근 829$): 6$.

Conradt, David P. 1978. The German Polity. Longman, New York.

Department of Energy. 1977. Final Communique of the Organizing Conference of the International Fuel Cycle Evaluation Conference. DOE No. 41, Washington, DC.

Dixon, Karl. 1978. "A Complete Fuel Cycle for Japan?" Pacific Community. $\underline{9}(3): 341$.

Federal Ministry for Research and Technology. 1977a. Energy Research and Energy Technologies Program, 1977-1980. Federal Ministry for Research and Technology, Bonn, FRG.

Federal Ministry for Research and Technology. 1977b. Zweite Fortschreibung des Energieprogramms. Federal Ministry for Research and Technology, Bonn, FRG.

Galland, Heino. 1978. "Partizipation in der Energiepolitik." Paper presented at Enternationale Studien Konferenz und Politik, June 5-9, 1978, Tutzig, FRG.

Henkel, Rolf-Peter. 1977. "Citizens' Action Organization Continues to Grow." The German Tribune. 15(728): 3.

"Hopes of Breeding Cash." 9 Juiy 1977. The Economist.

"Interview mit Klaus Barthe1t." 1977. Die Zeit. 32(49): 12.

"Reactor Congress in Mannheim." 7977. Nuclear News. 20(7): 56.

Redick, John. 1978. "Regional Restraint: U.S. Nuclear Policy and Latin America." ORBIS. 22(1): 188.

1977. Relay from Bonn. $8(6): 2$.

Statement: Chinese Government Information Office. Issued September 16, 1976. Taiwan, Republic of China.

Tahir-Kheli, Shirin. 1978. "Pakistan's Nuclear Option and U.S. Policy." ORBIS. $22(2): 307$.

Wilker, Lothar. 1978. "The Nuclear Transfer Policy of the Federal Republic of Germany." Paper presented at the 1978 annual meeting of the International Studies Association, February 1978, Washington, DC.

"Zur freielichen Nutzung der Kernergie." 7977. Bulietin des Pressund Informationsamtes der Bundesregierung. $36(15): 331$. 


\section{DISTRIBUTION}

No. of

Copies

OFFSITE

A. A. Churm

DOE Patent Division

9800 S. Cass Avenue

Argonne, IL 60439

W. Ballard

Division of Nuclear Power Dev.

Department of Energy

Washington, DC 20545

H. Kendrick

Fuel Cycle Evaluation, ETN

Department of Energy

Washington, DC 20545

DOE Technical Info. Center

A. Ayres

Allied-Gulf Nuclear Services

P. 0. Box 847

Barnwe11, SC 29812

R. E. Brooksbank

Oak Ridge National Lab.

P. O. Box X

Oak Ridge, TN 37830

W. J. Brumley

Savannah River Laboratory

Department of Energy

P. 0. Box A

Aiken, SC 29801

W. D. Burch

Oak Ridge National Lab.

P. 0. Box $X$

Oak Ridge, TN 37830
No. of

Copies

M.C.J. Carison

Hanford Engr. Dev. Lab.

Federal Building

Richland, WA 99352

F. R. Field

Savannah River Laboratory

Department of Energy

P. O. Box A

Aiken, SC 29801

J. C. Gibson

Sandia Laboratories

P. 0. Box. 969

Livermore, CA 94550

H. R. Kreiner

System Planning Corp. 1500 Wilson Blvd.

Arlington, VA 22209

R. A. Morris

Batielle Human Affairs

Research Center

Seattle, WA 98105

J. E. Rushton

Oak Ridge National Lab.

P. 0. Box X

Oak Ridge, TN 37830

C. R. Schuller

Battelle Human Affairs Research Center

Seattle, WA 98105 
PNL -2832

UC -15

No. of

Copies

ONSITE

DOE Richland Operations Office

H. E. Ransom

29 Pacific Northwest Laboratory

R. J. Sorenson

F. P. Roberts

R. G. Clark

R. J. Brouns

R. F. Eggers

R. J. Kofoed (13)

C. L. Brown

N. E. Carter

R. C. Liikala

G.

Long

Technical Files (5)

Publishing Coordination (2)

Distr-2 